\title{
Cameroon: Poverty Reduction Strategy Paper
}

Poverty Reduction Strategy Papers (PRSPs) are prepared by member countries in broad consultation with stakeholders and development partners, including the staffs of the World Bank and the IMF. Updated every three years with annual progress reports, they describe the country's macroeconomic, structural, and social policies in support of growth and poverty reduction, as well as associated external financing needs and major sources of financing. This country document for Cameroon, dated August 2009, is being made available on the IMF website by agreement with the member country as a service to users of the IMF website.

\author{
Copies of this report are available to the public from \\ International Monetary Fund $\bullet$ Publication Services \\ 700 19th Street, N.W. • Washington, D.C. 20431 \\ Telephone: (202) 623-7430 • Telefax: (202) 623-7201 \\ E-mail: publications@imf.org • Internet: http://www.imf.org
}

\section{International Monetary Fund Washington, D.C.}




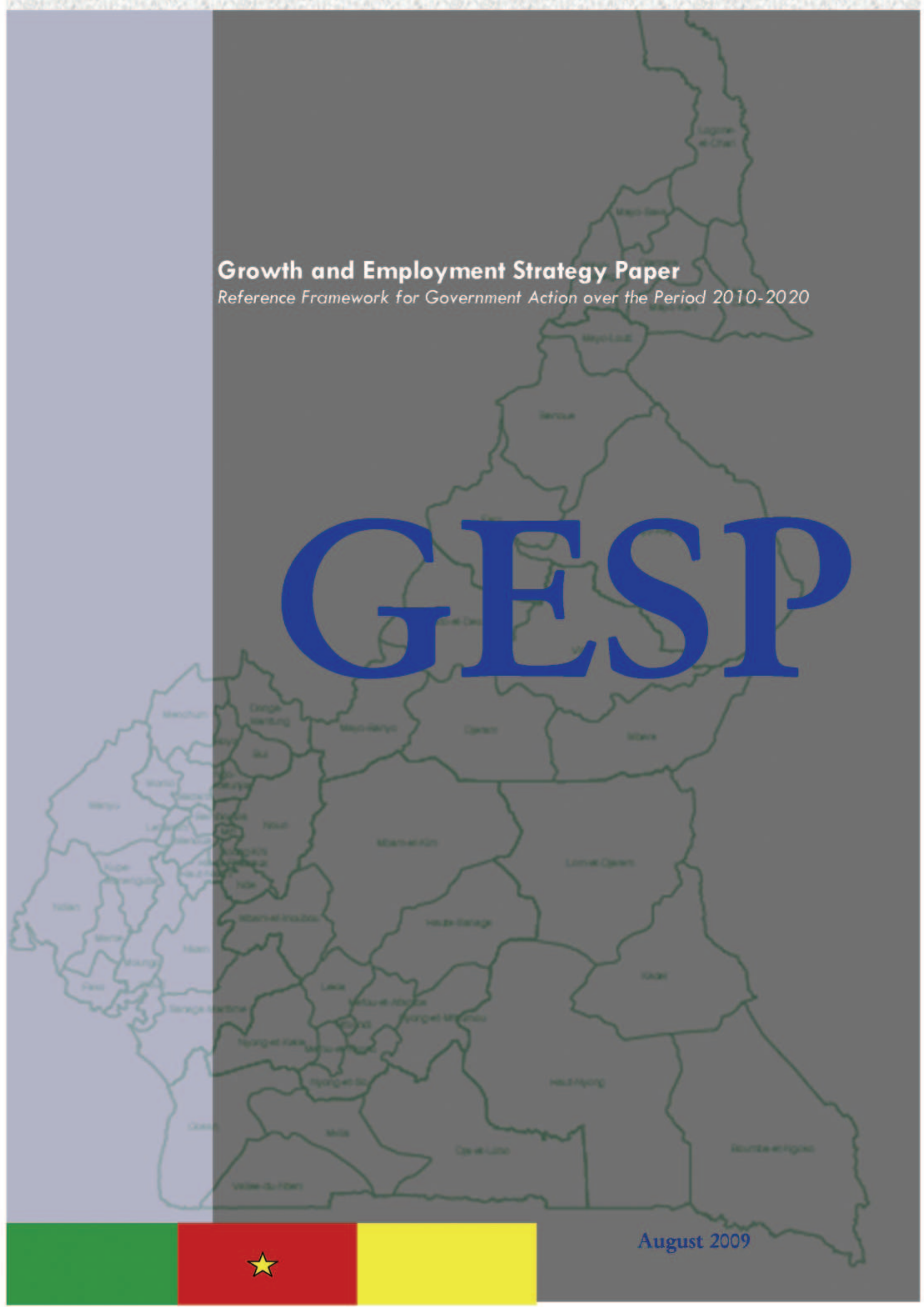




\section{LIST OF ABBREVIATIONS AND ACRONYMS}

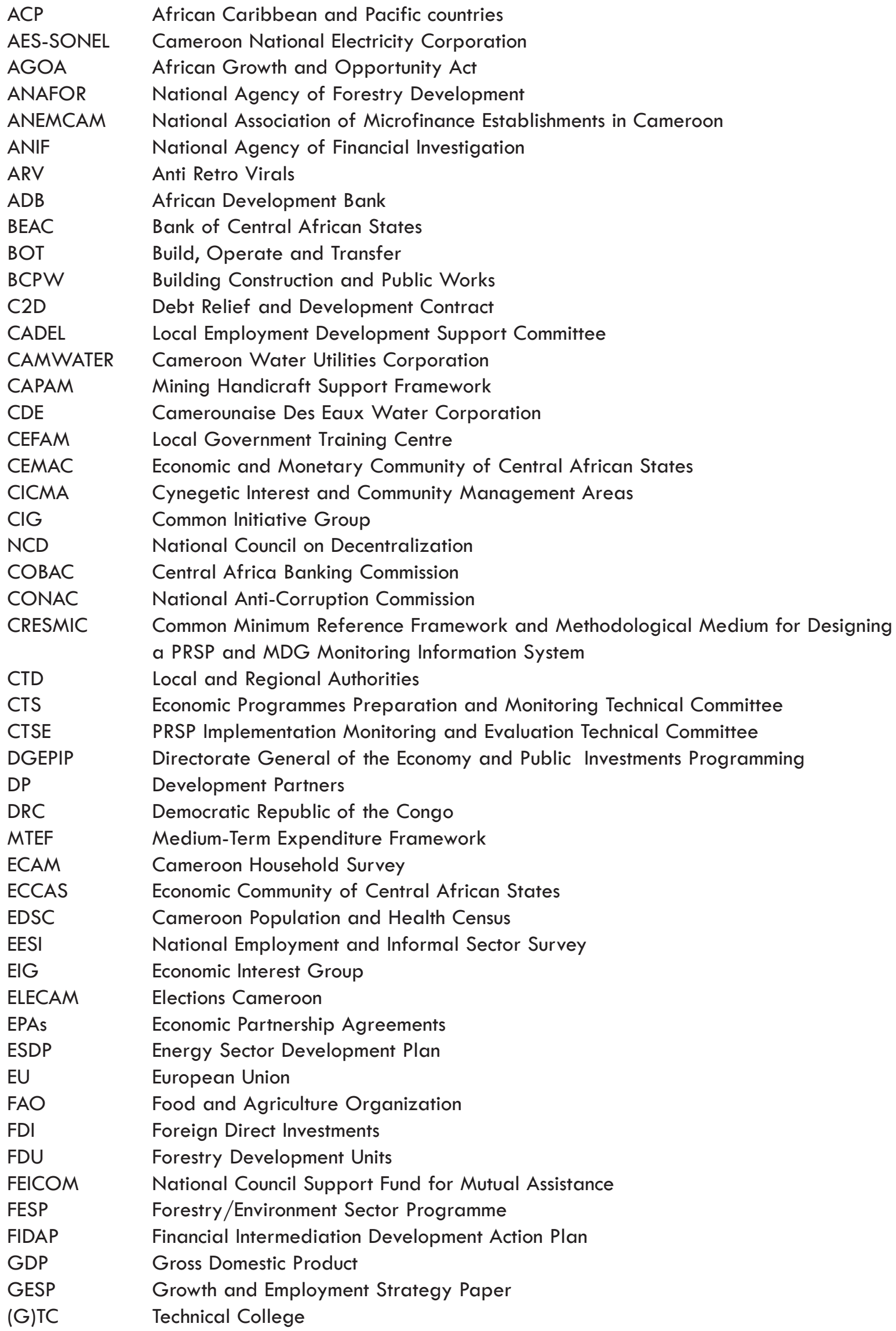




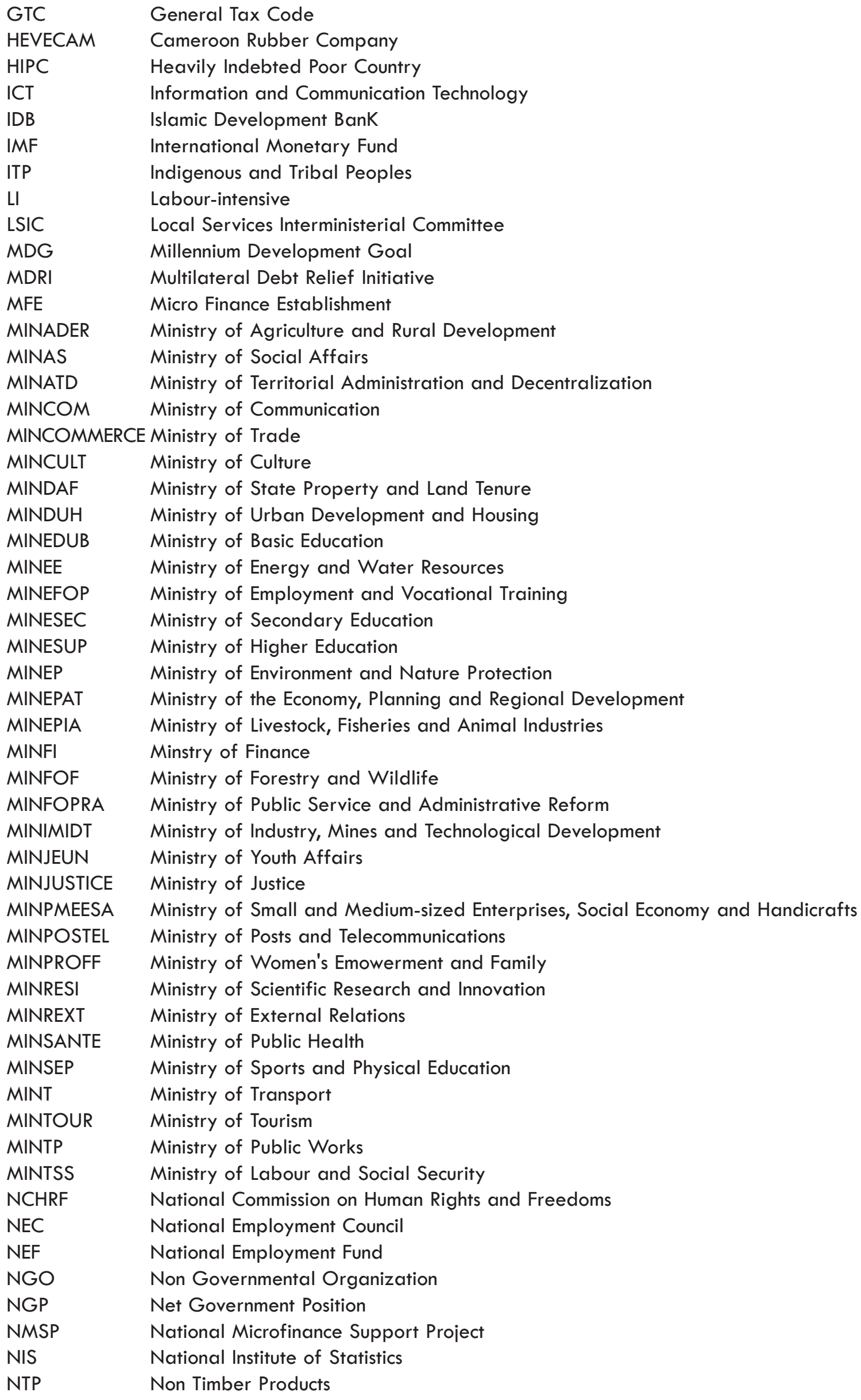


ODA

OHADA

OSP

REC

$\mathrm{NHC}$

PADMIR

PINORAC

PIT

PROMAGAR

PRGF

PRSP

RCP

REP

RMDP

ROM

SAR/SM

SFTT

SIGIPES

SME

SMI

SOCAPALM

SODECAO

STOP

SYGMA

TSP

UNDP

UNIDO

VSE

VAT

WEO

WTO
Official Development Assistance

Organization for the Harmonization of Business Law in Africa

Organization and Staffing Plan

Regional Employment Councils

National Hydrocarbons Corporation

Rural Microfinance Development Support Project

Project on the Introduction of Output Standards and Norms in Cameroon's Public Administration

Personnel Income Tax

Cameroon's Administration Modernization Programme

Poverty Reduction and Growth Facility

Poverty Reduction Strategy Paper

Regional Code Programme

Regional Economic Programme

Rural Microfinance Development Support Project

Results-oriented management

Rural Handicrafts Section/Home Economics Section

State Financial Transactions Tables

Computer System for Integrated Management of State Personnel and Salaries

Small and Medium-sized Enterprise

Small and Medium-sized Industry

Société Camerounaise de Palmeraies (Cameroon's Palm Company)

Société de Développement du Cacao (Cocoa Development Corporation)

Special Tax on Oil Products

Large Amounts Computerized System

Transport Sector Programme

United Nations Development Programme

United Nations Industrial Development Organisation

Very Small Enterprise

Value Added Tax

World Economic Outlook

World Trade Organization 


\section{CONTENTS}

LIST OF ABBREVIATIONS AND ACRONYMS

CONTENTS......

LIST OF BOXES, GRAPHS AND TABLES

PREFACE

EXECUTIVE SUMMARY

INTRODUCTION

CHAPTER 1 : REVIEW OF DEVELOPMENT POLICIES

1.1 MACROÉCONOMIC SITUATION

1.2 SOCIOÉCONOMIC SITUATION

1.3 OBSERVATIONS BY BÉNÉFICIARIES

1.4 MAJOR SECTOR CHALLENGES

1.5 OPPORTUNITIES AND THREATS

CHAPTER 2 : VISION AND GOALS

2.1 OVERVIEW OF CAMEROON BY 2035

2.2 DEVELOPMENT GOALS BY 2035

2.3 GROWTH AND EMPLOYMENT STRATEGY GOALS

2.4 KEY CONSIDERATIONS FOR STRATEGY IMPLEMENTATION

CHAPTER 3 : GROWTH STRATEGY

3.1 INFRASTRUCTURE DEVELOPMENT

3.2 MODERNIZATION OF PRODUCTION MECHANISM

3.3 HUMAN DÉVELOPMENT

3.4 REGIONAL INTEGRATION AND DIVERSIFICATION OF COMMERCIAL TRANSACTIONS

3.5 FUNDING OF THE ECONOMY

CHAPTER 4 : EMPLOYMENT STRATEGY

4.INCREASING DECENT EMPLOYMENT OPPORTUNITIES $\quad 83$

4.2 SATISFYING THE DEMAND FOR EMPLOYMENT

CHAPTER 5 : STATE GOVERNANCE AND STRATEGIC MANAGEMENT

CHAPTER 6 : MACROECONOMIC AND BUDGETARY GUIDELINES

6.2 SCENARIO " VISION "

6.3 RISK ANALYSIS

6.4 IMPACT ON MILLENNIUM DEVELOPMENT GOALS

6.5 INCIDENCE OF REFERENCE SCENARIO ON EMPLOYMENT

CHAPTER 7: INSTITUTIONAL FRAMEWORK AND MONITORING MECHANISM IMPLEMENTATION OF THE GESP

7.1 IMPLEMENTATION INSTITUTIONAL FRAMEWORK

7. 2 MONITORING/EVALUATION MECHANISM

\section{ANNEXES}

ANNEXE I : TABLE OF KEY RESULTS

ANNEXE II : MATRIX OF PRIORITY ACTIONS

ANNEXE III : LIST OF SECTOR PROGRAMME MONITORING SUPPLEMENTARY INDICATORS 


\section{LIST OF BOXES, GRAPHS AND TABLES}

\section{BOXES}

Box 1: Definition of budgetary policy

Box 2: Surveys on the living conditions of households 36

Box 3: Review of definitions and perception of poverty 39

Box 4: Organization of participatory consultations 44

Box 5a: Millenium Development Goals 53

Box 5b: Stakes of urban economic development $\quad 62$

Box 6: Aspects of ANAFOR's intervention 66

Box 7: Guiding principles $\quad 76$

Box 8: Some innovations in the State's Finance Regime schedule $\quad 78$

Box 9: Decentralization in Cameoron: progress and schedule 95

Box 10a: Some innovations introduced by Law n ${ }^{\circ}$ 2007/6 of December 2007

Box 10b: Methodology of the projection of MDGs indicators 121

Box 11:Importance of the quality of services to the poor $\quad 130$

Box 12: CRESMIC et SNDS 131

\section{GRAPHS}

Graph 1: Incidence of poverty trends between 1996 and 2007.

Graph 2: Public debt stock trends

Graph 3: Petroleum and non-petroleum GDP trends 107

Graph 4: Employment contribution to growth 109

Graph 5: Price trends $\quad 110$

Graph 6: Poverty rate simulated trends $\quad 122$

Graph 7: Weight insufficiency rate of children aged less than five years (in \%)

Graph 8: Net primary school enrolment ratios (in \%) 123

Graph 9: Maternal mortality rates (for 100000 births) 124

Graph 10: Graph 9 : Trends of employment growth per sector under the reference scenario (in \%) 125

\section{TABLES}

Table 1: Cameroon's population trends 33

Table 2: Gini index trends between 1996 and 2007

Table 3: Poverty trends 2001 - 2007

Table 4: Net school enrolment ratio (6-14 years) per region, gender, standard of living and $\begin{array}{ll}\text { environment of residence } & 40\end{array}$

Table 5: Percentage of households having access to safe drinking water, electricity and gas, per region environment of residence, according to standard of living 42

Table 6: Division of the employed per sector (in \%)

Table 7: Objectives of the Vision $\quad 52$

Table 8: A few targets in the area of infrastructure $\quad 55$

Table 9: Expansion of the road network

Table 10: Extension of tarred roads (in $\mathrm{km}$ ) 59

Table 11: Extension of roads to $2 \times 2$ (in $\mathrm{km}$ ) 59

Table 12: Agricultural production goals by 2015 (in thousands of tonnes) 64

Table 13: Debt sustainability ratios (in \%) 82 
Table 14: A few key indicators

Table 15: Growth sector trends

Table 16: Employment trends.

Table 17: National revenue trends ( $\%$ of the GDP)

Table 18: Public expenditure trends ( $\%$ of the GDP)

Table 19: Distribution of allocations per sector

Table 20: List of major projects of the SCE

Table 21: Key indicators of the balance of payments

Table 22: Trends in monetary situation

Table 23: Real growth rate trends (Vision's scenario)

Table 24: Employment trends (vision's scenario)

Table 25: $\quad$ Trends of public finances (vision's scenario)

Table 26: $\quad$ Impact of project execution delay in the energy sector

Table 27: Impact of a shift in major project execution in the Building Construction and

Public Works sector

Table 28: $\quad$ Funding needs (in billion CFA F)

Table 29:

A few key indicators

Table 30:

Growth sector trends

Table 31 :

Sector distribution of the GDP

Table 42: $\quad$ Employment trends in percentages of the GDP (vision's scenario ) 


\section{PREFACE}

The Government was able to maintain a stable macroeconomic framework and sustain positive growth rates up to 2008 by implementing the PRSP adopted in April 2003. However, the overall growth rate was not up to the expected level necessary for drastic poverty reduction.

Consequently, under the impetus of His Excellency PAUL BIYA, President of the Republic and in keeping with his policy of "Greater Achievements", which forms part of the long-term development vision, the Government has undertaken to revise the economic growth and poverty reduction strategy. This is proof of the will public authorities have to focus the strategy on the generation of wealth and on the creation of employment opportunities so as to guarantee a fair redistribution of the fruits of growth

The growth and employment strategy paper (GESP) is also a testimony of the Government's will to continue efforts aimed at full achievement of the Millennium Development Goals (MDGs). It is one of the second-generation PRSPs, and so has been designed by the Government, following a dynamic and open process, involving full participation of the population at the grassroots, civil society organizations, the private sector and development partners. The Cameroon Government expresses its deep gratitude to all of them for their support and diligence.

To prepare the GESP it was necessary to realize some major projects, notably : formulation of an economic development vision by 2035, review of sector strategies, participatory consultations, review of statistical surveys and studies for the period running from 2001 to 2008, conduct with support from some partners of the third household survey (ECAM III), reporting on and costing MDGs, mapping out macroeconomic and budgetary guidelines through which a medium-term budgetary framework was designed in compliance with growth estimates by the time of full implementation of the strategy.

The global economic crisis was considered in the preparation of the GESP. Strategies developed therein represent relevant solutions to the problems brought in by this crisis.

Firmly considering the challenge of growth and creation of employment opportunities as being at the very centre of its actions in favour of poverty reduction, the GESP is henceforth, in accordance with the Paris Declaration, the reference framework of government policy and actions as well as the point of convergence for cooperation with development partners. It is hence a vector of the search for growth and redistribution of its fruits right down to the most vulnerable segments of the population with special emphasis on women and the youth. The GESP, which is the first phase of implementation of the long-term development vision, is an overall and integrated strategy paper, a springboard of all action that will be taken over the next ten years.

Preparation of the GESP was, for all those who participated therein, a learning process aimed at continuous improvement. In this respect, the GESP has been designed to cover about ten years, but as a strategic planning paper, it is open to revision, as the need arises, so it can be tailored to the nation's socioeconomic trends and to international circumstances, through a repeated and participatory process.

Now that the country has a reference document addressing the issue of growth, the challenge lies in its proper implementation. In this regard, the Government plans to speed up the reforms underway and take all the appropriate steps, so that improvement of economic performances should be translated into concrete results such as the creation of employment opportunities, poverty reduction, and visible improvement in the living conditions of the population.

To overcome this challenge, the authorities plan to fully play their role while counting on the dynamism of the private sector, the involvement of civil society organizations, the mobilisation of the population and support from economic, technical and financial partners./-

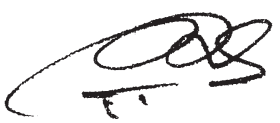

PHILEMON YANG 


\section{EXECUTIVE SUMMARY}

Cameroonian authorities used the participatory approach in designing the Poverty Reduction Strategy Paper (PRSP) in April 2003. For the purpose of monitoring and implementing this paper, the Government established this strategy's steering institutional framework comprising: (i) an Inter-ministerial Committee to monitor implementation of the PRSP, and (ii) a Technical Committee to monitor and evaluate implementation of the PRSP.

This revision of the PRSP aims to correct the irregularities or weaknesses identified during successive evaluations of the paper's implementation, and during participatory consultations in March 2008. The process of revising the strategy has resulted in the growth and employment strategy paper (GESP) and confirmed the option of involving people at the grassroots using the participatory approach. It has been the wish of the people that whatever strategy adopted should form part of a long-term development vision supplemented with multi-year development programmes. This recommendation has been considered with the formulation by the authorities of a development vision to be realized by 2035 and the adoption of a new financial regime in December 2007.

The GESP has been prepared within a context marked by a rising cost of living at the domestic level, the international financial crisis, and the global food and energy crisis. It is the empirical expression of an integrated framework of a medium-term sustainable human development for Cameroon and describes the country's progress towards achieving the MDGs and realizing the vision. Consequently, it is presented as: i) an integrated development framework; ii) a financial coherence framework; iii) a government action and external support coordination framework; iv) an advisory and consultation framework with civil society organizations, the private sector and development partners; v) a guide for analytical works to inform the management of development.

The GESP is divided into seven interdependent chapters dealing with: i) a review of development policies, ii) a long-term development vision and GESP goals; iii) a growth strategy; iv) an employment strategy; v) state governance and strategic management; vi) macroeconomic and budgetary guidelines, vii) an institutional framework and GESP implementation and monitoring mechanisms. A package of priority actions for GESP implementation appears in the annex. It is a summary of more detailed sector packages for programming and monitoring implementation of the seven sector strategies upon which the GESP is based, and is at the same time a source of reference and a coherence framework. The sector packages are compiled into a separate document which is annexed to the GESP.

\section{Review of development policies}

\subsection{Macroeconomic situation}

During the implementation phase of the PRSP, the GDP average growth rate stood at 3.32 per cent between 2003 and 2007. This average falls below that of 4.23 per cent recorded during the period spanning from 2000 to 2002, when Cameroon was not implementing any formal programme aimed basically at alleviating poverty. During the period under review, internal demand was the only growth determining factor, with an average contribution standing at 3.54 per cent (of which 3.12 per cent exclusively for consumption); investment expenditure contributed on average 0.44 per cent (with a low investment rate of 17.8 per cent on average between 2003 and 2007), while net exports were extremely low (0.22 per cent). Hence, economic growth in Cameroon continues to be fragile.

Prices have relatively been under control with an inflation rate of about 1.9 per cent. The foreign account between 2003 and 2008 shows a balance of approximately 44.1 billion CFAF. The balance of trade excluding petroleum shows deficits which tend to widen as the years go by, averaging -432 billion of deficit from 2003 to 2008. As regards currency trends, the period under review shows opposite counterpart trends of currency circulation marked by a large net accumulation of external assets, combined 
with a less significant increase of net credits on the economy and a drop in net domestic credits due basically to advances paid to the State. On average, long-term loans stood at less than 3.5 per cent of the total amount of loans granted.

This is proof that the banking sector does not carry out funding to such an extent as to support sustainable growth. As regards public finances, a drop in the national debt can be noted from 4890.3 billion CFAF in 2005 to 1427.6 billion in late 2008. This trend was basically due to debt relief agreements signed after the country's attainment of the completion point of the HIPC initiative, a prudent and coherent foreign debt policy, in keeping with macroeconomic guidelines, as well as respect of the deadlines set for repayment of foreign public debts. An examination of state financial transactions during the period running from 2003 to 2008 shows clearly that in terms of realization, the 'capital expenditure/total revenue and donations" ratio stood below 25 per cent.

\subsection{Socio-economic situation}

Evaluation of Millennium Development and national Goals. The MDG Monitoring national report, prepared in 2008, suggests that it is very improbable that the country will achieve these goals by 2015 . The gloomy balance sheet concerning the achievement of MDGs stems from the difficulties encountered in implementation of the strategy, as well as from the high implementation costs of related actions.

- MDG 1: Reduce extreme poverty and hunger: From 2001 to 2007, the national proportion of people living below the poverty line remained virtually stable, dropping from 40.2 per cent to 39.9 per cent.

- MDG 2: Ensure education for all: Between 2001 and 2007, the net primary school enrolment ratio witnessed a slight increase by 0.3 point. Concerning elimination of illiteracy among 15- to 24 yearolds, the rate remained virtually stable, increasingly slightly from 82.3 per cent to 83.1 per cent during the period under review.

- MDG 3: Promote gender equality and women's empowerment: The situation of women has been improving, particularly in primary education where the girls/boys ratio rose from 0.83 to 0.89 between 2001 and 2007. Furthermore, the eradication of illiteracy from among women aged 15-24 years has been stable about 0.88 . The same as for targets of MDG 2, Cameroon has sufficient potentialities to reach targets by 2015 .

- MDG 4: Reduce child mortality: Between 1998 and 2004, the mortality rate of children aged below five years dropped from 150.7 per thousand to 144 per thousand, with the national target by 2015 set at 75.8 per thousand. Despite the efforts made in the health domain, the national target may not be reached by 2015 .

- MDG 5: Improve maternal health: In 2004, of the overall number of deaths among women of childbearing age (15-49 years), 19 per cent could be attributed to maternal causes for the period running from 1998 to 2004, as against 26 per cent for 1991-1997. On the contrary, it can be noted that the proportion of deliveries with the assistance of qualified staff seems to be improving with an increase from 78.8 per cent in 1998 to 83.4 per cent in 2004.

- MDG 6: Combat HIV/AIDS, malaria and other illnesses: The third population and health survey conducted in 2004 suggested that the HIV/AIDS prevalence rate in 2004 stood at 5.5 per cent at national level with 6.8 per cent for women as against 4.1 per cent for men aged 15-49 years. Concerning malaria, the prevalence rate stood at 15 per cent in 2005 after dropping from 40 per cent in 2004. As such, the goal of reaching 3 per cent by 2015 seems achievable.

- MDG 7 Ensure environmental sustainability: Despite the increase in protected areas for the purpose of environmental sustainability ( 13 per cent in 2000 as against 18.8 per cent in 2008), the goal of reducing the proportion of people using solid fuels to about 42.2 per cent may by every indication not be achieved. In fact, it stabilized at about 82 per cent. As regards access to safe drinking water, the proportion of people with access to drinking water increased from 40.6 per cent in 2001 to 43.9 per cent in 2007, being a little more than half the target (72.1 per cent) to be reached by 2015 . 
The only target reached is that of proportion of the population with access to a better public sanitation system. It increased from 8.5 per cent in 2001 to 31.7 per cent in 2007.

- MDG 8: Establish a global development partnership: The partnership to be implemented aims particularly to control and reduce youth unemployment rates, especially in towns and cities, provide the underprivileged segments of the population with the essential medications they need, popularize the use of information and communication technology. The results recorded so far suggest that youth unemployment dropped in 2001 and 2007 from 14.3 per cent to 8.2 per cent.

Trend of income poverty. The low GDP annual growth rate during the period under review was a setback to its positive impact on the living conditions of households. And so income poverty, which reduced by 13 points between 1996 and 2001, stabilized in 2001-2007. In 2007, the third census estimated Cameroon's population at close to 17.9 million people of whom 7.1 million are poor. Spatial dimensions of poverty: At the spatial level, significant gaps have been identified in poverty trends between 2001 and 2007. Poverty has reduced sharply in urban areas by 5 points, particularly in the cities of Douala and Yaoundé, while in the rural areas poverty has increased by close to 3 points, especially in the countryside of the Northern region. Factors of poverty: The third population census helped in identifying the macroeconomic factors of poverty, meaning what causes poverty, thus contributing in marginalizing some segments of the population. Some of these factors are the household size, the level of education, the socio-economic group and access to means of production. Living conditions poverty: As regards education, the illiteracy elimination rate which increased by 7 points between 1996 and 2001 (from 61 per cent to 68 per cent) rose by 4 points to 71.9 per cent between 2001 and 2007. In the health domain, children less than five years old and people aged more than fifty years form the most vulnerable segment of the population. The morbidity rate is above 32 per cent in both age brackets. Malaria is the cause of 35 to 40 per cent of the overall number of deaths in health facilities, 50 per cent of morbidity among children below the age of five years, 40 to 45 per cent of medical consultations, and 30 per cent of hospitalizations. Regarding infrastructure and equipment services, it can be noted generally that 58.9 per cent of households own the houses they live in, 29.8 per cent are tenants and 11.3 per cent are lodged free of charge. Generally, of every two households one has access to safe drinking water. The proportion is the same for access to electricity while of every seven households one has access to cooking gas.

\subsection{Remarks by beneficiaries}

Le Gouvernement a organisé des consultations participatives pour obtenir l'opinion des populations sur le bilan de la mise en œuvre du DSRP I, l'impact des politiques et des propositions d'amélioration. D'une manière générale, les populations reconnaissent que les réalisations effectuées au cours de la période de mise en œuvre du DSRP (2003 - 2007), ont permis d'améliorer l'accès aux services sociaux de base. Cependant de nombreuses insuffisances qui freinent une réelle réduction de la pauvreté ont été relevées par les populations. Elles portent sur : i) l'enclavement des populations (l'électricité, les routes et les $\mathrm{TIC)}$; ii) l'accès à l'eau potable ; iii) l'accès aux intrants agricoles, à la terre cultivable et aux pâturage ; iv) le désengagement quasi total de l'Etat du monde rural ; v) l'insuffisance d'enseignants à tous les niveaux d'enseignement, leur déploiement déséquilibré ; vi) l'accès aux médicaments et aux plateaux techniques dans les hôpitaux ; vii) la gestion centralisée des marchés publics; et viii) l'insécurité grandissante et généralisée.

En vue de remédier à ces difficultés, des propositions d'amélioration ont été faites dans divers domaines : i) mettre en place une véritable politique de désenclavement du pays axée sur l'entretien routier, le bitumage des axes prioritaires, la réhabilitation des ouvrages d'art et l'ouverture de nouvelles routes. ii) poursuivre les programmes d'électrification rurale et réduire les coupures intempestives et régulières de courant électrique ; iii) poursuivre la construction des adductions d'eau (puits, forages, etc.), en tenant compte des spécificités régionales; iv) poursuivre la construction et l'équipement des salles de classe pour tous les niveaux d'enseignement, en respectant la carte scolaire pour éviter la mauvaise répartition observée, mettre en place et équiper des bibliothèques, rendre effective la gratuité de l'enseignement 
dans les écoles publiques primaires; v) rendre disponible les médicaments génériques, poursuivre la construction et l'équipement des centres de santé et l'affectation de personnels qualifiés; vi) promouvoir les emplois ruraux, les petits métiers; les emplois dans le secteur minier et forestier ; les activités à haute intensité de main d'œuvre (HIMO) et financer les activités des groupes vulnérables; vii) former les jeunes dans le domaine de l'exploitation minière, pour faciliter leur recrutement dans les sociétés d'exploitation minière, promouvoir la production et la commercialisation des produits forestiers non ligneux ; et viii) améliorer la qualité de la dépense publique, accélérer la décentralisation, améliorer l'accès à l'information sur la gestion des affaires publiques, et poursuivre la réforme du système judiciaire.

\subsection{Major sector challenges}

Despite implementation of the PRSP, Cameroon's economy has not witnessed any major structural change. It continues to face a number of challenges likely to hamper achieving the desired results. In fact, it continues to be fragile and rocked by structural weaknesses, relating to low competitiveness of the productive sector and deficiencies in key factors of production such as infrastructure and energy.

A non-competitive production sector. The main challenge faced in the rural sector is the transition to a semi-intensive and industrial rural production sector that will help: (i) ensure security and sufficiency in domestic consumption, (ii) provide raw material to the processing industry and create a domestic market and consumption for open industries and lastly, (iii) increase exports, thus improve on the trade balance. The manufacturing industry should account for 15 per cent of the GDP by 2020. That is the challenge the Government intends to address in the Cameroonian industry while that in the sector of services is developing the use of ICT and science and technology parks so the country can become a "net exporter" of services. Finally, the process of negotiating EPAs, which should lead to the creation of a free trade zone between the EU and ECCAS, also highlights a significant number of crucial challenges and stakes. High factor costs. The main factors of production, physical and human capital, have structural deficiencies which sector strategies have not fully addressed. As such, in the road sub-sector where 85 per cent of domestic transport activitytakes place, despite great progress at the operational and strategic level, the available means and the strategies introduced are not adequate to close the wide structural gap between demand and supply: only 10 per cent of the approximately $50000 \mathrm{~km}$ domestic road network is tarred, and the proportion of roads in good condition in 2005 stood at 24 per cent. The low production capacities and dilapidation of energy installations are a setback to the development of home enterprises and industries, and do not at the same time provide any incentive to investments in the country whose hydro-electric and gas potential is a source of great expectations. Despite the significant progress in ICT, serious problems of access and quality persist, with particularly an optic fibre wire, whose installation and commercialization are not yet fully effective, and an access index to the digital estimated at 0.16 in 2002 and making Cameroon one of the countries which have low access to this technology.

\subsection{Opportunities and threats}

For these many challenges to be overcome, the Cameroon government is conscious of its advantages, as well as its likely risk factors. Among the advantages are rich natural resources, and the package of reforms which have already been carried out in a country well known for its stable institutions. However, the various international economic crises may undermine the strength of a country whose economic fabric is still fragile and where most risks identified in the PRSP in April 2003 are yet to be cleared.

The April 2003 PRSP pointed to two types of risks as main factors: resurgence of internal shocks and persistence of structural rigidities. The Cameroonian authorities are aware that both problems have really been a hindrance to smooth implementation of the first generation PRSP. These varied risks are still current now that the GESP is being prepared: they are thus the main risk factors. 


\section{Vision and goals}

\subsection{Development goals by 2035}

The national strategic guidelines are centred on the long-term development vision (2035), of which this growth and employment strategy is part, covering the first ten years of the vision. To enhance and fully establish the economic recovery started a decade ago, the Government has prepared a Cameroon shared vision development paper to be fully implemented by 2035. It reads as follows:"CAMEROON: AN EMERGING, DEMOCRATIC AND UNITED COUNTRY DESPITE ITS DIVERSITY". The will to become an emerging, democratic and united country, despite its diversity has four overall goals, namely: (i) reducing poverty to a socially acceptable level; (ii) becoming a medium-income country; (iii) acquiring the status of a Newly Industrialized Country; and (iv) reinforcing national unity and consolidating the democratic process.

\subsection{Growth and employment strategy goals}

The GESP which will cover the first ten years of the long-term development vision will focus on accelerating growth, creating formal employment and reducing poverty, consequently, it aims to (i) increase the average annual growth rate to 5.5 per cent over the period 2010-2020; (ii) reduce the underemployment rate from 75.8 per cent to less than 50 per cent in 2020 with the creation of tens of thousands of formal positions per annum over the next ten years; (iii) reducing the income poverty rate from 39.9 per cent in 2007 to 28.7 per cent in 2020.

\subsection{Key considerations for implementation of the strategy}

To achieve the above-mentioned goals, the Government plans to implement coherently and in an integrated manner: (i) a growth strategy, (ii) an employment strategy, (iii) a strategy to improve state governance and strategic management. A number of basic and interrelated elements must be considered crucial and essential for effective implementation of the strategy : (i) progressive increase from 20 to 30 per cent (by 2020) of the share of public investment in overall state expenditure; (ii) massive allocation of resources to major projects, in order to put an end to the widespread insignificant public investment projects ; (iii) measures to considerably streamline contract awarding procedures; (iv) broaden economic policy options by activating the usual monetary policy possibilities.

\section{Growth strategy}

\subsection{Infrastructure development}

Aware of the important role played by infrastructure in facilitating exchange and promoting significant and sustainable growth through the competitiveness generated by the good quality of same, the Government plans to invest massively in infrastructure during the period of implementation of the strategy.

Energy. By implementing the energy maintenance, rehabilitation and capacity-building programmes of the country, Cameroon aims to finally put an end to the structural deficit; supplement energy needs to achieve the expected growth results, become an electricity exporter, and thus contribute to the country's trade balance. By 2020 the electricity production capacity is expected to reach $3000 \mathrm{MW}$. The energy sub-sector development programme has short, medium and long term projects, pursuing initially outlined specific goals. Among the short term projects feature, particularly, the Lom Pangar dam, the Yassa thermal station, and the Kribi gas station. In the medium term, the following are envisaged: the Memve'ele dam, the Nachtigal, Song Mbengue, Warak, Colomines and Ndockayo stations. In the long term, there are plans to develop several sites that have the potential to export energy. The overall cost of this programme that spans over a decade stands at 5853 billion CFA francs for the construction of electricity production and transportation facilities using major networks and at 663 billion CFA francs for the rural electrification programme. 
Building construction and public works. In the road sub-sector, the Government's medium and long term strategic guidelines, for the period of the strategy, are consistent with the bold Road Master Plan and the designed sector strategy. Road maintenance activities during the period of the strategy aim at a net improvement of the service quality (55 per cent of the network is in good condition), with the introduction of a relevant intervention strategy. Rehabilitation of the road network (2000 km of tarred roads to be rehabilitated by 2020), and increased tarring of earth roads (more than $3500 \mathrm{~km}$ by 2020) will complete execution of this programme. Intervention priorities will concern supporting major industrial and agropastoral projects, (trans-African, North-South, CEMAC network) regional corridors, the network of trunk ' $A$ ' roads, as well as major infrastructure projects to support the private sector (second bridge over River Wouri, the Yaoundé-Douala-Bafoussam-Yaoundé) road stretches. Major institutional reforms will be required to supplement this strategy. And so special emphasis will be laid on: (i) making road contractors responsible and more efficient (ii) enhancing planning and programming by preparing and implementing an intervention strategy which emphasizes respect for standards of the works executed to the detriment of thinly spreading out resources, (iii) reinforcing the park of civil engineering equipment, (iv) organizing the private sector in order to have a fabric of highly performing enterprises and consultancies, (v) looking for materials or processes capable of extending the duration of interventions, particularly in road maintenance and, (vi) resorting each time possible to labour-intensive techniques to reduce costs and promote employment.

Transport. Transport should be based on the country's comparative advantages in order to contribute properly to economic growth and poverty alleviation. A multidimensional approach will be the norm, so an integrated, highly-performing, nationwide, and transnational transport network can be built at an affordable cost. The Government will put emphasis on the development of new port and railway facilities attendant to growth-oriented priority projects. The idea will be mainly to i) construct a deep seaport in Kribi; ii) construct a deep seaport in Limbe; iii) construct an Oil Yard in Limbe; iv) construct new railways (plus $1000 \mathrm{~km}$ ) following international standards.

Information and communication technology. The strategic goals in the area of Telecommunications/ICT to be achieved by 2020 will be in particular to: (i) increase the telephone coverage percentage of landlines to 45 and the coverage percentage of mobile lines to 65; (ii) provide 40000 villages with modern means of telecommunication; (iii) provide the public with access of up to $2 \mathrm{Mb} / \mathrm{s}$ in all the towns and cities where there is a digital station; (iv) multiply by 50 the number of direct and indirect employment positions.

Postal and giro services. In this area, the strategy will help organize and increase public and private postal services by 2020 in such a way as to fully satisfy demand in quantity and in quality at affordable prices. Two programmes must thus be carried through: (i) making the network dense and improving national postal coverage in order to ensure geographical balance in postal services, (ii) developing the universal postal service in order to make postal services affordable to all.

Urban development and housing infrastructure. The challenge in this domain lies in creating an integrated national economic space. Not only will urban development be brought under control (urbanization rate of 57.3 per cent in 2020), nor will these only become producer and consumer centres necessary for the development of the industrial sector. Also, suburban towns and cities will develop and average and secondary towns will emerge with the capability of structuring economic activities in urban areas and of contributing to the development of surrounding rural areas. To achieve these goals, six strategies were identified: (i) maintaining and rehabilitating urban infrastructure, (ii) developing urban infrastructure (construction of $150 \mathrm{~km}$ of roads and of 17000 low-cost houses), (iii) improving access to basic urban services, (iv) controlling land occupation, (v) protecting vulnerable social groups, and(vi) building the institutional capacity of this sector.

Water and sanitation. Access to safe drinking water and to basic sanitation infrastructure in the rural areas is limited. As such, the government plans to improve on the situation by increasing the access rate to safe drinking water by 2020 to 75 per cent, and so: (i) rehabilitate existing infrastructure most of which was realized more than twenty years ago; (ii) extend existing networks which have lagged behind urban expansion and population growth; (iii) encourage the realization of large-scale connection pro- 
grammes. For the urban areas, the Government has opted, in its April 2007 urban water supply policy letter, for public/private sector partnership and the creation of two entities each responsible for infrastructure and distribution respectively. In the rural areas, the water supply policy targets the following main goals: (i) better planning of works in response to demand, increase coverage of services and elimination of cases of incoherence; (ii) making the investments carried out sustainable by improving maintenance, securing funding and projecting renewal funding, and (iii) less dependence on the State in order to base the sector's development on all the available active forces.

Land management. With a view to Cameroon's emergence, the authorities plan to draft a national land tenure management strategy with due regard for property administered or managed by the State. The GESP strongly seeks to eradicate the obstacles to a rational management of such property by setting the following overall goals : i) lifting land constraints to facilitate infrastructure development and improving on the business climate; ii) rationalizing the allocation of land resources and improving state property governance; iii) building the capacity of administrations in charge of lands, land tenure and state property; iii) facilitating regional integration and supporting implementation of decentralization.

\subsection{Modernization of the production mechanism}

Rural sector. After adoption in 2005 of the rural sector development strategy and the poor results achieved since the start of its implementation, the Government plans to launch a vast programme to increase agricultural output so to meet the food needs not only of the population, but also of agribusiness. In this regard, the government will modernize the production system. The idea will be to: (i) make accessible and available factors of production such as land, water, and farm inputs; (ii) promote access to technological innovations by reinforcing the research/agricultural extension interrelationship; and (iii) develop competitiveness of production industries.

The Government plans to lay emphasis on the development of agricultural hyper extension in different regions of the country according to their ecological peculiarities in order to realize economies of scale and increase production. In addition, serious efforts will be made to eliminate lack of access to production areas in order to ensure full development of plantation and subsistence agriculture.

Mining. The goals pursued in this sector consist in promoting and encouraging research, mining and the processing of mineral resources necessary for the economic and social development of the country. In order to develop the existing mineral potential of the country, the authorities plan to create a national mining corporation, which will establish joint ventures with private partners, better inform domestic and foreign private investors on the geological and mining potential of the country by providing them with reliable geological maps and data, developing training programmes in the mining industry for nationals.

Social economy and handicrafts. The government aims to improve the performance and output of social economy. To this end, the authorities are committed to (i) creating a political, institutional, legal and statutory framework appropriate for the development of collective entrepreneurship in Cameroon, (ii) developing human resources that can enable the component to thrive, (iii) promoting collective or group entrepreneurship as one of the reliable strategies by creating and developing viable social economy organizations and enterprises which could help effectively alleviate poverty while promoting economic growth. Moreover, the government has resolved to make handicrafts more attractive by supporting the sector's organization and structuring, building the capacity of artisans and consolidating artisan enterprises in its economic environment, as well as improving the marketing system.

Industry and services. The Government has undertaken to introduce the reforms required to make this sector's environment more attractive, and to establish an operational mechanism to act as incentive and stimulus to private investment, so the latter can effectively play its role as the driving force of economic growth. This will involve resolving problems of infrastructure shortage, reducing the difficulties faced in acquiring funding, sustaining a long-term general programme to develop the production industry, and in the mediumterm as well as in conjunction with some development partners, special programmes aimed at stimulating competitiveness in some industries with a high growth and enterprise (SME and SMI) expansion potential. 


\subsection{Human development}

The social sector development strategies will not only improve the people's living conditions, but also provide a powerful human capital, capable of sustaining economic growth. Accordingly, the authorities will continue carrying out investments in the various social categories, including health, education and vocational training, with special emphasis on youth and women, as well as coordinating and caring for the other socially vulnerable groups.

Health. Improving the health conditions of the population is a goal pursued both in social development and economic growth. The Government plans to achieve this goal by implementing the updated health sector strategy, in keeping with the MDGs. The strategy basically seeks to provide quality health services and care to all by improving supply and financing demand. The goal is to reduce morbidity by a third among the poor and most underprivileged segments of the population; mortality by two thirds among children aged below five years, maternal mortality by three quarters, HIV/AIDS prevalence by 50 per cent, and the death rate due to malaria to less than 10 per cent by the time of full implementation of the strategy. This strategy will affect four areas of intervention, namely: (i) health of the mother, the adolescent, and the child, (ii) fighting disease, (iii) promoting healthcare, and (iv) making health districts more viable. The interventions based on supply will be supplemented with strong demand-stimulating actions such as sharing health risks by encouraging the creation of health insurance associations and coverage of at least 40 per cent of the population through a health risk sharing system.

Vocational education and training. The Government plans to lay emphasis on the creation of human capital, notably through (i) a quality elementary education covering the primary and junior secondary level; (ii) a quality senior secondary education resting on a growing balance between grammar education and technical education, and laying the groundwork for higher studies in fields that are of priority to development; (iii) vocational training based on a modernized and considerably enhanced mechanism so as to be able to impart learners leaving elementary and secondary education with a wide range of knowledge oriented towards skills required on the employment market and empowering the beneficiaries to create employment, (iv) a university education with a professional focus ; $(v)$ expanded continuing training supplemented with a system for evaluating achievements through experience ; and (vi) effective mastery of numbers relevant to guaranteeing the quality of education, thus presupposing designing a transparent and credible influx regulatory system, enhancing the school guidance mechanism and improving the salary scale for technical positions.

The following measures seek to develop education and vocational training: (i) improving access to basic education, (ii) improving the quality of teachers and their working conditions, (iii) choosing appropriate syllabuses, and (iv) increasing and maintaining school infrastructure. As in the health domain, the State will rationally and efficiently ensure that schools are opened in developed areas that have other services (water, energy, health facilities, telephone), while also making sure that there are schools in the rural areas, so teachers can work in acceptable conditions.

Gender. To promote gender, the Government will continue sensitizing parents and the community, particularly in the rural areas where tradition and custom are rife to enable the girl child benefit from the same educational opportunities. In the same vein, the State and the community will see to it that girls are equitably represented in all sectors with regard to vocational training, higher education, and employment.

Social protection. In order to consolidate achievements and extend social security coverage, the Government plans to reform the central social protection mechanism in Cameroon. The purpose is to progressively involve all social groups that have so far been left on the margins of the system. An outline law should in the very near future lay out the coverage and funding principles, institutions and mechanisms of social security in Cameroon.

National solidarity. The Government will continue to set up specialized structures for the physically challenged and other vulnerable persons. Using the vulnerable approach, it plans to improve their access to training in all the sectors, further facilitate their integration into occupational circles so to reduce their 
level of dependence. Special facilities for entering buildings will be provided to them and emphasis will be laid on financial support to them in order to promote their self-employment.

\subsection{Regional integration and diversification of trade}

For growth to be sustainable and create employment, Cameroon's development and trade diversification policy will aim to enhance sub-regional and regional integration, as well as find new outlets in European, American or Asian markets. It will be based chiefly on crops while taking advantage of the rather favourable environment and ecology, and especially by progressing from the primary to the secondary sector.

Regional integration. The first challenge is to consolidate the CEMAC sub-region in order to take full advantage of the treaties signed pertaining to the free movement of persons and goods. In this regard, the Cameroon Government is fully responsible for stimulating the dynamics of this integration and imposing itself by not hesitating in assuming its leadership position in the sub-region. The second challenge is the market of the Economic Community of Central African States, where there are smaller markets with a high development potential such as those of the Democratic Republic of Congo and Angola. The third stake is that of intensifying economic ties with Nigeria and orienting them towards the formal sector. The trade development policy may later extend to the West African sub-region, to Southern Africa, East and North Africa.

North-South cooperation. The authorities will seek to consolidate European markets with the exchange of "traditional" products made up of raw materials or primary products (timber, cocoa, coffee, banana, rubber, etc.) on exportation, and heavy industrial products on importation. The recent signing of the Economic Partnership Agreement (EPA) with the European Union will gradually establish a free trade zone between ACP countries and member countries of the European Union. As regards the North American market, Cameroon will henceforth implement the AGOA provisions to take advantage of the export opportunities it provides especially in textile and cultural products.

Trade with emerging countries. South American and Asian countries will have to be explored and negotiated within the context of emerging countries seeking strategic positioning as well as political and diplomatic overtures. The policy of mutually beneficial cooperation advocated by member countries of this group (China, Brazil, India, Korea, etc.) and the high population density in these countries make them a good choice as development and trading partners.

\subsection{Financing the economy}

Fiscal policy. Aware that no sustainable economic recovery can be achieved without a vibrant investment funding policy, the Government is committed to enhancing measures taken as part of previous programmes. These programmes are the springboard of a fiscal policy that attracts both savings and cost cuts in acquiring funding. The authorities will ensure that the advantages accruing from provisions of the Investment Code and of the free trade zone will be taken into account, while the implementing instruments of the Investment Charter are being prepared, with the latter proposing that the above-mentioned regimes should be repealed.

Banking system. Together with its CEMAC partners, the State plans to spare no effort in resolving the problem of excess liquidity in the banking sector so it can provide medium and long term loans. If the need arises, the State will propose monetary regulation of actions that act as incentives and stimuli to banks by increasing their interest in prioritizing private investments as against ordinary banking services.

Micro finance. With a view to increasing and expanding basic financial services as well as to improving the quality of services provided by Micro Finance Establishments (MFEs), the Government plans to : (i) intensify proprietor, manager and employee training activities of MFEs; (ii) introduce a first-level MFE supervisory and monitoring mechanism by the national currency authority, compatible with the rules and regulations of COBAC; (iii) further enhance monetarization of our economy by extending self-regulation of MFE payment systems. 
Reinforcing mobilization of domestic savings. Activities relating to this policy will comprise: (i) developing Micro Finance institutions into commercial banks, (ii) revitalizing local financial markets I, (iii) increasingly mobilizing resources from the diaspora, and (iv) establishing specialized financial institutions.

Debt contracting strategy. The major guidelines of the debt contracting strategy hinge respectively on considering the Convergence Programme and the credit/liquidity crisis. Concerning convergence, the Government will pursue a prudent debt contracting policy and see to sustainable management of the national debt based on a debt contracting strategy compatible with the macroeconomic framework and medium-term budgetary goals. Furthermore, the Government will continue bona fide negotiations with private creditors who rejected the transactions to repurchase debts in 2003, in order to clear the debt owed the London Club, without failing to consider the comparability of the transaction. The Government will continue with its bold policy of rapidly servicing its national debt; in order to restore the confidence of businesses and partners, as well as not to cause new arrears to accrue.

\section{Employment strategy}

The growth and employment strategy addresses unemployment in three aspects, notably: (i) increasing decent employment opportunities; (ii) satisfying the demand for employment; and (iii) improving market efficiency.

\subsection{Accroissement de l'offre d'emplois}

Salaried employment. The Government relies basically on the development of SMEs to resolve massive unemployment. It plans particularly to address visible underemployment which is estimated at 11 per cent of the active working population. The intention is that by 2020 visible underemployment should be completely eradicated and the overall unemployment rate should be maintained at 7 per cent. The introduction of the programme to create employment opportunities for the most underprivileged social groups (youth, women, vulnerable groups and people living with disabilities) in the public service will thus supplement decent employment opportunities.

Targeted self-employment The authorities plan to promote self-employment to support the development of growth-stimulating sectors, particularly the rural sector, handicrafts and services. Specifically, it is expected that self-employment should contribute significantly in reducing visible underemployment to less than 50 per cent and in transforming informal sector undertakings to the formal sector of the economy. In the rural sector and in keeping with the policy of developing plantation agriculture, incentives in terms of measures will be introduced to facilitate the establishment of graduates from schools and colleges of agriculture through: (i) training in mounting large-scale agricultural projects; (ii) facilitating access to credits; (iii) facilitating access to modern agricultural inputs.

Furthermore, the execution of some major projects often brings about development of related activities of benefit to people living in the locality. And so specialized training programmes, taking into account the types of projects, will be developed to facilitate integration of local inhabitants into these activities. In view of the immense potential of handicrafts, the Government plans to develop each and every aspect thereof, so the sector can become a really attractive activity creating employment opportunities, generating revenue, and spurring growth. In the area of services, specialized programmes will be implemented to encourage the settlement of youth graduating from vocational training establishments, alongside the strategy to develop profitable industries (clothing, tourism, etc.).

Migration of the informal sector towards the formal sector: The strategy will basically consist of supporting actors in the informal sector in organizing their activities into very small enterprises (VSE) by: (i) flexible tax regulations; (ii) streamlined administrative registration including social security; (iii) training aimed at helping these actors to better monitor their activities through basic accounting; and (iv) assistance to establsih and funding.

Introduction of an environment with incentives : The strategy to be adopted in order to help the private sector play its economic role of creating employment opportunities will have two aspects: (i) reactivating 
the existing environment for tripartite consultations between economic administrations, different actors in the private sector, and civil society organizations in order to review and clear blockages to the creation of employment opportunities; (ii) implementing a package of measures as incentives to facilitating the creation of employment opportunities.

Implementation of the strategy to promote labour-intensive approaches. Four (04) aspects were identified: (i) developing an institutional political environment appropriate for LI approaches; (ii) building the capacity of stakeholders; (iii) promoting use of $\mathrm{LI}$ approaches in public investments; and (iv) enhancing knowledge of LI approaches. Particularly, in the domain of building construction and public works, the strategy will consist of using $\mathrm{LI}$ approaches in areas such as rural road maintenance and civil engineering projects.

\subsection{Satisfaction of the demand for employment}

i. The strategy will be based on increasing and diversifying training by: (i) improving and standardizing training modules and creating about 30 new training modules each year; (ii) diversifying training methods and fields of study taking into account profitable industries; (iii) reducing disparities in admission opportunities (geographical area, gender, specific groups) through in-depth reforms and restructuring of the location map of public vocational training institutions; and (iv) developing wholesale training by establishing a capacity-building and skills-development centre. Second, the demand for employment will be satisfied by optimizing the training system's domestic and foreign output. The Government also plans to improve management of the vocational training system by involving professional circles and enterprises.

\subsection{Improvement of efficiency of the employment market}

The aim is to make the employment market transparent and succeed in integrating the increasing number of applicants in professional circles. In this regard, it will be worthwhile to: (i) make many more enterprises clearly indicate their needs in human resources through formal channels, so as to have the best of chances to find people with the desired profiles on the market; (ii) help applicants for employment to mount good professional projects and so increase their chances of speedily finding employment; and (iii) ensure that actors are properly notified and informed about employment market trends.

Formal recruitment channels for applicants will be reinforced only if enterprise prospecting activities are intensified by the National Employment Fund and other structures, and the placements made are strictly monitored. Incentives and, if need be, coercive measures will be introduced to make enterprises indicate their priority needs in manpower to recognized public and private placement establishments.

Concerning recruitment services, one of the utmost priorities will be to build their capacities and step up vocational guidance by creating links between the National Employment Fund (NEF) and other public structures, in such a way as to set up employment agencies in all the divisions of the country and provide them with qualified manpower. Lastly, the employment strategy's implementing and monitoring/evaluation mechanism will be conducted at the strategic and operational level.

\section{State governance and strategic management}

\subsection{Governance and state of law}

Two major goals are pursued with regard to governance and the state of law: (i) guaranteeing more respect for individual rights and public freedoms to all, and (ii) reinforcing public affairs management. To achieve the above-mentioned goals, the authorities plan to intervene in four aspects a) reinforcing the state of law and the security of persons and property; b) improving the business environment; c) reinforcing the anti-corruption drive and fighting embezzlement; d) improving public affairs management citizen information and monitoring. 
Reinforcing the state of law and the security of persons and property In an attempt to improve Cameroon's socio-political environment, and in order to restore the confidence and serenity of citizens and investors, the authorities plan to work with a view to : i) improving the electoral system ; ii) improving access to and the quality of our justice system; iii) consolidating the national human rights promotion and protection mechanism; iv) reinforcing maintenance of law and order as well as security along the borders.

Improving on the business environment. As regards the business environment, government action will involve reinforcing monitoring and dialogue with the private sector on the business climate, pursuing harmonization of the legal framework with the OHADA law and implementing the investment charter.

Reinforcing the anti-corruption drive and fighting embezzlement. In order to significantly reduce corruption, the Government is committed to intensifying efforts aimed at combating this ill by reinforcing anti-corruption mechanisms, effectively involving the Executive, the Legislature, and the Judiciary.

Improving citizen access to information. In this respect, the authorities plan to orient their actions mainly towards (i) public affairs management participatory monitoring, (ii) systematic dissemination of information on public affairs such as development projects, monitoring/evaluation and audit reports (iii) intensification of rural community radios, taking into account the positive impact they were noted to have during the April 2003 PRSP implementation period.

\subsection{Strategic management of the State}

Deepening the decentralization process. Besides the effective creation of regions, the authorities plan to carry through, at their earliest convenience, the process of transferring responsibilities and resources to councils, continue with the capacity-building of elected council officials and technicians so a real local government service and administration in charge of decentralization can emerge, and to reinforce the economic role of councils. Planning, which by law is the responsibility of regions and councils, will be promoted particularly through systematic introduction of council and regional development plans, which will be used as a framework for dialogue, proper use of support from the central administration for regional and local development.

Continuing modernization of the public administration. The authorities intend to continue modernization of the public administration and make it a development tool by improving the institutional, administrative management, and governance framework. In this light, emphasis will be put on capacity-building in strategic planning (sector strategies and MTDFs, local development plans, progressive project management), regulation of the economy and public finance management.

Managing the State's human resources. Managing the public service staff strength and salary package to minimize cost and increase output is a strongly pursued goal when we consider what still has to be done in this area. In this regard, the authorities plan to continue ongoing efforts or those envisaged with a view to modernizing and making the public service more efficient by improving the institutional framework, streamlining administrative management procedures and promoting good governance.

Protecting the national economic space. Reacting to the development of illicit trade, which is a setback to an ensuing domestic production mechanism, the authorities envisage reinforcing fraud, contraband and major international trafficking elimination mechanisms, with the three-fold goal of facilitating, guaranteeing, and monitoring quality standards.

\section{Macroeconomic and budgetary framework}

Macroeconomic and budgetary framework help in the analysis of statistics from the guidelines laid out in the GESP on: (i) the overall growth pattern and sector contributions, levels of investment and financing the economy as a whole, (ii) the public expenditure pattern resulting from the allocation of budgetary resources to these sectors to finance the priority programmes identified, and (iii) prospects for creating employ- 
ment opportunities and poverty alleviation. This analysis has three stages: (i) simulation of a reference framework, (ii) simulation of a bolder variant based on the vision with the ultimate aim of making Cameroon an emerging country by 2035 , and (iii) risks analysis.

Simulating a reference framework. The non-petroleum GDP annual growth rate in the reference scenario would reach an annual average of 5.7 per cent between 2010 and 2020 as against 4 per cent over the past ten years, showing an increase of more than 1.7 growth points per annum. The primary sector would witness a 5 per cent annual growth rate during the period 2010-2020, peaking at 5.5 per cent in 2015 . Subsistence agriculture will be the main driving force behind this growth and account all alone for 70 per cent of the sector's GDP. The contribution of the secondary sector would be supported over the 2010-2020 period with a 5.1 per cent annual growth rate, mainly due to implementation of major energy projects and resumption of activity in the building construction and public works sector, which will rekindle a boom in the medium term of manufacturing industries. The tertiary sector would thrive as a result of the resumption of activity in the other sectors. Improvement in road and port infrastructure would be a stimulus to transport. Effective installation and use of the optic fibre would have a similar impact on telecommunications. As such, an average annual growth rate of 6 per cent is expected in this sector between 2010 and 2020 as against 5.5 per cent over the last ten years.

Economic growth continues to be supported by domestic demand. At the same time, public and private consumption continues to be sustainable during this period, with the share of consumption in the GDP estimated at 70.1 per cent in 2020. In the area of foreign trade, the drop in oil production would contribute in reducing exports up to 2010 , and this trend would be checked by prospects of a start of production in new fields, as well as an increase in the production of the chief export crops resulting from good performances projected in agribusiness and exports. In terms of volume, imports will increase by 6.2 per cent during the period 2010-2020 as a result of execution of major projects on infrastructure: the trade balance would drop during this period due to the import of capital goods. On the heels of the recovery expected in 2010, inflation should return to its initial level over the last ten years being 2.5 per cent in the medium term.

Despite dwindling oil production prospects and the entry into force of EPAs' ${ }^{\prime}$, revenue would in all make up more than 15 per cent of the GDP by 2020. The non-oil revenue ratio to the GDP will rise from 12.3 per cent in 2008 to 13.1 per cent in 2020. The tax pressure rate would be maintained at above 11 per cent in order to mobilize revenue from the taxation administration. Accordingly, the non-oil primary balance would improve by 2.1 points, increasing from -5.8 per cent in 2008 to -3.7 per cent of the GDP in 2020 . As for investments funded with domestic resources, they show an increase by 0.9 point; from 5.5 per cent in 2008 to 6.4 per cent in 2015 , before stabilizing at about 6.2 per cent by the time the strategy is fully implemented. Their share in overall expenditure will increase from 30.9 per cent in 2010 to 36.4 per cent in 2020.

Regarding monetary policy, the State will have to stretch hands into its reserves, reduce its deposits in the banking system, or possibly resort to statutory advanced payments. It is expected that credits to the economy will continue to increase from 12.2 per cent of the GDP in 2009 to 14.6 per cent in 2020 . At the time the GDP is increasing, the ratio of money supply to the GDP will increase by 1.2 points from 20.2 per cent of the GDP in 2008 to 21.4 per cent in 2020.

Simulating a bold variant of the vision. This scenario is based on the hypothesis of fully achieving the goals of the development vision by 2035. In the short term, the growth patterns recorded in the two scenarios are not significantly different in view of the time allowed for effective implementation of the different investment programmes. On the contrary, the non-oil GDP growth gap between the two scenarios is 2.5 per cent on average over the 2012-2020 period. In addition, the annual growth rate stands at 9.5 per cent, being 3.6 per cent above that of the reference scenario between 2016 and 2020 .

Investments will increase by 13.8 per cent between 2010 and 2020 as against 9.1 per cent in the reference scenario. This trend can be translated into a higher investment rate estimated at 31.0 per cent as

A survey ordered by MINEPAT to assess the impact of EPAs on foreign trade and public finances estimated that revenue losses will increase from 3.9 billion in 2010 to 168.2 billion in 2023 
against 23.4 per cent in the reference scenario. The significant non-oil GDP growth in the vision's scenario compared to the reference scenario makes it possible to mobilize considerable additional internal resources which will nonetheless be insufficient to support expenditure increases. In fact the gap between the two scenarios is gradually widening due to an increase by 3 points of the GDP in capital expenditure, compared to that of the reference scenario.

Risk analysis. Basically, they consist in modifying some key hypotheses of this scenario in order to assess the impact on the macroeconomic and budgetary framework, employment and poverty. The risk here lies in delays in execution of energy projects or postponement of implementation of major building construction and public works projects. Delayed execution of energy projects would lead to an average energy supply growth rate of 7 per cent instead of the initially envisaged 14 per cent during the period under consideration. The average annual GDP growth rate would drop by about 0.5 point per annum, being 5 growth points within ten years. Regarding public finances, losses in non-oil revenue would amount to 60 billion FCFAF on average per annum over the 2010-2020 period, compared to the reference scenario. Similarly, a simulation reducing by half the building construction and public works growth rate over the 2009-2020 period (delays pertaining to the deep seaport and road projects) is holding down GDP growth by about 0.4 point on average per annum, being a growth loss of 4 points in 10 years. Concerning public finances, losses amount to an annual average of 50 billion CFAF between 2010 and 2020 compared to the reference scenario.

In the same light, signature of EPAs will have an impact in the medium and long terms leading to net fiscal losses. A simulation of the impact of this agreement without the implementation of its local enterprises development and upgrading component show accrued losses in non oil-revenue amounting to CFA F 547.7 billion over the 2010-2020 period, including 459.6 billion between 2015 and 2020. This gap represents 0.4 per cent of the GDP on average over this period. The situation would exacerbate the needs in terms of financing, which would increase from 216.3 billion in 2010 to 1167.5 billion in 2020 .

Impact on poverty, the other MDGs and employment. Simulations were carried out to assess the consequences of the various growth patterns and budgetary choices on the medium-term trend of poverty and of the other MDG indicators. The income poverty rate would increase from 39.9 per cent in 2007 to 28.7 in 2020. Under hypotheses of the vision's scenario, the MDG target (25 per cent) would be reached in 2017. On the basis of rural sector development hypotheses in the reference scenario, the percentage of children less than five years old and who have insufficient weight may reduce by the time the strategy is fully implemented to 13.3 per cent in 2015 and to 10.2 per cent in 2020. This percentage may hit the MDG target $(8 \%)$ by 2020 . Under the reference scenario, the net primary school enrolment ratio will reach the targeted 100 per cent by the time of full implementation of the strategy after stabilizing at 88.6 per cent in 2015. On this basis and under the hypothesis of proper implementation of the health strategy, the maternal mortality rate will witness a change of trend to stand at 410 in 2015 and reach the target in 2019. Considering the vision's scenario, the maternal mortality rate will increase to 392 by 2015 and hit the target by 2017.

On the basis of the relationship between a boom in activity and creation of employment opportunities, a simulation of employment growth rates over the 2010-2020 period was conducted. During the period of implementation of the strategy, it is envisaged that the growth pattern of the reference scenario provides for a net creation of about 495000 employment opportunities on annual average (as against 690000 for the vision's scenario). An analysis of formal employment opportunities shows a net creation of about 90000 positions per annum over this period.

\section{Institutional framework and implementation monitoring mechanisms of the GESP}

\subsection{Implementing institutional framework}

Taking into account the role of the GESP as a national development strategy and reference framework of the Government's actions during the period under consideration, the institutional framework of its implemen- 
tation will be placed under the direct responsibility of the Head of Government, in the form of an interministerial GESP monitoring committee. Its main role will be to supervise overall implementation of the GESP, to see regularly to compatibility between all the Government's sector activities and the priorities laid down in the strategy paper, to determine mobilization of the resources necessary for its implementation, thus orient budgetary programming and assess the GESP implementation results, effects, and impacts on the country's economic and social development.

In the execution of its missions, the Inter-ministerial Committee shall be assisted by a GESP implementation monitoring and evaluation Technical Committee, which shall have a technical secretariat. This secretariat shall bring together senior staff from economic and financial administrations as well as from sector ministries. It shall comprise a central coordination unit and thematic groups. In the devolved services, GESP participatory monitoring Regional Commissions shall oversee and evaluate GESP implementation.

Introducing a results-oriented monitoring and evaluation system. The GESP information and monitoring/evaluation system will draw from Results-Oriented Management principles (ROM). This mechanism will make it possible for reliable information to be produced to better design policies, execute them and guarantee rational use of public resources. Implementation monitoring will simultaneously focus on means and strategies (resources, activities, products or goods and services provided). Monitoring results will help to assess to what extent results have been achieved. The interrelationship between both levels will depend on interaction between means and strategies on the one hand, and achievement targets on the other.

Developing results-oriented communication. Communication has been a major component of the PRSP I. If better managed, communication can lead to better products and achieve better results through information sharing, awareness campaigns, participation in and appropriation of the process by all the stakeholders. Implementation of a communication plan will help identify information needs for the various actors as well as the appropriate formats for each user. Similarly, this communication plan will help enhance dialogue and discussion of the strategy's key issues, as well as encourage information dissemination at all levels. In this regard, Government, MINEPAT and NIS websites will serve as communication channels to facilitate information sharing. In the same vein, news bulletins that are produced regularly in the domestic audiovisual and written media will be some of GESP and MDGs communication means.

\section{2 Monitoring/evaluation mechanism}

Information gathered from stakeholders will be centralized and analyzed by the Technical Committee, then presented to the Inter-ministerial Committee as mid-year and annual reports on GESP implementation. As part of GESP monitoring/evaluation, the statistical tool will depend on an information system drawing from CRESMIC, and be based on the National Statistics Development Strategy (NSDS) adopted by the Government after validation by the National Statistics Council in January 2009. 


\title{
INTRODUCTION
}

\author{
Historical background
}

1. Cameroonian authorities designed the first Poverty Reduction Strategy Paper in April 2003, following a participatory approach involving public administrations, businesses, civil society organizations, and development partners. Presented to the international community in August of the same year, the paper was adopted as reference framework for the intervention of all actors in Cameroon's economy. This strategy, based essentially on education and health sector strategies, laid emphasis on programmes on access to basic social services.

2. At the time of drafting of the PRSP, the income poverty rate, which had dropped drastically by 13.1 points compared to 1996 figures, was still as high as about 40.2 per cent of the population. To reduce it to the target level of 20 to 25 per cent in 2015 , the authorities banked on a 5.5 per cent average growth rate over the $2004-2007$ period and 7per cent between 2008 and 2015.

3. In addition, the Government introduced an institutional framework to steer the strategy which included: (i) a PRSP implementation monitoring Inter-ministerial Committee, and (ii) a PRSP implementation monitoring/evaluation Technical Committee. This enabled the Government to monitor and evaluate implementation of the strategy several times using the participatory approach.

4. As regards performance, growth rates remained below the level targeted by the authorities over the period of implementation of the PRSP (less than 4 per cent on average); and the poverty rate virtually remained unchanged at $\mathbf{3 9 . 9}$ per cent in $\mathbf{2 0 0 7}$ as per the results of the third National Household Survey (ECAM III).

\section{Context}

5. This revision of the PRSP is an endeavour to correct the deficiencies identified during successive evaluations of the paper's implementation, particularly during participatory consultations in March 2008, in order to really produce a strategy which aims at economic growth and upon which proper redistribution of the fruits of growth can be based. The Cameroon Government is committed to achieving the Millennium Development Goals (MDGs) it ratified in 2000, and so has ensured that this strategy takes them into account.

6. Regarding the revision process, the authorities reasserted the need to involve people at the grassroots, using a participatory approach, in order to better meet their aspirations. To this end, the March 2008 participatory consultations helped the population to voice their opinions about public policies and strategies.

7. It was the wish of the population that the strategies to be introduced in Cameroon should ensue from a longterm development vision supplemented with multi-year development programmes. This recommendation can be regarded as having been considered with the formulation by the authorities of a development vision by 2035 and adoption in December 2007 of the new financial regime.

8. The GESP has been prepared in an environment marked by a rising cost of living, which was the cause of the riots in the country in February 2008. Specifically, the context is that of international financial crisis, food crisis, and energy crisis.

9. In view of the above, it seeks to; i) address the issue of growth and employment ; ii) find solutions to problems relating to proper redistribution of the fruits of growth; iii) reduce energy shortages which impact on growth; iv) respond to problems accruing from the financial crisis and food crisis. 


\section{GESP features}

10. For the Government, the GESP is the empirical expression of an integrated framework of a mediumterm sustainable human development for Cameroon and describes the country's progress towards achieving the MDGs and realizing the vision. The GESP has a number of key features and functionalities already taken into account in the April 2003 PRSP, and reaffirmed by the Government following an adaptive and participatory process. The GESP is:

- An integrated development framework. In fact, the GESP provides an empirical and integrated development framework for Cameroon, where macroeconomic, sector and social policies are outlined to consolidate growth, create formal employment opportunities to reduce income poverty, and improve the other human development dimensions (education, health, security, culture, etc.). Specifically, the GESP marries the Government's macroeconomic and structural reform programmes with sector strategies (Education, Health, Infrastructure, Rural, Social, Industries and Services), thus ensuring that in the medium term these different pillars of economic and social policy enhance one another.

- A financial coherence framework. The GESP is also the Government's short- and medium-term "financial coherence" framework. It knits the growth-generated trend of own resources with the funding needs of sector strategies, ensuring in turn that the pace of execution of macroeconomic and sector macro strategies also affects the path taken by economic growth. In the same vein, the GESP provides a framework that ensures conformity between the Government's financial and budgetary policies with the goals supportive of productive and social sectors. The short- and medium-term assurance of financial coherence is provided in the Cameroon GESP through a sustained effort made in providing macroeconomic and budgetary guidelines.

- Government action coordination framework. GESP goals will be achieved only if public will and resources are effectively mobilized and directed towards strategic aspects pointed out in the paper, and if related programmes are properly executed. The case is the same for sector growth "projections" whose "likelihood" depends on effective implementation of reforms. And so Cameroon's GESP provides a reference framework helpful in better targeting and coordinating government action. It is also a coherence framework for all government development strategies, be it the seven sector strategies that are being developed at present (education, health, social development, infrastructure, rural development, industry and services, governance) or cross-cutting strategies (regional development, employment, decentralization, tax system, financial system and development funding, labourintensive, gender, vulnerable approach, etc.). It helps to adjust the order of priority and the sequence of implementation of government action plan to the current context at any time.

- An advisory and consultation framework with civil society organizations, the private sector, and development partners. Cameroon's GESP is the fruit of an intense participatory and consultative process. The Government organized countrywide participatory consultations in order to involve the population and civil society in identifying economic and social problems and in the strategy formulation. The Government plans to institutionalize this approach for the strategy's periodic monitoring and revision. In light of the Paris Declaration, the Government has introduced a consultation process with development partners and plans to make the GESP a reference for intervention by same, while assuming its leadership role. It also intends to enhance the process for implementing, monitoring, and revising the GESP as well as for mobilizing and coordinating foreign support.

- A guide for analytical works to shed light on development management. Preparation of the GESP has been underpinned by a series of large-scale analytical works aimed at shedding light on choices, defining priorities, and marrying goals with means. They include: revision of sector strategies, preparation of the economic development strategy by 2035, participatory consultations, review of 
statistical surveys and studies for the 2001 to 2008 period; and with support from some partners, the Government carried out major statistical operations to determine the scope of poverty in Cameroon (ECAM III).

11. The Growth and Employment Strategy Paper has seven chapters, namely:

- Review of development policies,

- Long-term development vision and GESP goals ;

- Growth Strategy ;

- $\quad$ Employment Strategy ;

- State governance and strategic management;

- Macroeconomic and budgetary guidelines,

- Institutional framework and GESP implementation mechanisms.

12. A separate document is annexed to the GESP and contains templates for programming and implementation of sector strategies. It is an integral part of the GESP. 


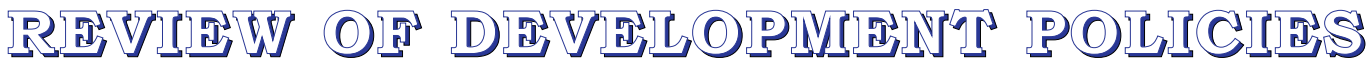

\subsection{MACROECONOMIC SITUATION}

13. During the implementation period of the PRSP, 2003 to 2007 , the GDP witnessed a 3.32 per cent real growth rate. This average falls below that of 4.23 per cent recorded during the period running from 2000 to 2002, when Cameroon was not implementing any formal programme aimed basically at poverty reduction. Regarding economic growth, the goals pursued as from April 2003 when the PRGF programme entered into force have not been achieved. Recent estimates for the 2008 financial year, showing a 3.1 per cent growth rate, maintain the growth pattern below that projected in the PRSP.

14. Concerning contributions to growth on average in the different sectors of activity, from 2003 to 2007 , the growth rate varies s follows:

- 0.78 per cent for the primary sector ;

- 0.02 per cent for the secondary sector ;

- 2.22 per cent for the tertiary sector (of which 1.84 per cent in the market tertiary) ;

- 0.3 per cent for net taxes on subsidies.

15.As regards GDP employment patterns during the period under consideration, real sector data show that domestic demand was the only driving growth force with an average contribution of 3.54 per cent (of which 3.12 per cent exclusively for consumption) ; capital expenditure contributed on average 0.44 per cent whereas net exports had an all-time negative contribution $(-0.22 \%)$. Thus, Cameroon's economic growth continues to be fragile.

16. These inadequate growth rates, which showed up over the period of execution of the PRGF programme, can basically be explained by the low investment rates compared to the GDP during the $2003-2007$ period: 17.8 per cent, whereas it had already risen to 18.9 per cent between 2000 and 2002 . The estimates for 2008 show an 18.1 per cent investment rate only.

17. Prices have relatively been under control with an inflation rate neighbouring 1.9 per cent, despite a peak of 5.1 per cent in 2006, which could be explained by the changing trends in food products, as well as those of the transport sector, due to a hike in fuel prices. In 2008, the inflation rate stood at 5.3 per cent.

18. External account patterns over the period running from 2003 to 2008 , suggest that the average balance amounts to about 44.1 billion CFAF. It would however be worthwhile to distinguish between the sub-period running from 2003 to 2005, which shows an average of -207.5 billion, and that from 2006 (Attainment of the completion point in April) to 2008, whose average overall balance stands at 295.87 billion. A look at the balance of current transactions following the same periodic break-up gives an average of $-391,3$ billion before the attainment of the completion point (2006); while the average balance stands at $-52,4$ billion after the completion point.

19. Balance of payments funding patterns (below the line), show that official reserves accrued at -206.8 billion on average during the period under consideration, with two peaks : in 2006, at attainment of the completion point (-475.9 billion) and in 2007 due to the favourable pattern of oil prices (-442.2 billion).

20. The non-oil trade balance has been showing recurrent deficits since 1996. These gaps have tended to increase over the years; with an average deficit of -432 billion over the period running from 2003 to 2008 . 
Exports are still not diversified and limited only to ten products for decades now, with the tonnages exported not really increasing. The economy thus continues to showcase supply inadequacies, which worsen as the years go by. It is hence not surprising that the external sector does not contribute in any positive way to economic growth.

21.Improvement in the current transactions balance, and in the balance of payments is globally a result of favourable current transfer patterns, on the one hand, with an average of 143.5 billion for the six years under consideration; and that of the investment and financial transactions account, on the other, with an average of 225.5 billion.

22. As regards monetary trends, a fact stands out during analysis of the available data on the period under study: an uneven trend of money supply counterparts marked by heavily accrued net foreign assets, coupled with less considerable net credits on the economy and with decreasing net internal credits due basically to advances paid to the State; an option taken by the latter in order to increase the available funding possibilities for the private sector.

23. In fact, in December 2003, net foreign assets amounted to 257.6 billion. After continuous progression over the full length of period under review, as could already be predicted by the accrued balance of payments official reserves, the sum of 1747.7 billion could be noticed at the end of December 2008. It follows that the open commitments coverage rate by foreign assets, also called, the foreign money supply coverage rate, improved over the years, rising above 85 per cent in December 2008 (the minimum required by BEAC rules and regulations being 20 per cent). These net foreign asset patterns basically resulted from well managed oil prices. As for net credits on the economy, they amounted to 907.8 billion in December 2003; four years after, it was only 1083.06 billion; the monetary situation in December 2008 shows that they stand at 1282.7 billion.

24. As a result of the drop in advances paid to the State each year, coupled with a continuous increase of these advance deposits into the banking system, the Net Government Position (NGP) has steadily been on a downward trend over the period under review. While the NGP amounted to 383.3 billion in December 2004 (net credits on the State amounting to 332.8 billion), it became negative from December 2006 (with - 81.2 billion, while net credits on the State stood at -145.1 billion). In December 2008, the NGP was -472.2 billion while net credits on the State stood at -599 billion. In all, net domestic credits have been dropping steadily: while they amounted to 1237.6 billion in December 2004, the monetary situation at the end of December 2008 shows 682.9 billion only.

25. Lastly, when we look at credit patterns granted by secondary banks according to their duration, we note that most of the credits are short term; with long term credits accounting for only 3.5 per cent on average of the total credits granted. These data confirm that the banking sector does not finance sustainable growth in Cameroon.

26. With the net foreign and net domestic credit trends presented above, the money supply pattern itself does not help identify the problems faced by businesses with regard to funding. For example, money supply increased by 50.48 per cent from 1428.6 billion in December 2004 to 2149.9 billion in December 2008; while net domestic credits dropped by 44.7 per cent from 1237.6 to 683.8 billion during the same period. The Government's option of not resorting to statutory advances at the Central Bank becomes an issue.

27. Concerning public finances, it can be noted that the national debt dropped from 4,890.3 billion CFAF in 2005 , to $1,990.7$ billion at the end of 2006 , being a drop by 59.3 per cent. It stood at 1427.6 billion at the end of 2008. This trend is a result of the drastic foreign debt reduction from 3652.1 billion at the end of 2005 to 882.4 billion in 2008 , due to debt relief measures taken after the country's attainment of the completion point of the HIPC initiative; a prudent and coherent foreign debt contracting policy with the macroeconomic framework, as well as respect of foreign debt reimbursement deadlines. The new dispensation will be of advantage in restoring growth and reducing unemployment. 
Box 1: Definition of budgetary policy

This concept must be understood in its broadest sense, notably : all the options the State has, as economic agent, in restructuring and ordering deductions, expenditure and the various methods of funding negative balances (where they are identified), or allocation of surpluses, in order to positively influence the trend of well defined macroeconomic variables such as economic growth.

The development that has taken place above has helped to establish a link between the inadequate average growth rate recorded over the past six years and the low investment level noted.

28. An examination of the Government's flow-of-funds table over the period running from 2003 to 2008 led to the following conclusions: the different finance laws set aside 22 per cent on average of expected revenue and donations for capital expenditure; when capital expenditure is compared to revenue and donations it gives a 16.6 per cent ratio. Hence, this holds both for allocations and realizations, 'capital expenditure/total revenue and donations" ratio was less than 25 per cent from 2003 to 2008 . Whereas it is well known that an efficient policy targeting sustainable growth for Cameroon requires that at least 25 per cent of the GDP be earmarked for investment; investment here understood as crude fixed capital creation ${ }^{2}$.

29. Under these circumstances, and without a monetary policy really supporting sustainable growth, as is the case in Cameroon, the Government can only rely on budgetary policy for macroeconomic regulation. The State will make efforts to devote an increasingly larger proportion of its revenue and donations for capital expenditure, so in the long run a ratio of between 35 and 40 per cent can be achieved. Furthermore, the State will ensure that the quality of public expenditure improves in general, and that capital expenditure improves in particular. However, achievement of these goals is not expected to compromise the advantages accruing from attainment of the completion point in April 2006.

30. That is why the Government reasserts its will of practising a policy of prudent debt-contraction and seeing to sustainable management of the national debt, based on a debt contracting policy coherent with the macroeconomic framework and with medium-term goals.

\subsection{SOCIOECONOMIC SITUATION}

31. Estimated at 17123688 people during the third General Population and Housing Census in November, the population of Cameroon is about 19.5 million in 2009. It will reach 26.5 million in 2020. This population is made up basically of young people, with youth less than 15 years old accounting for 45 per cent of the population as against 3 per cent for aged people above sixty-five years old. Women account for 50.5 per cent of the population.

Table 1: Cameroon population trend

\begin{tabular}{|l|c|c|c|c|}
\hline Population (in millions) & 2005 & 2010 & 2015 & 2020 \\
\hline Women & 8.6 & 10.1 & 11.6 & 13.4 \\
\hline Men & 8.5 & 9.9 & 11.4 & 13.1 \\
Total & 17.1 & 20.0 & 23.0 & 26.5 \\
\hline \multicolumn{4}{r}{} \\
\end{tabular}

2 Le raisonnement qui table sur un ratio minimum de 25\% suppose que les dépenses de capital de l'Etat sont assimilables à de la formation brute de capital fixe. Or, lorsque l'Etat affecte 100 FCFA à des dépenses de capital, les 100 FCFA dépensés ne se transforment pas entièrement en formation brute de capital fixe, dans la mesure où une partie de ce montant est nécessairement appelée à servir à des dépenses de consommation. 
32. Cameroonian authorities paid special attention to the Millennium Development Goals during the PRSP I implementation period. In order to assess the progress made in this regard, a national report written in 2008 , gives an update on the trends of pursuance of each goal. In general, current trends suggest that it is unlikely that the country will achieve the goals set for 2015. This poor balance sheet with regard to progress towards achieving the MDGs is due to the difficulties encountered in implementing the strategy, and to the high cost of implementation of actions relating thereto. Here is a look at the situation per goal:

\section{- MDG 1: Reducing extreme poverty and hunger}

33. From 2001 to 2007 , the proportion of the nation's population living below the poverty line has remained virtually stable, dropping from 40.2 per cent to 39.9 per cent while for the same period the poverty gap index dropped from 12.8 per cent to 12.3 per cent. Concerning food poverty, there are indications that the national proportion of children less than 5 years old suffering from hunger dropped from 22.2 per cent in 1998 to 19.3 per cent in 2006 . Whether it be the poverty rate or the proportion of children suffering from hunger, the goals to be achieved by 2015 , being respectively 25.1 per cent and 8 per cent, seem compromised taking into account the above trends.

\section{- MDG 2: Ensuring primary education for all}

34. Between 2001 and 2007, the net primary school enrolment ratio witnessed a slight increase of 0.3 point. The situation remained almost stagnant due to: (i) a timid increase in education provision; and (ii) lack of stimulation of demand (very few girls attend school in the Far North and Adamawa provinces). As regards the elimination of illiteracy among 15 to 24 year-olds, the rate stabilized, from 82.3 per cent to 83.1 per cent during the period under review. Though both indicators have not changed significantly in 6 years, they have remained sufficiently high for the goal of 100 per cent primary education to be achieved in 2015.

\section{- MDG 3 : Promoting gender equality and empowering women}

35. Trends recorded with regard to the goals pursued show that the status of women has greatly improved, particularly in primary education where the girls/boys ratio increased from 0.83 to 0.89 between 2001 and 2007. The ratio dropped slightly in secondary education where it dwindled from 0.93 to 0.86 during the same period. Furthermore, the elimination of illiteracy among 15-24 year-olds remained stable at 0.88 . The same as the targets of MDG 2, Cameroon has enough potentialities to hit the targets set for 2015, being 1 , for the three indicators concerned.

36. Regarding economic space, the rate of salaried activities by women in the non-agricultural sector greatly increased from 20.3 per cent in 2005 to 21.4 per cent in 2007. This gap can be attributed not only to improved ways of thinking but also to the fact that women generally face more difficulty in acquiring credits, land and producer goods. In 2009, the number of women-members of government is remarkable (five ministers and a minister delegate). Today, they make up 13.9 per cent of Parliament.

\section{- MDG 4 : Reducing infant mortality}

37. Between 1998 and 2004 , the mortality rate of children aged below five years dropped from 150.7 per thousand to 144 per thousand, the national target for 2015 being 75.8 per thousand. Despite the efforts made in the health domain, the national target may not be reached by 2015 considering its level in 2004. The case is the same for infant mortality which has recorded a reduction of 3 points in two years. The slight improvement has been due to expansion of vaccination coverage against meningitis, which jumped from 64.8 per cent to 78.8 per cent between 2004 and 2006, to the popularization of breastfeeding, and to the combat of childhood illnesses and malnutrition. 


\section{- MDG 5: Improving maternal health}

38. Between 1998 and 2004, maternal mortality increased from 430 to 669 per 100000 live births. In 2004,19 per cent of deaths of women of childbearing age (15-49 years) were due to pregnancy- related complications over the 1998-2004 period as against 26 per cent during the 1991-1997 period. Thus, despite the rise in maternal mortality noted previously, pregnancy-related deaths of women dropped. With the emergence of other causes of mortality (AIDS in particular), the maternal mortality rate has to drop to 350 per 100000 live births by 2015 in order to reach the MDG national target, which would be difficult to meet following recent trends. Other causes of death such as clandestine abortions have also been considered.

39. On the contrary, the proportion of deliveries by qualified personnel increased from 78.8 per cent in 1998 to 83.4 per cent in 2004 . If this upward trend continues, the proportion could close up to the target 100 per cent target by the year 2015 .

\section{- MDG 6: Fighting HIV/AIDS, malaria and other illnesses}

40. The third population and health survey conducted in 2004 revealed that the HIV/AIDS prevalence rate as at that time stood at 5.5 per cent nationwide, with 6.8 per cent of women infected as against 4.1 per cent of men between the ages of 15 and 49 years. The rate was even higher in urban than in rural areas with 6.7 per cent and 4 per cent respectively. High prevalence rates were recorded in the fourth richest quintile $(7.4 \%)$. Concerning malaria, the prevalence rate was estimated at 40 per cent in 2004.

\section{- MDG 7 : Ensuring environmental sustainability}

41. Despite the increase in protected areas to preserve the environment ( $13 \%$ in 2000 as against $18.8 \%$ in 2008), the target that the proportion of the population using combustible solids should reach about 42.2 per cent could not actually be met. In fact, this indicator remained the same between 2001 and 2008 at 82 per cent, with the immediate consequence that environmental degradation increased. Therefore, great effort should be made to implement a strategy in keeping with sustainable development principles.

42. Regarding access to safe drinking water, there is still much to be done, for the proportion of the population having access to drinking water only slightly increased. It rose from 40.6 per cent in 2001 to 43.9 per cent in 2007 , being more than half the target $(72.1 \%)$ to be reached by 2015 .

43. The only target reached so far is the proportion of the population with access to a good sanitation system. It jumped from 8.5 per cent in 2001 to 31.7 per cent in 2007 , making almost twice the target set at 17 per cent for the year 2015.

\section{- MDG 8: Establishing a global development partnership}

44. Achieving the MDGs needs both domestic and foreign aid, mobilizing huge funds to be injected into social sectors. The partnership to be implemented basically targets: mastering and reducing youth unemployment, especially in the urban areas; providing essential medications to the underprivileged, popularizing the use of communication and information technology; curbing gender inequality. The results obtained show that youth unemployment dropped from 14.3 to 8.2 per cent between 2001 and 2007.

\subsubsection{Trends in income poverty}

\subsubsection{1.2.2.1 Poverty trends and pattern}

45.The 2001-2007 period was marked by a GDP average annual growth rate of between 3 and 3.4 per cent, being per capita GDP average annual growth rates of 0.5-0.7 per cent per annum; a very low rate unlikely to have any positive impact on the livelihood of households.

46. Thus, income poverty that witnessed a 13-point drop between 1996 and 2001 remained stable over 
the 2001-2007 period. In fact, the incidence ${ }^{3}$ of poverty that stood at 40.2 per cent in 2001 dropped to 39.9 per cent in 2007 . The immediate consequence of this stable poverty rate was an increase in the number of poor people, due to population growth ( 2.7 per cent), which has continued to be very high. As such, of a population estimated at close to 15.5 million in 2001, 6.2 million people were considered poor. In 2007, ECAM3 estimated the population of the country at close to $17.9^{4}$ million with 7.1 million poor people.

47. There is more poverty in households headed by a man than in those headed by a woman. In fact, 41.6 per cent of households headed by a man are poor as compared to only 33.4 per cent of those headed by a woman.

Box2: Surveys on the living conditions of households

The quantitative or income-based approach hinges on the method of basic food and non-food needs identified using data from three Cameroon Household Surveys (ECAM 1, 2 and 3) conducted nationwide in 1996, 2001, and 2007. These surveys did not only help to assess the level of poverty and the living conditions of households in Cameroon, but also appraised trends within the framework of implementation of the first PRSP (POVERTY REDUCTION STRATEGY PAPER) in 2003.

The Cameroon household survey in 1996 (ECAM I), the first of a series, was carried out immediately after the end of the severe economic crisis the country witnessed for close to a decade. The survey also helped to assess the impact of the crisis and of the structural adjustment programme on living standards and conditions of households. It was conducted on a sample of effectively interviewed 1, 731 households.

The ECAM2 survey carried out towards the end of 2001 helped in updating the pattern of poverty and in designing reference indicators for monitoring the progress made in poverty alleviation. The survey was conducted in all 10 provinces of the country, including urban and rural areas, on a sample of 12,000 households, of which 10, 992 were actually visited. This served as a basis for designing the complete PRSP in 2003.

The ECAM3 survey carried out during the fourth quarter of 2007 helped to better assess the impact of projects, and programmes on households. Like ECAM II, it was a nationwide survey of 11,534 households.

48. The poverty severity index, which measures the population's aversion to poverty, or the inequalities among the poor, is at 5 per cent. This result shows that population of the poor is becoming homogeneous. In fact, this rate was 13.8 per cent in 2001 (ECAM2).

49. However, the scope of poverty has also remained unchanged: 12.8 per cent in 2001 and 12.3 per cent in 2007. In other words, not all the poor really benefited from the fruits of economic growth in such a way as to make a great distinction between their level of consumption and the poverty line, though 10 per cent of poor households benefited from the growth. This corresponds to the approximately 31 per cent of poverty intensity, making a deficit of CFA $83500 \mathrm{~F}$ on average per poor person.

50. The growth rate recorded during the period did not widen inequalities; on the contrary, inequalities reduced over a long period, as was seen in the drop of the Gini index during the 1996-2007 period.

51. In fact, this index that stood at 0.416 in 1996, dropped to 0.404 in 2001 and to 0.390 in 2007 . It is however interesting to note that inequality reduced more sharply in urban areas, with a lower Gini index in 2007 than that of the national level; unlike in 1996 and 2001.

Table 2: Trend of the Gini index between 1996 and 2007

\begin{tabular}{|l|l|l|l|}
\hline & 1996 & 2001 & 2007 \\
\hline National & 0.416 & 0.404 & 0.390 \\
\hline Urban & 0.419 & 0.407 & 0.352 \\
\hline Rural & 0.344 & 0.332 & 0.322 \\
\hline & Sources: ECAM1, ECAM2, ECAM3, INS & \\
\hline
\end{tabular}

The poverty severity index $(P 2)$ calculates poor household expenditure distribution on the basis of average poor household expenditure.

Or P1 relative average difference between the poverty line and the average poor household expenditure Determines revenue distribution or household expenditure on the basis of $100 \%$ equal distribution 


\subsubsection{Spatial dimensions of poverty}

52. At spatial level, major disparities in poverty rates were noted between 2001 and 2007. Poverty dropped sharply in urban areas (5 points) in the cities of Douala and Yaounde while the incidence of poverty instead increased ( 3 points) in rural areas, especially in villages of the three northern provinces.

53. In fact, more than half the number of people living in rural areas in 2007 were poor while only 12.2 per cent of those living in urban areas (50 thousand inhabitants or more) were poor. In the two cities of Yaoundé and Douala, about one of every twenty people was poor, as against five in the other cities. Almost 94 per cent of the people classified as the poorest quintile live in rural areas, as against only 2 per cent in Yaoundé, 2 per cent in Douala and 6 per cent in the other cities. The disparities noticed depend probably on access to revenue by the population in their area of residence.

Graph 1 Trend of the incidence of poverty between 1996 and 2007

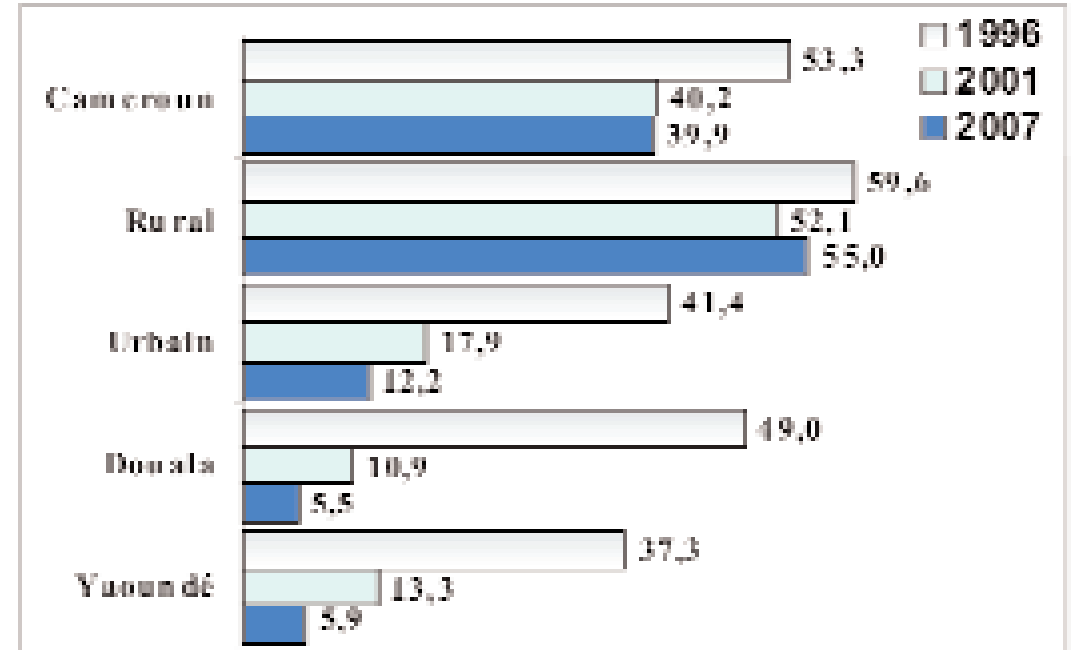

Source: ECAM 1, ECAM 2, ECAM 3, INS.

54. Apart from the East region and the northern part of Cameroon, the other regions witnessed an overall drop in poverty levels. Four regions, namely, the South West, West (which witnessed a significant drop in poverty levels by almost 12 points between 2001 and 2007), the South and the Littoral (excluding Douala) recorded a poverty rate of about 30 per cent, whereas it was estimated at 41 per cent in the Centre (excluding Yaoundé) and stood at about 50 per cent in the North-West, East and Adamawa.

55. And so apart from the Northwest and the East, the other southern regions recorded a poverty rate below the national rate of 39.9 per cent. Yaoundé and Douala and somehow the other cities benefited relatively more from the proximity of public and private services, providers of well-paid employment. 
Table3: Trend of poverty $2001-2007$

\begin{tabular}{|c|c|c|c|c|c|c|}
\hline & \multicolumn{3}{|c|}{2001} & \multicolumn{3}{|c|}{2007} \\
\hline & PO & P1 & P2 & PO & P1 & P2 \\
\hline National & 40.2 & 12.8 & 5.6 & 39.9 & 12.3 & 5.0 \\
\hline \multicolumn{7}{|c|}{ Area of residence } \\
\hline Urban & 17.9 & 4.3 & 1.6 & 12.2 & 2.8 & 1.0 \\
\hline Rural & 52.1 & 17.3 & 7.7 & 55.0 & 17.5 & 7.2 \\
\hline \multicolumn{7}{|l|}{ Region } \\
\hline \multirow[t]{2}{*}{ Douala } & 10.9 & 2.1 & 0.7 & 5.5 & 0.9 & 0.2 \\
\hline & 13.3 & 2.7 & 0.9 & 5.9 & 1.0 & 0.2 \\
\hline Adamawa & 48.4 & 15.4 & 6.4 & 53.0 & 14.5 & 5.4 \\
\hline Centre & 48.2 & 15.0 & 6.6 & 41.2 & 9.5 & 3.1 \\
\hline East & 44.0 & 15.4 & 6.7 & 50.4 & 15.7 & 6.2 \\
\hline Far North & 56.3 & 18.8 & 8.2 & 65.9 & 24.6 & 11.2 \\
\hline Littoral & 35.5 & 10.1 & 4.2 & 31.1 & 7.7 & 2.7 \\
\hline North & 50.1 & 15.5 & 6.4 & 63.7 & 21.0 & 8.6 \\
\hline North-West & 52.5 & 20.9 & 10.7 & 51.0 & 16.6 & 6.8 \\
\hline West & 40.3 & 11.1 & 4.2 & 28.9 & 6.6 & 2.3 \\
\hline South & 31.5 & 7.4 & 2.4 & 29.3 & 7.4 & 2.7 \\
\hline South-West & 33.8 & 10.5 & 4.5 & 27.5 & 6.9 & 2.5 \\
\hline
\end{tabular}

Sources: ECAM2, ECAM3, INS

56. Poverty rates in the North and Far North Regions are very high; about two of every three people were poor. The rate of abject poverty in these regions is also very high: 41 per cent in the Far North and 31 per cent in the North. About 40 per cent of people classified as the poorest lived in the FarNorth and 17 per cent in the North.

\subsubsection{Factors of poverty}

57. The third Cameroon household survey also helped to identify microeconomic factors of poverty, that is, the factors that cause poverty and contribute in marginalizing some segments of the population. Some of the factors are: household size, level of education, socioeconomic group.

58. Household size. The first significant result of the model presented above is based on the impact of population size on the standard of living of households. Notwithstanding the age or gender of an individual, his presence in a household contributes in reducing the living standard of the household. In fact, poor households generally have more members ( 6 at least for poor households as against 3 for rich households). This includes the fertility rate that has remained high, (the summary fertility index stands at 5 children per woman on average) and the fast-growing population (2.7\% at least per year), proves that population policies should continue to be taken into consideration in poverty reduction strategies.

59. Level of education. When the level of education of the household head and that of the spouse is high, it contributes significantly in raising the household's standard of living. A household whose head completed primary education records a better consumption rate by 11 per cent per adult equivalent. This impact stands at 26 per cent, 38 per cent and 75 per cent respectively for a household whose head completed secondary school, high school, and tertiary education. However, it can be noted that the level of education of the spouse has little impact in rural areas. As most spouses are women, this translates the fewer opportunities of decent positions in villages.

60. In terms of trends, a comparison between 2001 and 2007 reveals that a greater proportion of household heads completed high school and a higher institution of learning. This can be explained by the fact that the stock of human capital improved, thereby generating more income. But education improves the livelihood of households only when the head acquired a tertiary education, and rather worsens the living conditions of those whose head had secondary education (as they turn out larger in number). 
Box3: Review of some definitions and perception of poverty

In its 1998 Human Development Report on Poverty in Cameroon, UNDP considers poverty a complex situation that generally describes the scarcity of resources and deprivation of the possibility of choice and opportunity, which would bring along decent living conditions. Thus, poverty has many facets the most outstanding of which are poor health or low educational level, lack of access to knowledge, impossibility of exercising civil rights, absence of dignity and self-confidence, environmental degradation, etc.

For most people contacted on the ground during participatory consultations ahead of the preparation of the PRSP, poverty is, above all, the lack of material or financial resources to satisfy the basic needs of individuals, such as feeding, housing, healthcare, education safe drinking water supply, etc. The absence of services for these basic needs in some localities can also make individuals and even households that have the means to acquire them poor.

The state of poverty of a person or a group of persons is related to a very complex concept. Poverty is in itself comparable. In a group of people, the poor are, graphically, that part of the population whose living conditions are conspicuously worse than the "average" observed. To compare poverty levels one must work with three elements: a household wellbeing measuring indicator (for example a consumption or revenue aggregate), a poverty line, being a line indicating wellbeing below which a household would be considered poor, and poverty assessment indicators. At the global level, the poverty line was fixed at one dollar per day; this line is generally contextualised in time and space. In Cameroon, the poverty line in 2007 stood at CFA $269443 \mathrm{~F}$ per adult equivalent and per year as against 232547 in 2001, making a face value increase of 15.8 per cent. And so a household is considered poor in 2007 if on average an adult in this household lives on less than CFA $269443 \mathrm{~F}$ per year (being CFA $738 \mathrm{~F}$ per day or CFA $22454 \mathrm{~F}$ per month). This sum corresponds to the minimum necessary to satisfy the basic needs of an individual.

61. The socioeconomic group. The economic professional sectors, which are the institutional sector where the individual carries out his activity and the branch to which his establishment belongs, are also key factors of poverty. As regards the institutional sector, there is a net premium for a household whose head works for the government and in the formal private sector. In the urban areas, a household whose head works for the government has a per adult equivalent consumption rate of more than 16 per cent compared to that of an unemployed household head; for the formal private sector, this percentage stands at 14 per cent. The percentages are 14 and 22 respectively in the rural areas. On the contrary, there is no real difference between living in a household with an unemployed head and in one where the head is an informal sector worker in an urban area or in a rural area as a small holder. This is because the difference between working, not working and being unemployed to some extent is fuzzy, and taking into consideration all what it takes to join the 'petty' informal sector, individuals can easily switch from one position to another.

62. As regards the area of activity, results from the model reveal that there is a premium for working in administrative and financial services, and a disadvantage to work in the primary sector. Between 2001 and 2007, it can be noted that proportionately there are fewer households whose head works for the government and for the formal private sector (the two groups with very low poverty rates). Concurrently, the proportion of households whose head works for the informal sector is increasing. The combined effect of both is a drop in income levels. At the same time, factor proceeds for all household groups are on a downward trend; in other words, everything being equal, remuneration levels are on average low in all the institutions considered.

63. Access to factors of production (land, credit). This study clearly shows the impact of production factors and social capital as a positive factor for consumption and the wellbeing of households. Land ownership contributes in improving the consumption level per adult equivalent of the household. Data collected reveal that 53.9 per cent of households in Cameroon have at least a member who owns land (for farming or livestock breeding, etc) and the average land surface area owned is 2.4 hectares per household. This masks the disparity according to area of residence, regions and the standard of living. Trends suggest that the land factor played a better role in curbing poverty in 2007 than in 2001, only farm land areas are, said to have decreased between 2001 and 2007.

64. In addition, the mere fact of belonging to an association improves the level of consumption per adult equivalent from 9 per cent to 10 per cent in the rural and urban areas, respectively. For instance, associations play a key role in improving access to funds to finance income-generating activities. 


\subsubsection{Poor living conditions}

65. ECAM3 also collected data useful in analysing other forms of poverty, namely: "poverty of potentials" which refers to one's inability to afford the means ("different forms of capital") necessary for escaping the poverty zone, living well and building individual capacities. Thus, poverty here is the inability to seize the available opportunities due to poor health facilities, inadequate education and malnutrition, etc.

\subsubsection{Education}

66. Formal illiteracy eradication helps persons aged 15 years or more to read and write in English or in French. While the literacy rate made a 7-point jump between 1996 and 2001 (from 61 per cent to 68 per cent), it rose by 4 points between 2001 and 2007, making 71.9 per cent. Notwithstanding this growth rate, its current level indicates that much has to be done to completely eradicate illiteracy.

67. A look at the overall school enrolment ratio of children between the ages of 6-14 years reveals that in 2006/2007, of 10 children aged 6-1 4 years, about eight were attending school. This indicator improved as the years went by. From 67.5 per cent in 1976, it went up to 73.1 per cent in 1987; 76.3 per cent in 1996, 78.8 per cent in 2001 and 79.8 per cent in 2007.

68. The main reason for failure by children of primary or secondary school going age to attend school (6-19 years) is refusal by their parents or tradition (26.4 per cent). This is true irrespective of the household's standard of living. The second reason is the high cost of schooling (17.5 per cent). It was noted that the Northern part of the country was a poverty pole, but unexpectedly it is not in this part of the country that there are frequent complaints of the high cost of education, but instead in the Southern part.

Table 4. Net school enrolment ratio (6-14 years) per region, gender, the standard of living, and the area of residence

\begin{tabular}{|c|c|c|c|c|c|c|c|c|c|c|}
\hline \multirow{2}{*}{\multicolumn{2}{|c|}{ Region of survey }} & \multicolumn{3}{|c|}{ Men } & \multicolumn{3}{|c|}{ Women } & \multicolumn{3}{|c|}{ Total } \\
\hline & & $\begin{array}{l}\text { The } \\
\text { poor }\end{array}$ & $\begin{array}{l}\text { The } \\
\text { rich }\end{array}$ & Total & $\begin{array}{l}\text { The } \\
\text { poor }\end{array}$ & $\begin{array}{l}\text { The } \\
\text { rich }\end{array}$ & Total & $\begin{array}{l}\text { The } \\
\text { poor }\end{array}$ & $\begin{array}{l}\text { The } \\
\text { rich }\end{array}$ & Total \\
\hline \multirow{2}{*}{\multicolumn{2}{|c|}{ Douala }} & 96.6 & 96.8 & 96.8 & 100.0 & 99.0 & 99.0 & 98.7 & 97.9 & 98.0 \\
\hline & & 100.0 & 97.2 & 97.5 & 97.3 & 96.9 & 97.0 & 98.6 & 97.1 & 97.2 \\
\hline \multicolumn{2}{|l|}{ Adamawa } & 73.4 & 78.7 & 75.4 & 45.9 & 59.4 & 51.3 & 59.2 & 68.5 & 62.8 \\
\hline \multicolumn{2}{|l|}{ Centre } & 95.3 & 97.1 & 96.1 & 94.0 & 95.5 & 94.9 & 94.7 & 96.2 & 95.5 \\
\hline \multicolumn{2}{|l|}{ East } & 67.8 & 89.1 & 76.4 & 63.4 & 91.7 & 74.2 & 65.6 & 90.3 & 75.3 \\
\hline \multicolumn{2}{|l|}{ Far-North } & 59.0 & 60.7 & 59.4 & 39.7 & 50.6 & 42.6 & 49.8 & 56.0 & 51.5 \\
\hline \multicolumn{2}{|l|}{ Littoral } & 89.5 & 95.0 & 93.0 & 93.3 & 98.3 & 96.3 & 91.4 & 96.5 & 94.6 \\
\hline \multicolumn{2}{|l|}{ North } & 63.9 & 73.2 & 66.4 & 50.7 & 62.1 & 54.0 & 57.6 & 67.7 & 60.5 \\
\hline \multicolumn{2}{|l|}{ North-West } & 88.4 & 93.3 & 90.3 & 91.7 & 93.2 & 92.3 & 89.9 & 93.3 & 91.3 \\
\hline \multicolumn{2}{|l|}{ West } & 94.8 & 95.5 & 95.2 & 93.2 & 97.1 & 95.7 & 94.0 & 96.3 & 95.5 \\
\hline \multicolumn{2}{|l|}{ South } & 92.2 & 96.3 & 94.9 & 95.5 & 97.3 & 96.6 & 94.0 & 96.8 & 95.8 \\
\hline \multicolumn{2}{|l|}{ South-West } & 90.0 & 96.4 & 93.9 & 89.8 & 98.1 & 95.0 & 89.9 & 97.3 & 94.4 \\
\hline \multirow{3}{*}{ Cameroon } & Urban & 86.8 & 94.8 & 93.5 & 87.1 & 94.3 & 93.1 & 87.0 & 94.5 & 93.3 \\
\hline & Rural & 73.6 & 84.1 & 77.3 & 63.2 & 82.5 & 70.4 & 68.5 & 83.3 & 73.9 \\
\hline & Total & 74.8 & 89.4 & 82.1 & 65.7 & 88.4 & 77.5 & 70.4 & 88.9 & 79.8 \\
\hline
\end{tabular}

Source: ECAM3, NIS 


\subsubsection{Health}

69. Analysis per age bracket shows that children less than 5 years old and people aged above 50 years form the most vulnerable group. The morbidity rate is above 32 per cent in the two age brackets. A reduction in this rate would obviously lead to a drop in the infant-juvenile mortality rate and increase life expectancy from birth in Cameroon.

70. Malaria continues to be the main cause of mortality and morbidity within the most vulnerable groups. It is responsible for 35 to 40 per cent of the overall number of deaths in health facilities, 50 per cent of morbidity among children less than 5 years old, 40 to 45 per cent of medical consultations, and 30 per cent of hospitalizations.

71. However, the prevalence rate of HIV/AIDS was estimated at 5.5 per cent of adults in 2004 (EDSC-III). The prevalence rate is higher among women (6.8 per cent) than among men (4.1 per cent). The rate of declared HIV/AIDS screening shows the proportion of people having undergone screening; irrespective of whether they did or did not claim their results and of the period within which the screening was done. In Cameroon, this rate is estimated at 20.7 per cent.

72. The rate of health consultations in informal structures stands at 29.7 per cent. It has risen slightly compared to 2001 , when it stood at 24.5 per cent. The increase was the result of the widespread creation of health $\mathrm{CIG} / \mathrm{NGO}$ and increase in the number of informal vendors of medications, accounting for 18.4 per cent of consultations in informal facilities. This can further be explained by the strategy used by households to rush to cost-effective healthcare facilities and to consult a health practitioner at home. The recourse of the population to informal health facilities is even more common among the poor than among the rich.

73. Annual private expenditure on health per head measures the overall annual household expenditure on health depending on the number of inhabitants. At national level, the per capita annual expenditure on health is estimated at CFA $12774 \mathrm{~F}$, being a fall by approximately CFA $9261 \mathrm{~F}$ compared to the situation in 2001 .

\subsubsection{Infrastructure and equipment services}

74. Housing habits in Cameroon help to classify households in three groups: property owner households, tenant households, and free accommodation households. In all, 58.9 per cent of households live in their own houses, 29.8 per cent live as tenants, and 11.3 per cent have free housing. Poor households are mostly (83 per cent) owners of their houses.

75. Access to safe drinking water, electricity, or cooking gas can also be used to evaluate the living standards of households. On the whole, one of two households has access to safe drinking water. The proportion of households with access to electricity is moderate countrywide (about 40 per cent), but low in the rural areas (less than 10 per cent). Public lighting in Cameroonian towns is greatly lagging behind, with less than 40000 spots of light (compared to 400000 in Côte d'lvoire); the existing facilities are at an advanced stage of deterioration due to criminal damage and to the difficulty faced by municipalities to safeguard and maintain them. Regarding the number of towns supplied with electricity, they are less than 3000 of the 13104 Cameroon has, meanwhile only one of every seven households has access to domestic gas.

76. The situation is even worse for poor households, with only one of every four households having access to safe drinking water and one of every five households having access to electricity, while all or very few of them have access to cooking gas ( 0.6 per cent). 
Table 5: Percentage of households with access to safe drinking water, electricity, domestic gas, per region, area of residence and standard of living

\begin{tabular}{|l|c|c|c|c|c|c|}
\hline Sector & \multicolumn{9}{c}{ Division of workers } & Poverty \\
& Urban & Rural & Men & Women & Total & rate \\
Public & 8.8 & 1.9 & 5.4 & 2.2 & 3.8 & 8.2 \\
Formal private & 10.7 & 1.6 & 6.5 & 1.9 & 4.2 & 7.2 \\
Informal agriculture & 16.0 & 82.3 & 58.6 & 68.6 & 63.5 & 56.9 \\
Informal non-agriculture & 64.6 & 14.2 & 29.6 & 27.3 & 28.5 & 22.2 \\
Total & 100.0 & 100.0 & 100.0 & 100.0 & 100.0 & 43.1 \\
\hline
\end{tabular}

Source: ECAM3, NIS

77. Rats, mice and harmful insects in houses, noise pollution, repugnant odours, sludge, floods and physical violence are some of the problems faced by households. Of all these, the presence of mosquitoes (95.7per cent) and cockroaches (88.5 per cent) seems the most widespread nuisance both in the urban and rural areas, as well as in the homes of both the poor and the rich.

78. Concerning the distance to some public services, it can be noted that households live on average $11.6 \mathrm{~km}$ away from the nearest district hospital. However, poor households live farther away (17.9 km) from the hospital than rich households $(9.2 \mathrm{~km})$. On average people live about $8.5 \mathrm{~km}$ away from an AES-SONEL electric pole and two times farther away from a public tap. In towns, households live less than one kilometre away from a refuse dumping point, while no arrangement has been made for refuse collection in the rural areas.

\subsubsection{Employment}

79. Poverty indicators per type of position held by the household head help in showing that households headed by workers are more poverty-stricken (41.0 per cent) than those headed by nonworkers (29.9 per cent) or applicants (11.9 per cent). This paradoxical result is more common in the rural areas. In the urban areas, the poverty rate of unemployed and working class households is lower.

80. Underemployment affects seven of every ten workers (71.7 per cent). It is of broader scope in the rural areas (78.8 per cent) than in the urban areas (57.4 per cent). It is hence the real problem in Cameroon's employment market, with significant disparities according to region of survey and gender. 
Table 6: Division of the employed per sector (in \%)

\begin{tabular}{|c|c|c|c|c|c|c|c|c|c|c|}
\hline \multirow{2}{*}{\multicolumn{2}{|c|}{$\begin{array}{l}\text { Status } \\
\text { Regions }\end{array}$}} & \multicolumn{3}{|c|}{ Safe drinking water } & \multicolumn{3}{|c|}{ Electricity } & \multicolumn{3}{|c|}{ Domestic Gas } \\
\hline & & Poor & Rich & Total & Poor & Rich & Total & Poor & Rich & Total \\
\hline \multicolumn{2}{|l|}{ Douala } & 84.9 & 91.9 & 91.7 & 86.3 & 97.5 & 97.1 & 19.6 & 46.8 & 45.9 \\
\hline \multicolumn{2}{|l|}{ Yaoundé } & 85.9 & 93.6 & 93.3 & 90.8 & 98.5 & 98.2 & 7.4 & 56.5 & 54.8 \\
\hline \multicolumn{2}{|l|}{ Adamawa } & 34.1 & 47.5 & 42.2 & 9.8 & 34.9 & 25.0 & 0.0 & 5.5 & 3.3 \\
\hline \multicolumn{2}{|l|}{ Centre } & 16.7 & 22.7 & 20.9 & 38.7 & 50.2 & 46.7 & 0.1 & 10.4 & 7.3 \\
\hline \multicolumn{2}{|l|}{ East } & 15.5 & 19.0 & 17.8 & 11.8 & 29.6 & 23.2 & 0.0 & 5.7 & 3.7 \\
\hline \multicolumn{2}{|l|}{ Far-North } & 13.8 & 41.6 & 25.4 & 3.2 & 23.6 & 11.7 & 0.1 & 1.0 & 0.5 \\
\hline \multicolumn{2}{|l|}{ Littoral } & 55.3 & 68.7 & 65.6 & 57.4 & 69.7 & 66.9 & 4.1 & 14.2 & 11.9 \\
\hline \multicolumn{2}{|l|}{ North } & 12.7 & $\begin{array}{c}4 \\
2.1\end{array}$ & 26.7 & 4.5 & 29.2 & 16.3 & 0.0 & 2.3 & 1.1 \\
\hline \multicolumn{2}{|l|}{ North-West } & 42.5 & 58.9 & 52.9 & 12.2 & 41.4 & 30.6 & 0.0 & 7.3 & 4.6 \\
\hline \multicolumn{2}{|l|}{ West } & 28.7 & 46.3 & 42.3 & 36.8 & 62.1 & 56.3 & 0.1 & 10.6 & 8.2 \\
\hline \multicolumn{2}{|l|}{ South } & 30.9 & 30.1 & 30.3 & 61.9 & 74.3 & 71.8 & 1.0 & 10.3 & 8.4 \\
\hline \multicolumn{2}{|l|}{ South-West } & 29.4 & 53.4 & 49.1 & 17.3 & 39.8 & 35.7 & 0.3 & 14.6 & 12.0 \\
\hline \multirow{3}{*}{ Cameroon } & Urban & 68.9 & 88.3 & 86.8 & 64.8 & 92.5 & 90.4 & 4.8 & 39.7 & 37.0 \\
\hline & Rural & 20.0 & 31.7 & 26.8 & 12.1 & 30.9 & 23.1 & 0.1 & 4.2 & 2.5 \\
\hline & Total & 24.8 & 59.0 & 49.0 & 17.3 & 6.6 & 48.0 & 0.6 & 21.3 & 15.3 \\
\hline
\end{tabular}

Source : ECAM3, NIS

81. On the whole, 43.1 per cent of workers are poor. Workers in the informal agricultural sector are more poverty-stricken, and almost half of them are poor (56.9 per cent). It follows that workers of the informal sector are more exposed to poverty than those of the formal sector. Generally, the income generated in the informal sector does not help in poverty alleviation.

\subsection{OBSERVATIONS BY BENEFICIARIES}

82. Consultations helped to throw more light on the opinions gathered from the population concerning the implementation of PRSP I, the impact of policies and suggestions aimed mostly at improving infrastructure (roads, electricity and water supply, etc), agriculture, education and health.

83. Generally, the population is aware that achievements of the 2003-2007 PRSP implementation period helped to improve access to basic social services. However, the population pointed out the many deficiencies hindering poverty reduction.

84. Population enclaves due to difficult access to basic infrastructure such as electricity, roads, water, ICT was one of the issues raised by the people. Indeed, the implementation period of the PRSP was marked in some localities byfrequent power cuts. Rural electrification continues to be particularly challenging, and the population decried poor execution of rural electrification projects. Because roads were not maintained, they further degraded in most towns and access to regional and divisional headquarters continued to be difficult for the population in the rainy season.

85. Access to safe drinking water is a major concern for the Cameroonian population in general and for the northern part of the country in particular. In the northern region, insufficient wells and boreholes causes the population to share the few existing water points with animals, thereby exposing them to disease. In addition, women in some localities cover long distances to fetch water.

86. In the agricultural domain, the people complain of many difficulties faced to acquire agricultural inputs whose prices have practically doubled compared to past years. They also complain of the difficulties faced in acquiring arable land, and pastureland for animals. Moreover, the people lament the State's almost complete abandonment of the rural world. 
87. Access to national communication networks continues to be a problem in some regions along the borders, and this setback causes the population to rely on information broadcast by foreign sources.

Box 4 : Organizing participatory consultations

The Cameroon Government has revised the PRSP of April 2003 to produce a second-generation PRSP covering the 2008-2012 five-year- period, and following a participatory approach involving at every stage, all the actors in the area of poverty reduction. In this regard, participatory consultations were held nationwide in March 2008, with a view to sharing information with representatives of the grassroots population.

The goals set consisted in:

- presenting the actions and strategies implemented since 2003, within the framework of the current PRSP, to poverty alleviation actors and representatives of the population;

- gathering their opinions on the achievements recorded and impact of these achievements on their living conditions; - gathering suggestions on how to improve the policies being implemented to stimulate growth at national level.

After an inaugural seminar held in Yaounde on 7 March 2008 under the supervision of the Minister of Economy, Planning and Regional Development, eighteen teams made up of facilitators and rapporteurs went to the field on 10 March 2008. The purpose was to meet businesses in order to hold first-hand discussions pertaining to the living standards of the population and ways of improving their lot.

These consultations involved more than 6000 people, representing all social classes of the country. Female participation was estimated at 25 per cent of the overall number of people consulted and youth aged less than 35 years made up approximately 20 per cent. Following the various localities covered the consultation meetings involved organized groups, administrative officials and staff, resource persons, as well as accessible urban and rural dwellers. Separate consultations were held with the grassroots population, local administrators, marginalized or vulnerable groups (youth, people living with the HIV/AIDS...) whenever deemed necessary. Similarly, some consultations were held outside divisional headquarters for reasons of proximity.

The various teams prepared reports giving the opinions of the population on each issue tackled with regard to the goals of the activity. These reports were summarized at national level and presented at a national seminar held in Yaounde from 26 to 27 June 2008 to validate the results of these consultations.

88. Regarding education, teacher shortage at all levels, their unbalanced deployment, instability at their duty post, imbalance in the construction of classrooms, insufficiency of desks in classrooms, lack of sufficient means to buy books, failure to respect the policy of free primary education in some localities are some of the setbacks to achieving set goals in this domain.

89. Furthermore, access to medications continues to be a challenge, wherewithals in divisional hospitals are very incomplete, there is shortage or even lack of medical personnel in some health centres especially in the newly created centres; access to personnel for medical attention in government health centres is very often traded.

90. In the area of governance, centralised management of public contracts causes many problems at the level of monitoring on the ground, as well as poor implementation of the public contracts code. In addition, growing and widespread insecurity stands out as a major concern.

91. In order to solve the problems they encounter on a daily basis, the population made proposals to improve on various fields.

92. As regards road infrastructure, the population particularly demanded the introduction of a sound development policy for the country centred on road maintenance, the tarring of priority roads, the rehabilitation civil engineering works, and the opening of new roads. The idea was, for example, to implement a real policy for tarring roads linking all divisional headquarters to regional headquarters, and urban roads within all divisional headquarters and border roads.

93. In the energy sector, taking into account the role that this important factor of development plays in improving the living standards of the population, participants in the consultations proposed that the rural electrification programme should continue, so farmers may use the equipment for them to process their produce, facili- 
tate the work of women, and curb rural exodus among the youth. They also recommended that excessive and frequent power cuts should be reduced.

94. To solve the problem of water supply, the population recommended that the construction of water-points (wells, boreholes, etc) should continue, while taking into account regional peculiarities especially in the northern part of the country. In the southern part of the country, the population proposed that instead of continuing with sinking wells and constructing boreholes, it is necessary to give pride of place to pipe-born water, which is cheaper to maintain and can serve a larger population.

95. In the education and training sector, the population recommended that the construction and equipment of classrooms should continue at all educational levels, while respecting school mapping so as to avoid the imbalances in distribution so far identified. The opening of modern libraries and stocking them with textbooks recommended in the syllabuses would somehow solve some of the problems faced by underprivileged children and improve their school performances. In addition, free primary education in government schools would be enhanced only if the State provides guidelines on setting PTA levies that are perpetually on the increase. Also, the almost annual review of official school booklists should be avoided as much as possible.

96. Measures to be taken in the health domain should include supplying generic medications to all the health centres countrywide so patients may afford to be treated at cheaper rates, facilitating access to ARVs, and implementing free screening for HIV/AIDS related illnesses, as well as continuing construction and equipment of health centres and posting qualified personnel.

97. Many suggestions were made to promote employment opportunities and thus raise income levels. The main ones fall under the following themes: promoting rural employment; promoting petty occupations; promoting employment in the mining and forestry sector; promoting Labour Intensive Activities (LIAs) in the field of road maintenance, financing the activities of vulnerable groups (women, youth and the physically challenged.)

98. In the forestry and mining sector, actions to be taken will include training youth in mining in order to facilitate their recruitment by mining companies, and encouraging the production and marketing of local non-timber products like raffia.

99. Suggestions made to improve the governance related to (I) improving the quality of public spending, (II) accelerating decentralization, (III) improving access to information on the management of State affairs, and (iv) continuing the reform of the legal system.

\section{MAJOR SECTOR CHALLENGES}

100. In spite of implementation of the first generation PRSP for a period of five and a half years, Cameroon's economy did not witness any visible structural changes and continued to face a number of challenges likely to hinder the achievement of expected results. Thus, the economy continued to be fragile and was rocked by serious structural weaknesses, relating particularly to weak competitiveness of the production sector and to deficient key production factors such as infrastructure and energy. The Government is thus convinced that all these challenges call for reconsideration of the factors of competitiveness in Cameroon's economy and for a serious resort to new economic and institutional policy instruments to adjust the national production fabric so it can be internationally competitive.

\subsubsection{A non-competitive production sector}

101. Despite major achievements in certain sectors, Cameroonian authorities are conscious that the implementation of sector-based strategies in the majority of sectors did not really solve the many problems faced by the added-value-generating production sector. The country's agricultural sector is hence lagging behind in terms of advanced technology and is not very productive, the industrial sector is ill-organized and not fully integrated, and the service sector seems to be developing but is dominated by purely commercial activities, which have no significant impact on added value. All these lead to an unbalanced and archaic pattern of sector contribution to the GDP, a highly exposed economic fabric, open to fluctuating global prices of exported primary products, a small domestic market without any major opening to the sub-region and the world market. 
As for the private sector, it continues to suffer from the lack of specific support policies and from its own governance problems, especially tax evasion and inadequate managerial, technical and commercial skills in companies.

102. Implementation of the rural sector development strategy that has been going on since 2003 did not help in increasing outputs, because of failure to use improved and appropriate inputs, archaic farming methods and the ageing of orchards and the rural working population. Other drawbacks not directly linked to the sector are poor rural infrastructure, lack of appropriate funding bodies and a poor taxation system. The livestock and fishing sub-sector do not produce the expected results, due to rudimentary boats, organisational weaknesses of professions in the sub-sector, and poor accessibility to markets. Production in the timber sector has continued to be dormant or even on a downward trend because of persistent logging in the natural forests to the detriment of the creation of forest plantations, as well as the almost complete absence of local processing.

103. In spite of its impressive potential in the rural sector, the country continues to be sensitive to the external shocks and was a victim to the recent international food crisis. During the first half of the 2008 financial year, despite the fall of VAT on the import of basic cereals, Cameroon spent approximately CFA 120 billion francs for the importation of cereals. The Cameroonian productive system is not yet fully equipped for the local production of these cereals, and the challenge thus lies in increasing the local supply of substitutes and encouraging new eating habits.

104. The Government strongly believes that the main challenge of the rural sector is that of adopting a rural semi-intensive and industrial production. This will help: (I) ensure food safety and self-sufficiency at the level of domestic consumption, (II) supply to the processing industry and create a market and an internal consumption for various sectors, and finally, (III) increase exports and thus improve the balance of trade.

105. Cameroon's industrial sector is still dominated by extractive activities, the manufacturing component accounting for only 8 per cent of the GDP. The absence of a one-stop shop for companies and a not very friendly environment characterized by delays in setting up the bodies provided for in the Investment Charter are partly responsible for this situation. The Government needs to boost the manufacturing industry to approximately 15 per cent of the GDP by 2020 .

106. The development and excessive nature of the contribution of Cameroonian services to boost GDP do not reflect the soundness of this sector. It rather highlights the weaknesses of the primary and secondary sectors, and most importantly an economy that is plagued by low value added business transactions. The challenge in this sector will be to develop a sector of services directed towards intensive use of ICT as well as science and technology parks to make the country a "net exporter" of services like other developing countries.

107. The national private sector, which is the main development actor of the production sector, is unable to meet the request for it to improve its productivity. In fact, it is true that the companies are running in an environment replete with flaws at the level of competitiveness, the most disturbing of which are:

- malfunctionings undermining the freedom of undertakings and creativity;

- administrative bottlenecks which are incompatible with the requirement of responsiveness to private sector practices, and increasing the costs of transactions;

- self-governance problems, civic irresponsibility and low managerial capacities of promoters;

- threats due to persistence and proliferation of anti-competitive practices such as smuggling, customs fraud, counterfeiting, dumping;

- support infrastructure for private sector companies and organizations are almost non-existent, especially as regards training, research, economic development, technical assistance, access to information on external markets.

108. In addition, it should be noted that the EPA negotiation process which will result in the introduction of a new legal framework on economic cooperation so as to govern trade ties between the European Union and Central Africa under CEEAC (CEMAC, Sao Tome and Principe and the Democratic Republic of Congo), and in the creation of a free trade zone between the two areas; in accordance with the Cotonou Agreement, also highlights a good number of challenges and crucial issues. Such challenges and issues include in particular: (i) 
the net fiscal impact expected from the pattern of negotiated tariff dismantling (pace of trade liberalisation); (ii) modes of financing net fiscal losses (in compensation for the European Union or in increase in the domestic fiscal return); (iii) high cost and modalities for the management of tariff harmonisation between CEMAC on the one hand, the Democratic Republic of Congo and Sao Tome and Principe on the other; (iv) modalities of financing EPA development component, notably and mainly infrastructure and common policies indispensable to step up the regional integration process in Central Africa and programmes on the upgrading of enterprises in this region to render them more competitive and to face competition exacerbated by the shock of liberalisation. In January 2009, Cameroon signed an interim EPA which will be substituted with a comprehensive EPA; negotiations on the latter at the regional level are being delayed by persistent divergences over the development component which according to all Central Africa States is the component indispensable to transform the EPA into an effective tool to accelerate regional integration and development.

\subsubsection{High factor costs}

109. Defective physical infrastructure. Infrastructure forms the essential basis for development and economic competitiveness. It reduces production costs and facilitates transactions and activities, increases the volume of production and spurs social progress. Currently, the rate of access to economic infrastructure (roads, bridges, airports, seaports, energy production and distribution, pipe-borne water supply, public sanitation and railway networks, telecommunications, etc) or social infrastructure (health and educational infrastructure) is very low. Moreover, their state of repair is not optimum and so cannot support private sector development.

110. In the road sub-sector accounting for more than 85 per cent of national transport, the principal reforms introduced since implementation of the Transport Sector Programme (PST) in 1996 led to a number of important measures including: (I) privatizing and controlling road works; (II) instituting Road Funds for timely payment of services; (III) concentrating available means on priority networks, etc. In spite of significant improvement at the operational and strategic level, the means available and the strategies introduced are not enough to bridge the wide structural gap between supply and demand.

111. Thus, only 10 per cent of the approximately $50000 \mathrm{~km}$, which make up the national road network, is tarred, and the percentage of the network in good conditions stood at 24 per cent in 2005. The main challenge within the road sub-sector is to ensure that the main road network and rural roads, particularly farm-tomarket roads, are maintained, and to increase the number of tarred roads to a level likely to spur industrial development and the extension of services nationwide.

112. Because of poor planning within the energy sub-sector, the country had to face a structural deficit, whereas it has a huge hydroelectric potential. Thus, the main challenge in this sector and its scope is crucial for achieving GESP goals. It consists in significantly increasing production by developing the hydroelectric and gas potential, alternative energies and modernizing distribution networks. The country will endeavour to always meet domestic demand, and even export energy surpluses to the open sub-regional market.

113. At the global level, the fluctuation of petroleum prices makes the State's budgetary resources uncertain. The drop in the price per barrel from 140 US dollars in July 2008 to approximately 35 dollars in December 2008 shows the scope of this fluctuation. Petroleum revenue within the State's budget, which made a record 7.4 per cent of the GDP in 2008, will witness a significant downward trend in 2009. The restoration of prices by adjusting supply affects demand that is not sustained, due to economic crisis in rich countries. The Government is therefore obliged to step up mobilization of funds from non-petroleum products and to ensure more stringent management of the available resources.

114. Information and Communication Technology (ICT) has been booming in the country over the past years, within the framework of a rather successful privatization. However, some major access and quality issues are still to be addressed such as, for the latter, an optical fibre whose installation and marketing is yet to become fully effective and popular. Cameroon has an access index to digital technology estimated at 0.16 in 2002 and making the country one of those with low access to this technology. In this regard, the country plans to step up this index to 0.5 per cent in twenty years. The sector is expected to have a 7 per cent growth rate when the strategy is implemented.

115. The economic growth in force since 1995 has not led to any significant employment. It is happening within 
a context of liberalization of the labour market, where flexibility introduced by the 1992 Labour Code has been translated practically into negotiated salaries. In this context, unemployment affects 4 per cent of the active population due to the almost 100 per cent employment rate in the rural area, which does not however conceal the very alarming urban unemployment and endemic underemployment. The unemployment rate in Douala and Yaounde stands at approximately 20 per cent and underemployment affects more than 75 per cent of workers. This employment situation may also be attributed to vocational and professional training characterized by training not tailored to the needs of companies.

116. Conscious of this threat, the Government intends to place human resource training at the centre of its growth strategy. Major reforms need to be carried out to step up the capacity-building of the nation's human resources so Cameroon can become an emerging economy by 2035. To meet this challenge, there is need to: (I) encourage quality primary education for all and nationwide, (II) encourage quality secondary education in preparation for higher learning in priority technological fields of study to develop the national industry, (III) encourage professional training based on the mastery of technical skills prioritizing satisfaction of local needs, (iv) encourage university training with a professional focus, and ( $v$ ) encourage expanded in-service training, coupled with a system of using the experience gathered

117. This is the price to pay for ongoing institutional reforms aimed at modernizing the administration to bear fruits. The risk run by the country is that of handing down the current poverty to future generations if nothing is done to enhance capacity-building, since it is human capital that transforms material, financial, and logistical resources into development.

\section{OPPORTUNITIES AND THREATS}

118. In order to address these many issues, the Cameroon Government is not only conscious of its assets in this development endeavour, but also of the risk factors involved. Some of the assets are natural resources and the reforms already carried out in a country whose institutions are known to be stable. However, international economic crises are likely to weaken this country, which still has a fledgling economy. Most of the risks identified in the April 2003 PRSP are still topical.

\subsubsection{Assets}

119. Natural resources. Cameroon has varied and abundant natural resources. Its location in the Congo basin is a pointer to its forest potential whose exploitation is increasingly carried out in keeping with the tenets of sustainable management of resources. The country, with its various seasons and vegetation, is good for effective implementation of all types of intensive agriculture and animal husbandry techniques. There are huge quantities of bauxite, iron ore, nickel, cobalt, and rutile in its sub-soil. Its hydroelectric potential alone is estimated at $12.000 \mathrm{MW}$ per annum, meaning, more than 10 times the potential currently being exploited. If hydrocarbons such as petroleum and gas, and the natural tourist sites are included, it can be said with certainty that Cameroon has the sufficient comparative advantage to enjoy a prosperous economy using its natural resource potential.

120. Sub-regional integration. Cameroon is the economic leader of the sub-region. This position needs to be strengthened so that sub-regional integration becomes an opportunity to be used in ensuring and preparing for integration into the global economy. Within this framework, the Regional Indicative Program (RIP) supported by the European Union at the level of CEMAC offers the opportunity of using Community infrastructure to reduce transaction costs in Cameroon's economy with regard to its relations with the countries of the sub-region. The Regional Economic Programme (REP) on its part is set up in a dynamic community marked by solidarity and the quest for external shock absorbers in the sub-region. Indeed, REP projects would account for almost 50 per cent of the support granted to this element of external shocks; the integrating nature, contribution to generating employment; contribution to sub-regional trade and the potential of public/private partnership are important aspects to consider while choosing REP projects. The Cameroon Government intends to support such a vision, which is likely to have significant positive effects on its economy. The question of geo-strategy around 
the Gulf of Guinea arises today for security reasons regarding the supply of raw materials to Western countries, especially petroleum. Cameroon also intends to seize this sub-regional opportunity, through the incentives in its investment charter, to attract more investments in mineral and/or petroleum exploitation.

121. Reforms undertaken or being implemented. The Government is aware that the reforms introduced since the country's attainment of the decision point were not all successful, and the weaknesses in the implementation of some of these reforms contribute to failure to achieve the April 2003 PRSP goals. However, the success achieved by some of them can be used for satisfactory implementation of the second-generation PRSP. That is the case with public finance reforms and the attainment of the completion point, as well as of effective implementation of decentralization which is in the pipeline.

122. Decentralization. For some years now, the Government has been making efforts to make decentralization a reality. Decentralization is a veritable local development process seen as likely to release local energies in order to accelerate economic growth at the local level and respond to the need of mastering and piloting the nation's economy towards an equitable and harmonious countrywide development, without regional disparities in the long run. Following its conceptual approach, decentralization aims to create entities with the mission of mobilizing local resources to realize community-development objectives, while ensuring an optimum combination of local and external resources within the region in order to enhance the potential of implementing comparative advantages, so as to encourage regional development, inter regional dialogue and improve living standards. Decentralization would finally empower local and regional council authorities to target the poor population, so steps and measures can be taken to reduce poverty among them both at local and national level. The government believes that effective transfer of competence to the councils, scheduled to go into force as from 2010, will help improve poverty alleviation results.

123. The decentralization process will allow for gender integration regarding women's participation in decision-making and consideration of gender-specific needs in designing local development plans.

124. New public finance management. The State's new financial regime, which entered into force as from the 2008 financial year, is a new mechanism for managing public funds. It has innovations likely to lead to better management of public funds. The flexibility in transferring funds from one line to another granted in some measure to the user minister, the introduction of project programmes with authorization to be committed over several financial years, and making vote holders more accountable for the use they make of resources, will not only change the actions involved but also their implementation will give a fresh impetus to public finance management. Moreover, the introduction of the Medium-Term Expenditure Framework (MTEF) at central and sector level will make for better mastery of the overall medium-term budget estimates and for more rational allocation of resources based on expected results per sector.

\subsubsection{Threats and risks}

125. The April 2003 PRSP identified two types of risks as key factors: resurgence of exogenous shocks and persistence of structural rigidities. Cameroonian authorities are conscious that these two problems actually hampered smooth implementation of the first-generation PRSP. These multi-faceted risks continue to be topical even now that the GESP is being prepared; they are the natural main risk factors.

126. Exogenous shocks. Owing to the pattern of its exports, Cameroon will for a long time continue to depend on fluctuating prices of primary products, an unstable foreign exchange rate (dollar), and changing oil prices. In the short and medium term, the international financial crisis and its economic repercussions may lead to a recession in the country's economy. Concerning foreign trade, the export of rubber and timber, as well as of many other products will suffer this impact and hence drop. This will show up in budgetary resources, and will particularly reduce the State's investment capacity since priority will go to operating budgets which cannot be reduced.

127. With regard to the balance of payments, the gloomy picture of the labour market in their host countries exposes Cameroonian migrants to income losses just like other workers in these countries. It is thus worthwhile to envisage a drop in money transfers, which will impact on family assistance, building construction and the establishments of SMEs usually supported by these transfers. Regarding donor countries, it should be noted that 
the economic recession observed will translate into more limited budgetary resources excluding loans, and that their limited resources will have to be used to meet requests for financial support to the banking sector in a crisis and others. Arithmetically, this huge financial support granted to their banking system and to companies affected by the economic recession, is likely to reduce their contribution to public development aid. The suspension of development aid to Cameroon is all the more foreseeable, and the country must thus seek to effectively mobilize sufficient internal means to replace the funds from development aid currently flowing when they stop.

128. Persistence of structural rigidities. Among the structural rigidities identified as risks for PRSP implementation were persistent problems pertaining to absorption of external resources. These problems actually thrived, without the absorption of internal investment resources, as well as ordinary internal resources and those resulting from debt relief, and have not really been resolved. The risk engendered by this weakness has not been cleared, because it deeply affects the level of investment with consequences on growth and poverty alleviation. Within the framework of these structural rigidities, the Cameroon government is aware that the global economy, on which the country also depends, does not allow for hesitation regarding decision-making when problems have been identified. The government's responsiveness and careful respect of commitments are all major risk factors to be considered in the GESP. 


\section{CEAPPTER 2}

\section{VISION AND GOALS}

129. National strategic guidelines are centred on a long-term vision from which national strategies are designed. The current growth and employment strategy that covers the first ten years of the vision has set goals in keeping with the 2035 development goals. This chapter presents GESP goals based on the vision. It gives an overall picture of the vision, the goals pursued by the vision, those pursued by the GESP and key considerations for implementation of the strategy.

\subsection{OVERVIEW OF CAMEROON BY 2035}

130. To enhance and sustain the economic recovery that has been underway for a decade now, Cameroon had to design development policies with long-term goals. The bold Long-Term Vision that is a prerequisite for any development strategy thus became a necessity. Following a participatory approach bringing together all development actors of the Nation and founded on the "Greater Achievements" policy of the Head of State, the structural studies of the system, aspirations of the Cameroonian population and international commitments made by the Government, a shared Development vision for Cameroon by 2035 has ensued. It reads: "CAMEROON: AN EMERGING AND DEMOCRATIC COUNTRY UNITED IN DIVERSITY".

- Emerging Cameroon is a country embarked on a journey to sustainable economic and social development with a strong, diversified, and competitive economy. The economy will be characterized by a dominant industrial sector in general and manufacturing sector in particular (in GDP and exports), effective integration into the global economy. Poverty will be minimal and income per head will be such that the country will be classified as a medium-income country.

- Cameroon, democratic country, will be a State with stable institutions and effective separation of powers. The Judiciary will be truly independent and based on an amended and modified justice system tailored to local values and the economic context. The Cameroonian State will be powerful, sovereign, a catalyst of economic and social progress, and its authority will rest on popular legitimacy. It will be respectful of individual and collective freedoms. It will have a well-equipped and decentralized administration, qualified and motivated human resources.

- Cameroon, united in diversity will be a country in which unity and integration are visible in the respect of differences and identities. Values such as the respect of authority, cohesion, solidarity, integrity, work and pride will be watchwords for individual and collective behaviours. State affairs will be run on the basis of consultations, dialogue, tolerance, and mutual respect, recourse to mediation or justice. The safety and security of persons and property will be ensured nationwide.

\subsection{DEVELOPMENT GOALS BY 2035}

131. The will to become an emerging and democratic country united in diversity encompasses four general objectives, namely: (I) reducing poverty to a socially acceptable level; (II) becoming a medium income country; (III) becoming a Newly Industrialized country; and; (iv) reinforcing national unity and consolidating the democratic process. 
132. With the vision, Cameroon is asserting its desire to see the incidence of poverty drop below $1 / 10$, meaning that; only one of every ten Cameroonians would still be poor by 2035. The reduction of income poverty would lead to improved access to healthcare, education, training services, and basic infrastructure, including water supply, roads, and electricity.

133. Moreover, on its path to development, Cameroon must pass through the status of a medium-income country, thus necessitating a remarkable growth rate over a long period. It would also be necessary to lay emphasis on immediate assets (agriculture, mining extraction...) while ensuring an equitable distribution of revenue.

Table 7: Objectives of the vision

\begin{tabular}{|c|c|}
\hline GENERAL OBJECTIVES & SPECIFIC OBJECTIVES \\
\hline $\begin{array}{l}\text { 1- Reducing poverfy to a } \\
\text { socially acceptable level }\end{array}$ & $\begin{array}{l}\text { - Make the population an effective development factor } \\
\text { - Increase investments in infrastructure and production sectors } \\
\text { - Reduce the gab between the rich and the poor by improving } \\
\text { redistribution systems } \\
\text { - Improve supply and guarantee access to all to quality health care } \\
\text { - Improve safety and social security } \\
\text { - Increase supply, quality and adequacy of training } \\
\text { - Promote generation of decent positions }\end{array}$ \\
\hline $\begin{array}{l}\text { 2- Becoming a medium-income } \\
\text { country }\end{array}$ & $\begin{array}{l}\text { - Increase economic productivity } \\
\text { - Intensify silvo, agro-pastoral and fish farming activities as well as } \\
\text { mining exploitation, etc. } \\
\text { - Maintain macroeconomic stability } \\
\text { - Encourage mutation and the professionalization of services } \\
\text { - Encourage, popularize and upgrade research results }\end{array}$ \\
\hline $\begin{array}{l}\text { 3- Becoming a Newly } \\
\text { Industrialized Country }\end{array}$ & $\begin{array}{l}\text { - Intensify investments in infrastructure and production sectors } \\
\text { - develop a sound, competitive and diversified manufacturing sector, } \\
\text { that can transform the structure of external (exports and imports) } \\
\text { - Collect savings, finance growth and development, } \\
\text { - Modify the pattern of foreign trade and gain new markets } \\
\text { - integrate itself in } t \text { he international financial arena and improve } \\
\text { banking intermediation }\end{array}$ \\
\hline $\begin{array}{l}\text { 4- Strengthening national unity } \\
\text { and consolidating democracy } \\
\text { by promoting the ideals of } \\
\text { peace, freedom, justice, social } \\
\text { progress and national solidarity }\end{array}$ & $\begin{array}{l}\text { - Strengthen national solidarity } \\
\text { - Consolidate the State, guarantor of the general interest } \\
\text { - Promote the Rule of law and the credibility of the justice system } \\
\text { - Ensure greater community participation } \\
\text { - Consolidate social freedoms (expression, association\&) } \\
\text { - Reinforce the safety of persons and property } \\
\text { - Enhance decentralization and local development }\end{array}$ \\
\hline
\end{tabular}

Source: Vision formulation project

134. In order to become a Newly Industrialized country, growth must be sustained on a good number of products with proper integration of the various branches of activity. It will specifically be a question of significantly increasing the share of products from the manufacturing industry in the GDP and exports.

135. In addition, through the objective of reinforcing national unity and consolidating the democratic process, the country seeks to reinforce the ideals of peace, freedom, justice, social progress, and national solidarity. The vision of unity implies reinforcing the sense of belonging to the same nation so that this becomes visible in individual and collective behaviour. 


\subsection{GROWTH AND EMPLOYMENT STRATEGY GOALS}

136. Conscious of the stakes involved in vision 2035 for which Cameroon has adopted a bold position, the Government is determined to persevere in its course by meeting all the challenges from diverse origins. This strategy paper, which will cover the first ten years of the long-term vision, will centre on acceleration of growth, generation of formal positions and poverty alleviation.

- Increasing growth to an annual average of approximately 5.5 per cent during the 2010-2020 period

137. The Government currently plans to step up the annual pace of expanding economic activity from 3.3 per cent to approximately 5.5 per cent per annum over the 2010-2020 periods. State officials intend to boost the agricultural sector by increasing growth in the primary sector to approximately 5 per cent, taking into consideration the huge potential that could immediately be used within this framework. The manufacturing sectors and services will undergo major reforms, while taking into account time for response, the growth of these sectors will simply have to rise above the annual average of 5 per cent. This trend will help stop the decline of the primary and secondary sectors overshadowed by a boom in the sector of services, probably implying that Cameroon's economy will be considered a transaction forum without any real production or added value.

- Reducing the underemployment rate from 75.8 per cent to less than 50 per cent in 2020 by creating some ten thousand formal positions per year over the next ten years

138. Moreover, the government is aware that to become rich, the major way to poverty reduction, it should seek to have a high employment rate. Thus, growth will be achieved with a proper tacking of unemployment. The Government intends to redress this situation by integrating actors of the informal sector into the formal sector. The idea is generally to reduce the share taken up by the informal sector in national economic activity. At the same time, the Government hopes to create about ten thousand employment opportunities per year in the formal sector through its implementation of this strategy.

- Reducing the income poverty rate from 39.9 per cent in 2007 to 28.7 per cent in 2020 . This makes a marked difference from the millennium development goal

139. At the end of the period covered by the GESP, the Government intends to reduce income poverty to approximately 28.7 per cent as against 39.9 percent in 2007 . From a broader perspective, the GESP will continue to strive in achieving millennium goals which have a strong base within the long term vision and are relevant to improvement of the living standards of the population.

- Meeting the Millennium Development Goals (MDG) by the year 2020. The MDG are reviewed in the box below.

Box 5: Millennium Development Goals

1. Eradicate extreme poverty and hunger by halving the proportion of Cameroonians living below the poverty line and who suffering from hunger;

2. Achieve universal primary education for all by giving the opportunity to every child to be able to complete a full course of primary schooling;

3. Promote gender equality, women empowerment, by eliminating gender disparities in primary and secondary education, and if possible at all levels of education;

4. Reduce the mortality rate by two thirds among new-born children and those aged below five years;

5. Improve maternal health, through reducing maternal mortality by two thirds;

6. Combat and stop the spiral of HIV/AIDS, control malaria and other major endemic illnesses by reversing their trend;

7. Ensure environmental sustainability by halving the proportion of the population without access to safe drinking water, significantly improve housing by integrating the principles of sustainable development in national policies and reversing the current trend of losses of environmental resources;

8. Develop a global partnership for developing information and communication technology and applying policies and strategies for decent and productive youth employment. 


\subsection{KEY CONSIDERATIONS FOR STRATEGY IMPLEMENTATION}

140. In order to achieve the above-mentioned goals, the Government intends to introduce a threefold coherent and integrated strategy. It can be subdivided as follows (I) a growth strategy, (II) an employment strategy, (iii) a strategy to improve State governance and strategic management. Some basic and overlapping elements can be regarded as vital and essential to implementation of the strategy.

(i) The Government intends to gradually increase the share of public investment in the State's overall expenditure from 20 to 30 per cent (by 2020) and to manage it in such a way that it largely contributes to the construction of visible infrastructure. It is a question of fixing and respecting minimum percentages of studies credits and works credits

(ii) The allocation of huge resources to major public investment projects in order to put an end to thinly spread over public investments that have become commonplace over the past years and on which the PRSP implementation reports have made remarks throughout the implementation period. This measure will be proof of the Government's determination to launch large-scale projects and will thus reassure businesses within the framework of envisaged partnership agreements, for these major projects.

(iii) The Government also intends to significantly streamline market and budgetary control procedures. For budget control, it plans to introduce reforms required for effective entry into force of the State's new financial regime within the stated deadline.

(iv) State authorities plan to broaden economic policy options by doing all they can to apply monetary policy. The State plans to raise its Net Position with regard to the financial system (GNP) to reasonable levels if the need arises in order to finance public investment to support production.

(v) The Government also intends to do all it can to finally stop the absurd inability to absorb credits usually raised as an explanation for under-consumption of resources by administrations.

(vi) Public development aid (including donations) will henceforth largely be channelled (at least 70 per cent) towards the priority sectors of road infrastructure in order to open up production fields, support agricultural production, and construct the other basic and social service infrastructure, particularly in health and education. Within the framework of the Paris Declaration, the Government, while assuming its leadership role, intends to make the GESP a reference framework for whatever intervention by Partners. 


\section{GROWTEI STRATRH}

\subsection{INFRASTRUCTURE DEVELOPMENT}

\subsubsection{Objectives per sector}

141. The economic crisis of the mid '80's stopped infrastructure development, which started since independence, and destroyed maintenance efforts. Thus, infrastructure fell into an advanced state of dilapidation and was partly responsible for the low performance of Cameroon's economy during this period.

142. Immediately after the crisis, the Government started major reforms in the key sectors of infrastructure by increasingly entrusting major responsibilities to the private sector, by investing heavily to ensure the maintenance, rehabilitation, and development of communication and production infrastructure. Although these efforts helped to slow down the degradation of infrastructure, they are not yet enough for the country to improve its competitiveness by reducing the costs of factors of production.

143. Aware of the key role infrastructure plays in facilitating exchange and promoting significant and sustainable growth through the competitiveness generated by its good quality, the Government intends to invest massively in infrastructure during the implementation period of the strategy. Within the framework of well chosen partnerships, this willingness should help attract private funding for major projects. The overall goal pursued is to raise infrastructure so it can meet economic and social demand. The ultimate idea will be to restore the role of infrastructure in achieving economic and social development objectives.

Table 8: Some targets in the area of infrastructure

\begin{tabular}{|lcccc|}
\hline Indicator & $\begin{array}{c}\text { Average } \\
2000-2003\end{array}$ & 2010 & 2015 & 2020 \\
\hline Energy consumption per unit GDP (\%) & 27.7 & 30.0 & 33.5 & 37 \\
\hline Access to safe drinking water & - & - & 70 & 75 \\
\hline $\begin{array}{l}\text { Number of km of tarred roads for 1000 } \\
\text { inhabitants }\end{array}$ & - & 0.27 & 0.29 & 0.34 \\
\hline $\begin{array}{l}\text { Number of km of railways for 1000 } \\
\text { inhabitants }\end{array}$ & - & 0.06 & 0.07 & 0.10 \\
\hline $\begin{array}{l}\text { Number of telephone lines for 1000 } \\
\text { inhabitants }\end{array}$ & 6,7 & 10.0 & 12.0 & 15 \\
\hline $\begin{array}{l}\text { Urbanization rate } \\
\text { Number of km of urban roads } \\
\text { constructed as from } 2010\end{array}$ & 501 & - & 55 & 150 \\
\hline
\end{tabular}

Source : MINEPAT 
144. It is hence necessary to substantially increase the rate of access to infrastructure through supplying more than current demand. Specifically, it will entail doubling the size of the tarred road network, by increasing the number of $\mathrm{km}$ of tarred roads for 1000 inhabitants from 0.27 to 0.34 by 2020 . The railway density will move from $0.06 \mathrm{~km}$ for 1000 inhabitants to 0.10 . Regarding energy, there is need to double consumption, being a GDP per unit trend of 27.7 per cent currently targeted at 45 per cent by the year 2035 , or at 37 per cent by 2020. The number of telephone lines for 1000 inhabitants should increase from 6.7 for the 2000-2003 period to 15 by 2020 . In the urban sector, at least $150 \mathrm{~km}$ of roads will be tarred, while urbanization will be brought under control and its present pace will be slowed down to less than 57 per cent by the time of full implementation of the strategy. The access rate to safe drinking water will have to rise to 75 per cent. This corresponds to major investments to absorb the qualitative deficiencies noted and to increase storage and processing capacities. The basic option adopted is the construction of safe drinking water supply systems. The construction of wells and boreholes will come in only as a supplement to the process of providing pipe-borne water systems.

145. These goals will be realized in each sub-sector through the following strategic aspects: (I) repairs and maintenance through the realization of infrastructure maintenance programmes by the public and private sector as the need arises, (II) rehabilitation of existing public infrastructure, (III) national construction by executing new major tasks and development programmes capable of integrating public-private funding and partnerships, and finally (iv) building of the institutional framework, particularly through improvement of the regulatory framework, reinforcement of the Planning - Programming - Budgeting - Monitoring chain, the development of standardization and quality, private sector development and finally, human resource development.

146. Intervention choices will have to take into account the need for ensuring intra and inter-sector coherence. Intra-sector coherence will be particularly required in the transport infrastructure sub-sector which does not have an integrated intervention framework since the completion of the first Transport Sector Programme (TSP), despite the development of key sub-sector strategies. The Government is committed to designing a programme for the transport sector (TSP II), whose measures and actions will help establish coherence between various means of transport. Generally, intervention programmes in infrastructure will have to be used as priority criteria, the needs of the other sectors, especially those of the other priority programmes that appear in the GESP. The Government will hence have to give pride of place to infrastructural investments in growth poles as identified in production sector strategies.

\subsubsection{Infrastructure development strategies}

\subsubsection{Energy}

147. Electrical energy. Electricity shortages that have made livelihoods uncomfortable in households and helped in slowing down the country's economic growth since 2001 are subsiding with the construction and installation of several diesel thermal power plants and a heavy fuel thermal power plant increasing the production potential that AES-SONEL manages to $933 \mathrm{MW}$. However, the delay in implementing new power station projects identified in the long-term Electricity Sector Development Plan (ESDP 2030) further widened the gap between energy demand and supply. This is compounded by the dilapidation; saturation, and shortage of electricity production, transportation, and distribution equipment, leading to repeated interruption of electricity supply over long periods in towns and villages.

148. Electricity demand in the public sector (low and Medium voltage customers), which increases on an average of 6 per cent per annum is estimated at a capacity of $4700 \mathrm{GWh}$ (being, about $842 \mathrm{MW}$ ) in 2015; and $7600 \mathrm{GWh}$ (being, $1370 \mathrm{MW}$ ) in 2025. Industrial demand on its part, which is mainly determined by the energy requirements of the aluminium industry, is currently estimated at approximately $1315 \mathrm{GWh}$ (being, $150 \mathrm{MW}$ ). With implementation of the Edéa aluminium factory extension project, this demand will be worth around $500 \mathrm{MW}$ by 2015 . Implementation of the bold plan envisaged by the Government to 
develop the Bauxite-Aluminium sector in conjunction with its partners through the Greenfield project, and the development perspectives of the industrial zone of the future Kribi deep-sea port will involve additional energy requirements of over $13000 \mathrm{GWh}(1500 \mathrm{MW})$ from the year 2016 to the year 2025.

149. Regarding what goes before and in order to ensure that power supply is available countrywide at cost-effective rates in the long run, the Government prepared an Electricity Sector Development Plan to be fully implemented by 2030 (ESDP 2030). The ESDP by 2030 takes into account the trend of public sector demand and that of industry, and defines the means of production optimal investment plan for different scenarios of demand selected and for the country, which benefits from the rich hydroelectric potential, as well as natural gas reserves that Cameroon has. Its envisaged update will help improve its data and supplement them by including the preparation of a development scheme for a founding transport system.

150. To reduce the current energy deficit and that envisaged in the near future, several projects are at an advanced stage of development. They include the construction and installation in 2009 of a heavy fuel thermal power plant of $86 \mathrm{MW}$ in Yassa, situated at the entrance to Douala; the construction and installation of a natural gas power station of $216 \mathrm{MW}$ in Kribi, the construction and opening of a water stoppage tank in Lom Pangar to regulate flow of the Sanaga and saturate the hydroelectric power stations of Song Loulou and Edéa. The latter will have a capacity of $25 \mathrm{MW}$ to fuel the electricity network of the East region and a hydroelectric power plant of about $10 \mathrm{MW}$ in Mekin.

151. Several other medium and long term projects are envisaged such as: the hydroelectric stations of Nachtigal (330MW), Song Mbengé (950MW), Memve'ele (1 20MW-201 MW) Kikot (350-550MW), Niock $(270 \mathrm{MW})$, Ngodi (475MW), Song Ndong (250-300MW), Nyanzom (375MW), Bayomen (470MW), Mouila-Mogue (350MW), Bagangte (90MW) on the South Inter-connected Network (SIN). To optimize power generation in the Sanaga Basin where most of these power plants will be set up, these projects will be associated with the construction of civil works infrastructure of Pont-Rails, Bankim-Mapé, Litala, etc. On the North Inter-connected network, the hydroelectric station of Warak (50MW) Bini is planned, as well as the power stations of Colomines (Gbazoumbé) (12MW) and Ndokayo for the East network.

152. Apart from these projects, there are sites with a subregional energy export potential (Chad, CAR,) and regional energy potential (Nigeria). They are the Cholet sites (400 MW) in the Dia, Grand Eweng (386 MW) and Petit Eweng (230 MW) in Sanaga, Noun-Wouri (1200 MW) in Noun, Mandourou (67MW) and Mbinjal (66MW) in Faro, Lancrenon (34 MW) in Ngou, the M'béré tributary, as well as the Vogzom site (33 MW) in the Vina river, Munaya (200 MW) in the Cross-River, Kpaf (300MW) in Katsina, Mentchum (15$35 \mathrm{MW})$.

153. Similarly, in an endeavour to improve the quality of electricity, the provider of this public utility AES SONEL launched a programme to rehabilitate, reinforce and renovate production works, transportation and electricity distribution before 2012 in the 2005 financial year. The majority of actions already undertaken or in progress mainly concern rehabilitating and renovating the hydroelectric power stations of Edéa and Song Loulou, and rehabilitating and reinforcing transportation systems as well as creating new source stations. This programme will continue within the distribution network to rehabilitate average voltage lines, replace rotten poles and damaged components, extend networks and connect new subscribers.

154. For the population to have better access to modern energy facilities in priority sectors (education, health and water supply) and to contribute to poverty alleviation, particularly in the rural areas, the Government worked out a National Energy Action Plan for Poverty Reduction (PANERP). In the same vein, the Cameroon government started the process of establishing a rural energy fund in support of its policy of better access to energy. Through this fund, the Government hopes to mobilize more financial resources in order to finance its development programmes and projects of energy supply infrastructure to the population, particularly in the rural areas.

155. The overall cost estimates for these programmes stand at close to CFA 5853 billion francs for electricity production and transportation works using broadband networks and at CFA 664 billion francs for the rural electrification programme. Its installation will be supplemented with a number of attendant measures such as human capacity building and developing strategic planning instruments, following the example of the Energy Information System (EIS) or the Cameroon rural electricity chart. 
156. Petroleum products. The Limbe refinery built twenty years ago is already dilapidated and its processes are outdated. Access by the population to petroleum products and particularly to domestic gas is hindered due, inter alia, to inadequate storage facilities and unequal distribution of sale points, to the detriment of rural areas and the Northern part of the country, exposed to more shortages. Thus, not less than fifteen divisions lack domestic gas sale points. In this sub-sector, the Government will modernize and increase the capacity of petroleum refining and product storage infrastructure. In addition, it will continue to build new storage capacities in the areas where they are nonexistent, as well as implement measures likely to promote access by the population to domestic gas in rural areas and in ecologically delicate zones.

157. Renewable energy and biomass. Studies carried out highlighted the existence in Cameroon of an enormous potential in renewable energy, as well as clear possibilities of developing and using these forms of energy (solar energy, micro and mini hydroelectric stations and biomass) to satisfy national energy needs. However, apart from firewood used following crude means likely to intensify environmental degradation, particularly in areas with delicate ecology, their contribution to national energy assessment remains marginal. The Cameroon government will emphasize the use of renewable energy and rationalizing firewood consumption.

\subsubsection{Building Construction and Public Works}

158. Within the road sub-sector, the Government's medium and long-term strategic guidelines for the targeted period, in keeping with the bold Road Master Plan and sector strategy scenario, aim to expand the tarred road network from 10 to 17 per cent by 2020 . These guidelines will cover the following aspects:

- Improving road infrastructure provision, by initially stressing the rehabilitation and maintenance of existing road networks, and then their extension and development (both tarred highways and service roads);

- Introducing attendant measures necessary for enhancing performance within the sector, by: (i) optimizing the organization and performance of the industrial construction sector; (ii) building the capacity and competitiveness of Building Construction and Public Works businesses; (iii) improving administration in same sector, and (iv) developing and improving human resource management in the sector.

159. Road maintenance. Road maintenance activities will concern both trunk "A" road networks, secondary road networks, and rural roads. These activities will help to substantially improve the level of highway services, by ensuring that 100 per cent of trunk "A" roads are in good shape, as well as a significant proportion (30 per cent) of the rest of the road network.

160. Road protection activities will by 2035 help: (I) ensure load checks on 100 per cent of tarred roads (as against the current 30 per cent); (II) respect traffic regulations in the rainy season and the construction of rain gates on earth roads.

161. Rehabilitation of the road network. Taking into account the advanced state of degradation of tarred roads (48 per cent of the $5000 \mathrm{~km}$ are in poor or bad conditions), the rehabilitation programme will help preserve the heavy investments already carried out. Thus, essential resources will have to be mobilized during the 2010-2020 period in order to rehabilitate an average of $200 \mathrm{~km}$ of tarred roads per annum. Substantial resources will also be earmarked for the rehabilitation of earth roads.

Table 9 Expansion of the road network

\begin{tabular}{|llll|}
\hline State \Year & $\mathbf{2 0 1 0}$ & $\mathbf{2 0 1 5}$ & $\mathbf{2 0 2 0}$ \\
\hline Good & $12 \%$ & $26 \%$ & $\mathbf{5 5} \%$ \\
\hline Average & $23 \%$ & $32 \%$ & $\mathbf{1 9} \%$ \\
\hline Bad & $\mathbf{6 5} \%$ & $\mathbf{5 2} \%$ & $\mathbf{2 6} \%$ \\
\hline Source : MINTP
\end{tabular}

162. In the rural roads sector and regarding road servicing, rehabilitation efforts will aim particularly to: (I) open up production basins; (III) open up tourist sites; (III) rehabilitate semi urban rural roads; (iv) ensure access to risk zones and; $(v)$ ensure the presence of the country in border areas. 
163. The Government is committed to taking a complete stock of rural roads in the short term, which will highlight a composite indicator of accessibility, with the aim of preparing a rational and relevant intervention programme on this network.

164. The importance of structures as a crucial point for the construction of a road will make the government regularly inspect or even urgently rehabilitate the most dilapidated structures, as part of a programme following inspection activities carried out during the years 2009 and 2010. The second bridge over the Wouri, besides its importance in developing the private sector and growth, will make Douala the "hub" of regional integration, at the very centre of the integrating road network.

Table 10: Expansion of tarred roads (in $\mathrm{km}$ )

\begin{tabular}{|lllll|}
\hline Year & 2007 & 2010 & 2015 & 2020 \\
Length & 4918 & 5250 & 6300 & 8500 \\
\hline
\end{tabular}

\section{Source: MINT}

165. Tarring of the road network. The programme on tarring the network will stress the tarring of corridors, the CEMAC road network, the trans-African road network, the network structure, laying emphasis on the opening-up of secondary towns of the Douala and Yaounde metropolitan areas. Intervention priorities will accompany the major projects generating heavy transport and added-value. A motorway programme using the present general rules and regulations governing partnership contracts will if necessary be implemented, especially on the Yaounde-Douala-Bafoussam-Yaounde loop, the Yaounde-Nsimalen section and the Douala-Limbe road. The proportion of tarred road network will stand at 17 per cent by 2020: the idea will be to tar an average of $350 \mathrm{~km}$ of roads per annum.

Table 11: Extension of roads to $2 \times 2$ (in $\mathrm{km}$ )

\begin{tabular}{|l|c|c|c|}
\hline Year & 2006 & 2015 & 2020 \\
\hline Length & 0 & 65 & 480 \\
\hline
\end{tabular}

Source: MINTP

166. Implementation strategy. Taking into account the costly nature of road works, particular emphasis will have to be laid on: (I) searching for an optimum allocation of the annual budget between maintenance, rehabilitation and tarring; (II) making road project owners aware of their responsibilities and control missions through streamlining contract awarding and management procedures, as well as intensifying post-works control; (III) reinforcing civil engineering equipment; (iv) organizing the private sector in order to have a fabric of companies and powerful consultancies; $(v)$ reinforcing planning and programming by developing and implementing an intervention strategy that considers the respect of working standards to the detriment of thinly spreading contracts, (VI) looking for materials or processes capable of stepping up the sustainability of interventions, in road maintenance in particular, and (vii) recourse each time possible to labour intensive techniques to curb costs and promote employment.

167. In the construction (building) sub-sector, the government will ensure that inputs (cement, rods, etc) are available, so that supply can be equal to demand. Officials will encourage the local production of these materials, including secondary and finished products, as well as the acquisition of specific materials for major projects. About civil engineering, the government intends to provide the central administration, devolved and decentralized services with an appropriate working environment, while rehabilitating and building according to duly 
expressed needs. In order to ensure that services are properly executed, special attention will be paid to the capacity of project ownership and management. The government will ensure particularly that the role of State engineer granted to the structure in charge of construction is effectively recognized by all the stakeholders in project ownership.

\subsubsection{Transport}

168. The Government is aware that with the attainment of the completion point, the transport sector has to deploy a new strategic approach that integrates the constraints of the ever-changing modern world and the real levels of consumption, as well as the requirements and demands of the most underprivileged segments of the population. In addition, the geo-strategic situation of Cameroon in the Gulf of Guinea and the central African sub-region warrants that the country should have enabling policies to better determine trends and the dynamics of exchange while taking into account the exigencies of globalization. However, the political will to make Cameroon a hub of exchange in Central Africa has to be translated in such a way as to cope with stiff competition between countries of the sub-region, against the background of the raging international economic crisis.

169. Thus, the transport system will have to be based on the irrefutable assets of the country in order to effectively contribute to economic growth and alleviate poverty. A multifaceted approach will consistently be given priority, in order to build a low cost integrated, powerful transport system, covering the entire nation and effectively open to neighbouring countries.

170. The interventions aimed at transport infrastructure and other road maintenance and rehabilitation will target maintenance or improvement of service quality. Intervention priorities concern: (I) in the port sub-sector: dredging of a -8 metre deep access channel to the Douala port so it can be accessible to medium sized ships and maintenance of the Garoua river port; (II) In the airport sub-sector: the ongoing rehabilitation of the Garova, Dovala and Marova-Salak airports, where the works involve redoing the air terminal roof, the fence of the airport and the luminous beacon of the landing strip respectively; (III) In the railway sub-sector: rehabilitation of the railway section between Yaounde and Ngaoundéré $(126 \mathrm{~km})$; in the river sub-sector: progressive restoration of the navigability of certain lines formerly used for trade, such as the Douala - Yabassi on the Wouri, and Abong Mbang - Mbalmayo on the Nyong.

171. The Government will focus attention on new port and railway facilities attendant to the priority projects generating growth. It will entail, for example:

- The construction of a deep sea port in Kribi based on the B.O.T (Build, operate and transfer) principle. This port will comprise several terminals notably aluminium, hydrocarbons terminals, containers, and an iron wharf in Lolabe. It will mainly serve the extension of aluminium production and programmed mining as well as increased sea traffic.

- The construction of the Limbe deep sea port. This project will be at the very centre of the development of national ports and the Douala metropolitan area. It should also have a positive impact on the development of formal trade with Nigeria.

- The construction of the Limbe shipyard whose works are already ongoing reflects Cameroon's ambition to provide countries in the Gulf of Guinea and businesses notably oil companies operating in the area, a modern and competitive shipyard.

- The construction of new railway facilities according to international standards so as to complete the economic integration of the northern and southern part of the country on the one hand, and open up the neighbouring countries which do not have access to the sea on the other hand. The national railways master plan being developed will help in clearly determining priorities on the matter, but achievement of the objectives mentioned above will probably be given pride of place through the first four railway installation projects as listed below:

- Kribi - Ebolowa - Mbalam;

- Limbe - Dovala - Edéa - Kribi;

- Ngaoundéré - Garoua - Maroua - Kousseri;

- Edéa - Yaounde - Ngaoundal; 
- Belabo - Bangui;

- Yaounde - Belinga - Booué;

- Minim-Martap - Ngaoundal ;

\subsubsection{Communication and Information Technology}

172. Telecommunications/ICT. The strategic objectives of the Telecommunications/ICT sub-sector by the year 2020 will in particular include: (I) stepping up landline tele-density to 45 per cent and mobile tele-density to 65 per cent; (II) equipping 40000 villages with modern telecommunication means; (III) increasing the flow of data transfer to $3800 \mathrm{Mb} / \mathrm{s}$ in 2020; (iv) increasing by 50 the number of direct and indirect employment opportunities.

173. The implementation of this overall Telecommunications/ICT strategy is underpinned by three major aspects: (I) adapting and updating the legal, statutory and institutional, framework, (II) improving the quantity and quality of services provided and making them affordable, and finally, (III) increasing the use of ICT and the industrial fabric of ICT companies.

174 The effective implementation of this strategy should lead to the control of production costs of products and services, thereby significantly reducing rates, to massive use of ICT by all citizens nationwide, to setting up a legislative and statutory framework tailored to fit technologies and markets, to the total grid of the country's optical fibre of the country, to the capacity building of the sector's human resources.

175. In order to achieve the goals set by the Government in the Telecommunications/ICT field, a certain number of programmes must be executed. They will involve organizing the electronic communications system to have a good visibility and legibility of the sector's activities, to optimize the use telecommunications/ICT so as to have reliable and sufficient infrastructure, to facilitate the development of ICT in order to popularize them and make it possible for all citizens to use them, improve management of the spectrum of frequencies and ensure rational use of this scarce resource, to promote industrialization within the Telecommunications/ICT sector in order to develop procedures for the emergence of Telecom/ICT SME/SMls, to implement the programme of extending their services to rural or disadvantaged areas, thus reducing the digital divide between rural and urban areas, to organize the provision of services and the trend of various market components.

176. Postal and postal financial services. In the postal and postal financial department, the strategy adopted will help to organize and make public and private postal services productive by the year 2020 so as to fully satisfy demand in quantity and quality at affordable prices; it also aims at making the postal sub-sector contribute considerably to the growth of the nation's economy and to the creation of decent employment opportunities.

177. The Government thus intends to build a postal sector that massively integrates ICT in order to meet the quality supply needs of the universal service and to meet new customer requirements as regards mailing and postal financial services. This sector's objective is to organize the development of the postal market by introducing an appropriate legislative and statutory framework, an equitable regulation that guarantees fair competition between public and private businesses in the interest of consumers.

178. In the postal and postal financial service, two programmes must be carried out. They include: (I) expanding the network and improving the national postal coverage in order to ensure a geographical balance of postal services; (II) developing the universal postal service in order to make postal services available to all.

\subsubsection{Urban development and housing infrastructure}

179. The challenge of urban and regional development, as pointed out in the long-term vision, is that of creating an integrated national economic space. It is not only a question of controlling urban development and making urban centres production and consumption hubs required to boost the industrial sector, but also promoting the emergence of suburban towns, developing medium-sized or second class towns capable of structuring economic activities in urban areas and contributing to the development of neighbouring rural areas. 
Towns and cities, from the economies of scales they offer, are places where economic activities are concentrated. Compared to the three traditional economic sectors, the secondary and tertiary industries have as sphere of influence urban centres. The urban GDP is nearly 60 per cent of the total GDP, which shows the importance of economic stakes in urban development and the economic role of Cameroonian towns and cities.

Table: Urban GDP

\begin{tabular}{lccc} 
& 2000 & 2001 & 2002 \\
Secondary sector (without extractive industries) & 749 & 798 & 836 \\
\hline Tertiary sector & 1566 & 1649 & 1760 \\
\hline Secondary \& tertiary & 2315 & 2447 & 2596 \\
\hline Cost factors GDP & 3950 & 4139 & 4313 \\
\hline Urban GDP in the total GDP & $59 \%$ & $59 \%$ & $60 \%$
\end{tabular}

Source: (PRSP - April 2003; Table 5.2). However, the paradox noted is that though towns and cities generate a larger share of the GDP, widespread inadequate equipment significantly reduces the potential and role the urban sector has to play in the revival and consolidation of national economic growth.

180. For this purpose, the Government plans to control urban development and improve the livelihood and living conditions of the urban population continue to be an obligation for towns and cities to fully play their role of stimulating economic growth. For this reason, the government proposed the following objectives: (I) curb the pace of urbanization increasing (to 57 per cent in 2020); (II) build $150 \mathrm{~km}$ of tarred roads and 17000 low-cost houses, develop 50000 plots of land; (III) halve the percentage of the urban population which does not consistently have access to safe drinking water, electricity and ICT supply; (iv) reinforce industry, the private sector, governance and human resources in the urban sub-sector.

181. To achieve these goals, six strategies were identified: (I) maintaining and rehabilitating urban infrastructure, (II) developing urban infrastructure, (III) improving access to basic urban services, (iv) controlling occupation of land, (v) protecting vulnerable social groups and, (VI) building the sector's institutional capacities.

\subsubsection{Water and Sanitation}

182. In the urban areas, major towns, where the majority of the people live, almost all have safe drinking water supply. This gives a coverage rate of approximately 86.2 per cent. However, the reality of the situation of safe drinking water supply in urban areas is translated by the rate of direct access of households to drinking water, which is about 29 per cent for a number of subscribers currently estimated at 226 638. Apart from some actions which aim to realize the drainage system of rainwater in Yaounde and Douala, the almost nonexistence of waste water evacuation and collecting systems.

183. There is limited access to safe drinking water and basic sanitation infrastructure in the rural areas. As such, it is necessary to: (I) rehabilitate the existing infrastructure most of which was built more than 20 years ago; (II) extend the existing networks that lagged behind urban expansion and population growth, (III) encourage the realization of large-scale connection programmes.

184. The Government intends to increase the rate of access to drinking water to 75 per cent in 2020. Certain priority actions are to be implemented, especially carrying out 700000 connections in the urban areas, providing 40000 equivalent water points in the rural areas, 1200000 latrines, as well as rehabilitating 6000 water points in the rural areas.

185. In the urban areas, the Government has, within the framework of the urban water supply policy letter of April 2007, opted for public-private sector partnership made concrete by the creation of a powerful public capital company, the Cameroon Water Utilities Corporation (CAMWATER), in charge of, inter alia, construction, maintenance and management of production infrastructure, transportation and storage of safe drinking water, recruitment by invitation to tender of a private leasing company, la Camerounaise des Eaux (CDE) responsible, inter alia, for the production, distribution, maintenance of infrastructure and marketing of safe drinking water. 
186. In the rural areas, the supply policy supplemented with an action plan was prepared and adopted by all the stakeholders of the sector. This policy, based on the participatory approach of all sectors, has as main objectives: (I) better planning works while satisfying demand, improving coverage of the services and avoiding inconsistencies; (II) investments sustainability carried out by improving maintenance, ensuring the safety of funds and envisaging the funding of new projects and, (III) limited dependence on the State in order to ensure the sector's self-reliant development.

187. The Government plans to increase the rate of access to sanitation infrastructure from 15 to more than 60 per cent at the end of the targeted period. For this purpose, it will design a development programme of units of water system latrines in public establishments. In addition, the concept of clean-up campaigns managed by communities is in its pilot phase and will be extended.

\subsubsection{Property Management}

188. From the emergence of Cameroon, the government plans to develop a national property management strategy with special emphasis on State property. The GESP aims to eliminate obstacles to rational management of this property by pursuing the following overall objectives:

- solve the land problem in order to facilitate the development of communication infrastructure, boost the establishment of medium and large farms in the rural sector, control urban development and improve the business climate;

- rationalize the allocation of land resources and improve State property control;

- build the capacity of administrations in charge of land tenure and State property;

- facilitate regional integration and support implementation of decentralization.

189. The key programmes will be centred on the following specific strategic aspects: (I) delimiting plots according to primary and secondary sector demand; (II) drawing a national cadastral map taking into account the cadastral maps of local communities in Cameroon; (III) setting aside land reserves intended for the development of public interest projects (iv) developing plots for residential use.

190. Significant attendant measures will be introduced, especially: (i) carrying out reforms within the legal and institutional frame land tenure and State property; (ii) providing a consultation forum for various actors to manage possible land needs in the different sectors, modernizing instruments on the State's real estate and automobile park management; (iii) streamlining and reducing the time taken to go through land access procedures, and (iv) building human and material capacities.

\subsection{MODERNIZATION OF THE PRODUCTION SYSTEM}

\subsubsection{Rural sector}

191. The Government adopted the rural sector development strategy in 2005. By this it noted that its agriculture was in bad shape, structurally unable then to feed the Cameroonian population. The following obstacles to production were identified: (I) ageing of the rural population; (II) difficult access to land; (III) difficult access to inputs (fertilizer, improved seeds, etc...); (iv) difficult access to modern agricultural techniques and other agricultural research innovations; ( $v$ ) difficult access to credit; (VI) insufficient rural sector development support infrastructure (tracks, roads, warehouses, slaughter-houses, cold chains etc); (vii) difficulty in marketing production, often because of a very long marketing chain which thwarts the very essence of added agricultural value and slows down reinvestment.

192. The rural sector development strategy adopted in 2005 thus aimed to: (I) ensure food security and selfsufficiency for households and the nation; (II) contribute to economic growth and particularly to the growth of foreign trade and employment; (III) increase the incomes of rural producers (farmers, stockbreeders, fish far- 
mers, fishermen and people living along forest areas); (iv) improve the living conditions of the rural population, and $(v)$ ensure better use and sustainable management of natural capital as a production base.

193. Its implementation was carried out in a context marked by the food and financial crises. Already perceptible at the beginning of the year 2000, the food crisis worsened in 2007 and resulted in intense social demonstrations in February 2008 owing especially to price hikes for food products; caused inter alia by growing urbanization, highway robbery, the massive surge of refugees, the rise in the prices of agricultural inputs, the high demand for domestic products in the sub-regional market, the incidence of avian flu, etc. The recent financial crisis further compounded the situation in this sector. It is gradually affecting the cotton and timber sector and is characterized by cancellation of orders abroad, a drop in the turnover of some companies, difficult access to special credit, and reticence of some commercial banks to finance the activities of the sector.

194. The results achieved in this implementation are still below those envisaged: (I) export and food crop production is insufficient; (II) living conditions of the rural population are still precarious; (III) access to funding and the market continues to be limited; $(v)$ the institutional framework is not very favourable for the sector's development.

195. Faced with this situation, the Government plans to implement a vast programme to increase agricultural production with the aim of satisfying not only the food needs of the population, but also agribusiness. In this regard, it will proceed by modernizing the production system. This will consist in: (i) making the factors of production accessible and available, especially land, water, and agricultural inputs; (ii) promoting access to technological innovations by encouraging research/awareness campaigns; and (iii) developing the competitiveness of the production sectors.

Table 12: Agricultural production goals by the year 2015 (in thousands of tonnes)

\begin{tabular}{|lccc|}
\hline Production & 2001 & 2005 Estimates & 2015 Forecasts \\
\hline Cereals & 1341 & 1686 & $\mathbf{3 2 9 4}$ \\
\hline Roots and fubers & 3517 & 3836 & $\mathbf{6 3 1 9}$ \\
\hline Leguminous plants & 263 & 300 & $\mathbf{5 3 8}$ \\
\hline Oilseeds & 209 & 239 & $\mathbf{4 3 0}$ \\
\hline Vegetables & 1278 & 1405 & $\mathbf{2 4 0 0}$ \\
\hline Fruits & 2019 & 2282 & $\mathbf{4 0 7 6}$ \\
\hline Palm oil & 140 & 177 & $\mathbf{3 5 0}$ \\
\hline Cacao & 123 & 140 & $\mathbf{2 8 0}$ \\
\hline Arabica Coffee & 10 & 10 & $\mathbf{1 5}$ \\
\hline Robusta Coffee & 50 & 50 & $\mathbf{9 3}$ \\
\hline Cotton & $\mathbf{2 2 0}$ & $\mathbf{2 7 0}$ & $\mathbf{4 0 0}$ \\
\hline
\end{tabular}

Source : Poverty Reduction Strategy Paper for the rural sector (2005)

196. In line with these special programmes, the Government particularly plans to lay emphasis on the development of hyper agricultural extensions in different parts of the country according to their agro-ecological peculiarities in order to realize large scale outputs and substantially increase production. This action will be combined with an extensive opening-up of production zones to ensure the development of plantation and peasant agriculture.

197. This modernization will be carried out through the following four important structuring programmes: (I) developing food, animal, fish and forest production, (II) improving living standards, (III) sustaining management of natural resources and (iv) amending the institutional framework.

\subsubsection{Developing agricultural, animal, halieutic and forest production}

198. The Government's strategy will consist in increasing outputs and land surface areas to about 30 per cent compared to the 2005 percentage in order to ensure food security and strengthen growth and employ- 
ment in this sector. This objective will be achieved particularly through: (I) promoting medium and large-scale farms by facilitating access to farmland; (II) encouraging the creation of groups and instituting synergies of family companies in the form of co-operative societies or CIGs, with targeted and privileged State support to such rural organizations regarding access to agricultural inputs (fertilizer and seeds in particular), at affordable prices, access to new production techniques through mechanization, awareness campaigns and agricultural consultancies; access to agricultural credit with the opening of micro-finance establishments and banks interested in this specialized credit line, not excluding the plan to create an agricultural bank; access to markets through better organization of domestic marketing channels, neighbouring markets and support for the promotion of Cameroon's agricultural produce on the international market; (III) special support for youth development in rural areas; (iv) implementing development programmes and revamping permanent forest area production, developing forestry and wild life resources, and $(v)$ developing the sectors.

199. In the agricultural production sub-sector, the government plans to revamp the rice sub sector by reviving large farms such as those of Yagova, Maga, Santchou and Ndop in order to reduce dependence on imported rice, reinforce food security and fight the high cost of living. This revival through medium and large-scale farming will also be encouraged in implementation of the maize and cassava production development plan. It is through this that growing needs in food, poultry farming, and animal breeding as well as the industries will be satisfied.

200. Particular emphasis will also be laid on developing a more intensive agriculture in sectors with growth potentials and employment such as banana, plantain, sugar, sorghum and oil palm without leaving out other emerging sectors such as Irish potato, niébé and leguminous plants or niche products like horticulture.

201. As regards cash crops, priority will be given to revamping the cultivation of cocoa, coffee, banana and cotton. The actions will aim at improving growth and regeneration of plantations and extension of surface area under cultivation. The Government plans to support businesses in the above-mentioned subsector in order to allow them to face the specific challenges that could hinder their development.

202. In order to satisfy the nutritional needs of the population and to give out surpluses for exportation, the government's strategy in the livestock production subsector, will consist in promoting the development of the production of short cycle species (poultry farming, pig breeding, small ruminants, etc.). The government thus plans to facilitate and encourage the creation of medium and large-scale ranches, in order to practise intensive livestock breeding likely to re-boost exports. Efforts shall be made in order to introduce programmes on the settlement of new actors in the main production areas and per-iurban zones of major cities.

203. In the fish production domain, particular support will be given to the development of sea and continental fishing, as well as to commercial aquiculture. Concerning continental fishing, it will be worthwhile to grant more approvals to anglers for better exploitation of the enormous halieutic potential of the Bakassi area and combat the recurrence of illegal and irresponsible fishing practices. It will also be a question of setting up an effective monitoring, supervisory and control system of fishing. With regard to aquiculture, the activities will be centred on innovations, socio-professional structuring of the activities and capacity building of actors.

204. In the forestry subsector, attention will be focused on the development and revamping of the permanent forest zone and the development of forestry and wild life resources. This action aims, inter alia, to develop non-timber forestry products, promote the processing of forest waste into energy and implementation of methods and technologies of proper use of firewood, the development of hunting interest zones and community management and game ranching. As regards forestry production, efforts will be centred on stabilization of exploited volumes of lumber, around 2 million $\mathrm{m} 3$, better processing of same and of nontimber forestry products. In accordance with international guidelines regarding sustainable development, a basic strategic option of the government in this sector will be to promote the emergence and exploitation of forest plantations to the detriment of natural forests. 


\subsubsection{Improving living conditions in rural areas}

205. The programme for improving living conditions in rural areas seeks, on the one hand, to establish living conditions that will enable the underprivileged to integrate themselves into economic life and meet their primary needs by breaking down barriers in the areas of rural financing and socio-economic development, on the other hand. The government plans to achieve these objectives by developing and maintaining farm-to-market and rural roads, improving socio-economic infrastructure, supporting community and participatory development and community management of forest and wildlife resources.

\subsubsection{Sustainable management of natural resources}

206. The Government's strategy in this area seeks to organize and encourage specific initiatives, associations, partners, the civil society, etc. for sustainable and rational development of the environment. Accordingly, actions will be carried out for the environmental management of rural activities, biodiversity management and development of resources and reforestation, development of forest plantations. These actions will be continued and strengthened in phase II of the Forestry/Environment Sector Programme (FESP) and under the missions of the National Forests Development Agency (ANAFOR).

Box 6: ANAFOR's action phases

ANAFOR's development strategy centres on three strategic phases which cover the entire area of the structure. In the years ahead, ANAFOR will focus on: (i) developing forest plantations, (ii) building the capacities of stakeholders in silviculture, (iii) developing the institutional and cooperation framework.

- Phase 1: Supporting the establishment of forest plantations. The objective here is to harmonize actions for the creation of forest plantations. The idea is indeed to lure investors in the area of forest plantations. This phase does not necessarily deal with governance issues discussed elsewhere, but focuses on the technical aspect of attracting investors or launching the activity. The key indicator of this phase is the surface area of forest plantations.

- Phase 2: Capacity building of stakeholders in forestry. This phase aims to provide technical backstopping to all already established forestry operators, especially training, provision of information, etc. In order to gauge improvements, a log sheet will be used to evaluate the general level of operators' capacities on the various aspects of forestry activity.

- Phase 3: Developing institutional and cooperation framework. Under this phase, efforts will be geared towards clearing institutional hurdles and ensuring compliance with regulatory frameworks. This phase also seeks to establish dialogue with operators and develop appropriate cooperation frameworks. Progress in this phase will be measured by reports on institutional framework and cooperation.

\subsubsection{Improving the institutional framework}

207. The goal is to build the capacities of administrations, various structures involved, support bodies, professional associations and organizations of the sector for harmonious implementation of the strategy. This programme's actions will dwell mainly on (i) information system strengthening, (ii) legislative and statutory framework review, (iii) strengthening of coordination bodies and mechanisms, (iv) stakeholder capacity building and (v) funding mechanism development.

208. Concerning particularly the funding of agricultural and rural activities, and the emphasis laid on the emergence of medium-sized and large agricultural holdings as well as grouping of smallholdings into wellestablished cooperative societies and CIGs, the Government plans to renovate funding mechanisms of agricultural activities by relying on proximity banks without excluding interested commercial banks. The public investment budget as well as concessional funds of bilateral and multilateral cooperation will obviously further help to tackle the main issues of refinancing, loan conditions, and risk coverage in the rural sector. A tight control of micro-finance institutions, beneficiaries of this credit line will be requested by the Banking Commission. 


\subsubsection{Mining exploitation}

209. Despite the existence of a mining and gas code and their implementation instruments, the sector is still to go really operational. The sector currently has a double face: a booming cottage-type mining sector and a fledgling modern sector.

210. In the cottage-type mining sector, activities are flourishing especially in the East, South and Adamawa regions. This activity employs more than 15000 full time workers. In order to optimize the impact of activities, the government has set up a cottage-type mining support framework (CAPAM) which seeks to technically supervise small-scale miners, channel their production towards formal routes, develop support activities for women in order to deter them from moving from one place to another and settle down children in order to enrol them in school.

211. The yet-to-be-developed modern sector seeks to explore, exploit and process cobalt, nickel and manganese deposits near Lomie estimated at 54 million tonnes of ore at 5 per cent, iron deposits in M'balam estimated at 2.5 billion tonnes of iron at 40 per cent and in Kribi estimated at 350 million tonnes at 35 per cent , N'gaoundal and Mini-Martap bauxite deposits estimated at more than 1 billion tonnes at 43 per cent, Aknolinga rutile deposits with geological reserves of about 300 million tonnes at 0.9 per cent, Mobilong diamond deposits with reserves estimated at 700 million carats, etc.

212. The sector aims to foster and promote research, exploitation and processing of mineral resources necessary for the country's economic and social development. In order to develop the existing mineral potential, the authorities intend to (i) set up a national mining company which will establish joint ventures with private partnerships, (ii) set up a mining development fund, (iii) conduct impact assessment studies and improve the knowledge of private national and foreign investors on the geological and mining potential of the country by providing them with maps and reliable geological data collected in a mineral data base and presented in usable form, $(v)$ develop training programmes for nationals in the mining industry and bargaining skills in the area, and (vi) promote synergy among the various administrations involved in the development of extractive industries and coordinate their activities.

\subsubsection{Crafts and social economics}

213. Crafts and social economics carried out in associations, mutual insurance companies or friendly societies, EIGs, CIGs, cooperatives, unions and federations, etc. are vehicles of wealth and job creation. The government plans to make social economy efficient and profitable. In this connection, the authorities undertake to (i) create an enabling political, institutional, legal and statutory environment for the development of collective entrepreneurship in Cameroon, (ii) develop human resources capable of boosting the growth of this component, (iii) promote collective and group entrepreneurship as one of the dependable strategies for the establishment and flourishing of organizations, and companies of viable social economy which will help to alleviate poverty and shore up economic growth.

214. Achievement of these objectives depends on : (i) conducting a study to better understand and master the social economy sector, (ii) adopting an appropriate institutional, legal and statutory framework, (iii) promoting collective or group entrepreneurship (iv) putting in place appropriate funding tools and (v) promoting the culture of social economy. Similarly, the government is bent on making crafts more attractive through supporting the organization and structuring of the sector, building the capacities of craft workers and reinforcing the smallscale enterprise in its economic environment and improving the marketing system.

\subsubsection{Industries and services}

215. Today, the development of industries and services is facing several challenges and shortcomings such as: (i) the lack or poor functioning of infrastructure; (ii) statutory constraints; (iii) difficult access to funding; (iv) inadequate human resources training; poor standardization and quality. Moreover, the business climate and corruption are major impediments to the development of the industry and services sector.

216. The Government plans to carry out the necessary reforms to make this sector more attractive. It will under- 
take to fill the void in infrastructure in the areas of electric energy with the building of hydroelectric dams, information and communication technology through the construction of the national backbone, transport services by improving road, air, rail and maritime networks.

217. Extractive and iron industries: In the area of extractive industries, the overall guidelines of Government policy have been summarized above. They seek to better develop the country's mining potential through capacity building of cottage-type miners and attraction of foreign direct investors. As concerns the iron industry, the government will give priority to the processing of aluminium and steel in partnership with identified private national or foreign businesses. With regard to the bauxite-alumina-aluminium sector, the Government is resolved to carry out the first extension of the Cameroon Aluminium company (ALUCAM) on the Edea site (including the building of the Nachtigal hydroelectric plant) and the launching of the first part of the new aluminium electrolysis factory in Kribi, including the Song Mbengue hydroelectric plant and the associated transmission line during the GESP implementation period.

218. These major industrial and mining projects will integrate into a global backstopping method comprising the following activities:

- drawing up a local regional development programme attendant to any major mining development project;

- developing and introducing incentives for an institutional, legislative and statutory mechanism for the development of public-private partnership;

- developing a specific programme for upgrading local enterprises that backstops any major industrial project;

- promoting and marketing in the area of mining identified in potential investors;

219. Agribusiness: Agribusiness is a major outlet for agricultural production and a strong factor for intensifying activities and carrying out processing in the rural world. In a sector approach that gives priority to the development of a chain of values, the Government plans to systematically negotiate and design plans for developing industries that process local products (local flour, sugar, palm oil, plantains, maize, cocoa, cotton, etc...) and those of the sub-sector of animal industries (slaughtering and packaging, cold chains, etc...). Accordingly, in the poultry sector, implementation of the development plan adopted in 2008 started in the second half of 2008. It will continue in 2009/2010 in its second and third phases which respectively concern replenishing parental livestock and introducing industrial slaughtering, packaging and cold units. Implementation of the development plan of the banana sector negotiated with operators for the 2009-2010 period will also begin from 2009 and should speed up later as the land hurdle is gradually cleared. The development plan design of the maize sector, with industrial outlets as mainly feed mills and breweries, started in early 2009. In-a-not-too-distant future and after its ongoing redefinition, the Plantain Economic Processing Programme will be launched and should help not only to significantly increase plantain production but develop plantain flour processing as well. With regard to the sugar industry, the Government is planning to provide considerable support to businesses wishing to invest in the creation of integrated complexes ranging from sugar cane, sugar refinery to biofuel refinery.

220. Generally speaking and given the first encouraging results recorded so far, this approach of dialogue between the State and the private sector on a medium-term development plan per sector comprising clear productivity and competitiveness objectives will be continued methodically by giving priorities to sectors with a strong growth and job creation potential in a manner, likely to gradually cover the entire economic fabric.

221. Growth-sector Comptetitiveness Support Programme: In association with the World Bank, the Government is involved in a special growth-sector competitiveness support programme, which falls in line with the general approach of sector development described above. This programme focuses on a restricted number of non-agricultural sectors deemed the most buoyant for growth with a high potential for job creation and likely to contribute significantly to the diversification of exports in Cameroon. It is thus a match for the already mentioned Agricultural Competitiveness Support Programme. Considerable resources will be earmarked to shore up competitiveness in these sectors, including improvement of attendant infrastructure which will definitely be beneficial to the entire economy. The non-agricultural sectors concerned are: timber, textile-clothing, tourism and information and communication technology sectors. As regards the timber industry and its by-pro- 
ducts, its development plan will seek to increase the local processing of less well known species and the manufacturing and marketing of furniture. A sustainable forest resources management policy will be designed through a forest plantation development programme. As regards the textile, clothing and leather industry, its development plan will obviously integrate an anti-fraud mechanism and envisage a resolute action for prospecting export markets given the challenges faced by this sector.

222. Enterprise upgrading programme: In order to cushion the expected shock of opening customs borders under the implementation of Economic Partnership Agreements signed with the European Union, the Government plans to develop a global programme for upgrading enterprises and supporting standardization and quality under its general sector policy. The pilot phase of this programme which enjoys technical support from UNIDO and financial support from the European Union will start in 2009 in accordance with the ongoing preparatory work, and will concern about fifteen enterprises. The development of this global programme will take into account specific upgrading programmes envisaged in addition to the aforementioned major industrial and mining projects.

223. Tourism: The objective in this area is to double the number of foreign tourists each year as per the strategy. To this effect, the institutional mechanism of tourist promotion will be reviewed and strenghtened, taking into account competences of local and regional authorities in the domain as recognized by the law. It will be necessary to identify/select a restricted number of tourist sites with high development potential and then build integrated tourist products around them. A tourisst investment code will be introduced in order to boost private investments and employment creation in this sector and the budget will provide funds to enable the government contribute to this endeavour. Moreover, the Government will take measures to develop domestic tourism.

224. Trade: At the local level, the Government's objectives regarding trade consist in regularly supplying the domestic market in sound competitive conditions and, at the international level, in developing, promoting and helping to diversify foreign trade in goods and services with high added value.

225. Generally, the Government's strategy to develop the industry and services sector will comprise enabling measures which seek to:

- strengthen the financial sector;

- introduce an institutional support framework for improving the business climate and developing SMEs;

- develop infrastructure;

- promote investments and exports;

- promote technological innovation.

\subsubsection{Promoting technological innovations}

226. The lack of a clear vision underpinned by a national technological development strategy does not facilitate the promotion and development of available technological innovations. As regards protection and intellectual property, and despite Cameroon's membership in international organizations, insufficient human and material resources make these activities ineffective and as a result, we are witnessing an increase in piracy and contraband. Similarly, standardization and quality control are still underdeveloped. With regard to infrastructure, scanning capabilities are not enough and largely depend on unqualified laboratories.

227. In order to take advantage of the Economic Partnership Agreements and new opportunities provided by globalization, the Government plans to devise a technological development and intellectual property strategy centred on (i) the creation of an appropriate institutional and statutory framework and a balance between technological development and professional training, (ii) the implementation of technological development support structures, (iii) securing and strengthening the protection of industrial protection rights, and (iv) the promotion of clean technologies in the industrial sector. As regards standardization, emphasis will be laid on (i) health and phytosanitary standards (ii) compliance with the statutory provisions of main partners. 


\subsection{HUMAN DEVELOPMENT}

228. Despite huge financial resources injected in the education, health, water and energy sectors, access to basic services is still very limited and living conditions for a large segment of the population have even deteriorated.

229. In the health sector, the level of main indicators did not improve considerably between 2003 and 2006. The infant mortality rate climbed from 74 per cent in 2004 to 87 per cent in 2006 while maternal mortality increased to 669 per 100000 live births in 2004. The vaccination coverage rate is still below the desired objectives. The proportion of children between 12 and 23 months old who received eight doses of vaccines listed in the Expanded Programme on Immunization (EPI), namely : BCG, Measles, DTCoq1, 2 and 3, Polio 1, 2 and 3 stands at 49 per cent. Malaria is still the number one killer accounting for 40 per cent of deaths. HIV/AIDs prevalence was estimated at 5.5 per cent in 2004 accounting for 6.8 per cent among women and 4.1 per cent among men.

230. Five (5) years after execution of the PRSP, the results obtained in the education sector are still mixed. About 22 per cent of children aged between 36 and 59 months attend a preschool establishment with the highest percentage in Yaounde (54 per cent) and Douala (44 per cent). This is 2 per cent in the North and 5 per cent in the Far North. The crude primary school enrolment ratio stands at 80 per cent of which 82 per cent are boys and 77 per cent girls. The primary school completion rate stands at 23 per cent of which 36 per cent are in the urban area and 10 per cent in the rural area. As regards secondary school, the crude enrolment ratio is 38 per cent with an average of 10 per cent in the northern part of the country. Higher education is on its part facing serious teacher shortage, academic infrastructure inadequacy to accommodate large numbers of students from the secondary schools.

231. As regards the other social policies, despite the dynamism noticed in the management and integration of vulnerable people, much remains to be done to improve the livelihoods of the social segments concerned who are victims of social discrimination and exclusion.

232. Moreover, it was noticed that the current social security system does not meet social protection needs. Indeed, social safety nets do not include the non salaried sector (the social safety net rate of the population is 10 per cent only) and some services like health insurance are not covered.

233. Consequently, the Government undertakes to adopt strong measures in the social sector that seek not only to uplift livelihoods but also to have a solid human capital capable of bolstering economic growth.

234. Consequently, the authorities will continue carrying out investments for the various social segments in the areas of health, education and vocational training with emphasis on the youth and women. They will also supervise and empower other socially underprivileged groups.

\subsubsection{Health}

235. Improving the state of health of the population is for the Government a social development goal that is inextricably linked to the continuation of a sustainable economic growth policy. To achieve this goal, the Government plans to adopt a global approach giving priority to the systematic search for intersector synergies necessary for successful implementation of the Health Sector Strategy (SSS). These sector strategy goals have been updated and the target date slated for 2015 in line with the Millennium Development Goals (MDGs). This strategy mainly seeks to sustainably provide universal access to quality health services and care through increasing the provision of these services and adequately funding their demand.

236. In more concrete terms, the updated health sector strategy seeks to: (i) make 80 per cent of health districts viable; (ii) enable all health facilities of the strategic and intermediary levels to play their role of providing support and guideline remedy; (iii) reduce by $1 / 3$ the morbidity rate among the poor and most vulnerable population; (iv) reduce by $2 / 3$ infant mortality of children under 5 years old, and ( $v$ ) reduce maternal mortality by $3 / 4$. 
237. To achieve these specific objectives, five strategic phases were selected: (i) strengthening the health system, (ii) extending implementation of the minimum package of activities and the supplementary activity package in the health district, (iii) developing an operational guideline-remedy system, (iv) strengthening partnership in the sector and $(v)$ boosting demand to make it creditworthy.

238. These strategic phases will help to bring out the major actions on health services and care, grouped according to a nomenclature organized in 4 action areas: (i) the health of the mother, adolescent and child; (ii) disease control; (iii) health promotion and (iv) making the health district viable.

239. Actions in the area of maternal, child and adolescent health, seek to reduce maternal, neonatal and infant mortality. In the medium term, the following results are expected: (i) improved quality of care provided to women who are pregnant and in postpartum; (ii) increased access to quality obstetrical and neonatal care; (iii) increased access to family planning services; (iv) increased screening and management of reproductive cancer; $(v)$ increased screening and management of obstetrical fistula; (vi) provision of immunization care and services with a 92 per cent vaccination coverage (DTC3, VAR, VPO3, BCG); (vii) treatment access for HIV/AIDS infected children; (viii) increased access of children to IMCD; (ix) better control of malnutrition among the population; $(x)$ build the capacities of adolescents to adapt to daily life; (xi) improved health of students and children attending schools and (xii) universal access of orphans to quality care.

240. Disease control will continue and mainly seek to significantly reduce the morbidity rate, especially among poor and vulnerable people. Actions will centre on (i) HIV/AIDS control, (ii) malaria and tuberculosis control (iii) the fight against non-communicable diseases; (iv) the fight against neglected tropical diseases; (v) integrated monitoring of diseases and responses; (vi) management of international disasters and other public health events; (vii) health of the elderly and (viii) mental health and human behaviour.

241. As regards HIV/AIDS control, the Government will focus its actions on reducing (or at least maintaining) the prevalence rate of this disease and scaling up effective management of people living with HIV/AIDS. To this end, it will especially develop activities on: (i) HIV/STI prevention; (ii) voluntary counselling and screening; (iii) PLWHIV/TB-HIV; (iv) ARV resistance monitoring; (v) orphan and vulnerable children management; (vi) STI management; (vii) blood safety; (viii) feeding people living with HIV/AIDS. The fight against this pandemic will continue to be based on the multisector approach implemented since 2000. Considerable efforts will therefore be made to make ARVs available in all health districts.

242. With regard to malaria control, the Government's objective over the next decade is to significantly reduce the prevalence rate of this disease which, with a rate of 40 per cent, is the leading cause of morbidity and mortality in Cameroon. A more coordinated approach of malaria control will be systematically sought and established at all levels in order to make the initiatives of stakeholders involved in this fight more complementary and better harmonized, especially health services, hygiene and sanitation services, the education system and information and communication services. Decentralized local authorities (councils notably) will increasingly be entrusted with the responsibility of managing integrated malaria control at the local level. In the medium term, (by 2015), the following goals will be pusued by the Government: (i) 80 per cent of children under 5 will sleep in long lasting insecticide treated bed nets; (ii) 80 per cent of community relays will apply the malaria community management package in at least $4 / 5$ health areas of each district and (iii) 60 per cent of health units will apply the malaria management norms and standards in at least $4 / 5$ health districts in each region.

243. Health promotion will be done in three action intervention phases: (i) Integrated Communication for health programmes; (ii) Health, nutrition and environment; (iii) Primary prevention of malnutrition and non-communicable diseases. Actions regarding the health, nutrition and environment phase will be guided in order to optimize disease control, especially as regards: (a) environmental and body hygiene (fight against vectors, food hygiene, hand and body hygiene and improvement of the environmental living conditions in urban and rural areas: housing, household waste, construction/use of latrines, etc.; (b) food health safety (Promotion of food quality control, Norms promotion, Promotion of good practices in manufacturing/preparing and conservation, Consumer Health protection, ....).

244. Making the health district viable is a process whereby each Health District (178 in all at the moment) must achieve its technical, economic and institutional autonomy. In this connection, the health district is said to be viable when it is capable of identifying its health problems and satisfactorily solving them with the support of 
guideline-remedy facilities (care management and provision) of the national health system. To achieve this end, government efforts will be geared towards improving the provision of health services and care on the one hand and boosting health care demand on the other.

245. As regards health care provision, improving it will depend on: (i) reviewing the health map in order to streamline it by significantly reducing the wide dispersal of health facilities and concentrating public spending on health in health centres and districts selected after this evaluation. The review seeks to evaluate the real efficiency of the current system and adopt, for the future, measures which will enable the health districts to effectively provide quality health care using modern infrastructure and adapted biomedical equipment which works most often than not. The review will also evaluate the effective provision of available medications and sufficient trained and motivated human resources; (ii) the introduction of a real medications policy which will help to ease access to medicines and essential medical reagents and quality mechanisms (iii) the development of a quality insurance system on medications and essential medical reagents and mechanisms.

246. In order that access to quality health services should not be made more difficult for some people after this review, especially for those in the rural areas, health districts will be systematically provided with mobile health teams that have adequate means and are capable of administering on-the-spot primary health care and transferring the more serious cases to hospital facilities. The mobility or, efficiency of these mobile teams will definitely be strengthened through the implementation of investments envisaged in transport and communications infrastructure.

247. With regard to boosting demand, the Government seeks to improve creditworthiness in health demand. This creditworthiness will be all the more strong as appropriate solutions will be found for employment and salary issues to achieve the second goal of the national development strategy stipulated in this GESP. In addition and without delay, the Government will: enact a law to lay down the general framework of coverage of the population in mutual health insurance; (ii) promote health mutual insurance companies with the aim of establishing at least one health mutual insurance company in each Health District; (iii) ensure the coverage of at least 40 per cent of the general population with a health insurance sharing system.

248. To ensure that the process of making health districts viable is making progress and producing quality health care and services results capable of helping in achieving the MDGs on health, an integrated monitoring-evaluation system of the efficiency of the sector will also be developed and made functional. Systemic Quality Improvement will be one of the preferred tools not only of monitoring and evaluating implementation of the Health Sector Strategy but of boosting the quality of health services and care.

249. Finally, aware of the stakes and cost of implementing the Health Sector Strategy and relying on the Paris Declaration Principles on official development assistance efficiency, the Government and development partners agreed to seize the opportunities of the current Cameroon environment and introduce a Sector Approach in this area also known as Sector Wide Approach (SWAP). This SWAP approach is based on: (a) political will; (b) mutual trust and shared interest; (c) strong government commitment and exercise of its leadership; (d) continuation of the ongoing decentralization process; (e) the existence of a large skilled manpower; (f) increase in financial flows for health. To this end, the updated Health Sector Strategy will serve as a base for developing a Common Programme, which is an essential element of the Health SWAP.

\subsubsection{Education and vocational training}

250. In the general human development framework and in order to provide the nation's human resources with the skills necessary for building an emerging Cameroonian economy by 2035, the Government intends to lay special emphasis on the training of human capital through sustained implementation of the Education Sector Strategy. The reforms envisaged in this strategy and updated with regard to Vision 2035 objectives should culminate, after the GESP implementation, in an education and training system having the following characteristics (i) quality basic education covering the primary level and the first cycle of the secondary level accessible to the greatest number of children aged from 6 to 15 years and helping to raise the average level of education to that coherent with the vision of an emerging Cameroon by 2035; (ii) a quality second cycle secondary education based on a dynamic balance between general and technical education in preparation for higher studies in priority professional fields of studies for the development of an economy geared towards 
industrialization; (iii) vocational training based on a modernized and significantly strengthened system for imparting a solid package of knowledge centred on the mastery of skills required on the job market and preparing the beneficiaries for job creation, to students leaving the first and second cycle of general secondary education; (iv) university education with a professional focus; ( $v$ ) extended continuous training coupled with a system of developing learning through experience; and (vi) real mastery of student enrolment which is indispensable for ensuring quality education through defining a system of regulating transparent and credible flows, strengthening the educational counselling system and increasing the salary scale for technical professions.

251. To make this long-term development vision sustainable and break the intergenerational cycle of poverty, the government plans to make children aged from 0 to 8 years physically, mentally and morally healthy, well nourished, well educated and cultured, sound, fully enjoying their rights, respectful of their environment's social, cultural and spiritual values and living in a sound, safe and conducive environment by 2035 .

252. Thus, at the preschool level, the Government plans to extend nursery school coverage by developing community experience for the benefit of the rural population and with the strong involvement of decentralized local authorities. The private sector will also be encouraged to provide formal preschool education. This extension of preschool education should translate into improved infrastructure, personnel and the implementation of integrated and flexible programmes.

253. At the basic education level, the goal of universal primary education for all is still top priority. By 2015 , the universal completion of six school years should have been achieved, French-speaking and English-speaking programmes harmonized, the quality of education services significantly improved and private sponsoring of basic education limited to those parents who wish and can afford it.

254. The first cycle of general secondary education will also seek to reduce the repeaters rate and progress towards universalization in the long run in order to provide this level with minimum basic knowledge that every Cameroonian should have with regard to Vision 2035. This cycle will be divided into a sub-cycle of a two-year observation period and a sub-cycle of a three-year orientation period. This reform will be accompanied by a reduction in administration spending in favour of pedagogic inputs and support to the development of private education. At the end of this cycle, the first level of a strong regulation of flows will be put in place alongside strengthening the vocational training system.

255. The second cycle of secondary education should, during the GESP implementation period, be aligned with higher education and gradually adjust its student numbers to the intake capacity of higher learning institutions. Emphasis will be laid on quality improvement (more scientific fields of study, laboratories, computer equipment, etc...). It is expected that the private sector will play a greater role in education at this level.

256. As for technical education, the State will first of all seek to significantly improve its quality by tailoring training to real market needs and by forging partnerships with the productive sector of the economy in order to increase the provision of training. In an effort to rationally use available resources in personnel, infrastructure and equipment, the State will set up major technical education schools which will include on the same site Government Technical Schools (GTCs) and current technical high schools. The fields of study created within these schools will be adapted to agro ecological areas of Cameroon in order to have a breeding ground of professionals in the fishing, forestry and handicraft profession especially. This specialization will take into account the major projects to be executed in the country.

257. As regards vocational training, the Government plans to: (i) significantly increase the provision and improve the quality of vocational training by tailoring it to the profession and be able to really efficiently regulate flows at the level of the primary, secondary and high school cycles; (ii) further rationalize the management of the vocational training system, especially through the total overhauling of the 186 Rural Artisan and Home Economics Centres (REC/HEC) scattered across the country and building Vocational Training Centres that are limited in number, better equipped and more efficient; (iii) drastically reform the professional and knowledge-acquisition systems.

258. The growing popularity of vocational training should increase school regulation flows making them really operational as well as socially acceptable and economically effective. However, this requires some preconditions as setting up intake facilities for graduates, tailoring curricula to suit the job market and providing attractive salary scales for technical professions. 
259. For Higher Education, the authorities intend to better control student enrolments with the growing popularity of the flow regulation system. They plan to increase the number of students of the already regulated sub-system to 13.7 per cent in 2009, and 25 per cent in 2020. To this effect, regulation mechanisms should be extended beyond the current sub-system.

260. In the meantime, the auhtorities will continue investing in infrastructure and teaching staff. The professionalization of education will be more refined, the university free area project will be executed and support will be provided to meritorious students in order to encourage them to further their doctoral studies at home and thus increase the teaching staff strength while improving their working conditions. This should help stabilize them in their duty positions and check exodus towards other sectors or countries. That means grants and scholarships to students abroad will be reduced.

261. Moreover, graduates from professional schools (agriculture, engineering, public works, water and forestry, etc...) will be more involved in the economic development process of the country through integration contracts during the execution of major projects. An academic excellence support project which is in the pipeline will help to improve the quality of training in some very important fields of study in the future.

262. Implementation of the aforementioned reforms will be done at each education or training level, according to an action plan covering the following operational objectives: (i) improve access and equity; (ii) improve education and training efficiency and quality; (iii) forge efficient partnership with all stakeholders in education and training and (iv) improve system management and governance.

263. Consequently, as in the area of health, the State will carry out a far-reaching review of school, university and vocational training maps in order to improve efficiency and management and streamline the establishment of education and training institutions. In this light, it will give priority to the establishment of schools in sites that have provided services (water, energy, health facilities, and telephone) to enable staff to work in acceptable conditions. The concentration of services on the same site should help to improve the quality of these services.

264. Generally speaking, in order to avoid school dropouts, especially at the secondary school level and re-establish a practice which had proven its worth shortly after independence, the State will provide major establishments with a boarding school in order to guarantee the best conditions for success, supervision and security of children. The feeling of belonging to the same country, which has been battered in recent times, should thus be strengthened.

265. In collaboration with other partners, the State will take measures to increase supply and boost demand for education, especially the education of girls and young children, notably in areas where social and traditional bottlenecks sideline children and women from the education system.

266. Similarly, the State will provide the necessary supervision to students to develop entrepreneurial capabilities in them through training in specialized modules. Furthermore, the continuous training system will also be extended for better adaptation of technicians to modern practices and enable the beneficiaries to develop these gains in addition to fair salaries.

267. Other measures will be taken to facilitate implementation of the education strategy, namely: (i) earmark budget resources necessary for education; (ii) improve the student-teacher ratio to about 40 students per teacher; (iii) set up a support fund for vocational training and human resources, and technological centres; (iv) set up a research and higher education teacher training support fund; (v) regularly ensure the allocation of subventions to private education; (vi) promote a school and university health system based on prevention and clinical management.

\subsubsection{Sports and physical education}

268. The main guidelines of the sports policy which the government plans to implement under the GESP will be based on:

- Consolidation of governance in sports. This will rest on improvement of the sporting milieu, introduction of good management rules, introduction of an effective policy on the maintenance of existing and future infrastructure, and introduction of various incentives to enable the private sector bring in durable and 
multifaceted investments in sports;

- Supervision of sports associations by providing qualitative and quantitative training for supervisors (educators and trainers), strengthening sport research and excellence centres, promoting the organization of all types of competition, improving social safety nets for sportmen and sport professionals, facilitating the functioning of federations, etc.

- Development of sports infrastructure for elite and collective sport. In terms of elite sport, quality and multipurpose stadia will be built nationwide, thereby enabling the organization of international competitions. Concerning sports in schools and promotion of the sports practice by masses, the government, in conjunction with local and regional authorities will encourage, the construction of sport facilities for collective sports in accordance with law No 74/22 of 5 December 1970 pertaining to sport and socioeducative equipement, and law No 96/09 of 5 August 1996 to fix the charter of physical and sport activities as well as their implementing instruments,

\subsubsection{Gender}

269. For women empowerment, the Government will continue to raise awareness of parents and the community, especially in rural areas with many traditional customs bottlenecks in order to enable the girl child to enjoy the same conditions of access to education. In the same connection, the State and the community will ensure fair representation of girls in all sectors concerning vocational training, higher education and access to jobs.

270. Special focus will be put on conditions conducive to women empowerment and their best contribution to socio-economic development as well as on the supervision of children, youth and women through the creation and rehabilitation of supervision structures. The State will foster the initiation and training of women in appropriate farming techniques capable of reducing the onerous nature of their tasks and improve their output and ability to market their produce. In addition, social support will be provided to struggling women and children.

\section{3. 5 Social protection}

271. As part of the fight against poverty and exclusion, the Government has undertaken to consolidate achievements, structurally reorganize existing social security bodies and expand the social security scope of equipment, staff and professionals for many people notably for the groups that have been left out. In this regard, two outline laws have been drawn up. The first one relating to the social security regime entails a system comprising: (i) national health insurance fund (CNAM), (ii) the national fund for State personnel (CNPE); (iii) the national social security fund (CNSS), (iv) mutual health insurance companies (for social health protection) and social benefit companies (pension, old age, disablement, death, unemployment, etc). The second bill sets the overal health protection framework.

\subsubsection{National solidarity}

272. The Government will continue establishing specialized structures for disabled persons. It plans to improve access to training in all sectors, further facilitate their professional integration in order to curb their dependence. Special development projects to ease their access to buildings and financial support for selfemployment will be given special attention.

273. In order to take care of the aged who have been neglected and now under the care of private associations, the Government plans to undertake a social action for them by supporting existing structures, providing medical care and encouraging families to care for elderly relatives.

274. In order to prevent the marginalization of the so-called Indigenous and Tribal Peoples (ITP), the Government undertakes to further promote school and health facilities in areas where these groups live and facilitate their integration into the society, especially through specific training and supervision programmes while taking their environment into consideration. Measures will also be taken to facilitate their access to land 
for agricultural, breeding and fishing activities.

275. Authorities will continue to promote national solidarity by fighting against the social exclusion of marginalized groups and implementing local initiatives of family and individual mutual aid, support and supervision. The Government will also ensure the community management of vulnerable people, set up national solidarity funds and take the vulnerable approach into account when designing development policies and programmes.

\subsection{REGIONAL INTEGRATION AND TRADE DIVERSIFICATION}

\subsection{REGIONAL INTEGRATION AND TRADE DIVERSIFICATION}

276. In order to bolster a job-creating sustainable growth, the regional integration and trade diversification policy in Cameroon will be part of the outlook for strengthening sub-regional and regional integration and seeking market opportunities in Europe, America and Asia. It will be based mainly on produce while cashing in on a rather conducive environment and ecology and moving, above all, from a phase of raw materials to processed products.

\section{Box 7: $\quad$ Guiding guidelines}

All in all, Cameroon's trade strategy will be more offensive, ambitious and innovating. Hence the need for boosting our competitiveness both at the supply (streamlining costs of production, adopting standards and increasing quantities) distribution levels.

With regard to goods, it will be necessary to boost competitiveness, that is, the ability of national manufacturing units to monopolize, in a profitable and sustainable manner, large market shares by standing up to competition on foreign markets and being able to adapt to and prepare for future changes.

As the case may be, rational choices have to be made: (i) on imports to give priority to raw or industrial products considered as recurrent input, to shore up productivity of enterprises and less polluting finished products in compliance with the Kyoto Convention; (ii) on exports to gradually move from a stage of raw primary products to processed products regardless of whether they are soil or subsoil products. The indicator here is the improvement of trade balance and at the domestic level, a creation of wealth (added value) that creates jobs and generates income.

As regards innovation, Cameroon should bank on hitherto neglected buoyant areas such as cultural products and services. Efforts to conquer subcontracts in the area of ICTs should boost our services export potential. With the advantage of a young population most of whom are attending school, delocalization of services such as call centres, software engineering, distance data processing, telemedicine, etc by major international firms will find cheap and skilled labour in Cameroon.

Cultural products which are prerequisites for boosting Cameroon's image is another area for trade diversification capable of spurring growth and creating jobs in Cameroon.

Concerning Cameroonians living abroad, the Government plans to organize itself in order to make the most of its diaspora. The diaspora should be the first trade boosting agent in the various host countries. Not only with regard to imports but also, and above all, as regards the export of Cameroonian products. The presence of Cameroonian products on various markets will trigger development and diversification of both products and geographical trade destinations of Cameroon with the rest of the world. To achieve this, there is need to change the paradigm of government diplomacy. Cameroon must make peace with its diaspora.

In order to be able to develop and diversify trade as a support to growth and the creation of decent jobs, the State must undertake to put in place minimal execution and support conditions, especially as the private sector is the backbone for trade creation and distribution. A solid State promotion and supervision policy must be designed and implemented. Direct and indirect actions towards this end should focus mainly on: (i) developing communications and telecommunications infrastructure to ease the movement of persons, goods and services; (ii) improving competitiveness of enterprises and trade regulatory framework; (iii) developing growth clusters with high production and job creation potential; (iv) a better integration into regional and sub-regional trade; (v) promoting trade in arts and cultural products; (vi) making the Export Promotion Agency (APEX) operational; (vii) organizing and rationalizing marketing channels for food products (wholesale markets, border markets), (viii) supporting producers in processing, packaging and labelling their products; (ix) approving legal instruments governing and supervising electronic trade; (x) streamlining foreign trade procedures and regulations in order to bring the most efficient up to scratch and thus reduce transaction costs.

\subsubsection{Regional integration}

277. In order to achieve its development goals, Cameroon intends to explore all regional cooperation avenues to tackle some national issues, notably the undersizing of markets. In this light, the Government's ambition is to promote trade relations within ECCAS by relying on CEMAC and boost trade with Nigeria. 
278. The first challenge is to conquer the CEMAC area (36 million inhabitants) by cashing in on the advantages of provisions of treaties on the free movement of goods and persons. To this end, it is entirely up to the Cameroon Government to breathe new life into this integration and unequivocally impose its leadership in the sub-region.

279. The second challenge is the Economic Community of Central African States market (more than 100 million inhabitants) with high development potential markets like the Democratic Republic of Congo and Angola.

280. The third challenge is that of Nigeria. With the successful settlement of the conflict over the Bakassi peninsula and the agreements that followed, real demand expressed by this neighbouring country on a distance of more than $1000 \mathrm{~km}$ (136 million inhabitants) is increasingly getting stronger and formal. The Cameroon Government intends to boost trade with this country, which has some assets regarding SMEs in the area of industrial production (subject to coming out in the open and abandoning contraband). Trade between the two countries can cover a wide range, from primary products (oil), food and industrial products to services (energy supply).

281. The trade development policy could then be extended to the West, South, East and North African subregions. This network is the second phase of the strategy.

\subsubsection{North-South Cooperation}

282. The authorities will work for the consolidation of European markets with trade in "traditional" products comprising raw materials or semi-processed products (timber, cocoa, coffee, banana, rubber, etc) for exports and heavy industrial products for imports. The signing by Cameroon of the Economic Partnership Agreements (EPA) with the European Union in December 2007 will gradually establish a free trade area between ACP countries and European Union members. This should improve access of Cameroon products to the European market. This agreement will be explored in the best interest of Cameroon by facing up to the tax challenge and that of competitiveness of Cameroonian companies.

283. With regard to the North American market, Cameroon now intends to spare no effort in taking advantage of the AGOA provisions which provide export opportunities, especially in textile and cultural products.

\subsubsection{Trade with emerging countries}

284. South American and Asian markets will be explored and negotiated against a backdrop of emerging countries in search of strategic positioning and political and diplomatic leverage. The mutual interest cooperation option advocated by countries falling under this group (China, Brazil, India, Korea, etc.) and the high density of their population make them major trade development partners. Opportunities for import balancing in industrial products exist with cost advantages, while market shares are to be conquered for our exports in primary and processed products, notably in the area of food.

\subsection{FUNDING OF THE ECONOMY}

\subsubsection{Taxation}

285. Aware that there can be no real sustainable economic recovery without a real investment funding policy, the Government has carried out some tax reforms aimed at fostering or easing access to credit necessary for wealth creation. These measures, which it intends to strengthen in the current context of the global financial crisis, form the framework of a taxation policy that both attracts savings and cuts the costs of borrowing money.

286. The method adopted by the authorities sought to incite individuals and any economic agent with surplus liquidity to make deposits in lending institutions. It consisted in exempting taxes on income from such deposits. To provide companies and all investors with access facilities to credit necessary for wealth creation investments, many measures have been taken at the tax level. For the most part, these measures concern 
tax preferences and other income tax waivers on some normally taxable operations.

287. However, to achieve an optimal and satisfactory level of raising tax revenue capable of funding development policies, the tax administration strategy will be centred on (i) improving the tax business environment; (ii) continuing the streamlining of services; (iii) streamlining and controlling tax spending; (iv) broadening the tax base and securing revenue.

288. Improving the tax business environment will continue through: (i) implementing electronic declaration and electronic banking; (ii) overhauling declaration forms; (iii) establishing and implementing quality service indicators; (iv) improving taxpayer governance and information.

Box 8: Some innovations introduced by Law No. 2007/6 of 6 December 2007 relating to the State's financial regime

The new financial regime, as contained in Law No. 2007/6 of 26 December 2007, which has been applicable since the 2008 financial year, makes some corrections to the shortcomings noticed in the 7 February 1962 Ordinance to lay down the State's financial regime. It provides inter alia in its Section 9 that "appropriations shall henceforth be presented by sections, programmes, actions, articles and paragraphs". Section 15 of the same law further states that appropriations opened under the finance law shall be made up of commitment authorizations and payment credits, thus making it possible to proceed by multi-year and better circumscribed management of the State budget than in the past.

Efficiency and performance concerns are further justified by the clarification of the role of each player in the chain of execution of the State budget and the revision of the State accounting framework which henceforth requires the keeping of budgetary accounting, analytical accounting and general accounting records.

Finally, one of the biggest innovations introduced by the new financial regime has to do with increasing the powers of the parliament at all the stages of the management of the State budget, be it at the time of preparing, administering or controlling the execution of the budget passed and enacted into law. This strengthening of the role of the people's elected representatives aims to guarantee that the real and priority aspirations and needs of the population are taken into account in the State budget.

289. Continuing the reorganization of services will be done through: (i) the establishment of Tax Divisional Centres redesigned on the Medium-Sized Enterprises Centres model; and (ii) continuation of specialized management according to customer type and sector of activity: this managerial approach already trialled and tested in big and medium-sized enterprises, proved to be very interesting and efficient.

290. Streamlining and controlling tax spending will concern: (i) abolition of non relevant incentives; (ii) supervising the award of tax preferences granted to enterprises under special tax systems; (iii) monitoring and controlling compliance with tax preferences; (iv) systematic evaluation of tax spending.

291. Broadening the tax base will dwell on: (i) strengthening the computerization of tax information management; (ii) operation and development of data links with the Customs (mastering the import file) and Budget (mastering the file of State suppliers); (iii) improving the identification and registration system of taxpayers; (iv) eliminating sources of tax evasion and tax niche which lead to heavy loss of earnings for the National Treasury; and (v) overhauling the tax system in order to encourage stakeholders in the informal sector to join the formal sector.

292. The authorities will ensure the taking into account of advantages provided for in the Investment Code system and the free area system as stated above during the preparation of implementation instruments of the Investment Charter which laid down the principle for repealing the aforementioned systems.

293. Similarly, the Government plans to strengthen these measures and usher in more homogeneity and coherence among them in an effort to provide equal treatment among actors in these sectors that the lawmaker intended to promote. 


\subsubsection{Banking system}

294. Many measures and actions have been taken in order to increase banking competition and financial intermediation efficiency to ease access to bank loans. Similarly, in order to improve supply and the role of the banking system in the economy, BEAC has undertaken actions aimed at modernizing means of payment and eliminating impediments to the smooth functioning of banks.

295. However, the financial sector is still characterized by the low access to banking services, banking surplus liquidity, predominance of short-term loans mainly aimed at financing the day-to-day needs of enterprises and household consumption. Although monetary policy at the level of BEAC is still centred on price stability and excess liquidity management, banking conditions are undergoing constant change.

296. The State and its CEMAC partners intend to spare no effort in reducing bank excess liquidity so that banks will benefit from medium and long-term credit investment. If need be, the State will propose incentive and persuasive actions to monetary regulation in order to increase the interests of banks in giving priority to private investment funding over ordinary banking services.

\subsubsection{Microfinance establsihments}

297. In order to consolidate and expand basic financial services and improve the quality of services provided by Microfinance Institutions (MFE), the Government is planning to: (i) intensify actions for training promoters, managers and MFE workers; (ii) put in place a first level of supervision and control of MFEs by the national monetary authority in compliance with CEMAC regulations; (iii) further strengthen the monetization of our economy, especially through expanding the computerized automation of MFEpayment systems.

\subsubsection{Strengthening the mobilization of national savings}

298. Development of microfinance institutions into a status of proximity banks. The establishment of banks in major urban centres and the conditions for opening accounts limit the access of small savers to the structured financial sector.

299. These factors encourage the development of informal finance which is distributed across the country, but is bedevilled by serious shortcomings such as lack of professionalism, the unsustainable nature of the activity, an opaque management system and over concentration on the same market segments. They lead to harsh competition and poor channelling of financial flows.

300. The strategy will consist in better supervising them through an adapted institutional mechanism and distributing market segments in a way that will expand the geographical and sector base of their activities. The system will be supervised by apex institutions for the: (i) harmonization of cooperative initiatives collecting the resources of organized group actors (ClGs, cooperative societies, etc) and (ii) supervision of the various membership organizations found both in the administration and other sectors.

301. Breathing new life into local financial markets. The national stock exchange market is vital for attracting private capital, foreign capital especially, and helps to collect long-term savings and directing them to the funding of medium and long-term investments. Moreover, it helps enterprises to increase their capital through public issuance and spares them the rigidity of conventional banks. The Government is planning to optimize the functioning of the Douala Stock Exchange in order to increase capital movement.

302. Mobilizing the resources of the diaspora. Remittances from the diaspora constitute a huge source of foreign exchange earnings in addition to exports, foreign direct investment flows and official development assistance. In accordance with guidelines enshrined in the Vision 2035, The Government is planning to use various incentives to encourage Cameroonians to invest back home, through various mechanims including: institutional management of the issue by relevant authorities, strengthening of diplomatic supervision and protection of the diaspora abroad, various incentives to channel remittances from the diaspora to productive investments and public loans.

303. Creation of specialized financial institutions. The huge funding needs and diversification of socio-profes- 
sional categories makes it imperative to establish or promote institutions that are similar or complementary to banks. After prior evaluation, the Government is planning to put in place new specialized institutions such as: (i) a National Credit responsible for managing State foreign loans and granting loans on behalf of the State at the local level; (ii) a State National Market Fund whose role will be to fund public investment; (iii) a Depositrefund Fund already under implementation.

\subsubsection{Debt strategy}

304. After the attainment of the completion point which helped Cameroon to regain debt sustainabillity and improve its debt margins, new lending institutions ensued in search of higher profitability of their capital by proposing funding that is less concessional than that recommended to the country by the Bretton Woods Institutions (at least 35 per cent of grant factor) and attacking "vulture funds" which want to take advantage of the country's reimbursement capacity.

305. Unless precautions are taken, a combination of the aforementioned factors will cause Cameroon to be once again heavily indebted in the medium-term. An awareness of the existence of such risks led the Ministers of Finance of the CEMAC sub-region to adopt Regulation No. 12/07-UEAC-186-CM-15 on the reference framework public debt policy and management on 19 March 2007. This regulation, which is an important step for the legal and institutional reform of public debt management, obliges Cameroon to:

- set up a National Public Debt Committee to harmonize debt policy with other macroeconomic policies. Since the decree to set up this structure has already been signed, all that is left is to make it operational;

- prepare and append to the finance bill of each year, a public debt strategy paper which clearly states:

- the loan justification;

- debt ceilings and securities provided by the State;

- the portfolio structure of new loans;

- the indicative terms of new loans;

- the debt sustainability profile under a period of 15 years.

306. The implementation of this regulation should enable Cameroon to strengthen the middle office (strategic reflection) on debt policy. It will seek to determine and structure funding needs based on programmes and projects that have been selected and integrated beforehand in the macroeconomic framework which will then give the front office (negociation function) the specific guidelines on the characteristics of funding each need. This will help to provide the project or programme with adequate funding that is commensurate with its $\operatorname{cost}^{8}$ taking into account its output.

307. The main guidelines of the debt strategy concern management of the Convergence Programme and that of the credit/liquidity crisis.

8 This is to ensure compliance with the regulation which requires the interest rate of the loan funding a project to be lower than the output of the project. This project management microeconomic regulation can be seen at the macroeconomic level when examining debt dynamic equation, $, \mathrm{d} t=\frac{(r-g)}{(1+g)} d t-1+s p t-b t, \Delta d t$ being the change in debt in GDP percentage, $r$ the average interest rate of the debt portfolio and $g$ economic growth rate 
Graph 2: Public debt stock trends

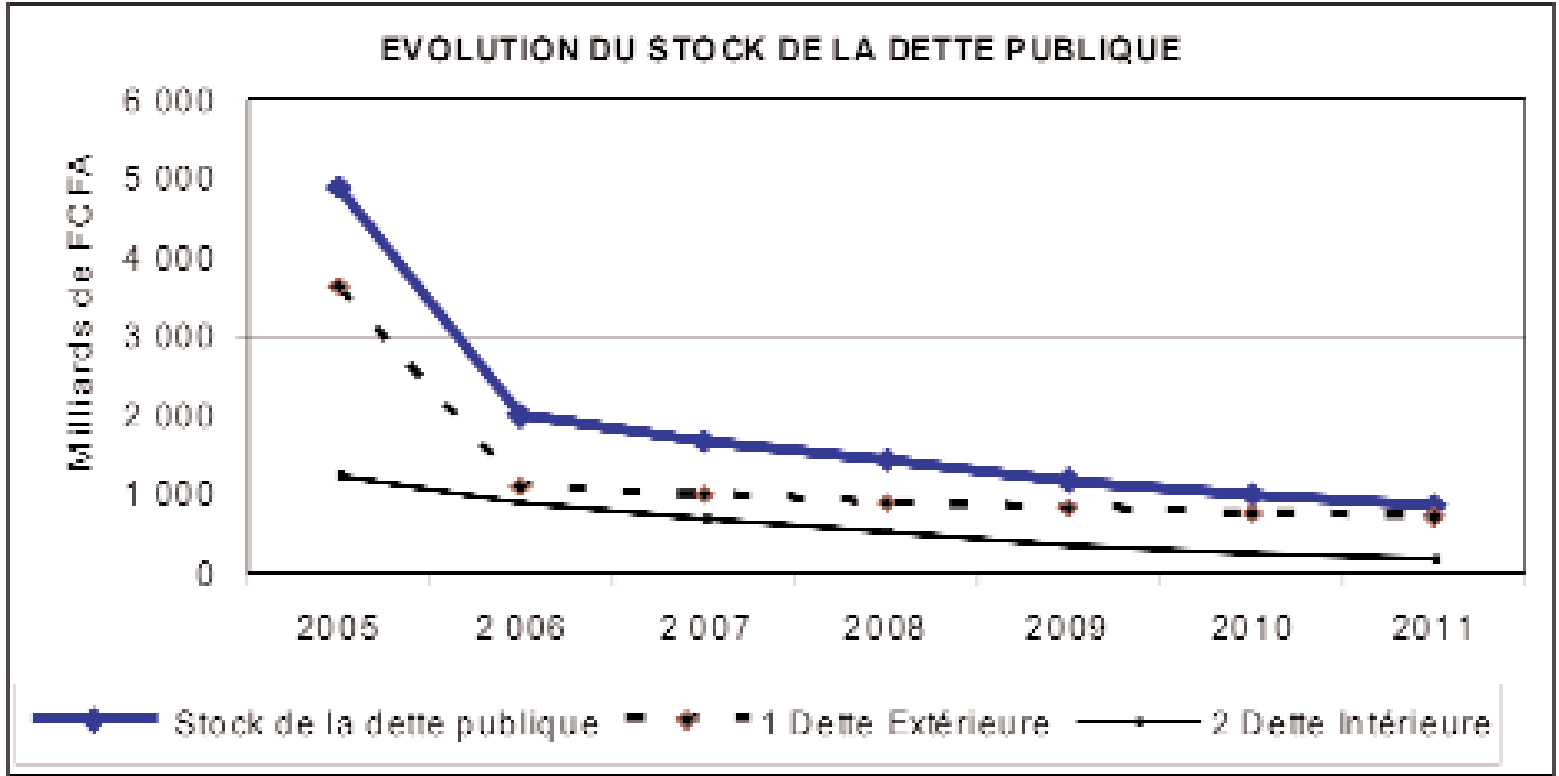

308. For the convergence programme, the Government will implement a cautious debt policy and will ensure the rational management of public debt informed on a debt strategy consistent with the macroeconomic framework and the mid-term budgetary objectives. It will be made up of the following elements: (i) undertaking an analysis of debt viability for each year and before entering into any loan higher than or equal to 0.5 per cent of the GDP; (ii) undertaking a comprehensive study of projects for which loans are being sought; (iii) going out to look for concessional financing as a matter of priority; (iv) setting the annual debt ceiling on a rational basis; $(v)$ carrying out regular analysis of the costs and risks connected with the management of the public debt portfolio (risk related to exchange and interest rates, refinancing, macroeconomics, etc. It will also contain provisions under which it shall be updated on a yearly basis and annexed to the finance law.

309. Furthermore, the Government will continue bona fide negotiations with private creditors who had turned down the debt redemption operation proposed in 2003, in order to service the debt owed the London Club, without forgetting the comparability of treatment.

310. The Government will pursue its aggressive payment policy without delay in the servicing of the national debt, which will help to win back the trust of businesses and partners, but also help to avoid accrued debts.

31 1. Ironically, the credit/liquidity crisis has spared sub-Saharan Africa due to its lag in the development of financial markets. However, this region is still exposed to economic repercussions. There is a high probability of witnessing a slump in the volume of grants and aid from advanced countries, the solemn declarations of the G8 notwithstanding. 
Table 13: Debt sustainability ratios (in \%)

\begin{tabular}{|lccc|}
\hline Production & $\mathbf{2 0 0 1}$ & 2005 Estimates & 2015 Forecasts \\
\hline Cereals & 1341 & 1686 & $\mathbf{3 2 9 4}$ \\
\hline Roots and tubers & 3517 & 3836 & $\mathbf{6 3 1 9}$ \\
\hline Leguminous plants & 263 & 300 & $\mathbf{5 3 8}$ \\
\hline Oilseeds & 209 & 239 & $\mathbf{4 3 0}$ \\
\hline Vegetables & 1278 & 1405 & $\mathbf{2 4 0 0}$ \\
\hline Fruits & 2019 & 2282 & $\mathbf{4 0 7 6}$ \\
\hline Palm oil & 140 & 177 & $\mathbf{3 5 0}$ \\
\hline Cacao & 123 & 140 & $\mathbf{2 8 0}$ \\
\hline Arabica Coffee & 10 & 10 & $\mathbf{1 5}$ \\
\hline Robusta Coffee & 50 & 50 & $\mathbf{9 3}$ \\
\hline Cotton & $\mathbf{2 2 0}$ & $\mathbf{2 7 0}$ & $\mathbf{4 0 0}$ \\
\hline
\end{tabular}

Source: $\quad$ Poverty Reduction Strategy Paper for the rural sector (2005) 


\section{CEAPPTPR S}

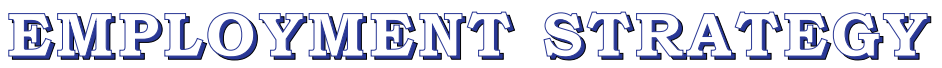

312. The General Employment Forum supported by the National Employment and Informal Sector Survey organized in 2005 respectively by the Ministry of Employment and Vocational Training (MINEFOP) and the National Institute of Statistics helped to make an appraisal of the employment situation in Cameroon and draw up a national employment and vocational training policy paper that was validated in 2007 . Also, with the support of the International Labour Office and with a view to the revision of the PRSP, the Ministry of Employment and Vocational Training recently in October 2008 conducted a study on the situation of the labour market information system in Cameroon.

313. The employment situation in Cameroon is characterized by a low rate of unemployment $(4.4 \%)$ in the strict sense of the term, whereas in its broad meaning, which better reflects the Cameroonian context, unemployment stands at about 13 per cent. This rate of unemployment does not however reflect under-employment which stands at 75.8 per cent. This situation developed concurrently with a huge increase of the informal sector which employs about 90 per cent of the employed labour force, which is in Cameroon estimated at about eight million people with less than two hundred thousand working in the public sector, about eight hundred thousand in the formal private sector and the rest in the informal sector, including those in the rural areas. Upon analyzing the underemployment situation in Cameroon, it ensues that invisible underemployment which comprises employed labour force earning a wage lower than the minimum guaranteed inter-occupational wage (SMIG), accounts for 64.8 per cent of the active population, while visible underemployment ( 11 per cent) concerns the people working involuntarily less than the allowed weekly duration of 40 hours per week.

314. The predominance of employment in the informal sector is indicative, on the one hand, of the inefficiency of public policies implemented in the area of employment, and, on the other hand, of the dynamism of the population and their entrepreneurship, which causes them to go in even for unstable positions.

315. Concerning the labour market, the absence of regular data collection on employment makes it difficult to monitor the situation on the ground and leads to the production of scattered and hardly comparable data. The absence of specific coordination for the labour market information system leads to the use of un-harmonized concepts and methodologies. In the area of training, no real survey has been conducted on qualifications and insertion (market situation and needs) which allow vocational schools and universities to revise their training programmes and adapt them to market needs.

316. In its National Employment Policy Statement, the Government has decided to henceforth make employment an important element of its development policy. It has therefore included employment as one of the three main strategic components of the Growth and Employment Strategy Paper (GESP), thus considering employment not only as a result of economic growth but also and above all as a promoting factor of such growth and a catalyst of poverty reduction. It therefore addresses the issue of employment in the GESP from three key points of view, namely: (i) increasing the number of decent positions, (ii) matching demand to supply of jobs; and (iii) enhancing efficiency of the job market.

\subsection{INCREASING DECENT EMPLOYMENT OPPROTUNITIES}

\subsubsection{Taxation}

317. The national employment policy has as main objective to promote full, decent and freely chosen jobs. The goal by the year 2020 is to completely offset visible underemployment and maintain the broad unemployment rate at less than 7 per cent. To this end emphasis will be laid, as a matter of priority, on the development of wage-earning employment, through support to the development and competitiveness of SMEs

\footnotetext{
9 Ratio of the number of unemployed persons to the active population. Leaving out invisibly unemployed persons could lead to an underestimation of unemployment rates.

10 This is the ratio of the population made up of employed people within the meaning of the ILO plus discouraged unemployed people to the active population (extended to discouraged unemployed people).

11 Minimum guaranteed interoccupational wage.
} 
and SMls. Promoting self employment will go a long way to supporting this central mechanism, by specifically encouraging a switch from the informal sector to the formal sector. Introducing specific employment promotion programmes for the most under-privileged segments of the society (youth, women, disabled persons, indigenous minority groups, etc.) and rejuvenating the public service payroll will complete the comprehensive employment availability mechanism.

\subsubsection{Development of SMEs and promotion of decent wage-earning employment}

318. The SME development strategy, which is at the centre of the Cameroon Economy Competitiveness Strategy, is still being developed. However, a situational analysis of this sector has been done and strategic activities identified. This activities will mainly concern: (i) removing the institutional constraints to the development of SMEs, particularly those related to infrastructure, the business environment, access to markets and access to funding; and (ii) promoting the establishment of growth centres along side sector development policies, in order to fully stimulate the development of value chains, and ensure as far as possible, widespread regional growth centres nationwide. For the implementation of the above-mentioned two activities to fully impact on employment, the Government will endeavour to create an overall enabling environment for employment creation around SMEs and private enterprises.

\subsubsection{Removing institutional constraints}

319. With regard to basic infrastructure (roads, energy, transport and communication, water and hygiene, etc...), the quantitative and qualitative improvement expected from the policies described earlier (cf. Chap. 2) will be beneficial first and foremost to SMEs and SMIs. The issue of storage and marketing facilities (periodic, permanent or border market stalls; slaughter houses and cold and refrigeration facilities; silos and storage warehouses; etc.) will be addressed case by case, within the cross-cutting framework of national sector development policies and the specific development policies of decentralized local authorities, depending on the needs which will be expressed and the initiatives the private sector will take.

320. For the business environment, the broad outlines of which are also treated under component three of the GESP dealing with issues of governance, it will be necessary, with respect specifically to SMEs, to undertake far-reaching reforms aimed at: (i) strongly accelerating the rate of setting up SMEs, by radically streamlining the necessary administrative procedures, including tax declaration and payment procedures, by carrying out a comprehensive review of the legal and statutory framework for the promotion of SMEs and by equipping the regions with SME incubators; (ii) significantly reducing the mortality rate of young enterprises (those younger than two years) through a set of attendant measures aimed at strengthening human and technical capacity as well as corporate governance; and (iii) promoting technological choices that are clearly job-oriented, especially in building and construction, agri-business (first processing, in particular), urban hygiene and sanitation ... etc.

321. The streamlining of procedures for starting business and tax procedures will entail carrying out an indepth review of the relevant statutory and regulatory instruments, on the one hand, and instituting, in conjunction with decentralized local authorities, one-stop enterprise creation shops, on the other. The review of legal instruments is expected to start in 2009 by reducing by half the number of tax return slips and end latest in 2012 with the harmonization of the various instruments and ensuring their compliance with international labour standards. The Government also plans to open authorized management centres as from 2009 to render accounting services and tax requirement services to SMEs. This first mechanism is expected to act as a major incentive for informal sector promoters to get registered with the taxation administration and to translate, as from 2010/2011, into a sharp increase in the enterprises and decent employment created.

322. The follow-through measures aimed at reducing the death rate of SMEs/SMIs shall be in line with both the overall crosscutting reform framework (financing, taxation, access to markets, etc.) and within sector-specific policy frameworks. Apart from medium term development plans of the above-mentioned sub-sectors, the government thus intends to base its actions, as already indicated, on a vast programme for upgrading enterprises and ensuring quality standardization, a programme established in May 2009 and which will actually be introduced as from the second semester of 2009. 
323. Benefiting from the technical support of UNIDO and the financial support of the European Union (9th and 10th EDF), this programme, which is mainly directed at SMEs, aims to strengthen the managerial skills of their leaders, enhance the technical quality of their production tools and boost their investment, including complying with quality and environmental protection standards. The Government expects this programme to have a significant positive impact on competitiveness, employment and the wage bill, and thus plans to spread it over a period of at least ten years in keeping with the speed of tariff dismantling agreed upon under the Economic Partnership Agreement signed with the European Union. It will thus take steps to ensure that, beyond the foreign funding announced and expected, the overall funding of this programme is based on a solid foundation financed under the special chapter opened since 2009 in the public investment budget and devoted to the development of productive sectors.

324. Away from this vast programme, but in line with its implementation, the Government plans to provide substantial support for the introduction and development of technical assistance and support structures to the non finance services of SMEs. As it did in the past at the time of creation of the former SME Assistance Centre (CAPME), the Government will thus request the technical and financial support of its development partners.

325. Concerning access to the market, the priority of the Government will primarily be to ensure that SMEs and SMls have satisfactory access to local and sub-regional markets, the area of action here being the Economic Community of Central African States (ECCAS) and Nigeria. To this end, the Government plans to: (i) see to it that within the framework of major works and projects, local market shares representing at least 30 per cent of the total cost of the investment are systematically reserved for SMEs and SMls; (ii) ensure that ongoing major projects for the provision of social housing are designed on the basis of the most intensive use possible of local materials, for which the technology is more affordable for local SMEs; (iii) make it mandatory to use labour intensive technology in the execution of some types of works, in particular, in the building construction and public works sector (notably the maintenance and construction of rural roads) and in public investment as a whole.

326. The instruments governing public contracts will thus be revised to include, as far as possible, the use of national SMEs and labour intensive approaches in terms and specifications, in accordance with the "Action Plan for the Implementation of the promotion strategy for labour intensive approaches in public investment programmes" drawn up by the Government in December 2008 with the support of the International Labour Organization. This action plan is made up of 4 (four) components: (i) developing an institutional policy favourable for labour intensive approaches; (ii) building the capacity of players involved; (iii) promoting the application of labour intensive approaches in public investments; and (iv) enhancing knowledge on labour intensive approaches.

327. To help SMEs to effectively use the new opportunities of access to markets so created, the recently established sub-contracting stock market will soon be launched, and is expected to find its first demonstration ground in 2010/2011 with the start of major projects for the extension of ALUCAM in Edea, construction of the Nachtigal Hydroelectric power plant, the Lom Pangar storage dam and a new aluminium smelting factory in Kribi. This sub-regional stock exchange is expected to facilitate the grouping of SMEs by activities as well as the harmonization or even combination of the factors of production; these SME associations, set up according to branches of activity and/or on a territorial basis, will benefit from the support of the State in their efforts geared towards improving the performance, competitiveness and governance of their members.

328. For access to financing, the Government believes that clearing this obstacle requires first addressing the central issues of risk guarantee and lending conditions for SMEs/SMls. It intends to provide answers to these questions: (i) within the general framework of the Action Plan for Strengthening Financial Intermediation in Cameroon (PARIF) now under formulation and which is expected to generally improve access to bank loans and services; (ii) within the framework of support to microfinance development, which is expected to be particularly beneficial to the agricultural sector and to very small-sized firms in general; and (iii) within the framework of establishment of specialized financial institutions for SMEs, and instruments suitable for risk management: easing tax and customs procedures, diversification of financial instruments such as venture capital; mutual bond; leasing; guaranteed funds; loan subsidies; etc. All these measures will 
be taken in collaboration with the private sector and development partners who will, more than ever before, be involved in the adoption of budget lines devoted to SMEs and SMls.

\subsubsection{Promoting the development of growth centres}

329. At the centre of its sector development policy, its regional development policy, and its decentralization policy, the Government plans to promote the development of regional growth, centres based on existing or yet to be organized production and employment zones. In this connection, the government plans to set up an integrated market that blends the development of promising growth and competitiveness sectors, construction and rehabilitation of major infrastructure in the growth centres, strengthening the capacity of local and regional authorities as well as fully addressing social (including employment) and environmental issues. The setting up of regional and local employment committees will, in particular, help to include the employment aspect in each key phase of this approach.

330. A growth centre covering the Atlantic coast and its immediate surroundings within a radius of 70 to $100 \mathrm{~km}$ is thus in the making with: (i) the existence of a diversified industry mainly concentrated in this zone; (ii) the now better articulated choice to boost growth by strongly developing extractive industries (oil, gas, bauxite-alumina-aluminium, nickel and iron ore, in particular), mainly through foreign direct investments; (iii) the Government's resolve as expressed in the document Cameroon Vision 2035 to make the most of the geo-strategic position of the country by developing and modernizing all the ports of Cameroon to make them an integrated and coherent system; and (iv) the initiative of the Douala City Council to draw up an Integrated Development Strategy for Dovala and its metropolitan area. The coming of this Atlantic pole, its capacity to generate decent jobs and attract investors will depend on how successful the harmonization and coordination efforts of these ongoing initiatives and studies would be.

331. A second national growth centre is developing around Yaounde. Beyond ongoing efforts to provide the capital city with modern infrastructure, the Government actually plans to equally include the long-term development of Yaounde in that of its metropolitan area. The emergence of other growth centres should go along side the progress made in the area of decentralization, at the regional level, in particular. It is however clear that city councils, which already make up important production and employment centres, all have to play a key role in the organization of the various growth centres.

\subsubsection{Introduction of an attractive comprehensive framework for the creation of wage-earning employment}

332. The strategy to be adopted to enable the private sector and SMEs/SMls in particular to play their economic role in terms of job creation will be divided into the following two components.

333. Firstly, it will be necessary to reactivate the tripartite consultation platform existing between administrations in charge of economic affairs, the various private sector and civil society players in order to review and dismantle all obstacles to job creation. Here, all the partners will be educated on job creation strategies in the private sector and on the measures necessary to stimulate employment creation activities.

334. Secondly, it will be necessary to provide some incentives to encourage job creation through:

- the mainstreaming of job creation into macroeconomic and public investment policies: this will be achieved by directing investments towards sectors and projects which contribute to job creation and have an immediate incidence on the economy and social development;

- the effective application of the direct incentives for job creation provided for by the law, in particular, the Investment Charter; tax incentives will specifically be considered to encourage enterprises which contribute to the skill acquisition system;

- the application of indirect incentives such as instituting an award for profitable firms which have kept their workers and, better still, created further jobs; providing support to enterprises through the training of personnel to be recruited; periodic organization of sectoral meetings on human resources management; etc. 


\subsubsection{Promoting self-employment}

335. The second component of the Government's employment creation policy will be hinged on developing a support mechanism targeting self-employment, from which it expects a significant contribution to the reduction of underemployment and a shift from the informal sector to the formal sector. The government has set as objective to drastically reduce the size of the informal sector to bring it to an insignificant level by the year 2035. By 2020, visible underemployment should be reduced by 50 per cent. Self employment will be encouraged with the determination to accompany the development of sectors that can be catalysts of growth, especially in agricultural, handicrafts and service activities.

336. In the rural areas, in line with the policy for the development of medium-scale and large-scale agricultural undertakings, incentives will be allowed to facilitate the establishment of youth and graduates of higher institutions of agriculture by: (i) training in large-scale agricultural project design; (ii) facilitating access to loans; (iii) facilitating access to modern farm inputs; and (iv) facilitating access to land. Start-up programmes with an initial objective to create more than 15000 self-employment jobs for youth are in the pipeline. Furthermore, the implementation of some major projects particularly aimed at structuring regional development will often lead to the development of related activities from which nearby communities could benefit. Thus, specific training, depending on the type of project, will be developed to facilitate the integration of these populations in the said activities. Local development programmes will also be introduced by the State and local and regional authorities to amplify the positive impact of these projects on local development and create several jobs in rural areas.

337. Considering the enormous potential of handicrafts, the Government plans to revitalize this sector in all its components, to make it a truly attractive activity capable of creating jobs, generating income and stimulating growth. The following 4 (four) components, each with a series of actions programmed in the short, medium and long term, are envisioned:

- support to the organization and structuring of the sector;

- strengthening the capacity of craftsmen;

- integration of the handicraft sector in the economic landscape;

- improvement of the marketing system.

338. In the services sector, specific programmes, to back the strategy for the development of promising sectors (textile, tourism, etc.) will be implemented to facilitate the establishment of young people who have received vocational training. Thus, the strategy will mainly be based on supporting informal sector actors to organize their activities into very small enterprises (VSE) by: (i)introducing a flexible tax regime; (ii) facilitating administrative registration, including social security; (iii) training with a view to helping these actors to better monitor their activities by keeping minimum records; and (iv) assisting promoters to establish and have access to funding.

339. On the one hand, the Government will act to provide social security through appropriate measures to be taken to ensure that policies tie in with the determination to transform the informal economy into a formal economy. Efforts will also be made to promote collective action at the grassroots level by strengthening or facilitating the creation of sector activity associations in the informal sector. On the other hand, access to specific funding mechanisms will be facilitated as well as avenues for marketing products.

340. Generally, the Government will endeavour to have a proper knowledge of the activities carried out and where. It will ensure that they are well identified, and then facilitate their access to loans to cover the cost of rents, equipment and other needs of actors in the sector.

341. As it is the case for SMEs/SMls, the Government plans, in particular, to use community banks to promote the financing of handicraft. Specialised budget lines funded under State resources or cooperation funds may be lodged in such establishments so as to better address issues of risk and conditions for granting loans to craftsmen. 
342. Public Service: To offset the current shortage of personnel and the ageing of senior staff of the civil service and provide sound solutions to the problems of public spending and governance, the Government plans to launch a plan for strengthening and rejuvenating its staff in the areas of economic planning and project management, mastery of information and communication technology, technical supervision in some corps (public works, mining, measurement, standardization, etc...), agricultural supervision in addition to traditional sectors such as education, health and justice.

341. Specific programmes for the employment of underprivileged segments of the population: The Government will pay particular attention to the situation of specific groups of people such as youth, women, vulnerable groups and disabled persons. In this connection, some actions are today being carried out through specific programmes including: (i) the National Pact for Youth Employment (PANEJ) whose policy document is the bedrock of youth employment promotion; it aims at giving youths the opportunity to learn a trade and thus increase their chances of finding a job, while making some money; (ii) the Informal Sector Actors Support Project (PIAASI), (iii) the Rural and Urban Youth Support Programme (PAJER-U) etc. The Government plans to rationalize these different programmes, whose scopes of activity usually tend to overlap, leading to a lot of inefficiency, and making it difficult to have a clear picture of Government policy and the impact it is supposed to have on the poorest segments of the population.

\subsection{MATCHING TRAINING WITH JOB PROFILES}

344. Vocational training will be directed towards concrete results, aimed at making training more efficient and less expensive. It will include both the participatory approach and the competence-based approach. The Government will lay emphasis on matching training with jobs, through more rigorous planning of the training being offered and dependable forecasts on the resources necessary for the training selected to be actually and properly delivered. Particular emphasis will be laid on technical training which is more likely to facilitate industrial development.

345. To this end, the strategy will focus first of all on increasing and diversifying the range of training offered by: (i) improving and standardizing training terms of reference with the creation of about 30 training programmes per year, taking into account the size of enterprises and starting with promising sectors; (ii) diversifying training methods and training programmes (training in a school setting, alternating training in schools with vocational training internships), with the objective being to offer good quality training at reduced cost; (iii) reducing disparities in terms of access (geographical zones, gender, specific groups) by carrying out far-reaching reforms, rationalizing and restructuring State-owned vocational training centres; this will, in particular, help to better provide training opportunities in major cities since they have more companies and thus have a stronger need for training centres to be specialized in order to avoid having a situation where all specialities are offered in all training centres; and (iv) developing the training of trainers by creating a skill development centre.

346. The second pillar for matching training with demand will be the optimization of internal and external output of the vocational training system by:

- ensuring access to ICTs in vocational training centres;

- monitoring graduates in their professional integration;

- ensuring availability of and access to training references, high quality teaching manuals and material;

- promoting hygiene, health, and security within vocational training centres;

- validating professional achievements and certifying competencies;

- developing professional guidance by providing each division with an guidance structure.

347. In order to spur efficient cooperation with other players, incentives will be granted for: (i) effective participation of professional structures in drawing up training programmes, training and assessment of trainees by setting up collaboration frameworks and defining the sphere of competence of each actor; (ii) the promotion of a State/Private sector/local authorities partnership both at the local and at the central and international level, and (iii) the diversification of funding sources. 
348. Some of the incentives envisaged are: (i) for enterprises involved in the development of programmes, training of trainees and trainers: exclusive allocation of apprenticeship tax to vocational training, tax-free donations, etc.; (ii) for private promoters of training centres: tax exemption for imported instructional material, subsequent subventions from the State, assignment of State trainers, etc...

349. Tax and administrative incentives will also be granted to companies that accept to participate in professional integration programmes, to ease the integration of jobseekers in companies.

350. The Government equally plans to improve the management of the vocational training system by: improving the legal and institutional framework; promoting good governance; and coordinating the steering of vocational training by a structure designated for this purpose.

\subsection{IMPROVING EFFICIENCY OF THE JOB MARKET}

351. The objective here is to make the job market more transparent and achieve the professional integration of the highest number of jobseekers possible. For this, it will be necessary to: (i) increasingly get enterprises to express their human resources needs more clearly and through formal channels, in order to maximize their chances of finding the required profiles on the market; (ii) accompany jobseekers to better outline their professional plans and thus increase their chances of quickly finding a job; and (iii) carry out good communication on the trends and evolution of the job market and ensure that reliable information is given to the players.

352. The capacity of formal employment bureaux will be strengthened with the intensification of corporate prospecting drives organized by the National Employment Fund and other structures and by scrupulously monitoring the placements made. Incentives or where necessary punishment will be put in place to get companies to, as a matter of priority, make their needs in manpower known to authorized public and private organizations in charge of receiving jobseekers.

353. As for receiving and accompanying jobseekers, a first priority will be to strengthen reception and professional orientation capacity by making the National Employment Fund (NEF) work in close collaboration with other public structures, with a view to setting up employment agencies in all the divisions of the country and provide them with qualified human resources capable of giving an attentive and personal ear to jobseekers in order to draw up a good personal professional statement for a successful orientation.

354. The drawing up of personal professional statements should culminate in professional projects. These projects, designed by candidates with the support of employment coaches, describe the objectives of integrating the candidates and can lead to either the candidate going to the job market to apply for a wageearning job or the creation of a self-employment or micro-enterprise project.

355. The candidate will receive some relevant support such as techniques of looking for jobs, employment workshops, personalized support measures, etc. Some unskilled candidates, who may not receive training, will be directed towards labour intensive projects such as town hygiene and sanitation, road-repairs, building and construction.

356. Candidates with projects and having entrepreneurial skills will receive support in the following ways: design of feasibility studies; financing of projects; training in business administration; monitoring and supervision up to the maturity of the activity. This action will be backed by the various programmes of the services in charge of employment and SMEs.

357. Finally, particular attention will be paid to improving the employment and vocational training information and management system, through a systematic gathering, processing and dissemination of job market and training information. Government programmes for job creation and recruitment into the civil service will particularly be given wide publicity nationwide, through the public and private media.

358. An implementation, monitoring and evaluation mechanism of the employment strategy will be introduced at two levels, strategic and operational.

359. At the strategic level, itsestablishment will contribute to avoid conflict in the formulation, execution and 
implementation of the employment component in economic and social policies. As such, a National Employment Board (NEB) will be established and will serve as the umbrella organization for Regional Employment Boards (REBs) and Support Committees for the Development of Local Employment (CADEL).

360. At the operational level, a service platform will be set up. It will be made up of the National Employment Fund (NEF), the National Institute of Statistics (INS) and other public institutions that support employment. The service platform is a consultation and cooperation framework for national and regional political and professional stakeholders and decision-makers. Its objective will be to develop an offer of services based on professional integration and reintegration, from orientation to coaching in employment, the creation of activities through the acquisition of skills, and the drawing up of business plans. 


\section{CEAPPAPR S}

\section{GOVRRNANCR AND STRATRGIC

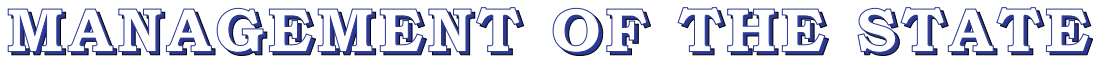

361. The promotion of governance, since it refers to the judicious and efficient use of the potential and the different resources available and contributes to projecting the image of the country at home and abroad, is one of the main challenges Cameroon must face as it seeks to realize its goal of becoming an emerging economy, a country that is democratic and united in diversity by the year 2035. In this perspective, the powers that be have identified the stringent measures and actions that are likely to bring added value to the economic and social development policy of Cameroon. Such highly cross-cutting measures and actions are aimed at:

- consolidating the function of depository of the general interest of the State by strengthening the latter in its role as facilitator and regulator of economic and social activity;

- improving the business environment, and consolidating public-private sector partnership as well as corporate governance;

- improving citizen and civil society participation of in public affairs management.

\subsection{GOVERNANCE AND THE RULE OF LAW}

362. Since 2003, the Government has been determined to improve governance through implementation of several actions. A National Governance Programme (NGP), which is the Government's structural strategy in this respect and has a priority action plan, has gone afoot and was revised recently to update its vision, objectives and conditions for their implementation.

363. Under this programme, remarkable actions have been recorded, in particular, with regard to strengthening democracy, security, reform of the judiciary, public contract awarding system, intensification of the anticorruption drive, etc. With this, Cameroon has been able to modernize its electoral system, which culminated in the setting up of ELECAM; a contracts code has been enacted and is in force; the Audit Bench is operational; the reform of the judicial system is on course; efforts to tackle corruption have been stepped up through repressive actions against unscrupulous vote holders and with "Operation Sparrow Hawk" as an illustration.

364. However, the implementation of these measures and actions has not yielded the expected results. Crime wave is still high; slowness in the decision-making process and in the implementation of measures and actions adopted strongly hampers the development of investment. Furthermore, the Investment Charter, enacted in 2001, has not yet been completely implemented, the corruption perception index is still high, the contracts awarding procedure is considered to be rather long and the business environment is still largely unattractive.

365. Under its Vision 2020 Development and Growth Strategy, the Government plans to consolidate achievements and focus on priority actions that are likely to bring added value to the economic and social development policy, notably (i) continuing the modernization of the political system, (ii) accelerating the implementation of reforms relating the improvement of the business environment, (iii) improving citizen participation in the running of public affairs.

366. Two main objectives have been set within the framework of governance and the rule of law: (i) guarantee individual rights and public liberties for all, and (ii) improve the running of public affairs. In particular, for the protection of individual rights, the government will endeavour to step up its efforts to check violence against women.

367. To attain the above-mentioned objectives, the authorities intend to hinge their actions on the following four points:

- Promoting the rule of law and ensuring the security of goods and persons; 
- Improving the business climate;

- Stepping up efforts to tackle corruption and embezzlement;

- Improving information on and popular control of the running of public affairs.

\subsubsection{Promoting the rule of law and ensuring the security of goods and persons}

368. With a view to improving the socio-political situation of Cameroon, and in order to restore confidence and serenity among citizens and investors, the authorities have opted to: (i) improve the electoral system; (ii) enhance access to and the quality of the justice system; (ii) consolidate the national human rights promotion and protection mechanism; (iv) reinforce law and order, security at the borders and civil protection.

369. At the level of the electoral system, the authorities plan to pursue the electoral modernization process to facilitate effective participation by the population in elections, through free and transparent polls. In this light, the effective establishment of ELECAM, the Constitutional Council as well as the computerization of the entire process, have been identified as priorities.

370. As regards continuation of the reform of the judiciary, in the current context where the aspirations of the population for an independent judiciary accessible to all are apparently hard to reconcile with the current administrative organization, actions and measures will mainly be aimed at giving credibility to the justice system by strengthening the independence of the judicial power and facilitating access to and improving the quality of justice. In this wise, focus will be on mechanisms likely to strengthen the independence of judicial officers, continuing with the construction of court houses, recruiting and building the capacity of personnel, computerizing procedures, equipping services and promoting ethics and the professional code of conduct.

371. Consolidating the human rights promotion mechanism, for its part, will be based on strengthening the capacity and the means available for the National Commission on Human Rights and Freedoms (NCHRF) to operate effectively, establishing an efficient network of human rights NGOs and Associations as well as a coordination platform to facilitate their interaction with public authorities and the NCHRF as well as compliance with relevant international conventions.

372. With regard to the reinforcement of law and order, security around the borders and civil protection some of the actions to be undertaken are stepping up the fight against organized crime in major towns and against highway robbers on all the roads in the country. To this end, the authorities intend to continue setting up law enforcement units, recruiting personnel, and ensuring effective security at the borders.

373. In order to effectively address the issue of high vulnerability of the population to major threats and the negative effects of natural disasters that affect both its goods and environment, the government will introduce a strategy focused on three areas: (i) promotion of prevention through information of the public, sensitization and education of the people; (ii) development and implementation of a contingency plan aimed at ensuring efficient protection against such threats; and (iv) adoption and execution of measures to rehabilitate and manage victims.

\subsubsection{Improving the business climate}

374. Government action in this respect will mainly be geared towards stepping up monitoring and dialogue with the private sector on the business environment, continuing the harmonization of the legal framework with the OHADA law and implementing the Investment Charter.

375. Stepping up monitoring and dialogue with the private sector on the business environment will be done through: (i)establishing and ensuring the effective takeoff of the Cameroon Business Forum (CBF), a new forum for dialogue between the Government and the private sector under the chairmanship of the Prime Minister, Head of Government and for which the two parties recently signed an agreement on its establishment and functioning, in partnership with the International Finance Corporation (IFC); and (ii) effectively embracing and owning the Business Climate Survey (BCS), an instrument for monitoring the business climate and identifying the reforms necessary to improve it, drawn up and under trial for the past three years by national employers in a partnership. 
376. Harmonization of the legal framework with the OHADA law is expected to facilitate the establishment of all the legal structures, procedures and instruments provided for under the community law. In particular, this will entail translating the OHADA Uniform Acts into English and continuing with the training of stakeholders in the sector.

377. The implementation of the Investment Charter should, for its part, help to kick-start the activities of the Investment Promotion Agency, the Export Promotion Agency, the Entrepreneurship Institute, the Standardization and Quality Assurance Agency and the National Regulatory and Competitiveness Council with a view to improving the business climate and streamlining formalities for establishing a business.

\subsubsection{Stepping up the anti-corruption and embezzlement drive}

378. To drastically curb corruption, the Government undertakes to step up the actions necessary to tackle the phenomenon by strengthening anti-corruption mechanisms with the effective involvement of the executive, legislative and judicial branches of power. The actions to be carried out are as follows:

- ensuring systematic accountability;

- systematically taking sanctions against unscrupulous vote holders and recovering embezzled funds;

- intensifying popular education and awareness raising campaigns on moral values, general interest and public good as well as better communication on actions already taken and sanctions effectively meted out to persons convicted as part of the anti-corruption drive;

- implementing the action plans of the National Anti-Corruption Commission (CONAC) and the National Agency for Financial Investigation (ANIF);

- strengthening the strategies and means of the Supreme State Audit.

\subsubsection{Improving the access of citizens to information necessary for controlling the running of public affairs}

379. Here, the authorities intend to base their actions mainly on (i) stepping up the participatory monitoring of the running of public affairs, (ii) systematically disseminating information on government decisions, in particular, on development projects, monitoring and evaluation and audit reports. Particular attention will be paid to the Public Investment Budget monitoring and evaluation mechanism, which in January 2009 underwent a third general reform aimed at reinforcing both parliamentary control and control by citizens in the implementation of public investment programmes and projects. Similarly, the civil society will be greatly involved, through various relevant mechanisms, in the implementation and monitoring of programmes for poverty alleviation at the base.

380. Cameroonian authorities are fully aware of the role of door-to-door communication in ensuring that citizens have information to be able to make informed decisions on how to increase their incomes, the marketing of their produce, important decisions to be taken with regard to employment, education, health, etc. In this wise, the promotion of community radio stations, which started with the First Generation PRSP, considering the positive impact observed, is expected to continue by providing support for the establishment of several hundreds of community radio stations for women, and youth, especially in rural areas.

\subsection{STATE STRATEGIC MANAGEMENT}

381. As part of the strategic management of development, the authorities set among other objectives to provide the citizens and investors with unequivocal medium-term and long-term directives for greater visibility and clarity in the environment, an uncertainty reduction factor. In this light, they intended to take measures to strengthen the capacity of the State in:

- planning and setting national development priorities;

- formulating and implementing general and sector policies;

- developing strategic initiatives in priority sectors;

- programming and monitoring infrastructure development projects, giving fresh impetus to the regional development and housing policy;

- formulating human resource development policies; 
" formulating laws on sector orientation and programming;

- strengthening the capacity of the various players of the economy;

- implementing a system of incentives;

- formulating and implementing policies on decent employment;

- building the capacity of regulatory structures;

- assessing the implementation of policies;

- pushing the public contracts system reform further.

382. The Government will endeavour to gradually implement the development vision in the long-term, in view of the numerous challenges the State has to face in a context of, inter alia; (i) the sometimes violent expression of the expectations of the population who would also like to be more involved in the running of public affairs; (ii) a probably unprecedented international financial crisis, which, before our very own eyes and in successive waves, is turning into a severe economic crisis which has already hit Cameroon; (iii) low or inadequate economic growth rate for several years compared with a sustained population growth, such that it has not been possible to reduce poverty for nearly seven years; (iv) low level of the overall productivity of the economy in virtually all the sectors and simultaneously leading to a food crisis, an energy crisis, an employment crisis and serious malfunctions of the national banking and financial system; $(v)$ the wider opening of borders as required by the WTO as part of trade with the European Union and the urgent need to further and broaden regional integration as a collective strategy for the integration of Central Africa in the global economy; (vi) rapid technological advances; and (vii) the need to reconcile the interventions of the State with Cameroon's irreversible option for a market economy.

383. The authorities are aware of the fact that, more than ever before and beyond its bounden duties in the areas of sovereignty and security, the State has to play an important role in the strategic planning of development, as well as implementation of an economic regulation policy and well targeted actions. They therefore intend to accelerate the decentralization process and pursue modernization of the public administration, in order to meet the challenges of governance.

\subsubsection{Deepening the decentralization process}

384. A remarkable change can be observed since the enactment of the three laws of 22 July 2004 on decentralization. This new statutory mechanism lays down the conditions for transferring competences and resources to decentralized local and regional authorities, the rules applicable to regions and councils, the conditions for the exercise of supervisory authority and decentralization monitoring bodies.

385. However, despite the remarkable progress made, some kind of slowness continues to hamper the implementation of decentralization and finds justification, among others, in the late operationalisation of the monitoring bodies provided for by the orientation law, notably the National Council on Decentralization and the Inter-ministerial Committee on Local Services, partial implementation of reforms relating to FEICOM and CEFAM, delay in the formulation or adoption of laws to lay down the tax regime of decentralized local and regional authorities and the local tax system, as well as implementation instruments which make concrete the transfer of powers and resources to local and regional authorities, the non completion of the studies that precede the drafting of some implementation instruments.

386. To remedy this situation, the authorities intend, in addition to effectively setting up regions, to push through, and in the shortest time possible, with the process for the transfer of powers and resources to local and regional authorities, strengthen the capacity of locally elected officials and council technicians for the advent of a truly local public service and the service in charge of decentralization, and strengthening the economic role of local and regional authorities. 
Box 9: Decentralization in Cameroon: progress and schedule

Institutional and legal framework: Following the constitutional revision of 18 January 1996, Cameroon has become a decentralized unitary state made up of regions and councils as regional and local authorities. The decentralization implementation process received a boost with the promulgation on 22 July 2004, of three laws namely: law no. 2004/017 on the orientation of decentralization, law no. 2004/018 to lay down the rules applicable to councils and law no. 2004/019 to lay down the rules applicable to regions, followed by the publication in 2005, of the 'Orientation Strategy Paper on the implementation of decentralization' prepared by the Ministry of Territorial Administration and Decentralization (MINATD). Since then, the legal framework of decentralization in Cameroon has been completed through successive amendments in the following areas:

- Mode of election of local officials: these are laws no. 2006/004, no.2006/005 and no. 2006/010 of 14 July and 29 December 2006 that respectively lay down the mode of election of regional councilors, the conditions for the election of senators and to modify the conditions for the election of municipal councilors;

- The budgetary, accounting and financial framework of local authorities: these are: (i) decree no. 2006/182 of 31 May 2006 to reorganize the Special Council Support Fund for Mutual Assistance (FEICOM); (ii) joint instruction no. 336/IC/CNIL/MINATD/MINFI of 15 February 2006 on the application of decree no. 98/266/PM of 21 August 1998 to approve the council sector plan and the adoption of the council budgetary nomenclature; (iii) decree no. 2007/1139 of 3 September 2007 to lay down the mode of issue, recovery, centralization, distribution and transfer of additional council taxes; (iv) law no. 2009/011 of 10 July 2009 on the financial regime of regional and local authorities.

- Administrative map and functioning of administrative units in Cameroon: these are decree no. 2007/155 of 23 April 2007 to create new sub-divisions; decree no. 2007/117 of 24 April 2007 to create councils; decree no. $2007 / 116$ of 23 April 2007 to lay down the number of councilors per council; decree no. 2008/015 of 17 January 2008 to create twelve city councils; decree no. 2008/0752/PM of 24 April 2008 to specify some modes of organization of the deliberating and executive organs of councils, city councils and council unions; decree no. 2008/376 of 12 November 2008 on the administrative organization of Cameroon; decree no. 2008/377 of 12 November 2008 to lay down the powers of heads of administrative units and the organization and functioning of their services; circular no. 2008/001/CAB/PM of 11 January 2007 relating to the local coordination of devolved State services;

- Management of the decentralization process: these are order no. 130/CAB/PM of 9 February 2006, on the creation, organization and functioning of a consultative committee for the implementation of decentralization; decrees no. 2008/013 and 2008/ 014 of 17 January 2008, respectively on the organization and functioning of the National Decentralization Council (NDC) and the organization and functioning of the Interministerial Committee for Local Services (ICLS).

Transfer of powers and resources: Government option is to carry out the first effective transfers of powers and resources in 2010. Circular no. 2008/013 of 17 January 2008 relating to the inclusion of decentralization in sector strategies has already called on the various central administrations to mainstream decentralization in the deployment of their services and policies on the field. Besides, the Prime Minister set the deadline of June 2009 for Ministers to forward their respective programs for the transfer of powers and resources to the ICLS. A schedule for validated transfers shall then be established. These first transfers shall exclusively be made to councils and city councils, as the regions are not yet in place.

The powers to be transferred are those which, in conformity with article 15 of the law on the orientation of decentralization, are necessary for their economic, social, health, educational, cultural and sports development. Resources to be transferred are financial, material and human resources inherent in the transfer of powers.

As concerns financial resources, the principle in on-going preparatory reflections and decisions is that every transfer of power should simultaneously and automatically be matched by the provision by the State, of financial resources amounting to at least the equivalent of State expenditure for the budgetary year preceding the date of the transfer of powers. Beyond these linked transfers, the law-maker has provided for a General Decentralization Fund (GDF) to finance the transfer of responsibilities. Finally, to strengthen the financial autonomy of RLAs, a bill on local taxation is under study.

Concerning the transfer of human resources, the principle is for the RLAs to freely recruit their personnel. State personnel could come in as support staff on secondment or transfer. A training plan for the personnel of regional authorities has been drawn up and is being implemented with the assistance of development partners, in order to make up for the shortage of council personnel in terms of quality and quantity. The adoption of the sample council organizational chart and the status of the personnel of territorial administration would enable a better definition of required personnel qualifications and needs. 
387. Concretely, the implementation of sector strategies should, particularly, be based on the decentralization process. All activities aimed at improving the living conditions of rural and urban inhabitants will see the involvement of local and regional authorities as first rate players. Local and regional authorities could enter into a formal partnership with the State to promote growth and employment, through some instruments such as plan contracts and town contracts. Local and regional authorities will thus receive funds for the implementation of programmes, both for State resources (ordinary internal and HIPC resources) and for official development assistance.

388. Planning, which is a function recognized by the law for regions and councils, will particularly be encouraged with the systematic institution of council and regional development plans, which will serve as frameworks for dialogue, harmonization and pooling of assistance received from the State intended for regional and local development. This local planning process, which has benn operational in several councils for three years now, will continue nationwide.

\subsubsection{Continuing the modernization of the public administration}

389. The authorities intend to continue modernization of the public administration and to make it an instrument at the service of development, especially by improving the institutional framework, administrative management and governance. In this light, emphasis will be laid on: (i) capacity-building in strategic planning, regulation of the economy and public finance management, (ii) human resource management, and (iii) protection of the domestic economic sphere.

390. In terms of strategic planning, the authorities will focus on defining guidelines for national economic policy and its various aspects in the budget, taxation, monetary, financial and commercial domains. Thus, this will entail pooling efforts, directing investments in a medium and long term perspective, through an integrated and coherent approach aimed at achieving the objectives of the GESP, in particular, and the long-term development Vision, in general.

391. To fully and effectively play this role, they will ensure modernization of the State's mechanisms, instruments and operational structures particularly through the systematization of sector strategies and their division into ministerial road maps, the generalization of medium term expenditure frameworks and programme budgets, substantially improving the State's financial management and applying all the other provisions of the new State financial regime. Ultimately, the entire public policy planning, programming, budgeting and monitoring process (referred to as PPBM) should come out strengthened and modernized.

392. The public finance modernisation plan (PFMP) finds its justification in the context of public policy interventions, which have undergone profound changes due to different factors (oil crises, debt crisis, democratisation, decentralization, etc.) and the need to adapt institutional and structural reforms to these changes, in order to remove subsequent malfunctions observed.

393. The PFMP is aimed at producing a comprehensive reference and monitoring framework for the continuation of ongoing reforms and implementation of additional and/or new measures. The main objectives of the PFMP are to: (i) improve public finance management to consolidate budgetary discipline, redirect public resources towards growth and poverty reduction priorities and thus enhance the efficiency of the role of the State and public services; (ii) effect a change in management approaches and behaviours of the administration in keeping with the principles set forth in the new financial regime to establish a results-based public finance management method.

394. The specific objectives and results expected from implementation of the PFMP are: (i) budgeting based on policies, sector policies and multi-year results-based programmes, (ii) Mechanisms for internal resource mobilisation by financial services, are efficient within an integrated system, (iii) external resources are mobilized and managed efficiently and included in the State's budget and used following national procedures, (iv) a new accounting system is established to enhance accuracy, exhaustiveness and regularity in the preparation of accounting and financial statements, $(v)$ a more judicious management of funds and debt which allows for better control of domestic outstanding debts, (vi) a rational, coherent and efficient control chain, (vii) sound human resource and wage bill management to improve the efficiency of the administration, (viii) strengthening the institutional capacity of the Minister of Finance and financial management to adapt to the new principles 
of the reform and bring about change.

395. The PFMP is broken down into 9 components, the most important of which are: implementation of the financial regime, institutional reform of MINFI, strengthening the programming cycle, sound budget execution, Funds/Debt/Accounting management, revenue and taxation, the computer and information system, mastery of the wage bill.

Box 10: Some innovations introduced by Law No. 2007/6 of 6 December 2007 relating to the State's financial regime

The new financial regime, as contained in Law No. 2007/6 of 26 December 2007, which has been applicable since the 2008 financial year, makes some corrections to the shortcomings noticed in the 7 February 1962 Ordinance to lay down the State's financial regime. It provides inter alia in its Section 9 that "appropriations shall henceforth be presented by sections, programmes, actions, articles and paragraph". Section 15 of the same law further states that appropriations opened under the finance law shall be made up of commitment authorizations and payment credits, thus making it possible to proceed by multi-year and better circumscribed management of the State budget than in the past.

Efficiency and performance concerns are further justified by the clarification of the role of each player in the chain of execution of the State budget and the revision of the State accounting framework which henceforth requires the keeping of budgetary accounting, analytical accounting and general accounting records.

Finally, one of the biggest innovations introduced by the new financial regime has to do with increasing the powers of the parliament at all the stages of the management of the State budget, be it at the time of preparing, administering or controlling the execution of the budget passed and enacted into law. This strengthening of the role of the people's elected representatives aims to guarantee that the real and priority aspirations and needs of the population are taken into account in the State budget.

396. With regard to the New Financial regime, one of the main difficulties encountered in honouring commitments made by the Government under the PRSP adopted in 2003 was the inadequate provision for these commitments in the State budget. The 7 February 1962 Ordinance, which guided the preparation of the State budget until 2007, made public officials to be more interested in the compliance and regularity of budgetary operations than in considerations of performance and efficiency in the delivery of the public services to be financed.

397. The new budgetary framework is expected to guarantee the more efficient materialization of State commitments and better monitoring and evaluation of the measures and objectives outlined in the growth and employment promotion strategies.

398. The authorities are aware that the reform of the public investment budget (PIB) requires first determining the level of public investment in relation to the development objective set in the strategy, in particular, the rate of overall investment in relation to GDP, the rate of annual public investment in relation to the State budget, the rate of the Public Investment Budget (PIB) in relation to the general State budget, aggregating the different variations of these rates in time leads to lasting growth and sends a strong signal to the private sector. In this light, they will endeavour to draw up a cooperation strategy which will help to determine the level of foreign debt that is sustainable and however compatible with the exigencies of GESP priorities. They will further ensure that the design and implementation of projects stem from rational budgetary choices, the quality of projects, the preparation, implementation, and monitoring of major projects.

399. At the level of the economic regulation policy, this entails, among others, designing and establishing the institutions responsible for ensuring compliance by all stakeholders with the applicable rules on competition; standards, in particular, environmental standards; organisation of work; as well as mechanisms governing external trade. Economic regulation should notably facilitate transparency in the markets, guarantee free competition and avoid harmful monopolies, as well as promote implementation of best practices which help to preserve the solvency and credibility of the financial system as a whole. A general review of already existing regulatory boards will be conducted during the GESP implementation period with a view to improving their future performance. 
400. As far as support to the development of the private sector is concerned, the authorities will also promote, through the negotiation and implementation of development plans by production sectors and business upgrading programmes, the development of the local private sector within the framework of a partnership based on the development of value chains and the competitiveness of Cameroonian companies. In this light, they will take steps to provide (i) direct and indirect financial support to partners, (ii) supervision and technical assistance to businesses, (iii) support for the promotion of products "made in Cameroon", notably by organizing trade fairs to promote and disseminate economic and social information, (iv) support and encouragement necessary for the professional organization of sectors and trades, the development of a sub-contracting stock market and the widest application of the national preference clause provided for in the Contracts Code.

401. In order to further attract foreign direct investors, the authorities also intend to be directly involved in production, notably in partnership with the private sector, in accordance with the provisions of Law No. 2006/12 of 29 December 2006 to lay down the general partnership contracts regime. For the major structural projects referred to, in particular, by this law, the Government will ensure, through consultation and dialogue with private partners, the promotion of local enterprises, notably SMEs/SMls, by demanding, as it is already the case with some projects, that about one third of the planned investment in each project should be reserved for local SMEs and SMls and that the strategic partner should invest in the preparation and implementation of a specific programme for upgrading the local companies chosen, so that they are able to supply the goods and services without negatively affecting the quality and overall cost of the project.

402. Implementation of these guidelines is expected to lead to remarkable improvement in the design, implementation, monitoring and evaluation of the public investment budget, the mounting of investment projects maturation mechanisms, defining clear, rational and shared criteria for project selection, development of efficient participatory and computerized mechanisms for the gathering and dissemination in real time of dependable information accessible to all on the physical and financial implementation of projects.

\subsubsection{Management of the State's Human Resources}

403. Having an exact idea of the staff strength and the wage bill of the civil service, to reduce costs and improve its performance, is still a goal to be achieved going by the actions which still have to be taken in this domain. Among these actions are the complete de-freezing of recruitment, deploying SIGIPES in the rest of the ministries, finalizing the map of duty posts, finalizing preliminary studies to the formulation of performance standards, finalizing the national plan for the training of State employees, establishment of organization charts in all the administrations and following them for appointments, etc.

404. On these issues like on many others, the authorities therefore intend to continue with ongoing or planned actions aimed at modernizing and enhancing Public Service efficiency by improving the institutional framework, reviewing administrative management procedures and promoting good governance.

\subsubsection{Protection of the national economic sphere}

405. The deregulation of economic activities pursued over the past years and trade liberalization have been coupled with the development of new forms of illegal trade, which can constitute threats to the national economic sphere. Smuggling and counterfeiting of goods, as well as various forms of trade fraud, have developed considerably, reaching proportions that constitute a real threat to the survival of several national industrial sectors such as the textile and clothing industries, toy industries, pharmaceutical industries or motor car spare parts manufacturing industries, cosmetic, tobacco and sugar industries, which have been hardest hit.

406. Illegal trade, which is the handiwork of an increasingly sophisticated underground economy, has jeopardized the achievement of some State economic objectives, led to job cuts in the formal sector as well as loss of tax revenue, and become a threat to the health of the population considering the potentially dangerous substances contained in counterfeit products.

407. In response to these phenomena which hamper the development of the national production capacity, the authorities thus intend, under this strategy, to strengthen mechanisms for checking fraud, smuggling and major international trafficking in a triple objective of facilitation, security and control of quality standards. They will 
take measures to (i) ensure compliance with the rules laid down by the World Trade Organization under trade protection agreements and national requirements relating to standardization, quality and safety of imported products, (ii) introduce procedures which are streamlined, foreseeable and profitable in terms of the facilitation expectations expressed by companies, (iii) establish the external trade statistics that public authorities and businesses need, (iv) secure trade at the borders by combating counterfeiting and the adverse effects of the underground economy, ( v) formulate a national regulation on safeguards and establish a national antidumping administration necessary to back efforts geared towards protecting the national economic sphere. 


\section{CEAPPAPR 6}

\section{IVACROICONOMVIC AND BUDGISARY ARAIVIDORES}

408. This chapter analyzes the quantitative implications of guidelines of growth and employment strategy on:

- the aggregate growth profile as well as sector contributions, investment levels and the financing of the entire economy (macroeconomic framework);

- the public expenditure profile ensuing from the allocation of budgetary resources to various sectors to finance identified priority programmes (budgetary framework);

- prospects for job creation and poverty reduction, in particular the number of jobs created each year, trends in income poverty and other MDG indicators (education, health, access to drinking water, etc.) resulting from the growth and public expenditure profile.

409. This analysis comprises three stages: (i) simulation of terms of reference; (ii) simulation of a "bolder" option based on a vision to make Cameroon an emerging country by 2035; and (iii) risk analysis.

410. Simulation of terms of reference. The aim is to establsih a macroeconomic and budgetary framework that can be financed and is feasible on the basis of policy simulations and programmes, including (i) a non oil GDP growth rate and sector contributions by production sectors; (ii) a profile of budgetary resource allocation to sectors/ministries in line with government priorities; and (iii) induced progressions of the number of employment opprotunities created, the impact of poverty and other development indicators.

411. In other words, this reference scenario bridges the gap between government priorities (stability of the macroeconomic framework, growth and employment) and the needs of sector ministries with financing capacity (internal and external resources) as well as that of the absorption of budgets and physical execution of programmes and projects in the various sectors targeted.

412. Simulation of a bold option based on the vision. The aim is to obtain a 7 per cent average annual growth rate over the period 2010-2020. This option of the terms of reference seeks to quantify additional financing needs to achieve the vision's goals.

413. Risk analysis. The Government takes into account the many risks to which the reference scenario is exposed. Indeed, this scenario hinges on improvement of the international economic environment and effective implementation of economic and social policies.

414. Accordingly, risk analysis consists in modifying some of the key assumptions of this scenario to measure its impact on the macroeconomic and budgetary framework, employment and poverty. Ultimately, any interference with the assumptions of the reference scenario will often lead to deviations from the macroeconomic and budgetary framework, as well as prospects for employment creation and poverty reduction.

\subsection{REFERENCE SCENARIO}

\subsubsection{Methodology}

415. The objective of the reference scenario is to bridge the gap in the medium term between: (i) the need to maintain a stable macroeconomic framework by pursuing its economic and social programme; (ii) the achievement of sustained growth through implementation of major investment projects and revival of production in sectors that can boost growth; and (iii) the need to reduce a social deficit through the creation of decent employment and improvement of access to basic social services by the population. 
416. The participatory approach which is central to the preparation of the Growth and Employment Strategy Paper guided the technical work relating to the formulation of the terms of reference. This process comprised three stages.

417. Analysis of priority action plans. Technical meetings were held with sector ministries to identify priority actions and make sector growth estimates. The estimation of the cost of implementing these priority actions and implications of their programming on the budget were then analyzed.

418. Macroeconomic framework. The medium-term aggregate growth profile was obtained using a macroeconomic model by combining previous estimates with the statistical analysis of sector performance of recent years.

419. This oerall growth profile combined with mobilization of non oil revenue as well as assumptions on the growth of oil GDP helped make a projection of public revenue as well as budget balances on the basis of the progression of public expenditure (operation and investment). Information on the available external funding then helped reduce funding needs by maintaining it at levels likely to be curbed in the medium term.

420. Budgetary framework. On the basis of projections of budgetary resources stemming from the macroeconomic framework and progression of expenditure, additional simulations were made using the budgetary framework instrument to determine the principles of allocation of resources and the profile of budget allocations by sector. Thus the budget appropriations by sector were projected over the period 2010-2020.

421. A second series of discussions was then held with sector ministries to make the central budgetary framework consistent with the main sector programmes over the period 2010-2020 with a view to sector budget appropriations projected in the budgetary framework instrument. Several iterations were necessary to obtain an overall convergence. In other words, it was necessary to consolidate various actions to have a coherent, sound and sustainable expenditure framework in the medium term.

\subsubsection{Main assumptions on growth levers}

\subsubsection{Agriculture}

422. The Government strategy seeks to modernize production facilities, improve food security, fight against the high cost of living and reinforce the growth of the sector in the long term. The objective is to increase output and surface areas under cultivation, develop profitable sectors with high productivity and competitive potentials, strengthen agricultural extension and counselling, develop the supply of inputs (fertilizers, seeds, etc.).

423 Subsistence farming. The global food crisis characterized at the local level by an increase in the prices of foodstuffs, including those of agricultural produce, showed the poor performance of agricultural systems and methods of production. It was caused not only by an increased deficit in supply with respect to national, sub-regional and global demand but also increased dependence on the outside world.

424. In view of the threat of this situation to the food security of the population and social peace as was the case during the riots of February 2008, the Government decided to ensure a significant and rapid increase in the supply of agricultural produce. Thus, it seeks to revive the production of rice in large plantations (Yagoua, Maga, Santchou, Ndop), develop the production of corn and cassava in order to support the development of animal husbandry and poultry farming. In 2009, the Government signed a financial agreement covering 20 years with India to finance the cultivation of over 5000 hectares of rice and 5000 ha of corn. Lastly, emphasis is laid on the development of the productive sectors like banana, plantain, sorghum and palm oil. Accordingly, the production of the sector is projected at an annual average of 5.3 per cent over the period 2010-2020

425. Industrial and export agriculture. The aim of the government strategy is to revive the production of major cash products. With regard to cocoa, SODECAO launched a vast programme for the production and distribution of cocoa seedlings since 2006. The objective of this action is to distribute about six million seedlings every year, corresponding to the establishment of 5000 hectares of new modern cocoa farms each year 
426. The impact of this action on production should be observable as from the 2010 harvest. Surplus production from these new plantations is projected at 50000 tons by 2020. Furthermore, other actions are being implemented to boost production, in particular the continuation of close supervision of operators.

427. Concerning palm oil, the gradual start-up of the production of new agri-business and small-holder plantations and the improvement of production facilities will help revive production. This trend is expected to be sustained, in particular, through the recapitalization of SOCAPALM.

428. In view of the signing of the provisional partnership agreement with the European Union, the production of banana for export is expected to increase through a steady increase in the surface area under cultivation. With regard to rubber, the surface areas under cultivation by the CDC and HEVECAM will begin to be tapped in 2010.

\subsubsection{Animal husbandry}

429. The sector benefited from an emergency programme within the context of the fight against the high cost of living and the Government's determination to increase the consumption of animal protein which currently stands at $11 \mathrm{Kg} / \mathrm{INH} / \mathrm{yr}$ so as to meet FAO standards of $42 \mathrm{Kg} / \mathrm{INH} / \mathrm{yr}$. This sector strategy during the first years is focussed on development of the breeding of short cycle species (non-conventional breeding, small ruminants, pigs, poultry, aquiculture and fisheries).

430. The quality of cattle will be improved in the medium and long term in order to increase the yield per capita. In the domain of poultry, the population of layers/producers will be increased so as to limit the import of hatches eggs. This is expected to increase by 5 per cent the average annual production of this sector during the period 2010-2020.

\subsubsection{Silviculture and logging}

431. Production in this sector is expected to plummet in 2009 due to the current global crisis in the housing sector. Demand in the wood sector is expected to increase in view of the revival of the global economy. Notwithstanding the fact that almost all FMU have already been allocated, the construction of dams and establishment of factories (exploitation of cobalt and nickel) will lead to recovery of volumes of wood. In addition, the strategy in this sector seeks to increase the value of forestry and wildlife resources, promote new species, gradually exploite council forests and start exploitation of community forests. The sector should experience an average growth of 2.5 per cent between 2010 and 2020 .

\subsubsection{Extractive industry}

432. According to projections by the National Hydrocarbons Corporation (SNH), oil production will drop by 10.4 per cent in 2010 as a result of the decline in the production of some deposits. Between 2011 and 2014 , this production could increase with the going on stream of new wells. The activity of this sector shows a downward trend during the rest of the period although production is expected to rise by 30 per cent in 2016 as a result of the start of production of the Elombo well. The effects of this decline will be somewhat mitigated by the start of exploitation of cobalt, nickel and flared gas on Cameroonian platforms.

\subsubsection{Energy}

433. The significant developments programmed in this sector help anticipate a major improvement in the production capacity of electricity in the next few years. It includes the commissioning at the end of 2009 of the Yassa thermal power plant (86 MW), the Kribi gas-fired thermal power plant $(216 \mathrm{MW}$ ) in 2013, the Lom Pangar dam (120 MW) in 2014, the Nachtigal dam (330 MW) in 2014, and the Memve'ele hydro-electric power station $(201 \mathrm{MW})$ in 2016 . These developments will help boost annual energy production by 2.9 per cent and 13 per cent respectively over the periods 2009-2011 and 201 2-2020. 


\subsubsection{Building construction and public works}

434. The building construction and public works sector distinguishes itself as one of the main levers of the growth and employment strategy. The option of the Government is sufficiently to direct investments to this sector to finance structural projects in order to make the economy more competitive.

435. In view of the programming of a certain number of transport infrastructure construction projects, the period 2009-2015 will experience an annual growth rate of about 8 per cent. This concerns, in particular continuation of the tarring of major roads such as completion of the construction of the Ayos-Bonis road to open up the East Region, the tarring of the North-South corridor (Garoua Boulaye-Ngaoundere), the trans-African (Bamenda-Mamfe-Ekok-Nigeria Border) highway, the rehabilitation of the Yaounde and Douala urban road systems and continuation of tarring of the Yaounde-Kribi road, Sangmelima-Ouesso, Bamenda-Enugu (Nigeria) and CEMAC (Kribi-Congo Border) road network. The start-off of construction works on the Kribi Deep Sea port and the Lom Pangar Dam, as well as the Nachtigal, Song Mbengue and Song Dong dams.

436. Furthermore, between 2016 and 2020, the highway programme will be implemented, particularly on the Yaounde-Douala-Bafoussam-Yaounde stretch, the Yaounde-Nsimalen and Douala-Limbe sections. Such projects will bring the annual average growth rate of this subsector to 8.8 per cent over this period.

437. Concerning building construction, after the scarcity of cement in 2008 which led to a 6 per cent decline in activities, activity has resumed with the increase in the cement production capacity.

\subsubsection{Telecommunications}

438. The telecommunications development strategy hinges on continuation of investments for the modernization of infrastructure, extension of geographic coverage, gradual installation of the optical fibre, the extension of the mobile and landline telephone networks and the upgrading of the quality of services and provision of new attractive products.

439. This strategy aims, inter alia, to extend the national network by 90 per cent in 2020 as compared to 26 per cent in 2008 and to upgrade the rate of flow of data from $200 \mathrm{Mb} / \mathrm{s}$ in 2008 to $3800 \mathrm{Mb} / \mathrm{s}$ in 2020. On the strength of these assumptions, the sector is expected to experience a 7 per cent growth rate by 2020.

\subsubsection{Manufacturing industries}

440. The programme aimed to upgrade enterprises within the framework of the Economic Partnership Agreement signed with the European Union, government plans to enhance the processing of raw materials (wood, produce from subsistence and cash crop farming, etc.) through various incentives and competitiveness gains resulting in the drop in production costs owing to improvement in transport infrastructure, energy and telecommunications, augur well for an increase in investments in manufacturing industries. This is translated by the ALUCAM extension project, full operation of the CIMENCAM new grinder, and the introduction of a new processing line at SIC-CACAO. Accordingly, the sector is expected to record an average growth rate of about 5 per cent during the period 2010-2020 as compared to 2 per cent over the last ten years.

\subsubsection{Transport}

441. Transport services are related to primary and secondary sector activities. The performance of the latter should have an impact on development of the sector.

442. The upward trend in the production of major export products supported by adjustment in the timber and cotton sectors envisaged at the end of 2010 and the revitalization of the other export crops (cocoa, banana, etc.) should intensify land transport activities, in particular cargo traffic. Another growth lever in this sector would come from the exploitation of cobalt, iron ore, nickel, gas and bauxite programmed for the period 2010-2020. The sector is therefore expected to record a 7 per cent average annual growth rate between 2010 and 2020. 
443. Rail transport depends largely on performance of the timber and cotton sectors. Thus, after the collapse of world demand for these products due to the global financial crisis, this sector experienced a 5.2 per cent decline in 2008. However, the execution of major gas and mining projects is expected to boost the growth of this sector. Projections show a 0.3 per cent decline in 2009-2011 and a 3 per cent increase between 2012 and 2020.

444. Regarding air transport, the global financial crisis that began in 2008 would affect the activities of this sector, particularly through a drop in the volume of traffic. The sector is expected to experience growth as from 2011 with the envisaged end of the crisis in developed countries and the takeoff of Camair-Co. Furthermore, the execution of major projects that have been earmarked as from 2014 (Kribi Deep Seaport, exploitation of bauxite and iron ore, etc.) should help intensify the traffic of air transport. Consequently, average annual growth in the sector is expected to be in the region of 1 per cent between 2009 and 2011 and 6 per cent between 2012 and 2020.

445. The execution of major projects programmed in the mining sector as well as those related to the building construction and public works sector will lead to an increase in marine traffic in view of the increased import of equipment. Sector growth is projected at 3 per cent per annum over the period 2009-2011. The start of the Kribi Deep Seaport earmarked for 2014 should boost this sector. On this basis, framework projects an average growth rate of 5 per cent per year over the period 2012-2020.

\subsubsection{Trade}

446. The strategy lays emphasis on concerted supervision (Ministry of Trade, businesses) of largely consumed products. In order to increase the contribution of this subsector to growth, the government plans to invest, in the upcoming years, in the control of standards and quality, improvement of consumer protection, prevention of quality products fraud and reduction of smuggling.

\subsubsection{Tourism}

447. The development of the tourist industry would experience significant progress in 2009-2020. The objective is to receive 3500000 tourists per year by 2025. To this effect, specific products will be developed per region, sites will be constructed and improved, accommodation facilities will be increased notably through the increase of the number of hotels.

\subsubsection{Non-market services}

448. The public service foresees a 2.5 per cent increase in manpower per year. The number of active wage earners on the payroll will move from 179033 in December 2008 to 194083 in December 2009 and will stand at 260364 in 2019.

449. The Government intends to maintain a sustained pace of public expenditure, in particular, with regard to infrastructure. Public expenditure recorded a significant increase in 2008 as a result of the increase in manpower and revision of the salary sclae. In view of retirement and recruitment, a 4.8 per cent annual growth rate is expected between 2010 and 2020. .

\subsubsection{Business climate}

450. Surveys on the investment climate showed that tax pressure, lack of financing, poor governance and corruption are the constraints that hinder investment. The flow of foreign investments dropped by 7.7 per cent in 2007 whereas they recorded significant growth in sub-Saharan Africa.

451. In general, the rate of investment which stands around 17 per cent is considered inadequate with respect to the level of 25 per cent necessary for obtaining continuous and sustainable growth. In that respect, government action will focus particularly on harmonization of the legal framework and implementation of the investment charter, continuation of the activities of the Cameroon Business Forum and the establishment of a business 
development one-stop shop and streamlining of formalities for declaration of payment of taxes. In addition, the Government plans to take advantage of the institutional framework of partnership contracts to mobilize direct foreign investments.

\subsubsection{Budgetary planning}

452. An analysis of the macroeconomic performance recorded by Cameroon shows a timid revival of economic activities due to inadequate production infrastructure (energy, roads, ports, telecommunications, etc.). In order to reduce this deficit, the competent authorities hope to increase the share of capital expenditure in the State budget to 20 to 30 per cent by 2020, despite the risky nature of oil revenues. The share of capital expenditure on real resources will increase at an average of 0.4 point of the GDP per year. In addition, implementation and sustained monitoring of major infrastructure projects will be translated by an improvement of private investments which will increase at an average of 0.8 point of the GDP per year.

453. The Government is committed to improving the efficiency and quality of its investment plan through an enhanced public investment execution programming and monitoring mechanism based particularly on the new financial regime and participatory framework introduced.

\subsubsection{Human capital}

454. The Government is keen on carrying on the execution of investments in the health, education and vocational training domains. In the health domain, the objective is to reduce morbidity by a third among the poor and most vulnerable segments of the population; mortality among children aged below five years by two thirds and maternal mortality by three quarters, HIV/AIDS prevalence by 50 per cent and to reduce the rate of malaria-related deaths to less than 10 per cent by 2020.

455. With regard to education, the objective of actions is to improve the internal and external efficiency of the different levels of primary, secondary and higher education. The Government plans to improve access to education and vocational training.

\subsubsection{Prices}

456. The hypotheses retained here are those of the World Economic Outlook (WEO) for the prices of raw materials. The framework governing the monetary and foreign policies of the CEMAC zone and the actions initiated by the Government for the supply of essential goods and building materials are expected to help check the level of inflation. Furthermore, reinforcement of local production through various initiatives aimed at promoting sectors that enhance growth, and substituting imports will help limit the impact of imported inflation.

\subsubsection{Consequences on the macroeconomic and budgetary framework}

\subsubsection{GDP growth profile}

457. The planning resulting from this reference scenario shows the intention of the Government to promote diversification of its economy so as to reduce dependence on oil exports. It takes into account the contraction of demand and the fall in the prices of export raw materials owing mainly to the induced effects of the international financial and economic crisis. 
Graph 3: $\quad$ Trends in oil and non oil GDP

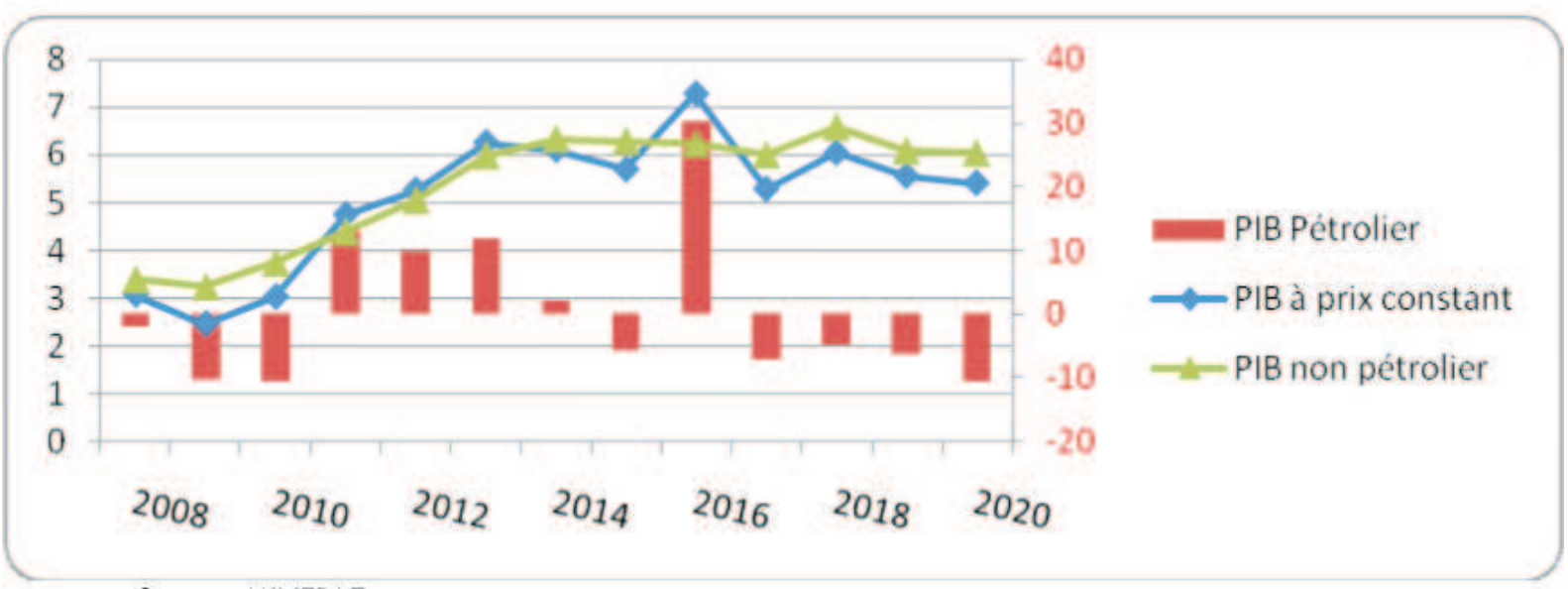

Source: MINEPAT

458. The annual growth rate of non oil GDP is expected to attain an annual average of 5.7 per cent between 2010 and 2020 as compared to 4 per cent during the last ten years, representing an increase of 1.7 point of growth. The ratio of non oil revenue to the GDP is anticipated at 13.1 per cent in 2020 compared to 12.3 per cent in 2009, representing an increase of about one percentage point, which is a result of enhanced efforts to mobilize revenue collection by taxation authorities. Thus, the non oil primary balance is expected to improve by 2.1 points from -5.7 per cent in 2008 to -3.9 per cent of GDP in 2020.

Table 14: Some key indicators

\begin{tabular}{|c|c|c|c|c|c|c|c|}
\hline Years: & 2008 & 2009 & 2010 & 2011 & 2012 & $2013-2015$ & $2016-2020$ \\
\hline Real GDP grawth & 3.1 & 2.5 & 3.0 & 4.8 & 5.3 & 6.0 & 5.9 \\
\hline CIODP & -1.8 & -10.2 & $-10,4$ & 130 & 9.8 & 2.8 & 0.3 \\
\hline Non of che & 3.4 & 3.2 & 3.7 & 4.4 & 5.1 & 8.2 & 6.2 \\
\hline Real GDP growth per espits & 0.2 & -0.4 & 0.1 & 1.8 & 2.3 & 3.0 & 2.8 \\
\hline Roal GDP' growth excl. sil per capita & 0.5 & 0.3 & 0.8 & 1.4 & 2.1 & 3.2 & 3.2 \\
\hline Rutio of non oil nevenas on GDP & 12.0 & 12.4 & 12.4 & 123 & 123 & 12.3 & 12.6 \\
\hline Rute of priblis investment ( $\%$ of GiDP) & 2.9 & 2.9 & 3.0 & 29 & 29 & 2.9 & 2.7 \\
\hline Bolmes primary exel wil $(\%$ of GDP) & -5.7 & $-4,9$ & -5.2 & -4.8 & .4 & -4.3 & -3.3 \\
\hline
\end{tabular}

5owrE MINEPAT

\subsubsection{Analysis of sector trends}

459. The analysis of sector contributions of GDP highlights possible gains related to diversification of the economy with emphasis on the revival of agriculture, processing of raw materials and initiation of major infrastructure projects.

460. The primary sector, which is considered a priority, would experience a 5 per cent average annual growth over the period 2010-2020 and peak at 5.5 per cent in 2015 . Subsistence agriculture is the mainstay of this growth and accounts for 70 per cent of the sector's GDP. On the whole, food production would experience an average 5.3 per cent increase over the period 2010-2020 as compared to an average of 4.1 per cent over the last ten years, representing an annual progress of one growth point. 
461. Growth in the export agriculture sub-sector is expected to improve from 2.6 per cent in 2009 to an average of approximately 4.5 per cent between 2010 and 2020. The growth rate of the livestock subsector will also increase from 2.7 per cent in 2008 to 3.8 per cent in 2009 , then to an average of 4.9 per cent over the period 2010-2020. During this period, the contribution of sylviculture will be timid due to the progressive decline in the forest potential. An average 2.5 per cent growth rate is anticipated between 2010 and 2020 as compared to 4 per cent during the last ten years.

462. Contribution of the secondary sector would be constant over the period 2010-2020 with a 5.1 per cent average annual growth rate. This performance is due mainly to implementation of major energy projects as well as renewed activity in the building construction and public works sector whose average annual growth rate is 7.7 per cent. An additional supply of energy will help boost the activities of manufacturing industries whose average annual growth rate is expected to stand at 6 per cent over the period 2016-2020.

463. The tertiary sector is strongly correlated with activities of the other sectors. Thus, it will be revitalized due to renewed activities in building construction and public works as well as the primary sector. These renewed activities would stimulate trade, catering and hotel activities. Improvement of road and port infrastructure would boost activities in the transport sector. This would be the same for the start of the optical fibre in the telecommunications sector. Thus, this would lead to an average annual growth rate of 6 per cent between 2010 and 2020 compared with 5.5 per cent during the last ten years.

Table 15: Sector growth trends

\begin{tabular}{|c|c|c|c|c|c|c|c|}
\hline & 2008 & 2009 & 2010 & 2011 & 2012 & 2013-2015 & 2016-2020 \\
\hline Primary sector & 3.4 & 3.1 & 4.2 & 4.8 & 5.1 & 5.2 & 4.9 \\
\hline Subsistence agriculture & 5.3 & 4.7 & 4.8 & 5.1 & 5.4 & 5.8 & 5.2 \\
\hline Industrial and export agriculture & -1.9 & 2.6 & 3.6 & 4.5 & 4.6 & 4.6 & 4.6 \\
\hline Animal husbandry, hunting & 3.0 & 3.8 & 4.1 & 4.1 & 4.4 & 4.5 & 5.4 \\
\hline Fisheries & 2.5 & 2.5 & 2.5 & 2.5 & 3.0 & 3.0 & 3.0 \\
\hline Silviculture and logging & -5.5 & -10.0 & 0.0 & 5.0 & 4.5 & 2.8 & 2.0 \\
\hline Secondary sector & -0.5 & -0.1 & 0.6 & 5.6 & 5.5 & 5.3 & 5.8 \\
\hline Extractive industries & -1.8 & -9.8 & -10.0 & 12.5 & 9.4 & 3.3 & 1.0 \\
\hline Including hydrocarbons & -1.8 & -10.2 & -10.4 & 13.0 & 9.8 & 2.8 & 0.3 \\
\hline Other manufacturing industries & 1.9 & 3.0 & 2.3 & 2.8 & 3.2 & 4.0 & 5.0 \\
\hline Agribusiness & -0.1 & 0.8 & 3.2 & 3.9 & 4.6 & 5.8 & 6.8 \\
\hline Electricity. gas and water & 4.3 & 2.0 & 3.0 & 3.5 & 4.0 & 14.5 & 16.7 \\
\hline Building construction and public works & -6.2 & 11.3 & 6.5 & 7.5 & 7.6 & 7.8 & 8.0 \\
\hline Tertiary sector & 5.0 & 3.6 & 3.8 & 4.3 & 5.2 & 6.8 & 6.5 \\
\hline Trade, restaurants and hotels & 4.1 & 3.2 & 3.6 & 3.6 & 5.0 & 7.1 & 7.3 \\
\hline Transport, warehouses, communications & 4.5 & 3.3 & 4.9 & 5.7 & 6.4 & 6.5 & 6.4 \\
\hline Banks and financial institutions & 7.6 & 5.3 & 4.2 & 3.8 & 5.0 & 7.5 & 6.7 \\
\hline Other commercial services & 7.3 & 5.2 & 4.2 & 5.8 & 6.7 & 8.2 & 6.8 \\
\hline Intermediate, indirect, measured services (SIFIM) & 3.1 & 3.9 & 3.8 & 5.7 & 6.6 & 8.2 & 6.8 \\
\hline Non commercial services of APU & 5.2 & 3.1 & 2.7 & 3.0 & 3.3 & 5.0 & 4.0 \\
\hline Other non commercial services & 3.9 & 4.1 & 4.6 & 5.1 & 4.4 & 4.6 & 4.6 \\
\hline GDP at factor costs & 3.1 & 2.5 & 3.0 & 4.8 & 5.3 & 6.0 & 5.9 \\
\hline GDP & 3.1 & 2.5 & 3.0 & 4.8 & 5.3 & 6.0 & 5.9 \\
\hline
\end{tabular}

Source: MINEPAT

\subsubsection{Analysis of uses of GDP}

464. Economic growth remains sustained due to local demand whose contribution to GDP growth was 1.8 per cent in 2008. Execution of major infrastructure projects would lead to a steady increase in public and private investments over the period 2010-2020. The volume of investments will increase at an annual rate of 9.1 per cent during this period. 
465. At the same time, public and private consumption during the period would remain constant, driven respectively by new recruitments into the public service and the resulting inclusion on the payroll, payment of the national debt and recruitments in major construction sites. Thus, the share of consumption in GDP would remain stable. It would be 70.1 per cent in 2020 and experience an upward trend during the period, and driven primarily by private consumption (an average growth rate of 5.4 per cent over the period 2010-2020).

466. With regard to foreign trade, the decline in oil production would lead to a reduction in exports until 2010. As from 2011, this trend would be mitigated by the prospects of production of new oil fields as well as increase in the production of main export crops due to the good performance envisaged in industry and the export of agricultural produce.

Graph 4: Contributions of employment to growth

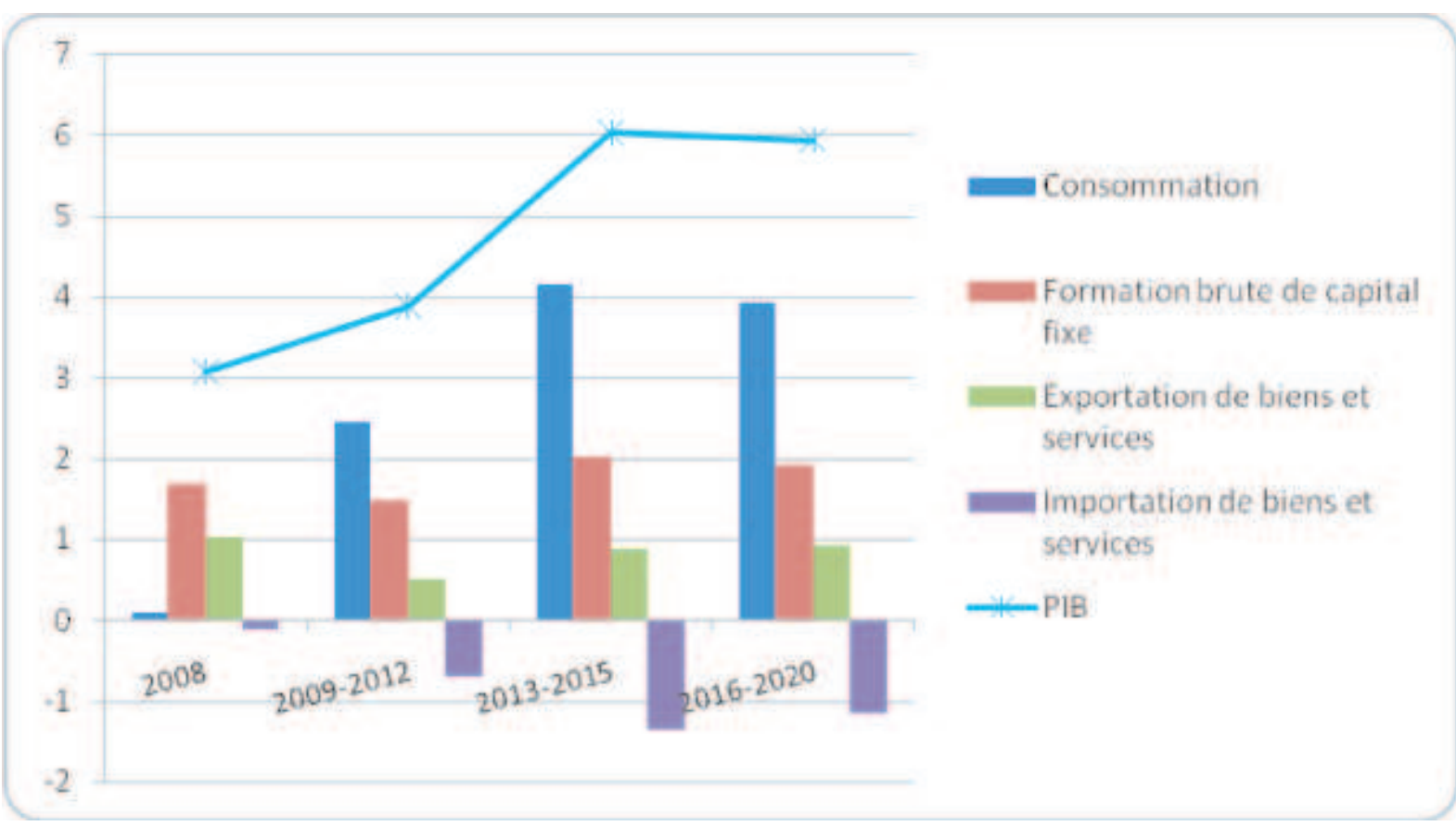

Source: MINEPAT

467. The volume of imports will increase by 6.2 per cent over the period 2010-2020 as a result of execution of major infrastructure projects. The strategy gives more importance to investment. This would lead to a degradation of the trade balance during the period owing to the importation of capital goods.

Table 16: Employment trends

\begin{tabular}{|c|c|c|c|c|c|c|c|c|}
\hline & \multicolumn{4}{|c|}{ In $\%$ of GDP (at current prices) } & \multicolumn{4}{|c|}{ Percentage of variation, in volume } \\
\hline Years & 2009 & 2012 & 2015 & 2020 & 2008 & 2009-2012 & 2013-2015 & $2016-2021$ \\
\hline Gross fixed capital formation & 18.7 & 20.5 & 22.0 & 24.5 & 9.7 & 7.6 & 9.4 & 8. \\
\hline Private sector & 15.8 & 17.6 & 19.0 & 21.8 & 6.5 & 8.3 & 9.7 & $\overline{8:}$ \\
\hline Public administration & 2.9 & 2.9 & 2.9 & 2.6 & 29.4 & 3.8 & 7.7 & $\overline{3.1}$ \\
\hline Consumption & 82.4 & 77.9 & 76.3 & 75.6 & 0.1 & 3.3 & 5.7 & 5 . \\
\hline Private sector & 71.5 & 68.4 & 67.7 & 68.1 & -1.1 & 3.6 & 6.1 & $\overline{5 .}$ \\
\hline Public administration & 10.9 & 9.5 & 8.6 & 7.5 & 9.1 & 0.8 & 2.9 & 2. \\
\hline Net external demand & -1.1 & 1.6 & -11.1 & 0.0 & & & & \\
\hline Exports & 18.6 & 19.5 & 4.28 & 12.7 & 4.9 & 2.5 & 4.6 & 5.1 \\
\hline Gross oil exports & 6.6 & 8.3 & -5.55 & 4.3 & -1.8 & 0.6 & 2.8 & $\overline{0 .}$ \\
\hline Gross exports of goods excluding oil & 7.8 & 8.0 & 5.29 & 6.5 & -0.1 & 3.3 & 5.1 & 5.: \\
\hline Imports & 19.7 & 17.9 & 15.4 & 12.7 & -0.6 & 3.8 & 7.1 & 5. \\
\hline Import of capital goods & -6.4 & -6.7 & -3.7 & -1.9 & 5.6 & 7.4 & -12.4 & -7 \\
\hline
\end{tabular}

Source: MINEPAT 


\subsubsection{Prices}

468. Inflation is expected to return to its historic level in the last ten years, that is 2.5 per cent in the medium term. The pressure exerted on prices by food products, mitigated by the implementation of tax exemption measures, would help maintain the inflation rate at 3 per cent in 2009. After the anticipated significant degradation of terms of trade in 2009 following the contraction of global demand, this scenario envisages the stagnation of prices over the remaining period of the strategy. The nonoil GDP deflator would experience a similar trend.

Graph 5: Price trends

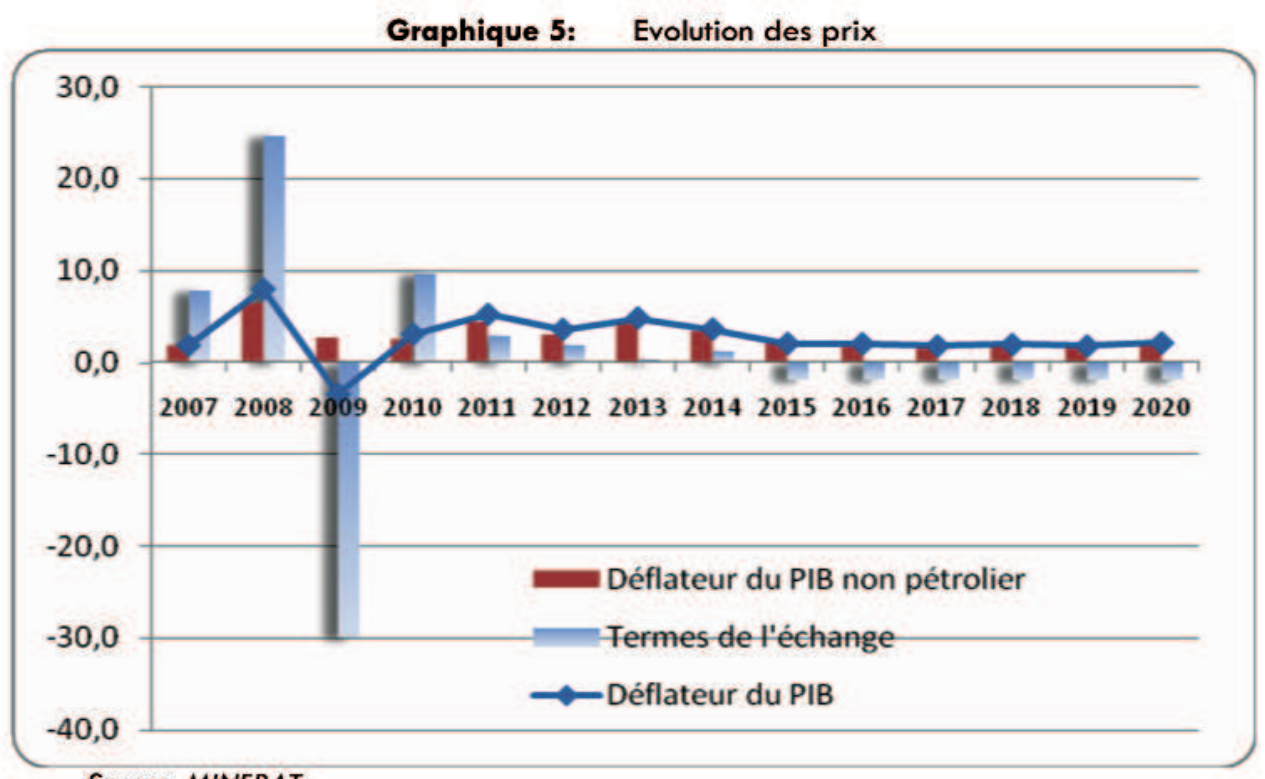

Source: MINEPAT

\subsubsection{Public finance}

469. Revenue. Oil revenue projections are based on the profiles of production volume, price per barrel in dollars of the IMF's World Economic Outlook, anticipated foreign exchange rate of the dollar and maintenance of the key of distribution of production between the State and oil companies. In view of the declining production trend, the budget policy is primarily centred on increased efforts to mobilize non oil revenue.

Table 17: National revenue trends ( $\%$ of GDP)

\begin{tabular}{|l|c|c|c|c|c|c|c|c|c|c|c|c|c|}
\hline Year & $\mathbf{2 0 0 8}$ & $\mathbf{2 0 0 9}$ & $\mathbf{2 0 1 0}$ & $\mathbf{2 0 1 1}$ & $\mathbf{2 0 1 2}$ & $\mathbf{2 0 1 3}$ & $\mathbf{2 0 1 4}$ & $\mathbf{2 0 1 5}$ & $\mathbf{2 0 1 6}$ & $\mathbf{2 0 1 7}$ & $\mathbf{2 0 1 8}$ & $\mathbf{2 0 1 9}$ & $\mathbf{2 0 2 0}$ \\
\hline Total revenue & 19.4 & 16.5 & 15.2 & 15.8 & 16.2 & 16.3 & 16.2 & 16.2 & 16.5 & 15.7 & 15.6 & 15.5 & 15.5 \\
\hline Oil revenue & 7.4 & 4.1 & 2.8 & 3.5 & 3.9 & 3.9 & 3.8 & 3.7 & 4.0 & 3.2 & 2.9 & 2.7 & 2.5 \\
\hline Non oil revenue & 12.0 & 12.4 & 12.4 & 12.3 & 12.3 & 12.4 & 12.4 & 12.5 & 12.5 & 12.6 & 12.6 & 12.8 & 12.9 \\
\hline Tax revenue & 11.3 & 11.1 & 11.0 & 11.0 & 11.0 & 11.1 & 11.2 & 11.3 & 11.3 & 11.4 & 11.4 & 11.6 & 11.8 \\
\hline \multicolumn{1}{c}{ Taxes on inter. exch. } & 2.0 & 1.8 & 1.8 & 1.7 & 1.7 & 1.6 & 1.5 & 1.5 & 1.3 & 1.1 & 1.0 & 1.0 & 0.9 \\
\hline Non tax revenue & 0.7 & 1.3 & 1.4 & 1.4 & 1.3 & 1.3 & 1.2 & 1.2 & 1.2 & 1.2 & 1.2 & 1.2 & 1.2 \\
\hline Non oil revenue/non oil GDP & 13.4 & 13.0 & 12.9 & 12.9 & 13.0 & 13.1 & 13.1 & 13.1 & 13.2 & 13.2 & 13.1 & 13.2 & 13.3 \\
\hline
\end{tabular}

Source: MINEPAT

470. On the basis of recent downward adjustments of growth in 2009 and persistence of the global economic crisis, budgetary revenue will stand at 16.6 per cent and 15.5 per cent of GDP, respectively in 2009 and 2010 as compared to 19.9 per cent in 2008. Despite a possible decline in oil production and effectiveness 
of EPA ${ }^{12}$, total tax revenue will be maintained at more than 15 per cent of GDP by 2020 . Indeed, the ratio of non oil revenue on GDP will rise from 12.3 per cent in 2008 to 13.1 per cent in 2020, representing an increase of one percentage point of the GDP. The nominal growth profile of tax revenue will remain on an upward trend.

471. Expenditure. One of the axes of this government strategy is to develop productive and social infrastructure within a stable macroeconomic framework. The policy of public expenditure is based on this preoccupation and plans to lay emphasis on the quality of expenditure while avoiding budgetary errors. Efforts are thus being made to contain current expenditure and identify resources for investment.

472. Based on the above hypothesis, a non oil deficit in primary income is expected during the period of the strategy, notably because of the realization of public investments in the building construction and public works sector and because of recruitments in the Public Service during the early years of the strategy. Meanwhile, this deficit will reduce gradually from 5.8 per cent of the GDP in 2008 to 3.7 per cent in 2020, showing the government's desire to financing infrastructure as a priority from non petroleum revenue.

473. An analysis of basic expenditure shows that the expected profit on the non petroleum primary revenue shall be the fruit of efforts to master and imbue efficiency in public expenditure. As for resources funded from internal resources, they will record a 0.9 per cent increase in points, from 5.5 per cent in 2008 to 6.4 per cent in 2015 before stabilising around 6.2 per cent at the end of the strategy. Their share in the total expenditure will increase from 30.9 per cent in 2010 to 36.4 per cent in 2020 . This translates the will of the government to continue in its efforts aimed at controlling public expenditure mainly through control of current expenditure and to revive the economy through an ambitious investment programme.

Table 18: Public expenditure trends (\% of GDP)

\begin{tabular}{|l|c|c|c|c|c|c|c|c|c|c|c|c|c|}
\hline & 2008 & 2009 & 2010 & 2011 & 2012 & 2013 & 2014 & 2015 & 2016 & 2017 & 2018 & 2019 & 2020 \\
\hline Total expenditure & $\mathbf{1 8 . 0}$ & $\mathbf{1 7 . 7}$ & $\mathbf{1 7 . 9}$ & $\mathbf{1 7 . 4}$ & $\mathbf{1 7 . 0}$ & $\mathbf{1 7 . 0}$ & $\mathbf{1 7 . 0}$ & $\mathbf{1 6 . 9}$ & $\mathbf{1 6 . 5}$ & $\mathbf{1 6 . 3}$ & $\mathbf{1 6 . 3}$ & $\mathbf{1 6 . 1}$ & $\mathbf{1 6 . 0}$ \\
\hline Current expenditure & 12.8 & 12.4 & 12.3 & 11.8 & 11.3 & 11.1 & 10.8 & 10.6 & 10.3 & 10.2 & 10.2 & 10.1 & 10.0 \\
\hline Salaries & 5.1 & 5.8 & 5.8 & 5.7 & 5.6 & 5.6 & 5.4 & 5.4 & 5.1 & 5.0 & 5.0 & 4.9 & 4.8 \\
\hline Other goods and services & 4.7 & 4.5 & 4.4 & 4.1 & 3.9 & 3.8 & 3.7 & 3.6 & 3.7 & 3.7 & 3.8 & 3.9 & 4.0 \\
\hline Transfers and subventions & 2.6 & 1.7 & 1.8 & 1.7 & 1.6 & 1.5 & 1.5 & 1.4 & 1.3 & 1.3 & 1.2 & 1.2 & 1.2 \\
\hline Payment of interests & 0.3 & 0.3 & 0.3 & 0.3 & 0.2 & 0.2 & 0.2 & 0.2 & 0.2 & 0.2 & 0.1 & 0.1 & 0.1 \\
\hline Capital expenditure & 5.4 & 5.3 & 5.6 & 5.6 & 5.7 & 5.9 & 6.2 & 6.3 & 6.2 & 6.2 & 6.1 & 6.0 & 6.0 \\
\hline Global amount, basic income & 1.9 & -0.9 & -2.3 & -1.1 & -0.4 & -0.4 & -0.5 & -0.4 & -0.3 & -0.3 & -0.5 & -0.4 & -0.4 \\
\hline Primary income & 1.8 & -0.8 & -2.3 & -1.4 & -0.5 & -0.5 & -0.6 & -0.5 & -0.4 & -0.4 & -0.6 & -0.5 & -0.4 \\
\hline Primary non petroleum revenue & -5.7 & -4.9 & -5.2 & -4.8 & -4.4 & -4.4 & -4.4 & -4.2 & -3.8 & -3.6 & -3.5 & -3.2 & -3.0 \\
\hline Capital total expenditure & $\mathbf{3 0 . 0}$ & $\mathbf{2 9 . 9}$ & $\mathbf{3 1 . 2}$ & $\mathbf{3 2 . 3}$ & $\mathbf{3 3 . 3}$ & $\mathbf{3 4 . 7}$ & $\mathbf{3 6 . 5}$ & $\mathbf{3 7 . 1}$ & $\mathbf{3 7 . 4}$ & $\mathbf{3 7 . 7}$ & $\mathbf{3 7 . 4}$ & $\mathbf{3 7 . 5}$ & $\mathbf{3 7 . 6}$ \\
\hline
\end{tabular}

Source: MINEPAT

474. The following analysis on the allocation of expenditure per sector will contribute in throwing more light on the problem of the optimal expenditure pattern and its relationship with the objectives of the strategy.

\subsubsection{Budgetary framework}

475. Analyses of the budgetary framework made it possible to define the medium term profile of allocation of budgetary resources to the different sectors. This profile translates the government's strategic guidelines to respond to the funding requirements of sectoral programmes under budgetary constraints.

6.1.3.6.1 Methodology.

476. The two major steps of the approach adopted to draft the global medium term budgetary framework is as follows:

12. A study carried out by MINEPAT to assess the impact of EPAs on external trade and public finances estimated that loss in revenue will increase from 3.9 billion in 2010 to 168.2 billion in 2023 
- Determining the amount to allocate. The overall amount of the budget has to be determined first (the national income and the internal land external expenditure), based on the government's flow of fund table derived from the macro reference framework. The amount of money allocated to sectors is obtained after determining the level of public investment necessary and reduction of the amount on debt servicing;

- Allocation of amounts to sectors and ministries. Intersectoral budgetary allocations on the year of programming are simulated taking into account the major projects which induce growth, standby structural projects and inevitable administrative needs.

\subsection{Analyses of allocation's profiles}

477. While paying attention to the objective of macroeconomic stability, expenditure on infrastructure and expenditure for the benefit of the rural sector shall both be reinforced. Thus, expenditure allocated to the productive sector will increase from 4.4 per cent in 2009 to 9 per cent of the total allocation between now and the year 2020. As for the infrastructure sector, it will increase to more than 16 per cent as against 11.1 per cent in 2007. Amounts allocated to education and health will increase respectively by 1.5 and 4 percentage points from 2009 to 2020 .

Table 19: Distribution of allocation according to sector (in billions of CFAF)

\begin{tabular}{|l|c|c|c|c|c|c|c|c|c|c|c|c|}
\hline & 2009 & 2010 & 2011 & 2012 & 2013 & 2014 & 2015 & 2016 & 2017 & 2018 & 2019 & 2020 \\
\hline Education & 18.4 & 18.6 & 18.6 & 19.2 & 19.2 & 19.3 & 19.6 & 19.6 & 19.7 & 19.7 & 19.7 & 19.8 \\
\hline Health & 5.2 & 5.9 & 6.3 & 6.9 & 7.6 & 7.9 & 8.2 & 8.2 & 8.2 & 8.2 & 8.3 & 8.3 \\
\hline Social Development and Employment & 1.1 & 1.2 & 1.2 & 1.3 & 1.4 & 1.5 & 1.6 & 1.7 & 1.7 & 1.7 & 1.7 & 1.7 \\
\hline Culture, sports and leisure & 1.9 & 1.9 & 1.9 & 1.9 & 1.9 & 1.9 & 1.9 & 1.9 & 2.0 & 2.0 & 2.0 & 2.0 \\
\hline Production and trade including & 6.0 & 6.7 & 7.1 & 7.5 & 7.8 & 8.0 & 8.2 & 8.2 & 8.2 & 8.2 & 8.2 & 8.2 \\
\hline the rural sector & 5.1 & 5.7 & 5.6 & 6.0 & 6.2 & 6.4 & 6.6 & 6.6 & 6.6 & 6.6 & 6.6 & 6.6 \\
\hline Productive Infrastructure & 14.8 & 17.4 & 18.4 & 18.3 & 18.3 & 18.3 & 18.3 & 18.3 & 18.3 & 18.3 & 18.4 & 18.4 \\
\hline General Administration and finance & 6.4 & 6.4 & 6.5 & 6.5 & 6.5 & 6.6 & 6.6 & 6.6 & 6.6 & 6.6 & 6.6 & 6.6 \\
\hline Defence and Security & 9.9 & 9.9 & 9.9 & 10.0 & 10.0 & 10.1 & 10.1 & 10.1 & 10.1 & 10.2 & 10.2 & 10.3 \\
\hline Sovereignty and Governance & 6.3 & 6.3 & 6.3 & 6.4 & 6.4 & 6.5 & 6.6 & 6.6 & 6.6 & 6.6 & 6.6 & 6.6 \\
\hline Total & 100.0 & 100.0 & 100.0 & 100.0 & 100.0 & 100.0 & 100.0 & 100.0 & 100.0 & 100.0 & 100.0 & 100.0 \\
\hline
\end{tabular}

Source: MINEPAT

\subsection{Major investment projects}

478. The strategy is based on starting major investment projects identified as necessary to increase the growth potential of the economy at an appropriate time. Most of these major projects over the next few years will comprise the project for the construction of the Lom Pangar dam, the Memve'ele hydro electric dam, the Kribi port, the second bridge over the Wouri whose cost and programming is detailed in the table below. 
Table 20: List of major projects of the GES

\begin{tabular}{|c|c|c|c|c|c|c|c|c|c|c|}
\hline \multirow[b]{2}{*}{ Projects } & \multirow{2}{*}{$\begin{array}{l}\text { Global } \\
\text { cost in } \\
\text { (billions) }\end{array}$} & \multirow{2}{*}{$\begin{array}{c}\text { governm } \\
\text { ent } \\
\text { share (*) }\end{array}$} & \multicolumn{8}{|c|}{ Programming of government's share of the project } \\
\hline & & & 2010 & 2011 & 2012 & 2013 & 2014 & 2015 & $\begin{array}{l}2016- \\
2020\end{array}$ & $\begin{array}{l}2010- \\
2020\end{array}$ \\
\hline 1. Lom Pangar & 140 & 100 & 40 & 30 & 30 & & & & & 100 \\
\hline 2. Kribi port & 300 & 180 & 47 & 40 & 43 & 50 & & & & 180 \\
\hline 3. Second Wouri bridge & 85 & 85 & - & 30 & 25 & 20 & 10 & & & 85 \\
\hline $\begin{array}{l}\text { 4. Memve'ele hydroelectric } \\
\text { dam }\end{array}$ & 145 & 145 & 10 & 23 & 40 & 45 & 27 & & & 145 \\
\hline Yaoundé-Douala highway & 600 & 300 & - & - & 30 & 40 & 70 & 90 & & 230 \\
\hline $\begin{array}{l}\text { Other major projets including : } \\
\text { Kribi gas station } \\
\text { - Construction of chemical } \\
\text { fertilizer production factories } \\
\text { - Development of optical fibre } \\
\text { network } \\
\text { - Construction of new aluminium } \\
\text { factories } \\
\text { - Development of agro- } \\
\text { pastoral hyperextensions } \\
\text { - Construction of } 1000 \mathrm{~km} \text { of } \\
\text { railway }\end{array}$ & 3270 & 1635 & 13 & 37 & 25 & 45 & 118 & 147 & 1250 & 1635 \\
\hline Total & 4540 & 2375 & 110 & 160 & 193 & 200 & 225 & 237 & 1250 & 2375 \\
\hline
\end{tabular}

Source: MINEPAT, $\left({ }^{*}\right)$ Most of the costs are estimated on the basis of studies and available or known information

\subsubsection{Balance of payments}

479. The export of goods after the drop of 2009 will increase over the period 2010-2020; this will be spurred mostly by the dynamism of non petroleum exports. Exportation of crude oil will drop after 2016. Expenditure on the import of goods will also record an increase as from 2010. The balance of services will continue to record a deficit, notably because of an increase in expenditure due to maritime freight, insurance and technical assistance. There is an expected deficit in the balance of goods and services on average over the entire period.

Table 21: Key Indicators of the balance of payments

\begin{tabular}{|c|c|c|c|c|c|c|c|c|c|c|c|c|c|}
\hline Year & 2008 & 2009 & 2010 & 2011 & 2012 & 2013 & 2014 & 2015 & 2016 & 2017 & 2018 & 2019 & 2020 \\
\hline \multicolumn{14}{|c|}{ on $\%$ of GDP } \\
\hline Trade balance & 3.8 & -3.6 & -3.3 & -1.6 & -0.3 & 0.7 & 1.1 & 0.3 & 1.4 & 0.0 & 0.2 & -0.3 & -0.9 \\
\hline $\begin{array}{l}\text { Amount of current } \\
\text { account : public } \\
\text { transfers included }\end{array}$ & -1.0 & -4.9 & -5.4 & 4.0 & -3.0 & -1.7 & -1.0 & -1.4 & -0.2 & 0.0 & -1.5 & -2.0 & -2.6 \\
\hline $\begin{array}{l}\text { Amount of current } \\
\text { account : public } \\
\text { transfers excluded }\end{array}$ & -1.7 & -5.8 & -6.1 & -4.5 & $-3,4$ & -2.0 & -1.2 & -1.6 & -0.4 & 0.0 & $-1,7$ & $-2,2$ & -2.8 \\
\hline Global amount & 2.7 & -2.4 & -2.0 & -0.4 & 1.6 & 2.5 & 3.0 & 2.3 & 2.2 & 0.0 & 1.5 & 0.7 & -0.1 \\
\hline \multicolumn{14}{|c|}{ Growth rate } \\
\hline Terms of trade & 24.6 & -30.0 & 9.7 & 2.8 & 1.8 & 0.3 & 1.1 & -1.9 & -1.9 & -1.9 & -1.9 & -1.9 & -1.9 \\
\hline $\begin{array}{l}\text { Prices of non } \\
\text { petroleum exports }\end{array}$ & 35.3 & -33.6 & 10.9 & 4.1 & 2.5 & 1.0 & 1.9 & 0.0 & 0.0 & 0.0 & 0.0 & 0.0 & 0.0 \\
\hline Import prices index & 10.7 & -3.5 & 1.3 & 1,3 & 0.7 & 0.7 & 0.7 & 1.9 & 1.9 & 1.9 & 1,9 & 1.9 & 1.9 \\
\hline Exchange rate & 7.8 & 3.7 & -1.0 & -1.3 & -1.3 & -1.3 & -1.3 & 0.0 & 0.0 & 0.0 & 0.0 & 0.0 & 0.0 \\
\hline
\end{tabular}

Source: MINEPAT

480. The income account will continue to record a deficit over the entire period of the strategy because of the dividends which will be paid to foreign investors and payment of interests on public external debt. The amount of current transfers, which were planned on the basis of growth in developed countries, will record a surplus over the entire period, from 1.7 per cent in 2008 it is expected to rise to 1.0 per cent of the GDP in 2020.The amount of current account will increase based on the balance of goods and services. It will also record a deficit throughout the period.

481. The capital account will record a surplus throughout the period. The case will be the same for the financial account, because of expected foreign investments within the framework of different projects in the mining, 
oil, power and building construction and public works sector and especially because of financial transactions (loans, commercial loans relating mainly to the purchase of capital equipment).

\subsubsection{The monetary situation}

482. Net foreign assets will increase steadily depending on the profile of oil production and the import of equipment needed for implementation of major projects. To that end, the State will have to draw more from its reserves, will reduce its deposits on the banking sector, or use the possibility of having recourse to statutory advances. There is an expected continuous increase in the credits of the economy which will move from 12.2 per cent of the GDP in 2009 to 14.6 per cent in 2020 . At the same time, the GDP will increase; the ratio of the money supply to the GDP will record an increase of 2.7 points during the same period from 20.2 per cent of the GDP in 2008 to 21.4 per cent in 2020.

Table 22: Trends in the monetary situation

\begin{tabular}{|c|c|c|c|c|c|c|c|c|c|c|c|c|c|}
\hline Exercices & 2008 & 2009 & 2010 & 2011 & 2012 & 2013 & 2014 & 2015 & 2016 & 2017 & 2018 & 2019 & 2020 \\
\hline Avoirs Extérieurs Nets & 1747,3 & 1450,2 & 1225,5 & 1194,9 & 1285,5 & 1764,6 & 2328,3 & 2791,8 & 3573,2 & 4098,6 & 4538,3 & 4851,2 & 4969,2 \\
\hline BEAC & 1444,8 & 1227,0 & 993,1 & 923,1 & 970,1 & 1415,9 & 1960,3 & 2426,0 & 3162,0 & 3693,1 & 4128,7 & 4439,4 & 4561,3 \\
\hline$B C M$ & 302,5 & 223,2 & 232,4 & 271,9 & 315,4 & 348,7 & 368,0 & 365,7 & 411,2 & 405,5 & 409,6 & 411,9 & 407,9 \\
\hline Crédits Intérieurs Nets & 682,9 & 911,2 & 1207,4 & 1435,0 & 1554,1 & 1717,5 & 1902,0 & 2101,2 & 2385,2 & 2645,4 & 2990,5 & 3359,9 & 3750,2 \\
\hline Créances Nettes sur l'Etat & $-599,8$ & $-454,1$ & $-252,8$ & $-162,6$ & $-206,1$ & $-247,5$ & $-285,4$ & $-318,9$ & $-348,4$ & $-363,3$ & $-355,2$ & $-337,1$ & $-326,7$ \\
\hline Position Nette du Gouvernement & $-473,0$ & $-392,3$ & $-191,0$ & $-100,8$ & $-144,3$ & $-185,7$ & $-223,6$ & $-257,1$ & $-286,6$ & $-301,5$ & $-293,4$ & $-275,3$ & $-264,9$ \\
\hline BEAC & $-438,7$ & $-376,0$ & $-187,4$ & $-95,9$ & $-126,9$ & $-157,9$ & $-188,9$ & $-219,9$ & $-250,9$ & $-264,9$ & $-264,9$ & $-264,9$ & $-264,9$ \\
\hline Créances Brutes & 12,7 & 12,2 & 52,2 & 181,2 & 150,2 & 119,2 & 88,2 & 57,2 & 26,2 & 12,2 & 12,2 & 12,2 & 12,2 \\
\hline Dépôts & 451,4 & 388,2 & 239,6 & 277,1 & 277,1 & 277,1 & 277,1 & 277,1 & 277,1 & 277,1 & 277,1 & 277,1 & 277,1 \\
\hline $\mathrm{BCM}$ & $-34,2$ & $-16,3$ & $-3,6$ & $-4,9$ & $-17,3$ & $-27,8$ & $-34,7$ & $-37,2$ & $-35,7$ & $-36,6$ & $-28,5$ & $-10,4$ & 0,0 \\
\hline Autres créances nettes sur l'état & $-126,8$ & $-61,8$ & $-61,8$ & $-61,8$ & $-61,8$ & $-61,8$ & $-61,8$ & $-61,8$ & $-61,8$ & $-61,8$ & $-61,8$ & $-61,8$ & $-61,8$ \\
\hline Crédit à l'Economie & 1282,7 & 1365,3 & 1460,2 & 1597,6 & 1760,1 & 1964,9 & 2187,4 & 2420,0 & 2733,5 & 3008,7 & 3345,7 & 3697,1 & 4076,9 \\
\hline Masse Monétaire & 2149,9 & 2276,1 & 2417,2 & 2616,8 & 2849,4 & 3137,4 & 3446,4 & 3766,0 & 4188,1 & 4556,7 & 5000,9 & 5459,1 & 5949,0 \\
\hline Monnaie Fiduciaire & 430,6 & 455,9 & 484,1 & 524,1 & 570,7 & 628,4 & 690,3 & 754,3 & 838,8 & 912,7 & 1001,6 & 1093,4 & 1191,5 \\
\hline Dépôts à Vue & 888,6 & 940,7 & 999,1 & 1081,6 & 1177,7 & 1296,8 & 1424,5 & 1556,6 & 1731,0 & 1883,4 & 2067,0 & 2256,4 & 2458,8 \\
\hline Dépôts à Terme & 830,7 & 879,5 & 934,0 & 1011,1 & 1101,0 & 1212,3 & 1331,7 & 1455,2 & 1618,3 & 1760,7 & 1932,3 & 2109,3 & 2298,6 \\
\hline Autres Postes Nets & 280,3 & 85,4 & 15,7 & 13,2 & $-9,8$ & 344,6 & 783,9 & 1126,9 & 1770,3 & 2187,3 & 2528,0 & 2752,0 & 2770,4 \\
\hline \multicolumn{14}{|l|}{ Ratios au PIB } \\
\hline Masse monétaire & 20,2 & 20,4 & 20,4 & 20,2 & 20,1 & 19,8 & 19,9 & 20,1 & 20,2 & 20,5 & 20,8 & 21,1 & 21,4 \\
\hline Crédit à l'économie & 12,1 & 12,2 & 12,3 & 12,3 & 12,4 & 12,4 & 12,6 & 12,9 & 13,2 & 13,5 & 13,9 & 14,3 & 14,6 \\
\hline Crédit à l'Etat & $-5,6$ & $-4,1$ & $-2,1$ & $-1,3$ & $-1,5$ & $-1,6$ & $-1,6$ & $-1,7$ & $-1,7$ & $-1,6$ & $-1,5$ & $-1,3$ & $-1,2$ \\
\hline Base monétaire & 6,0 & 6,0 & 6,1 & 6,0 & 6,0 & 5,9 & 5,9 & 6,0 & 6,0 & 6,1 & 6,2 & 6,3 & 6,3 \\
\hline
\end{tabular}

Source : MINEPAT 


\subsection{SCENARIO " VISION "}

\subsubsection{Main hypothesis on the pillars of growth}

483. This scenario is based on the hypothesis of total realization of the objectives of the 2035 development vision.

484. In the rural sector, development will be based on the intensification of silvo agro pastoral activities and promotion of means of exploitation in order to improve on productivity through access to land and modernization of production techniques.

485. In the extractive industry, the execution of projects on the extraction of iron ore in Mbalam, cobalt-nickelmanganese in Lomie, during the period of the strategy, will help compensate, to some extend, for the constant drop in oil production

486. In the energy sector, the objective will be to increase the energy production capacity to $3000 \mathrm{MW}$ by 2020 through (1) the realization of major projects on dams and hydroelectric power stations (ii) improvement on renewable energies (iii) extension and modernization of transport and distribution installations and equipment.

487. The strategy for the development of transport infrastructure will be based, among others, on the objectives of densification and improvement of their quality. In the area of roads, the major objective is to increase the current 10 per cent proportion of tarred roads to more than 30 per cent by the time of full implementation of the vision through the rehabilitation of $250 \mathrm{~km}$ of roads and tarring of $450 \mathrm{~km}$ of roads on average per annum by the time of completion of the vision.

488. Concerning Cameronn's sea frontage, the strategy will be to take utmost advantage of the country's strategic position through the construction and commissioning of Kribi and Limbe deep sea ports.

489. In the area of telecommunications, the objective is to increase the digital access index from 0.61 to 0.47 in 2035 , to increase five fold the number of telephone lines and increase the network coverage of mobile telephone networks.

490. In the manufacturing sector, the industrialisation strategy lays emphasis on the processing and development of commodities. The objective is to increase the added value of manufactured goods in the GDP from 10 to 23 per cent.

491. The realization of the vision's objectives will make it possible to anticipate a higher growth profile of the GDP than that of the reference scenario. Meanwhile at short term, the growth profile obtained in the two scenarios do not differ significantly because of the necessary deadline for effective implementation of the different investment programmes and funding constraints relating to international financial crisis. On the other hand, on average over the period 2012-2020, the growth gap of the non petroleum GDP is 2.5 per cent between the two scenarios. Even more, between 2016 and 2020, the annual growth rate will be 9.5 per cent, that is, 3.6 per cent above that of the reference scenario.

492. Over the period 2012-2020, the primary sector will record an annual average increase of 7.1 per cent, that is, 2.1 points above that of the reference period. This will be driven mostly by agricultural food crops which will record an average annual increase of 7.3 per cent. This gap can be justified by increased efforts in the modernisation of the production machinery through the development of more intensive agriculture in sectors with greater growth potential. The development of the sector will also be due to the development of the stock breeding sub-sector. It will in fact, record an average growth rate of 9.3 per cent over the period as against 5 per cent in the reference scenario. Growth in the sector shall depend on the one hand, on the development of big and small ranches for cattle breeding.

493. With the dynamism in the manufacturing industries and the building construction public works industries, 
the secondary sector will record an annual growth rate of 8.7 per cent between 2012 and 2020, 3 points higher than the reference secnario. In the manufacturing sector, agribusiness will record an average of 7 per cent growth as against 4.5 per cent for the reference year. This performance will be due mostly to the development of processing industries for local raw materials (plantain, sugar, palm oil, corn, cocoa, cotton etc..The other industries are expected to benefit from the development of the building materials industry (cement, iron...) and the intensification of the processing of wood, leather, base metal, etc... This will make it possible to realize an average growth rate of 10.3 per cent over the period 2012-2020 as against 6.2 per cent in the reference scenario. In the building construction and public works sector the implementation of major infrastructural projects in the transport and energy sectors and road improvement will contribute to acceleration of growth in this sector. This will make it possible to record an average growth rate of 10.5 per cent over the period 2012 2020 as against 6.2 per cent for the reference period. The gap between the two growth profiles will be clearly perceptible as from 2015. Thus for the period 2012-2020 there will be an average growth rate of $12.2 \%$ as against $7.9 \%$ in the reference scenario.

Table 23 Trends in the real growth rate (scenario vision)

\begin{tabular}{lccccccc}
\hline \hline & 2008 & 2009 & 2010 & 2011 & 2012 & $2013-2015$ & $2016-2020$ \\
Primary sector & $\mathbf{3 . 4}$ & $\mathbf{3 . 1}$ & $\mathbf{4 . 2}$ & $\mathbf{4 . 8}$ & $\mathbf{5 . 3}$ & $\mathbf{6 . 6}$ & $\mathbf{7 . 7}$ \\
Agriculture of foodstuff products & 5.3 & 4.7 & 4.8 & 5.1 & 5.5 & 7.1 & 7.7 \\
Industrial and export -oriented Agriculture & -1.9 & 2.6 & 3.6 & 4.5 & 5.7 & 6.9 & 8.4 \\
Breeding, hunting & 3.0 & 3.8 & 4.1 & 4.1 & 4.9 & 7.4 & 11.3 \\
Fishing & 2.5 & 2.5 & 2.5 & 2.5 & 3.0 & 3.0 & 3.0 \\
Silviculture and forest exploitation & -5.5 & -10.0 & 0.0 & 5.0 & 4.5 & 2.8 & 2.0 \\
Secondary sector & -0.5 & -0.1 & 0.6 & $\mathbf{5 . 7}$ & $\mathbf{5 . 7}$ & $\mathbf{6 . 4}$ & 10.5 \\
Extractive Industries & -1.8 & -9.8 & -10.0 & 12.5 & 9.4 & 3.3 & 1.0 \\
$\quad$ Including : Hydrocarbons & -1.8 & -10.2 & -10.4 & 13.0 & 9.8 & 2.8 & 0.3 \\
Agribusiness & 1.9 & 3.0 & 2.3 & 2.8 & 3.2 & 4.0 & 9.5 \\
Other manufacturing industries & -0.1 & 0.8 & 3.2 & 3.9 & 4.6 & 7.7 & 13.0 \\
Electricity, gas and water & 4.3 & 2.0 & 3.0 & 3.5 & 4.0 & 14.5 & 17.4 \\
Building construction and public works & -6.2 & 11.3 & 6.5 & 8.5 & 9.0 & 9.7 & 14.3 \\
Tertiary sector & $\mathbf{5 . 0}$ & 3.6 & 3.8 & 4.5 & $\mathbf{5 . 7}$ & $\mathbf{7 . 9}$ & $\mathbf{9 . 6}$ \\
Commerce, restaurants and hotels & 4.1 & 3.2 & 3.6 & 3.8 & 5.6 & 9.4 & 11.3 \\
Transports, warehousing, communications & 4.5 & 3.3 & 4.9 & 5.7 & 6.4 & 7.1 & 10.8 \\
Banks and financial institutions & 7.6 & 5.3 & 4.2 & 4.0 & 5.7 & 6.7 & 8.3 \\
Other merchant services & 7.3 & 5.2 & 4.2 & 6.0 & 7.3 & 7.9 & 8.4 \\
SIFIM (Indirect, measured, internal services.) & 3.1 & 3.9 & 3.8 & 5.9 & 7.2 & 7.9 & 8.4 \\
Non Merchant APU services & 5.2 & 3.1 & 2.7 & 3.3 & 3.8 & 5.7 & 5.3 \\
Other non merchant services & 3.9 & 4.1 & 4.6 & 5.1 & 4.4 & 4.6 & 4.6 \\
GDP AT FACTORS COSTS & 3.1 & 2.5 & 3.0 & 4.9 & $\mathbf{5 . 6}$ & $\mathbf{7 . 2}$ & $\mathbf{9 . 5}$ \\
GDP & 3.1 & 2.5 & 3.0 & 4.9 & 5.6 & $\mathbf{7 . 2}$ & $\mathbf{9 . 5}$ \\
\hline \hline
\end{tabular}

Source: MINEPAT

494. The tertiary sector will record and annual average of 8.7 per cent as against 6.5 per cent in the reference scenario. This performance will be mostly due to changes in trade, hotels, and restaurant, transport, warehousing and communications sectors. In the area of services, special attention will be paid to development of the great tourist potential of the country. Transport activity will be intensified with the realization of a vast programme of rehabilitation and extension of the road network.

\subsubsection{Analyses of use of the GDP}

495. Investments will increase from 13.8 per cent between 2010 and 2020 as against 9.1 per cent in the reference scenario. This change is translated by a higher investment rate which will be 31.0 per cent as against 23.4 per cent in the reference scenario. This translates the fact that the realization of the vision's objectives will 
require a higher level of investments than in the reference scenario. The share of non petroleum exports in the GDP and import of equipment will be respectively, 7.7 per cent, and 6.5 per cent as against 7.0 per cent and 3.7 per cent in the reference scenario. This translates the dynamism which should reign in the manufacturing sector.

Table 24: Trends in employment. (Vision scenario)

\begin{tabular}{|c|c|c|c|c|c|c|c|c|}
\hline \multirow[b]{3}{*}{ Year } & \multirow{2}{*}{\multicolumn{4}{|c|}{$\begin{array}{l}\text { In } \% \text { of GDP (at current } \\
\text { prices ) }\end{array}$}} & \multicolumn{4}{|c|}{ Percentage variation in volume } \\
\hline & & & & & & 2009- & & 2016- \\
\hline & 2009 & 2012 & 2015 & 2020 & 2008 & 2012 & 2013-2015 & 2020 \\
\hline Gross formation of fixed capital & 19.8 & 21.7 & 25.4 & 33.2 & 10.7 & 20.2 & 23.7 & 29.8 \\
\hline Private sector & 16.6 & 18.2 & 21.4 & 29.6 & 6.3 & 17.0 & 19.9 & 26.1 \\
\hline Public Administration & 3.2 & 3.5 & 3.9 & 3.6 & 37.8 & 3.3 & 3.7 & 3.7 \\
\hline Consumption & 81 & 76.9 & 75.3 & 67.3 & -0.1 & 79.8 & 75.8 & 70.6 \\
\hline Private Sector & 70.3 & 67.2 & 66.4 & 60.3 & -1.4 & 69.4 & 66.7 & 63.0 \\
\hline Public Administration & 10.7 & 9.7 & 8.9 & 7 & 9.1 & 10.4 & 9.1 & 7.6 \\
\hline Exports & 18.6 & 18.7 & 17.6 & 14.2 & 4.9 & 18.7 & 18.5 & 16.0 \\
\hline Crude oil Exports & 6.6 & 7.5 & 7.1 & 3.8 & -1.8 & 7.1 & 8.0 & 5.8 \\
\hline Non petroleum Exports & 7.8 & 7.8 & 7.8 & 8.5 & -0.1 & 7.9 & 7.7 & 8.0 \\
\hline Imports & 19.6 & 18.3 & 18.3 & 14.8 & -0.6 & 18.7 & 18.0 & 16.4 \\
\hline Imports of capital & & & & & & & & \\
\hline equipment & 6.4 & 6.6 & 7.5 & 8.8 & 5.5 & 6.7 & 7.2 & 6.6 \\
\hline
\end{tabular}

\subsubsection{Funding needs}

496. The high increase in the non petroleum GDP during the period 2010-2020 in the scenario vision compared to the reference scenario will make it possible to identify significant internal additional resources as from 2014 to support the increase in expenditure. However, these additional resources will turn out insufficient. In fact the expenditure gap between the two scenarios worsens progressively over the entire period. This is largely due to capital expenditure which increases by three points higher than that of the reference scenario. 
Table 25: Trends of public finances (Vision scenario)

\begin{tabular}{|c|c|c|c|c|c|c|c|c|c|c|c|c|c|}
\hline Year & 2008 & 2009 & 2010 & 2011 & 2012 & 2013 & 2014 & 2015 & 2016 & 2017 & 2018 & 2019 & 2020 \\
\hline Total revenue & 19.4 & 16.5 & 15.2 & 15.8 & 16.2 & 16.3 & 16.5 & 16.5 & 16.7 & 15.9 & 15.5 & 15,3 & 15.2 \\
\hline Oil revenue & 7.4 & 4.1 & 2.8 & 3.5 & 3.9 & 3.9 & 3.8 & 3.6 & 3.9 & 3.0 & 2.7 & 2,4 & 2.1 \\
\hline Nonoil revenue & 12.0 & 12.4 & 12.4 & 12.3 & 12.3 & 12.5 & 12.6 & 12.8 & 12.9 & 12.9 & 12.8 & 13,0 & 13.1 \\
\hline Tax revenue & 11.3 & 11.1 & 11.0 & 11.0 & 11.0 & 11.2 & 11.4 & 11.6 & 11.7 & 11.7 & 11.6 & 11,8 & 11.9 \\
\hline Imports on inte. Exch. & 2.0 & 1.8 & 1.8 & 1.7 & 1.7 & 1.7 & 1.7 & 1.7 & 1.6 & 1.4 & $1 . .2$ & 1,1 & 1.1 \\
\hline non tax revenue & 0.7 & $1 . .3$ & 1.4 & 1.4 & $1 . .3$ & $1 . .3$ & $1 . .2$ & $1 . .2$ & $1 . .2$ & $1 . .2$ & $1 . .2$ & 1.2 & 1.2 \\
\hline Total expenditure & 18.0 & 17.7 & 17.9 & 17.7 & 17.4 & 17.4 & 17.4 & 17.9 & 17.2 & 16.7 & 16.2 & 15.9 & 15.7 \\
\hline Current expenses & 12.8 & 12.4 & 12.3 & 11.8 & 11.3 & 10.9 & 10.6 & 10.7 & 10.0 & 9.6 & 9.3 & 9.0 & 8.9 \\
\hline Salaries & 5.1 & 5.8 & 5.8 & 5.7 & 5.6 & 5.6 & 5.5 & 5.4 & 5.0 & 4.7 & 4.6 & 4.3 & 4.0 \\
\hline Other goods and services & 4.7 & 4.5 & 4.4 & 4.1 & 3.8 & 3.6 & 3.5 & 3.7 & 3.6 & 3.5 & 3.5 & 3.6 & 3.9 \\
\hline Transfers and subventions & 2.6 & 1.7 & 1.8 & 1.7 & 1.6 & 1.5 & 1.5 & 1.4 & 1.3 & 1.2 & 1.1 & 1.0 & 1.0 \\
\hline Payment of interests & 0.3 & 0.3 & 0.3 & 0.3 & 0.2 & 0.2 & 0.2 & 0.2 & 0.2 & 0.1 & 0.1 & 0.1 & 0.1 \\
\hline Capital expenditure & 5.4 & 5.3 & 5.6 & 5.9 & 6.2 & 6.4 & 6.8 & 7.2 & 7.2 & 7.1 & 6.9 & 6.9 & 6,8 \\
\hline Internal funding & -1.9 & 0.7 & 1.7 & 0.6 & -0.7 & -0.7 & -0.6 & -0.5 & -0.4 & -0.3 & -0.2 & -0.1 & -0.1 \\
\hline External funding & -0.1 & 0.1 & 0.4 & 0.3 & 0.3 & 0.3 & 0.3 & 0.4 & 0.3 & 0.2 & 0.2 & 0.2 & 0.2 \\
\hline \multirow[t]{2}{*}{ Primary total amount } & 1.8 & -0.8 & -2.3 & -1.6 & -0.9 & -0.8 & -0.8 & -1.2 & -0.3 & -0.7 & -0.6 & -0.5 & -0.4 \\
\hline & & -4.9 & -5.2 & -5.1 & -4.9 & -4.7 & -4.6 & -4.9 & -4.1 & -3.7 & -3.2 & -2.9 & -2.5 \\
\hline Primary non petroleum amount & -5.7 & 0.0 & 0.2 & 0.5 & 1.3 & 1.1 & 1.0 & 1.2 & 0.4 & 0.7 & 0.5 & 0.4 & 0.3 \\
\hline
\end{tabular}

Source: MINEPAT

\subsection{RISK ANALYSIS}

497. The reference scenario of the GESP is a projection of growth profiles and social development indicators made on the basis of key hypothesis on the national economic environment and the effective implementation of major projects in the energy, and building construction and public works which depend on the ability of Cameroon to mobilize the domestic and external resources. The business environment is equally a determining factor in mobilization of growth induced investments. In any case, any significant change which takes place in the rate of execution of projects may have a negative impact on the growth rate, and consequently on job creation and poverty reduction. The following section analyzes the magnitude of these deviations and their incidence on the growth and revenue profile.

498. The analysis of the impact is carried out from reference scenarios. They consist in modifying some hypotheses of this scenario and to assess the magnitude in terms of deviation of the growth rate and its implications on public finances.

\subsubsection{Delays in implementation of projects in the energy sector}

499. The development of a reliable system of electricity production is a condition for modernization of the economy and expansion of activities in the private sector. Thus the growth profiles defined in the reference scenarios have given a catalytical role to this sector. To that end, the failure to respect the energy calendar would compromise the competitiveness of the industry and the chances of diversifying the economy.

500. To show the importance of this sector, the effects of a weaker growth of energy supply around 20102020 were simulated by an average growth rate of energy supply of 7 per cent instead of 14 per cent initially programmed for the period. The consequences on the GDP are significant. The average annual growth rate will reduce by about 0.5 point per year that is five growth points in ten years. This reduction will be basically due to a slow down of the non petroleum GDP. At the level of public finances, this gap will lead to modi- 
fication of the revenue structure in percentage of the GDP. Compared to the reference scenario, losses in terms of non oil revenues are estimated at 60 billion CFAF on average per year over the period 2010-2020.

Table 26: Impact of project execution delay in the energy sector

\begin{tabular}{|l|c|c|c|c|c|c|c|c|c|c|c|c|c|}
\hline \multicolumn{10}{|c|}{ Changes compared to the reference scenario } \\
\hline & 2009 & 2010 & 2011 & 2012 & 2013 & 2014 & 2015 & 2016 & 2017 & 2018 & 2019 & 2020 \\
\hline \multicolumn{10}{|c|}{ Growth rate } \\
\hline GDP & 0.0 & 0.0 & 0.0 & -0.1 & -1.1 & -1.6 & -1.2 & -1.0 & -1.0 & -0.5 & 0.6 & -0.1 \\
\hline Non & 0.0 & 0.0 & 0.0 & -0.1 & -1.1 & -1.6 & -1.2 & -1.0 & -1.0 & -0.5 & 0.6 & -0.1 \\
\hline \multicolumn{10}{|c|}{ In billion } \\
\hline Total revenue & 0.0 & 0.0 & 0.0 & -0.1 & -2.0 & -15.6 & -40.1 & -62.9 & -82.7 & - & - & -110.4 \\
\hline Non petroleum & 0.0 & 0.0 & 0.0 & -0.1 & -2.0 & -15.6 & -40.1 & -62.9 & -82.7 & - & - & -110.4 \\
\hline \multicolumn{10}{|c|}{} \\
\hline Expenditure & 0.0 & 0.0 & -32.0 & -54.7 & -80.3 & - & - & - & - & - & - & -137.6 \\
\hline Investment & 0.0 & 0.0 & -32.0 & -54.7 & -80.3 & - & - & - & - & - & - & -137.6 \\
\hline
\end{tabular}

Source: MINEPAT

\subsubsection{Differences in execution of major projects of the building construction and public works sector}

501. The building construction sector stands out as one of the major levers of SCE growth. Failure to realize some infrastructural programmes and projects notably in the construction of the Kribi deep sea port and the different road projects will have a negative impact on the GDP growth. Thus, given the importance of this sector for the strategy of government, a simulation which reduces by half the growth of building construction and public works by about 0.4 points per year on average, that is 4 growth points in 10 years. In terms of public finances, the losses are around 50 billion on annual average between 2010 and 2020 compared to the reference scenario.

Table 27: Impact of shift in major projects execution in the building construction and public works sector

\begin{tabular}{|c|c|c|c|c|c|c|c|c|c|c|c|c|}
\hline \multicolumn{13}{|c|}{ Changes compared to the reference scenario } \\
\hline & 2009 & 2010 & 2011 & 2012 & 2013 & 2014 & 2015 & 2016 & 2017 & 2018 & 2019 & 2020 \\
\hline \multicolumn{13}{|c|}{ Growth rate } \\
\hline GDP & 0.0 & 0.0 & 0.0 & -0.1 & -1.1 & -1.6 & -1.2 & -1.0 & -1.0 & -0.5 & 0.6 & -0.1 \\
\hline Non & 0.0 & 0.0 & 0.0 & -0.1 & -1.1 & -1.6 & -1.2 & -1.0 & -1.0 & -0.5 & 0.6 & -0.1 \\
\hline \multicolumn{13}{|c|}{ In billion } \\
\hline Total revenue & 0.0 & 0.0 & 0.0 & -0.1 & -2.0 & -15.6 & -40.1 & -62.9 & -82.7 & - & - & -110.4 \\
\hline Non petroleum & 0.0 & 0.0 & 0.0 & -0.1 & -2.0 & -15.6 & -40.1 & -62.9 & -82.7 & - & - & -110.4 \\
\hline Expenditure & 0.0 & 0.0 & -32.0 & -54.7 & -80.3 & - & - & - & - & - & - & -137.6 \\
\hline Investment & 0.0 & 0.0 & -32.0 & -54.7 & -80.3 & - & - & - & - & - & - & -137.6 \\
\hline
\end{tabular}

Source: MINEPAT

502. Generally, delays in the implementation of projects programmed in the strategy both in the supply of electrical energy and improvement of infrastructure will induce a slowdown in growth and a reduction of the overall competitiveness of the economy.

\subsubsection{Signature of EPAs excluding the development component}

503. Cameroon signed the interim Economic Partnership Agreement (EPA), under negotiation between the European Union (EU) and Central Africa. Yet, the signature of such EPA without the comprehensive integration of the components of development and upgrading of local enterprises will lead to a drop in domestic public resources and inflow of EU imports. Thus, with the lack of support to local industries, production by local industries will suffer competiton of EU products with low prices and better quality. The loss in competitiveness will 
lead to a drop in demand of local products, a decline in the production of local enterprises and a shift of trade to the benefit of the Eu zone. The consequence on public finance will be a decrease in domestic revenue and a decline in customs revenue.

504. The dismantling of tariff should concern, in the short term, inputs that are already partly or totally exempted. Thus, the impact of the conclusion of these agreements on public finance will be seen in the medium and long term and will be translated by net fiscal losses. Simulation of the impact of such an agreement without the implementation of its development component and upgrading of local enterprises show accrued losses of CFA F 545.7 billion in non petroleum revenue over the period 2010-2020, with 459.6 billion between 2015 and 2020. On average, this gap would represent 0.4 per cent of the GDP over the last period. This situation would exacerbate the funding need which would increase to 1167.5 billion in 2020 from 216.3 billion in 2010.

Table 28: Funding needs (in billion CFA F)

\begin{tabular}{|c|c|c|c|c|c|c|c|c|c|c|c|}
\hline Years & 2010 & 2011 & 2012 & 2013 & 2014 & 2015 & 2016 & 2017 & 2018 & 2019 & 2020 \\
\hline Funding needs with the EPA (1) & 216.3 & 181.2 & 97.7 & 103.4 & 194.8 & 382.6 & 265.4 & 463.8 & 595.3 & & \\
\hline Gap (1) - (2) & 3.1 & 21.5 & 36.9 & 78.1 & 142.5 & 205.1 & 259.5 & 319.8 & 315.2 & 365.9 & 493.5 \\
\hline
\end{tabular}

Source: MINFI

\subsection{IMPACT ON MILLENIUM DEVELOPMENT GOALS}

505. After drafting the two main scenarios of the macroeconomic and budgetary framework, additional simulations were carried out to assess the consequences of different growth profiles and budgetary choices on the medium term changes of poverty and other indicators of the MDGs. This concerns mostly the changes in the rate of income poverty and that of indicators of other MDGs relating to education, health, and food... a simulation on the number of employment opprotunities created as a result of implementation of these different scenarios was equally carried out. 
Box: 10: Methodology of forecasting with MDG indicators

\section{Forecast of the incidence of income poverty}

The methodology used here to estimate the rate of poverty which will be deduced from the growth scenario is micro simulation. The idea at the grass roots is to simulate the impact of growth on the indicator of living standards, and hence on the rate of poverty from a data file made after an enquiry among households (ECAM3).

To this end, the sector of activity of the head of the household is taken into consideration (primary, secondary or tertiary) and we develop the hypothesis that the well being of the family will evolve at the same rate as the sector of activity to which he belongs. Thus recursively, we can calculate the wellbeing of families and therefore the rate of poverty. The following equation summarizes this situation:

$$
c_{i, t}=c_{i,-1}\left(1+g_{t}^{S_{1}}-\tau_{t}^{S_{1}}\right.
$$

Where $: 8^{5}$ is the indicator of living standards of the household $\mathrm{i}$ in the year $t$, The indicator of living standards of the base year is the one calculated in ECAM3;

$\tau_{t}^{S_{1}}$ is the growth rate of the sector of activity $\mathrm{Si}$ for the year $t$;

$s$ is the rate of increase of the population in the sector of activity $\mathrm{Si}$ for the year $t$;

$S$ is used to designate the primary, secondary and tertiary sectors and the rest (the retired, the unemployed and the inactive) which are usually residual for the head of the household.

Hypotheses to support these forecast admit that: (i) The weight of expenditure on food in household expenditure remains stable; (ii) The marginal propensity to consume remains stable over the period; (iii) The distribution of income will depend on the economic growth differential between the sectors of activity; (iv) The relative price of food products compared to other goods in the economy remain stable.

\section{Forecasts of other MDG indicators}

The methodology of forecasts consisted in simulating the changes of other indicators of MDGS depending on the growth profile and expenditure allocated to the sectors concerned. It is based on a model which links the dynamism of these indicators to the real increase in the GDP and that of public expenditure in different sectors directly involved in realization of these MDGS. By way of illustration, the changes of MDGS in the health sector depend on that of the real GDP and budgetary allocations in this sector. The formula is as follows:

$\log \left(M D G_{i}\right)_{t}=\alpha i * \log \left(G D P_{t}\right)+\beta_{i} * \log \left(G_{i}\right)_{t}+\varepsilon_{i t}$

Where $G$ stands for public expenditure in the sector $i, M D G ~ I$, indicator $i$ of MDGS.

The Average increases in real GDP as well as the real increase in public expenditure in sectors which are specifically targeted by the other MDGS were obtained from the exploitation of different data bases (INS, WDI, UNSTAT, LDF...) over the past 25 years. The reporting of other MDG indicators, (ECAM I à III, MICS I et III, EDS I à III...) made it possible to identify hallmarks for these objectives. From these data, the elasticity was estimated. This was applied to the growth profile, the budgetary allocations of different scenarios on the programming year in order to identify the incidence on the development of MDG indicators between the period 2015-2020.

\subsubsection{Trends in the incidence of income poverty}

506. The poverty rate remained relatively stable around 40 per cent between 2001 and 2007. From simulation results, it is suggested that under the reference scenario, the rate of income poverty is expected to drop with a favourable change in other social development indicators; this development will however not make it possible to attain the targets fixed for 2015. In fact, with an average increase in per capita income of 2.3 per cent during the period 2010-2015, the rate of poverty will only attain 35.2 per cent in 2015, largely away from the target of 25 per cent. 
Graph 6: Simulated trends in poverty

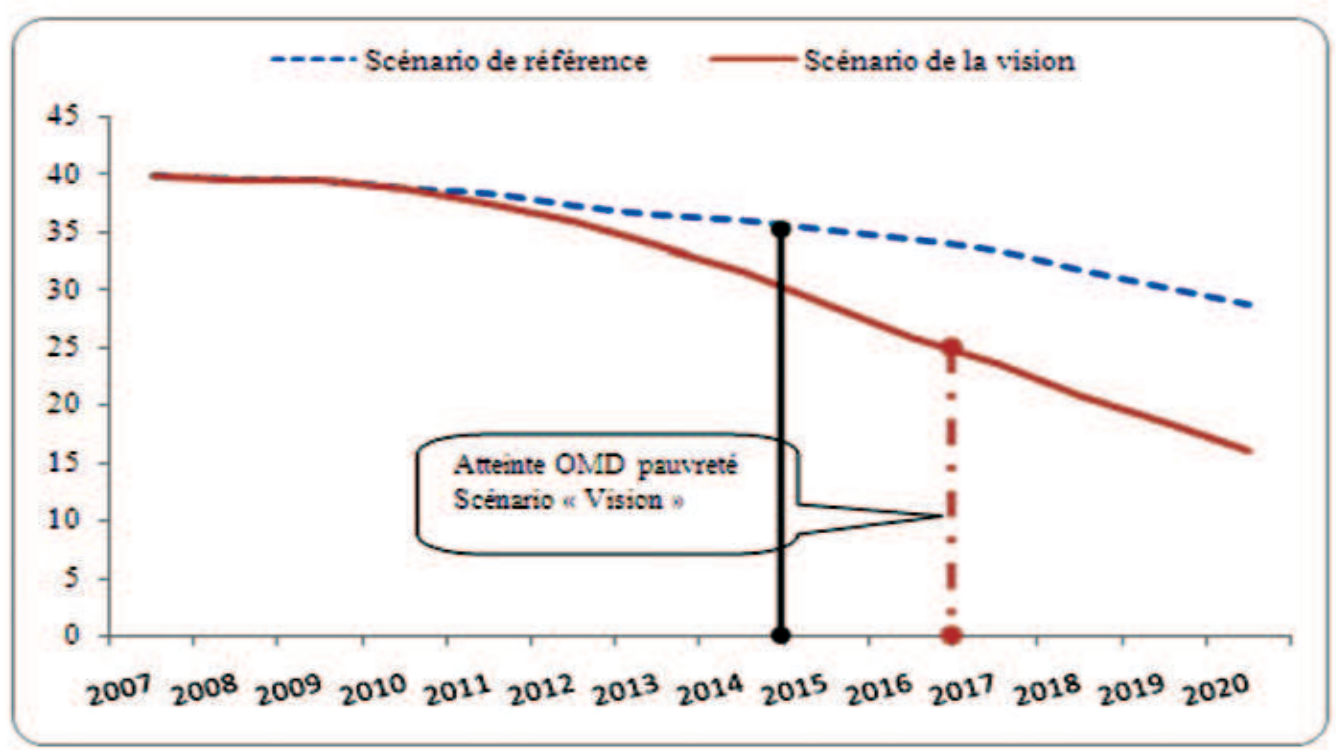

507. On the other hand, by 2020 , forecasts show that there will be improvements which however will not make it possible to envisage the convergence of MDG indicators towards targeted objectives. Thus the poverty rate is expected to stand at 28.7 per cent in 2020, that is, 3.7 per cent lower than the 25 per cent limit. However, under the hypothesis of a low redistributive effect or of excess concentration of fruits of growth, the gap compared to the target may widen.

508. Under the hypothesis of the vision scenario, simulation results show that Cameroon is expected to substantially reduce income poverty. This result will only be possible if growth, sustained at the rate of 7.6 per cent between the years 2012-2017 is accompanied by remarkable progress in pro-poor redistribution of wealth. In fact, the target will be attained in 2017 , two years after the initial estimates.

\subsubsection{Food/Nutrition}

509. The proportion of children below five who are below weight increased from 18.1 per cent in 2004 to 19.3 per cent in 2006, showing that the nutritional state of children still remains a cause for concern, the target in 2015 fixed at $8 \%$ per cent

510. Under the reference scenario, the share of public expenditure in the rural sector (agriculture and stock breeding in particular) will increase from 5.6 per cent in 2009 to 9 per cent in 2020 . This increase translates the will of the government to accelerate growth in agropastoral production. To that end, the percentage of children below 5 who are underweight may reduce rapidly by the time of full implementation of the strategy to 13.3 per cent in 2015 and to 10.2 per cent in 2020 . 
Graph 7: Weight insufficiency rate of children below five (in \%)

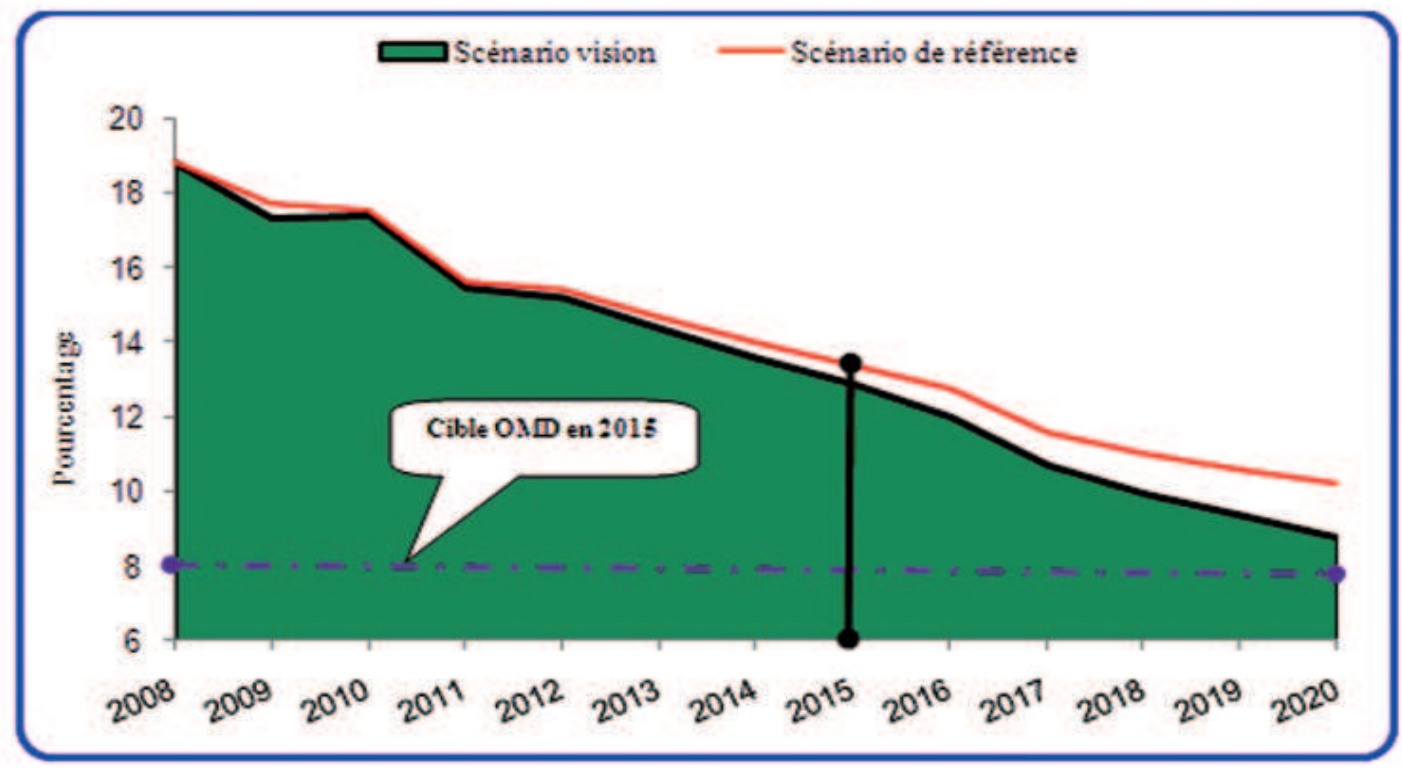

511. As for vision scenario, there will be an expected net improvement in the indicator by 2020: the percentage of children below five who are under weight should be close to the target of 8 per cent.

\subsubsection{Education}

512. The net rate of school attendance in primary ${ }^{13}$ school (6-1 1 years) remained quite stable between 2001 and 2007, whereas the rate of completion is improving relatively, from 59.1 per cent to 71.5 per cent.

513. Under the reference scenario, the share of public expenditure "education" will increase from 15.9 per cent in 2009 to 17.4 per cent in 2020 . On the basis of this, the net rate of primary school attendance will converge around the target of 100 per cent by the time of full implementation of the strategy after stabilizing at 88.6 per cent in 2015 .

514. In the diagram of the vision, progress in education will be faster: the net rate of school attendance in primary schools will be 90.3 per cent in 2015 and will attain the target in 2018 .

Graph 8: Net primary school enrolment ratios (in \%)

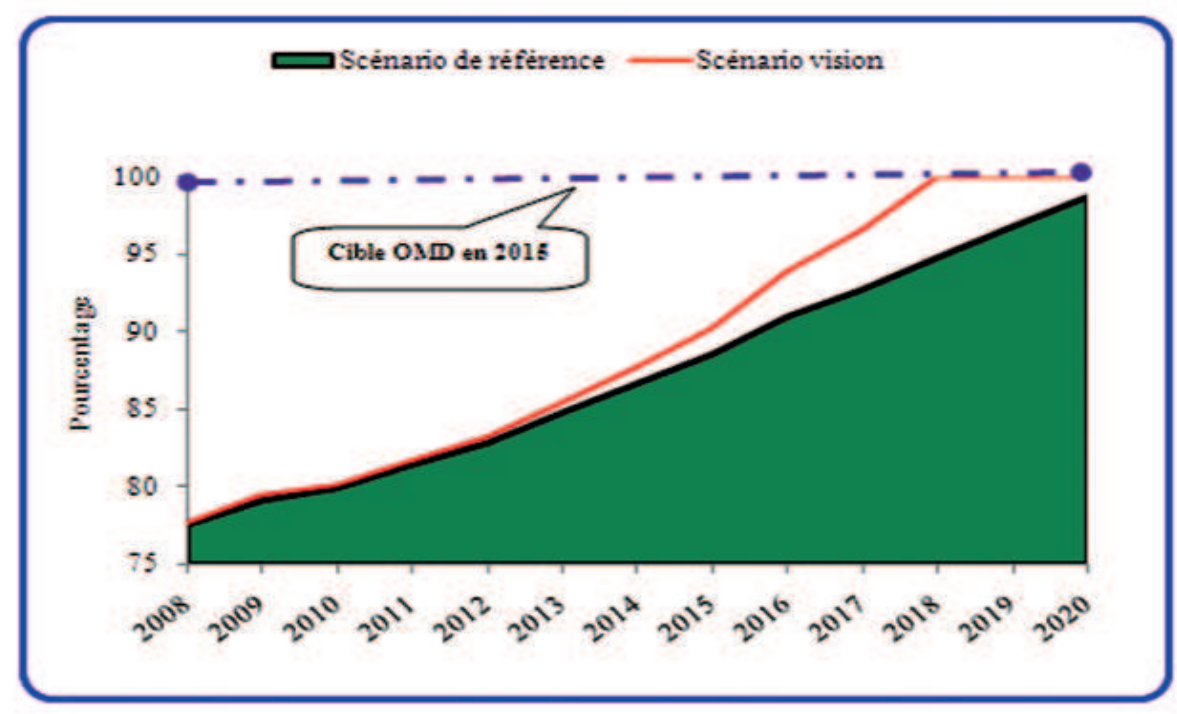

13. Percentage of primary school children (6-11 years) who effectively attend primary school 


\subsubsection{Health}

515. The health situation of the population continues to be a preoccupation for the government: under-five mortality rate, despite an improvement between 1998 and 2004, remains very far from the target. Maternal health has degraded seriously: from 430 deaths of women for 100000 live births in 1998 to 669 in 2004, as against a target of 350 at national level and 108 at international level by 2015 ; the fraction of births assisted by qualified health personnel fell from 62 per cent in 2004 to 59 per cent in 2006.

516. In the reference scenario, the portion of public expenditure for health is expected to increase from 5 per cent in 2009 to 9 per cent in 2020. On this basis and assuming the efficient implementation of the strategy that is being finalized, maternal mortality rate trends will be reversed, standing at 410 in 2015 and reaching its target in 2019 . Considering the vision scenario, the maternal mortality rate will stand at 392 by 2015 and attain its target as from 2017.

Graph 9: Maternal mortality rates (for 100000 births)

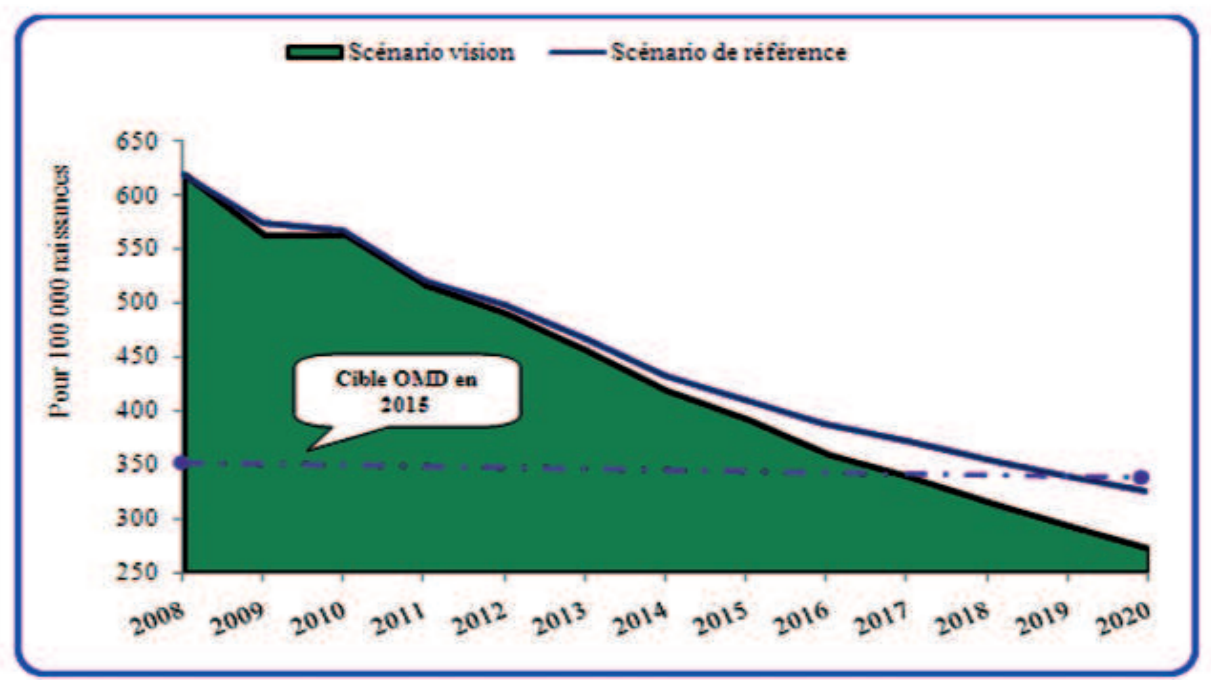

517. On the whole, the outcomes of the impact of growing income poverty and social indicators show that despite the significant effort already made by the government over the past years, much remains to be done concerning resource mobilization and efficiency gain of policies and actions under the different sector strategy programmes.

\subsection{INCIDENCE OF THE REFERENCE SCENARIO ON EMPLOYMENT}

518. The simulation method which was used to assess the impact of generated growth in employment, following the reference scenario, was based on the Okun ${ }^{14}$ law which establishes a comparison between increased activity and job creation. The simulation of employment growth rates for the period 20102020 was based on the elasticity of each activity sector and econometric studies that were conducted by KAPSOS ${ }^{15}$ in 2005. Hence, for the period 1991-2003, one GDP growth point in the primary sector

\footnotetext{
${ }^{14}$ In economics, the Okun law describes the ratio of GDP growth rate to employment rate variation. Below a certain growth rate, unemployment increases; above this rate, it reduces, with constant elasticity. Experts in economics believe the Okun law represents hope that growth may lead to a drop in unemployment.

${ }^{15}$ KAPSOS. S (2005): The employment intensity of growth: Trends and macroeconomic determining factors.
} 
corresponded to 0.77 employment point generated in this sector. Similarly, this elasticity stood at 0.73 in the secondary sector and 0.76 in the tertiary sector.

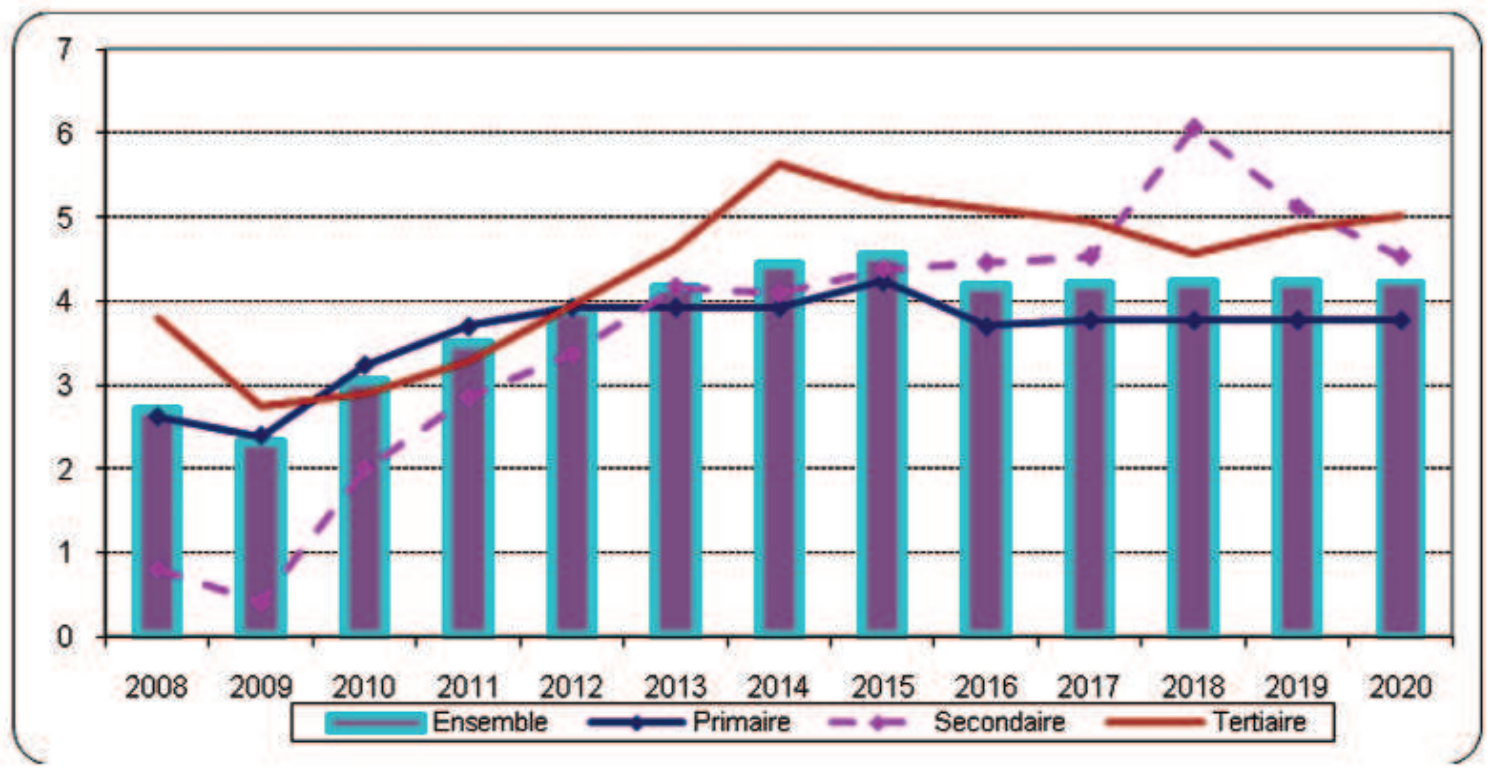

Graph 10 : Trends of employment growth per sector under the reference scenario (in \%)

519. During the period of implementation of GES, it was estimated that the reference scenario growth profile will, in average annual terms, correspond to the creation of about 495000 jobs $(690000$ for the vision scenario), against 490000 over the last ten years. In relative terms, more employment opprotuinites will be created in the tertiary sector, notably, with projected investments in the telecommunication and transport sectors and growth gains from other sectors. This will generate approximately 47500 jobs per year, in relation to improved energy supply and expansion of building construction and public works. The primary sector will continue to be the leading employer, accounting alone for more than $50 \%$ per cent of employment created per year, that is about 281000.

520. An analysis in terms of formal employment shows the creation of about 90000 employment opportunities per year during the period of the strategy. To ensure that local labour benefits from employment creation, the employment and vocational training strategy emphasized the promotion of technical training, particularly in agro-pastoral activities, in order to respond to the expectations from the implementation of major projects. 


\section{CEAPPIPR 7}

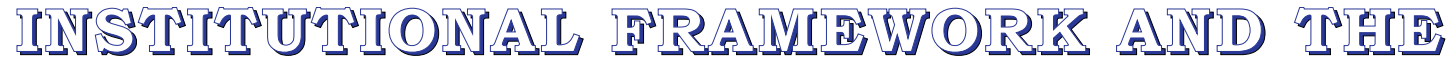

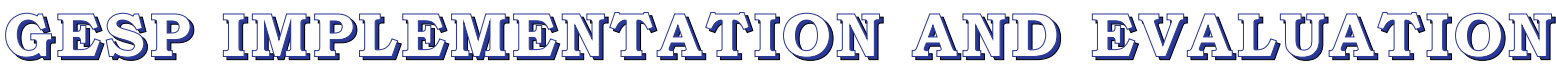 IIICCIANISIII}

\subsection{IMPLEMENTATION INSTITUTIONAL FRAMEWORK}

521. The GESP will be implemented by the State and its external services as principal project owner. Hence, all the ministries, public bodies, local government services and regional authorities will be the institutional players for implementation of the GESP. The private sector and civil society, as partners of the State, will also participate in the definition and execution of some specific components. Development partners will participate in providing appropriate technical and financial assistance to the State and the other development players mentioned above, depending on the needs expressed.

522. The efficient and effective implementation of activities defined in the GESP is crucial to the success of the strategy. Such implementation will be based on an approach that gives priority to the accountability of structures in charge of execution of the different programmes and projects contained in the Strategy, following a line of action in conformity with results-oriented management principles.

523. Hence, accountability in managing the strategy will be shared and exercised within the framework of a partnership, in accordance with the principle of redefinition of the roles of players as adopted during the evaluation of PRSP I and whose Vision for Cameroon by 2035 sets out new guidelines. Therefore, the State will increasingly place its economic role under the paradigm "strategic and pragmatic State", and will focus its action in the areas of development planning, market regulation support to the emergence of the private sector and civil society, in order to enable them better play their roles. Special emphasis will therefore be laid on the capacity building of public and private sector players, civil society, and development of partnerships.

524. Regarding the role of GESP as a national development strategy and a reference framework for government action for the period under consideration, the institutional framework for its implementation will be under the direct authority of the Head of Government. It will be in the form of a GESP monitoring inter-ministerial committee, expected to replace the existing committee and which will be expanded to all the other members of government and, in addition, may meet in a select group, depending on the challenges. It may also, as the need arises, include the participation of representatives of the private sector and civil society. Its main role will be to ensure overall supervision of the implementation of GESP, constantly ensure conformity to the Paris Declaration Operationalization Plan, as well as all government sector plans of action on the priorities defined in the strategy, define plans for mobilizing the resources required for its implementation, adopt the final content of annual programmes to be executed under the GESP priority plan of action and, consequently, define budgetary programming and assess the outputs, effects and impacts of the implementation of GESP on the economic and social development of the country.

525. The inter-ministerial committee will be assisted in the discharge of its duties by a monitoring and evaluation technical committee for the implementation of GESP. Under the authority of the minister in charge of planning, the technical committee, to be chaired by the Secretary-General of this ministry, will be responsible for assisting the inter-ministerial committee in the technical coordination of monitoring and evaluation activities for the implementation of GESP. In this respect, it will conduct the various processes for monitoring and evaluating GESP implementation activities.

526. The technical committee, whose composition will be reviewed to better reflect the diversity of players 
involved in the implementation of GESP, will comprise representatives of the different government services and some public bodies, local and regional authorities, professional associations of the private sector, civil society organizations and the State's technical and financial partners.

527. The technical committee will have a technical secretariat under the authority of the committee chairperson and the technical coordination of a coordinator. It will comprise cadres of economic and financial services, as well as sector ministries. It will carry out the main duties of the technical committee and work in close collaboration with the different MINEPAT and MINFI Regional Delegations, as well as the National Institute of Statistics (NIS). It will have a central coordination unit and theme groups.

528. At local level, GESP monitoring participatory Regional committees will ensure evaluation of the implementation of GESP. They will also be reorganized.

529. The priority actions to be carried out within the institutional framework described above are as follows:

- review of public policies;

- public expenditure programming for the implementation of GESP;

- resource mobilization and establishment of partnerships with a view to GESP priorities;

- specific assessment of employment-related issues and access to public utilities by the poor;

- introduction of a results-oriented monitoring and evaluation system;

- communicating on outputs.

530. Review of public policies. Such review will seek to verify, at regular intervals and at least every three years, the relevance of sector strategies and their coherence, at the conceptual level, with the vision for the development of Cameroon by 2035 and, on the ground, with cross-cutting strategies (development financing, taxation, cooperation/Paris declaration, etc...) and spatial strategies (regional development, regional integration). To this end, the function of planning will be rehabilitated and enhanced within ministries and all the players involved in the implementation chain. The use of practical instruments for strategic planning, risk management, progress assessment and evaluation of activities will be encouraged and made systematic.

531. The issues pertaining to gender and specific groups, as well as those concerning the effects of climate change will be examined in the planning, programming and budgeting phases, in order to sufficiently mainstream them in the economic and social development process.

532. Public expenditure programming for implementation of GESP. It will consist in defining, between three to five years in the medium term, and budgeting on annual basis, concrete actions to be implemented in a coherent manner, through an ambitious but realistic programming of development projects and programmes. This exercise which is crucial to the finanical programming of public policies within a closer period of 3 to 5 years is certainly subjected to the requirement consistency with the GESP which represents the first level of operationalization over an overall period of 10 years, and with the Vision 2035 which is the second level of operationalization over the targeted period of 25 years. It will be based on a set of legal and financial instruments set out according to the different players.

533. At the central level of the State, GESP implementation will be based systematically on sector and ministerial Medium-Term Expenditure Frameworks (MTEF) permitting, on the one hand, major inter-sector and intrasector arbitrations in the allocation of State resources and, on the other hand, providing ministries with budgetary visibility in the medium term, and which is essential for drawing up and adopting their programmes of action, in particular, their Priority Investment Programmes (PIP). The expected results, notably, significant and steady improvement of the quality of public expenditure through better rationalization of annual estimates, will benefit from the generalization of budget-programmes prescribed by the recent law relating to the State financial regime. The direct action of ministries will be supplemented by the introduction of major programmes to combat poverty at the base, programmes rallying the multitude of current initiatives and capable of efficiently channelling State resources and those of its development partners towards micro projects chosen by the people themselves.

534. At the level of local and regional authorities, focus will be on the systematic design of regional and coun- 
cil development plans, in accordance with the powers vested on the said authorities concerning development and planning. The coherence of these regional and council development plans with planning instruments at central level will be done through planning contracts between the State and Regions, on the one hand, and Regions and councils on the other hand. The contracts will, under concrete projects, define the nature and level of participation of each partner.

535. Regarding the private sector, its contribution to the success of GESP implementation will be measured through its capacity to produce wealth and create jobs. In its role of strategic State, and for every major production sector, the State will negotiate medium-term integrated development plans with the private sector, aimed at boosting investment, productivity and the competitiveness of enterprises operating in the sector. It will accompany the efforts made by the enterprises in implementing integrated development plans through : (i) special programmes to enhance competitiveness in sectors with the highest growth potential ; (ii) special programmes to upgrade home SMEs and SMls involved in the execution of major structuring projects in the industrial and infrastructure sector and; (iii) a comprehensive programme to increase the proficiency of enterprises in the other sectors, giving priority to enterprises that contribute to the development of the added value chain. Legal and financial instruments for the implementation of the above-mentioned actions will be direct support framework agreements signed with professional associations in the sectors involved and proficiency contracts concluded with each enterprise benefiting from these programmes.

536. Special attention will be paid to the role civil society organizations can play in GESP implementation. The State will ensure, among others, their significant participation in specific programmes to combat poverty at grassroots level, in the participatory monitoring of public investments and GESP in general. Resources aimed at strengthening their response capability, representation and governance will be expressly provided for in each programme in which they are involved and included in their specifications.

537. Resource mobilization and establishment of partnerships with a view to GESP priorities. Significant effort will be made to mobilize domestic and external resources in order to meet growth and employment challenges which are government priorities for GESP. This commitment will be translated by: (i) pursuing implementation of the programme to streamline and modernize public finances; (ii) reforming the financial sector with a view to enhancing and improving the efficiency of the national financial intermediation system; (iii) stepping up effort to mobilize Official Development Assistance and improve its efficiency, in accordance with the principles of the Paris Declaration; and (iv) intensifying the promotion of the country's image before direct foreign investors, supported by progress achieved in improving governance and the business climate and the establishment of public-private partnership contracts.

538. Systematic continuation of tax reforms and the customs modernization plan, jointly with the sectors' competitiveness programme and the upgrading of enterprises would permit public finances to better resist international financial crisis shocks and shocks expected from trade liberalization within the framework of the Economic Partnership Agreement with the European Union. The Public Finances Modernization Interministerial Committee that was set up recently will be the body in charge of coordinating State activities for implementation of the Public Finances Modernization Programme, a programme supported by technical and financial partners within the framework of dialogue on public finances.

539. The mobilization of development partners in GESP implementation will be carried out through the Paris Declaration Operationalization Plan, multi-annual framework cooperation agreements with each partner and specific agreements for the financing of programmes and projects. The Government indeed intends to propose GESP to all development partners as a reference framework to align their economic and technical cooperation strategies with Cameroon. Hence, implementation of GESP will be subject to permanent and structured dialogue between government agencies in charge of monitoring its implementation and the community of development partners. Such dialogue will seek specifically to: (i) match the assistance strategies of development partners with GESP and MDGs; (ii) harmonize policies and procedures for the intervention of development partners, (iii) allocate resources on the basis of tangible outcomes; (iv) design a performance evaluation system between the government and its partners based on the principles of mutual responsibility accountability and co-responsibility of development assistance outcomes.

540. Specific assessment of employment-related issues and access to public utilities by the poor. Aware that growth alone is not enough to roll back poverty significantly, the government plans to set up a new insti- 
tutional framework to assess employment-related issues and access by the poor to tradable and non-tradable public utilities. To this end, a National Employment Council will be set up, established at regional level as Regional Employment Councils and at local level as Local Development and Employment Support Committees. These consultation bodies will be backed at the operational level by the National Employment Observatory and the National Employment Fund whose reform is envisaged.

541. Regarding access by the poor to public utilities, emphasis will be placed on : (i) rapid creation and functioning of the Rural Energy Fund which will notably give new impetus to the Rural Electrification Programme, (ii) greater efficiency in the execution of rural water supply programmes, notably by giving priority, as much as possible, to the construction of safe drinking water supply networks in councils, because the construction of boreholes and wells is very expensive and, in the end less efficient, and should be reduced to the minimum ; (iii) systematically designing and introducing more efficient mechanisms to promote access by the most destitute to other essential public utilities, with the participation, as much as possible, or even under the leadership of the Regions and councils concerned.

Box 11: Importance of the quality of services to the poor

\section{Forecast of the incidence of income poverty}

The 2004 World Development Report published by the World Bank highlighted certain factors that limit access by the poor to quality public utilities. The report stated that the poor do not have access to such utilities because of bias in favour of the rich, often for political reasons, poor allocation of resources in favour of primary services, absenteeism of poorly remunerated staff and the remoteness of education and health facilities, particularly in rural areas.

Although many countries claim they give priority to social services in their budget programming, they hardly deliver quality services, as shown in the limited impact of public expenditure in the improvement of social indicators.

542. In this respect, civil society will play an important role to educate the population and seek local solutions to the problem of access by the poor to essential public utilities. The different aspects of the multi-dimensional problem of poverty will be taken into account in such a way as to define additional activities under programmes. Different strategies will be designed in rural and urban areas in an attempt to design appropriate integrated programmes defining their specific poverty indexes (poverty threshold, quality of life index, etc) for each area.

543. In the medium term, and within the framework of decentralization, every Region or Division, town or council, will draw up its own programme to fight poverty, in line with the guidelines of the national programme.

544. Introducing a results-oriented monitoring and evaluation system. The GESP information, monitoring and evaluation system will draw from lessons learned and be based on the principles of results-oriented management. This will enable the production of reliable information for better formulating policies, implementing them and ensuring rational use of public resources.

545. Monitoring will be carried out according to a dual approach: monitoring of implementation and monitoring of outputs. Monitoring results will focus simultaneously on means and strategies (resources, activities, products or goods and services delivered). The link between the two is the interaction between means and strategies, on the one hand, and targets, on the other. Targeted outputs must be determined according to means and resources.

546. Hence, the system will be based on the following guiding principles: respect of the mandate of the different structures, definition of procedure manuals and precise performance indicators, production of quality data (reliability, regularity and utility), Use of data for decision making and partnership in designing and managing the system.

547. Specifically, the priority actions will concern: (i) delivery of quality services by all players; (ii) communicating on outputs; (iii) strengthening the statistical information system; and (iv) reviving coordination and follow 
up and evaluation mechanisms.

548. Communicating on outputs. Communication constituted a key element of PRSP I. However, better managed, communication enables to achieve higher outputs by encouraging information sharing, awareness campaigns, participation and ownership of the process by all the actors.

549. The implementation of a communication plan will help in identifying the communication needs of the different actors as well as formats tailored to each user. Similarly, this communication plan will help strengthen dialogue and discussion on key strategy-related issues and facilitate the dissemination of information at all levels. Within this framework, government Internet sites, MINEPAT and NIS could serve as a vehicle to facilitate exchange of information. In the same vein, regular publishing of information bulletins in the audiovisual media and newspapers will be part of means of communicating on GESP and MDGs.

\section{2 MONITORING AND EVALUATION MECHANISM}

\subsubsection{Institutional framework}

550. To be efficient and exhaustive, monitoring and evaluation of GESP implementation requires full participation by all actors involved in implementation of the Strategy. Information gathered from these actors will be centralized and presented to the Inter-ministerial Committee in the form of semester and annual reports on the implementation of GESP.

\subsubsection{Statistical prodecures}

551. For the monitoring and evaluation of GESP, statistical procedures will be based on an information system inspired by CRESMIC and based on the National Statistics Development Strategy (NSDS) adopted by the government after its validation by the National Statistics Council in January 2009.

Box 12: CRESMIC and NSDS

The reference framework for joint minimum methodological support for monitoring PRSP and MDGs (CRESMIC) was drawn up by AFRISTAT.

The National Statistics Development Strategy (NSDS) was validated by the National Statistics Council, with a view to its adoption by the government, will enable SSN to contribute efficiently to the monitoring and evaluation of development policies, programmes and projects.

552. This kind of information is aimed at the timely definition of a common platform for information to public authorities, the private sector, development partners and civil society in order to (a) enable the smooth steering of poverty reduction activities, (b) obtain, through reliable information, the subscription of those concerned by these activities;

553. The system will be organized around: (i) a number of poverty analysis objectives; (ii) a set of quantitative and qualitative indicators; and (iii) collection operations helping to produce these indicators.

554. The need for a new approach stems, on the one hand, from the need to include in GESP monitoring, the specific progress achieved in the attainment of Millennium Development Goals (MDGs) as an international commitment of our country and, on the other hand, to create synergy at the internal level by involving other institutional actors in the analysis of system's outputs, with a view to better formulation and interpretation of actions to be conducted.

555. The specific objectives of this mechanism include (i) improving knowledge on poverty issues; (ii) ensuring harmonization, coherence and coordination of the system of collecting, processing, analyzing and dissemina- 
ting results at all levels; (iii) determining a set of relevant indicators helping to objectively measure the progress achieved in poverty reduction and human development ; (iv) measuring outputs, effects and impact of activities periodically ; $(v)$ ensuring accessibility of reliable information to all actors and; (vi) building the capacities of national structures in monitoring and evaluation.

556. Four dimensions and three sub-systems were identified for setting up an operational SIRP. The four dimensions include:

- Human resources dimension: this seeks to promote a programme for building operational capacities in a context marked by scarcity of human resources, particularly for sector statistical services.

- Institutional dimension: it consists especially in strengthening coordination of SSN in view of "optimal" dissemination of information. It is at this level that issues relating to financing the system to ensure the sustainability of quality production and better dissemination of statistical data will be managed. These activities will be directed by the National Statistics Council in its projected new organization.

- Spatial dimension : this represents the "specifications" of the information system that must specify information to be gathered and how to organize information for each priority sector, sensitive geographic zone, population type, etc as well as disaggregation levels to be retained.

- Time dimension: this concerns the introduction of an impact assessment system of actions undertaken. This dimension seeks to ensure regular reporting and measuring the rate of changes recorded as compared to set objectives. This supposes the production, at given intervals, of a progress report to be notified to all the stakeholders, including their possible feedbacks.

557. The three sub-systems are as follows:

- The poverty monitoring and household living conditions sub-system: is concerned with the systematic production of indicators on household living conditions and/or basic information for each priority domain defined in GESP. It especially provides output indicators and impact indicators based on approaches of income poverty, lack of basic needs, lack of skills or opportunities or social exclusion. This will be the responsibility of NIS and SSN.

- The GESP programmes and projects execution monitoring sub-system: mainly concerns input and output indicators for physical and financial information to be produced at central and local level, based on the Medium-Term Expenditure Framework (MTEF) and programme budgets.

- The policies or programmes impact assessment sub-system: concerns specific studies. These studies have a more limited scope and are aimed at assessing whether the activities undertaken in favour of target groups effectively achieved the expected outcomes. This sub-system helps to ensure coherence between the first two sub-systems and provides material for the formulation of policies.

558. The link between the three sub-systems stems from the logical chain of the outputs of a project or programme. To attain objectives in economic policy monitoring and strengthen the concept of accountability, this mechanism proposes a list of indicators and a number of statistical operations to be carried out in order to ensure the production of the selected indicators. These statistical operations are contained in NSDS which is in line with GESP, and the list of indicators is provided in the annex of the document.

559. The role of the National Institute of Statistics (NIS) is crucial in the organization and functioning of the information system. The mandate of NIS and role it is expected to play in supporting policies and strategies will be further clarified.

560. The operationalization of this mechanism is in line with implementation of the National Statistics Development Strategy (NSDS), one of whose major challenges to date, if not the most important, is the strengthening of institutional coordination mechanisms in order to ensure better monitoring of GESP and MDGs. 


\subsection{PARTICIPATORY MONITORING}

561. The overall purpose of participatory monitoring is to institute constructive and durable dialogue between the different actors (State/private sector/civil society/development partners). The government intends to introduce a system for the participatory monitoring of GESP whose basic information coordination and management unit will be the council. To this effect, the institutional mechanism for participatory fmonitoring will comprise four levels: national, regional, divisional and council.

562. At national level, monitoring and evaluation activities will be carried out by ST/CTSE. It will be the backbone of the mechanism and in charge of monitoring implementation of GESP in every domain. At local level, monitoring and evaluation will be carried out by local participatory monitoring committees.

563. Participatory monitoring of GESP will be that aspect of its monitoring and evaluation which enables public authorities, private sector, civil society, development partners and target groups to consult regularly on: the level of execution of programmes, output evaluation, impact assessment, choice of corrective actions in case of malunctionings and the quality of constructions.

564. The main objectives are notably to: ensure ownership of the participatory development process, improve transparency and accountability of the different actors, improve the quality and relevance of services (especially as concerns public utilities) and control of the GESP monitoring process.

565. Different actors were identified and their roles summarized below:

- Target groups and beneficiary communities: They should organize themselves to define their needs and priorities. Similarly, it is partly their duty to control the effectiveness and quality of the constructions.

- Locally elected officials (Mayors, Members of parliament, Senators): they must report on implementation of the poverty reduction strategy in their localities. They are expected, in the light of GESP, to propose accompanying measures and actions at their level to help improve implementation of the strategy. They are the people's representatives and hence have a key role in making proposals to update implementation and monitoring of the strategy.

- Administrative services: must supervise GESP implementation and ensure participatory monitoring. It is the key actor in the implementation of the strategy and, in this capacity, must ensure actual delivery of the envisaged public utilities. They design the key monitoring indicators.

- Civil society: is the key instrument in safeguarding governance-related concerns, as a power-check and partner in GESP implementation. It ensures that the government honours its commitments and is accountable for its actions. It particularly safeguards the interests of vulnerable groups.

- Development partners: they act as an external regulatory instrument of the process by ensuring the effective participation of every player in the participatory monitoring of the strategy. They also make concrete proposals and provide multi-faceted support at all stages of participatory monitoring.

- Private sector: In keeping with State divestiture from the productive sector and the liberalization of the economy, the private sector was recognized as the engine of growth, a major employer and the State's partner in implementing the strategy. It presents to the other actors involved in participatory monitoring, particularly to the primary targets, actions that will be carried out at its level. 


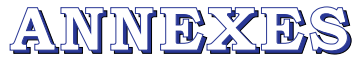




\begin{tabular}{|c|c|c|c|c|c|}
\hline No & Indicator & $\begin{array}{l}\text { Baseline } \\
\text { Year }\end{array}$ & 2010 & 2015 & 2020 \\
\hline \multicolumn{6}{|c|}{ Macroeconomic framework } \\
\hline \multirow[t]{3}{*}{1.} & GDP growth rate & & & & \\
\hline & Reference scenario & $2.5(2009)$ & \multicolumn{3}{|c|}{$\begin{array}{c}>5.4 \text { (annual average for the } 2010-2020 \\
\text { period) }\end{array}$} \\
\hline & Vision scenario & $2.5(2009)$ & 3,0 & 7,7 & 10,0 \\
\hline 2. & Inflation rate & $5.3(2008)$ & \multicolumn{3}{|c|}{$<3 \%$ (CEMAC convergence criteria) } \\
\hline 3. & $\begin{array}{l}\text { Primary budgetary balance excluding oil } \\
\text { (GDP \%) }\end{array}$ & $-5.7(2008)$ & -5.2 & -4.2 & -3.0 \\
\hline 4. & $\begin{array}{l}\text { Balance of payment current account (GDP } \\
\% \text { ) }\end{array}$ & $-1.0(2008)$ & -5.4 & -1.4 & -2.6 \\
\hline 5. & Money supply (GDP \%) & $19.7(2008)$ & 21.1 & 21.1 & 22.4 \\
\hline 6. & Credit to the Economy (GDP \%) & $11.8(2008)$ & 12.7 & 13.6 & 15.4 \\
\hline & Credit to the State (GDP \%) & $-5.5(2008)$ & -1.3 & -1.0 & -0.7 \\
\hline \multicolumn{6}{|c|}{ Real sector } \\
\hline \multicolumn{6}{|c|}{ 8. Overall investment rate (GDP \%) } \\
\hline & Reference scenario & $17,9(2008)$ & 19,7 & 22,0 & 24,5 \\
\hline & Vision scenario & $17,9(2008)$ & 19,7 & 25,4 & 33,2 \\
\hline \multicolumn{6}{|c|}{ 9. Public investment rate (GDP \%) } \\
\hline & Reference scenario & $2,9(2008)$ & 3,0 & 2,9 & 2,6 \\
\hline & Vision scenario & $2,9(2008)$ & 3,0 & 3,9 & 3,6 \\
\hline & GDP pattern & & & & \\
\hline & Primary sector & $20,9 \%(2008)$ & $21,9 \%$ & $20,0 \%$ & $18,9 \%$ \\
\hline & Secondary sector & $31,5 \%(2008)$ & $24,8 \%$ & $24,0 \%$ & $23,4 \%$ \\
\hline 12. & Tertiary sector & $47,6 \%(2008)$ & $53,2 \%$ & $56,0 \%$ & $57,7 \%$ \\
\hline \multicolumn{6}{|c|}{ Poverty and living conditions } \\
\hline & Total population (in million inhabitants) & 17,1 & 20,0 & 23,0 & 26,5 \\
\hline & GDP growth rate/capita & $-0,4$ & \multicolumn{3}{|c|}{$\begin{array}{l}>2.5 \text { (annual average for the } 2010-2020 \\
\text { period) }\end{array}$} \\
\hline 15. & Poverty incidence $(\%)$ & $39,9(2007)$ & $\cdot$ & 35,2 & 28,7 \\
\hline & Proportion of underweight chidren (\%) & $18,1(2007)$ & - & 8 & - \\
\hline & $\begin{array}{l}\text { Maternal mortality rate (for } 100000 \text { live } \\
\text { births) }\end{array}$ & $669(2004)$ & & 410 & 325,6 \\
\hline 18. & Urbanization rate & $50,1(2003)$ & - & 55 & 57 \\
\hline \multicolumn{6}{|c|}{ Formation and use of human capital } \\
\hline & $\begin{array}{l}\text { Primary school completion rate (\% of } \\
\text { corresponding age group) }\end{array}$ & $64 \%(2007)$ & 63,2 & 78 & 95 \\
\hline 20. & $\begin{array}{l}\text { Proportion of students enrolled in scientific } \\
\text { and technical courses in secondary school } \\
(\%)\end{array}$ & 10 & 11 & 13,4 & 16,4 \\
\hline 21. & $\begin{array}{l}\text { Proportion of students enrolled in scientific } \\
\text { and technical courses at university (\%) }\end{array}$ & 5 & 5,5 & 7,7 & 10,8 \\
\hline \multicolumn{6}{|c|}{ Infrastructure } \\
\hline & Proportion of tarred road network (\%) & $10(2008)$ & 10,3 & 12,6 & 17 \\
\hline 23. & Energy consumption per GDP unit (\%) & 27,7 & 30,0 & 33,5 & 35,0 \\
\hline 24. & Digital access index & 0,16 & 0,17 & 0,21 & 0,26 \\
\hline & $\begin{array}{l}\text { Number of land and mobile telephone lines, } \\
\text { and subscribers per } 100 \text { inhabitants }\end{array}$ & 10,3 & 15,1 & 25,9 & 40,5 \\
\hline
\end{tabular}




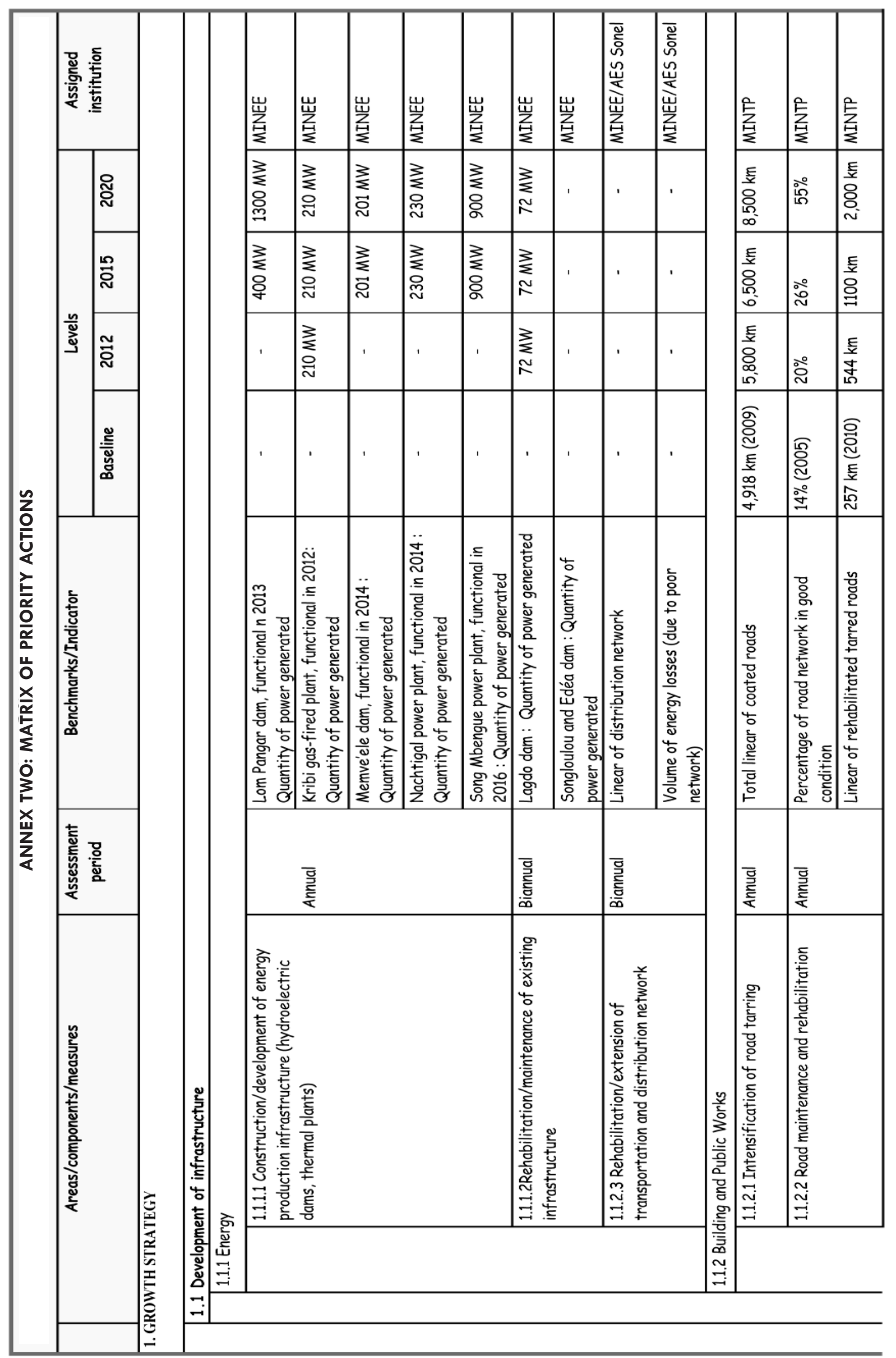




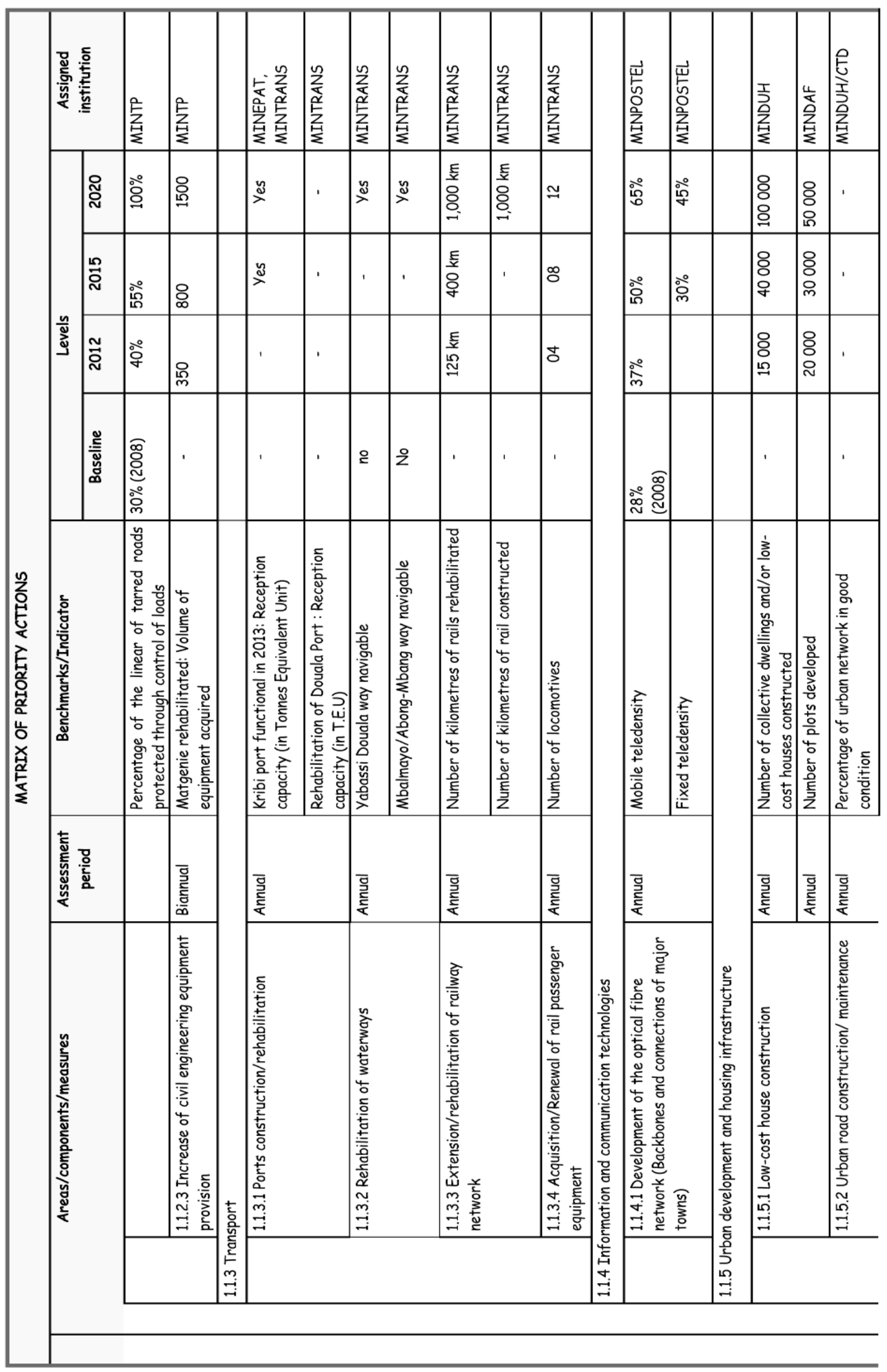




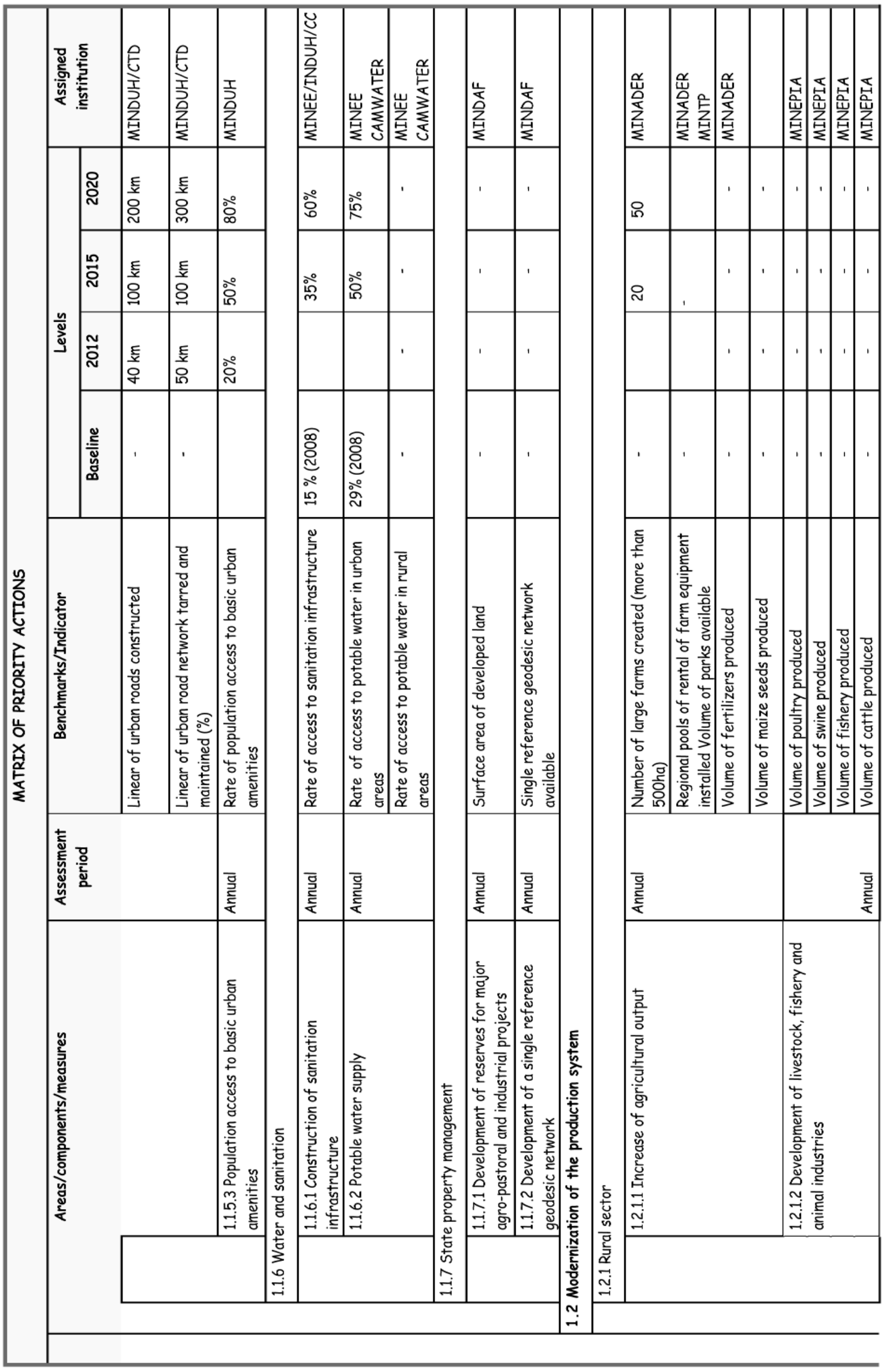




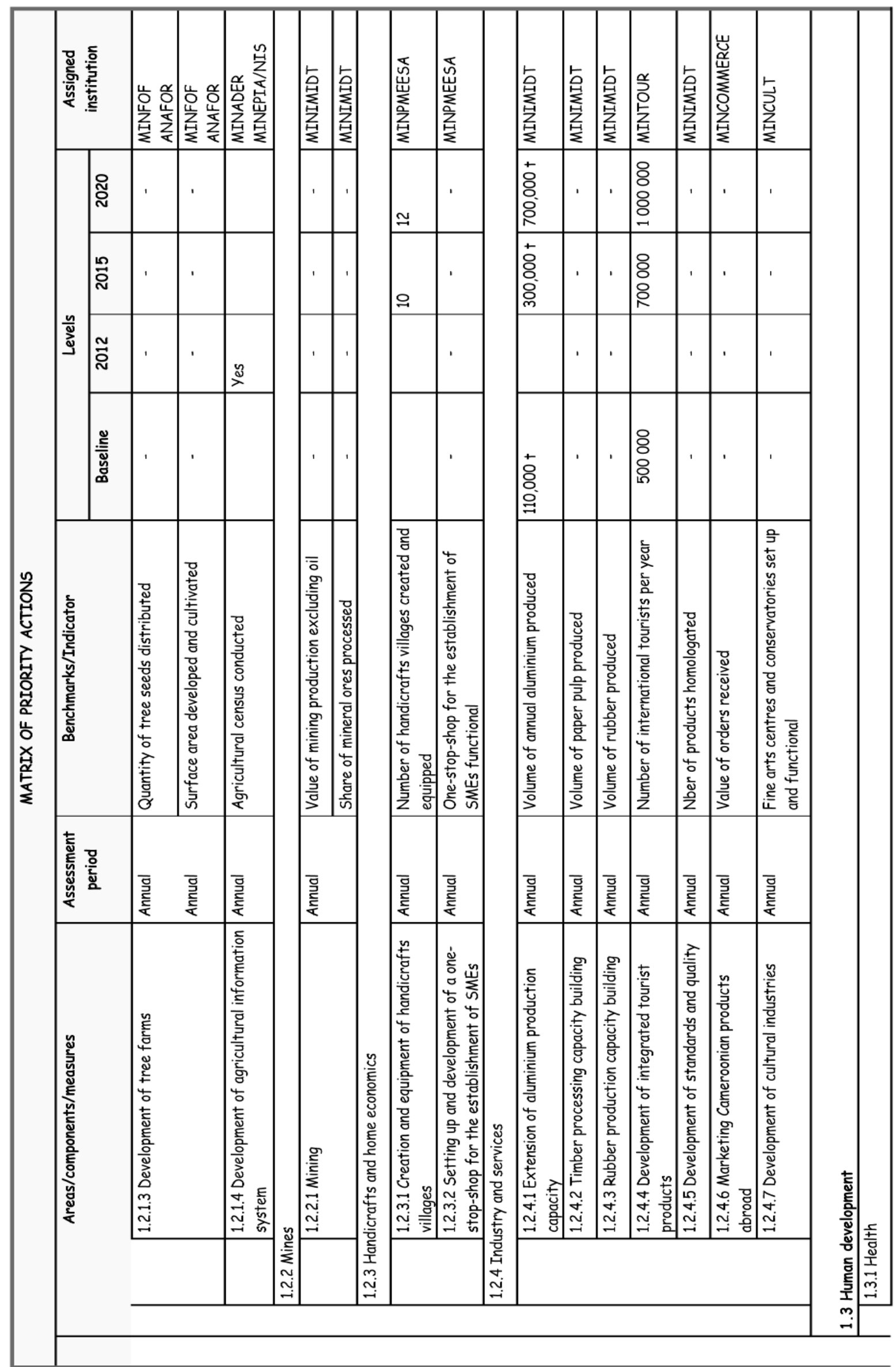




\begin{tabular}{|c|c|c|c|c|c|c|c|c|c|c|c|c|c|c|c|c|}
\hline & 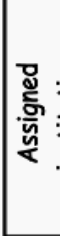 & & 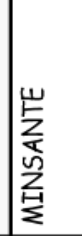 & 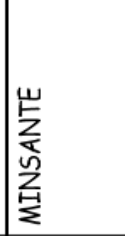 & 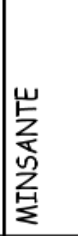 & 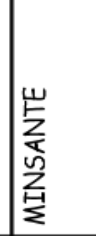 & 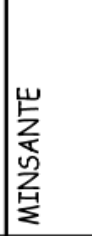 & 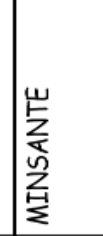 & 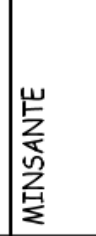 & 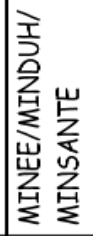 & 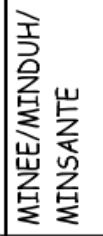 & 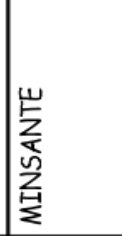 & 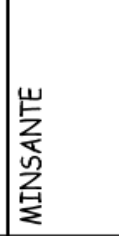 & 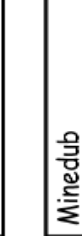 & 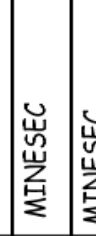 & \\
\hline & & జั๊ & ठ̊ํ․ & to & ॐ̊ำ & $\stackrel{\circ}{\circledR}$ & ' & ठ̊ํ & ठ̊ำ & ○ें & ஓ̊ & ठั̊ & 茅 & ठ̊ㅇ & & \\
\hline & & 恣 & ळे & 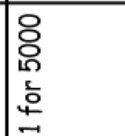 & ठั้ & ठ̊̊ & ' & ठ̊ํㅇ & ウ̊ำ & 器 & ถึ่ & ळें & o̊ & ஓ̊ & ' & \\
\hline & בับ & $\cong$ & ठ্ं & 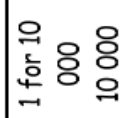 & ڤ̊ำ & ○े & ' & ठ̊ํㅇ & ஓ̊ & ठ̊ํ & ठ̊ํㅇ & প̊̊̆ & ○̊ำ & ' & ' & \\
\hline & & 蒙 & 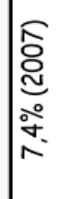 & 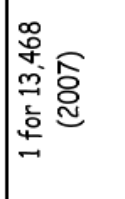 & 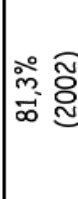 & 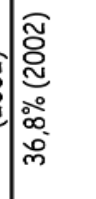 & 命 & | & 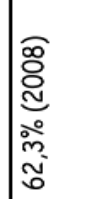 & 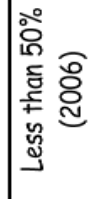 & 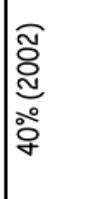 & 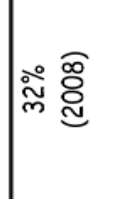 & 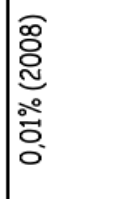 & 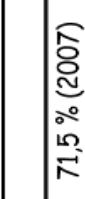 & & \\
\hline 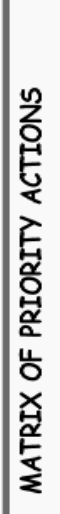 & 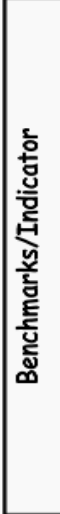 & & 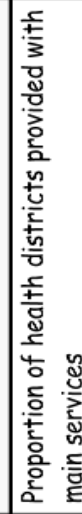 & 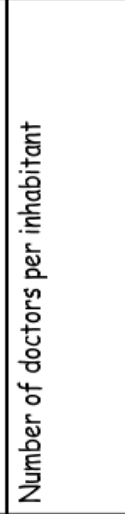 & 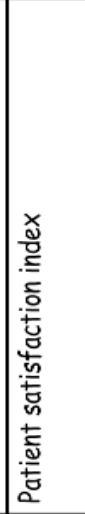 & 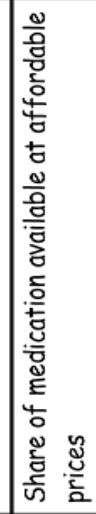 & 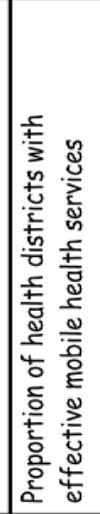 & 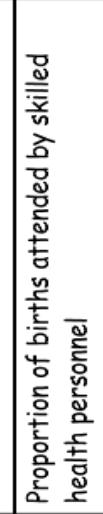 & 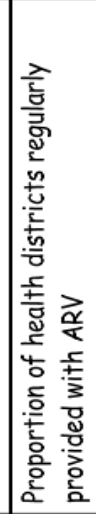 & 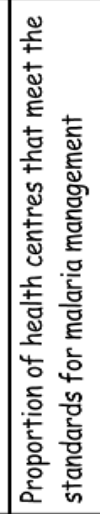 & 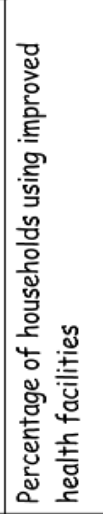 & 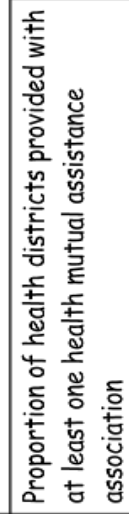 & 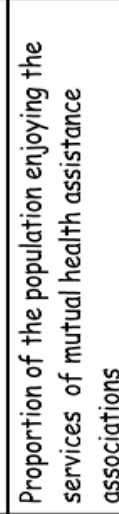 & 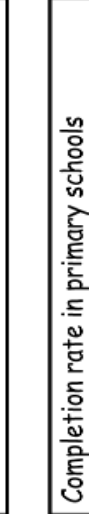 & 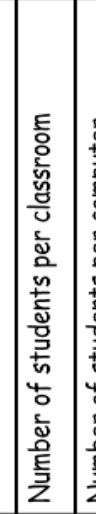 & \\
\hline & 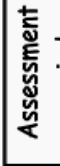 & & 哥 & $\mid \bar{x}$ & 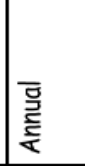 & 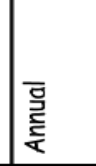 & 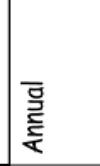 & 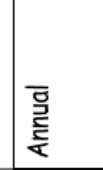 & 可 & 哥 & 可 & 可 & 哥 & 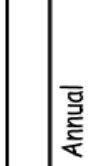 & $\mid \overline{\underline{g}}$ & \\
\hline & 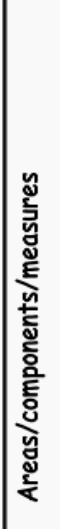 & & 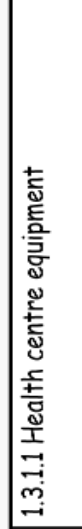 & 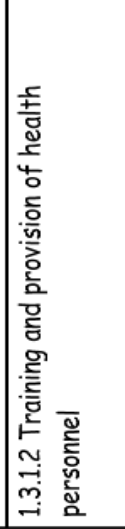 & 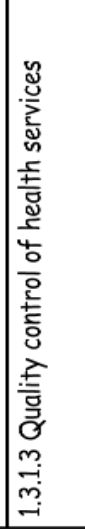 & 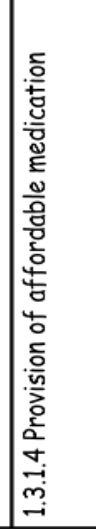 & 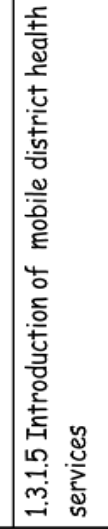 & 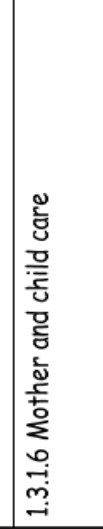 & 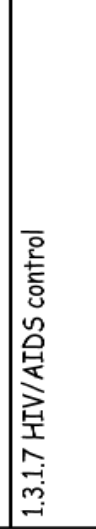 & 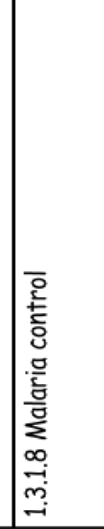 & 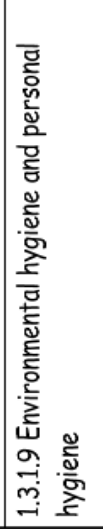 & 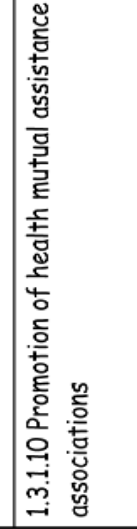 & & 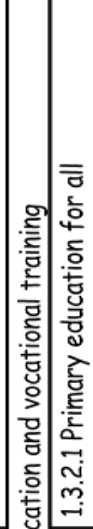 & 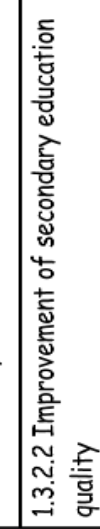 & \\
\hline & & & & & & & & & & & & & & 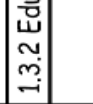 & & \\
\hline
\end{tabular}




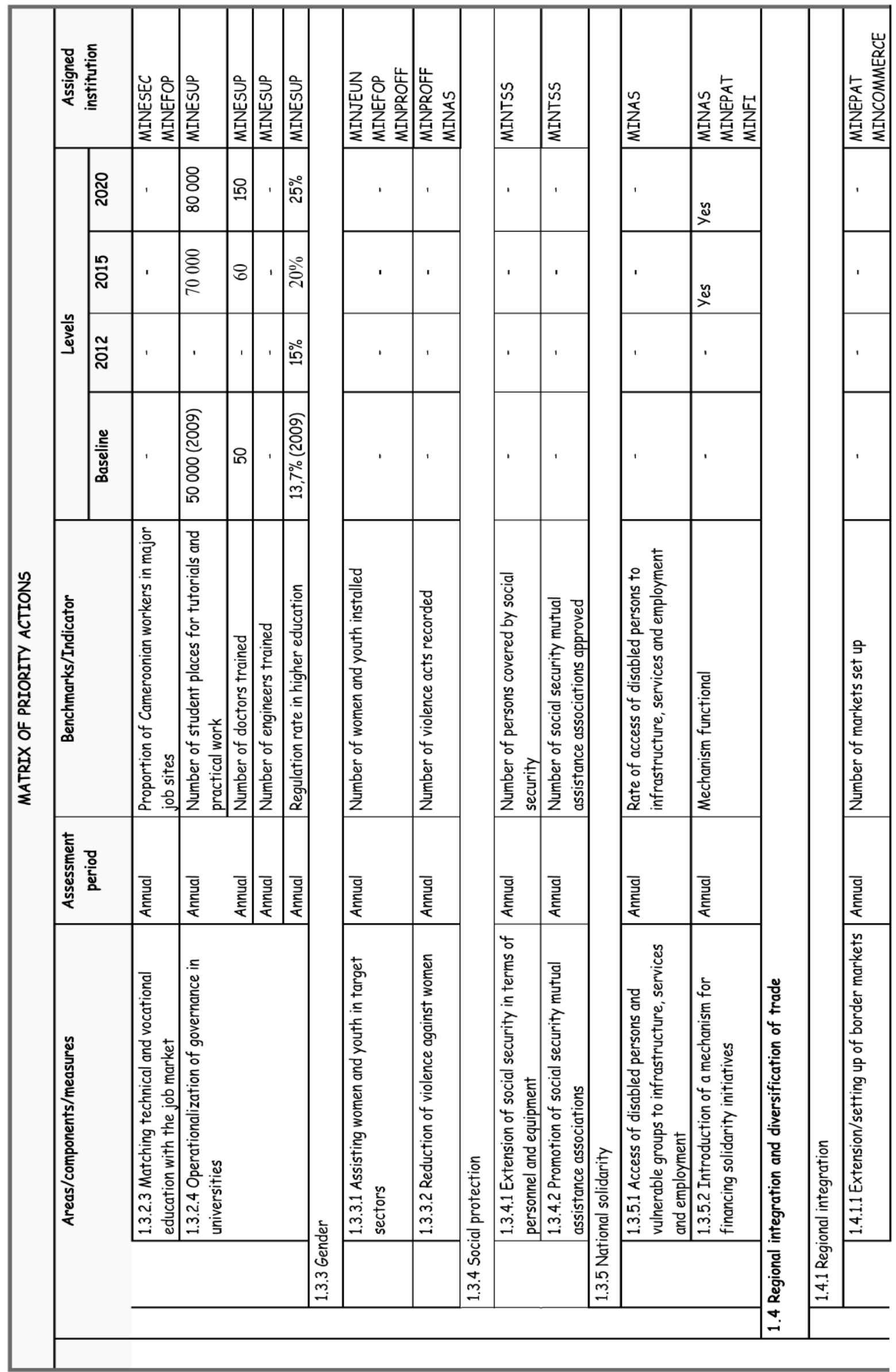




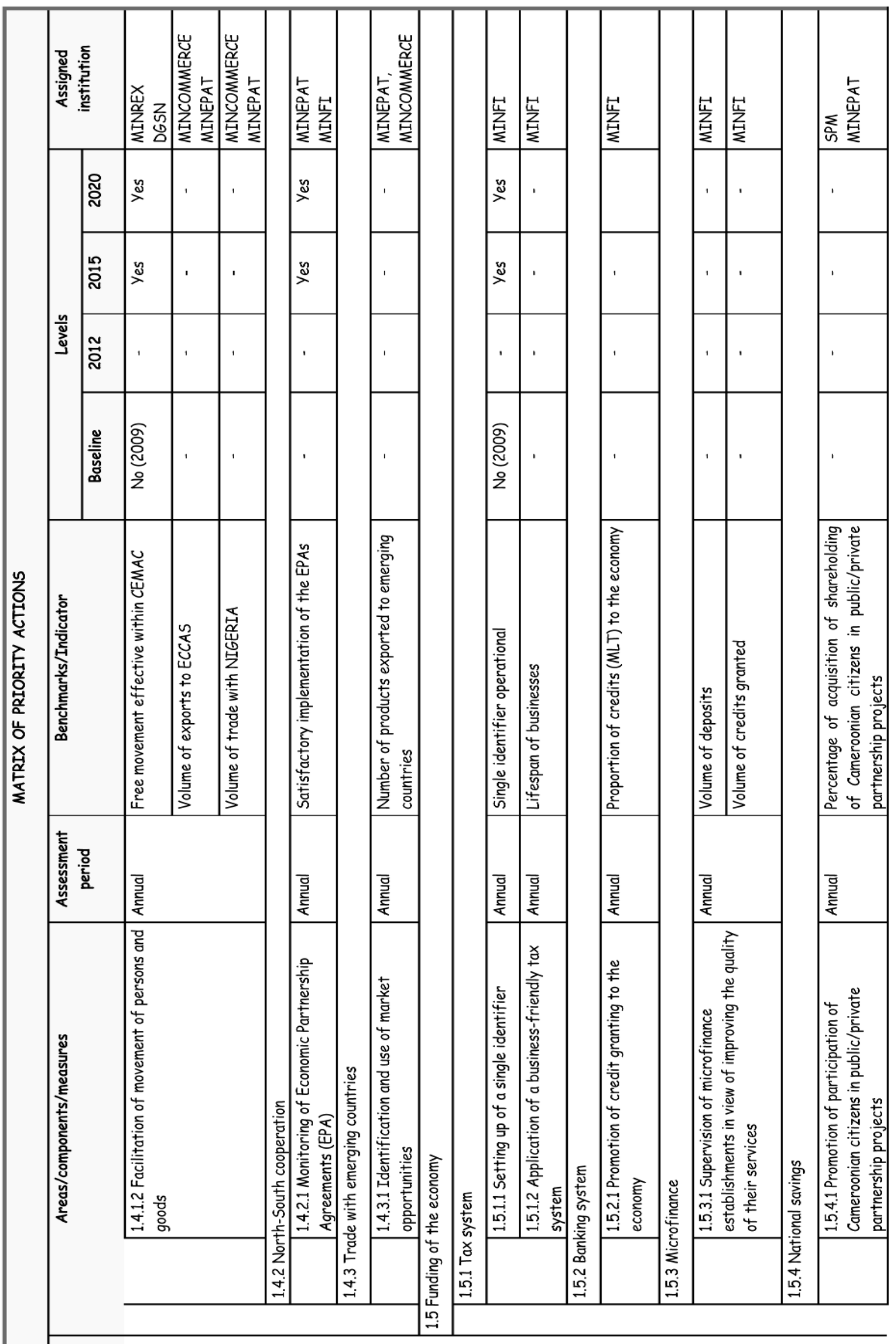




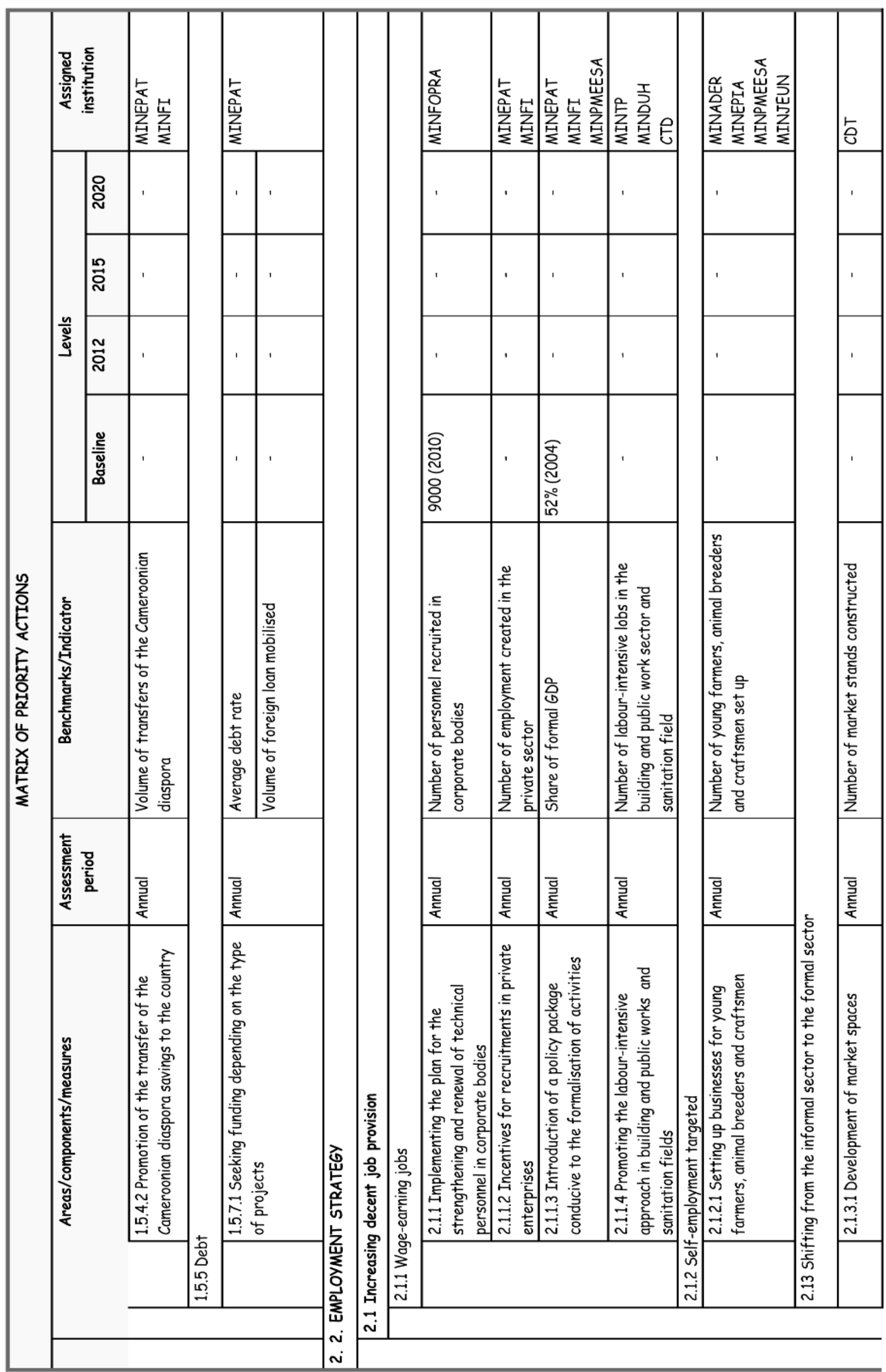




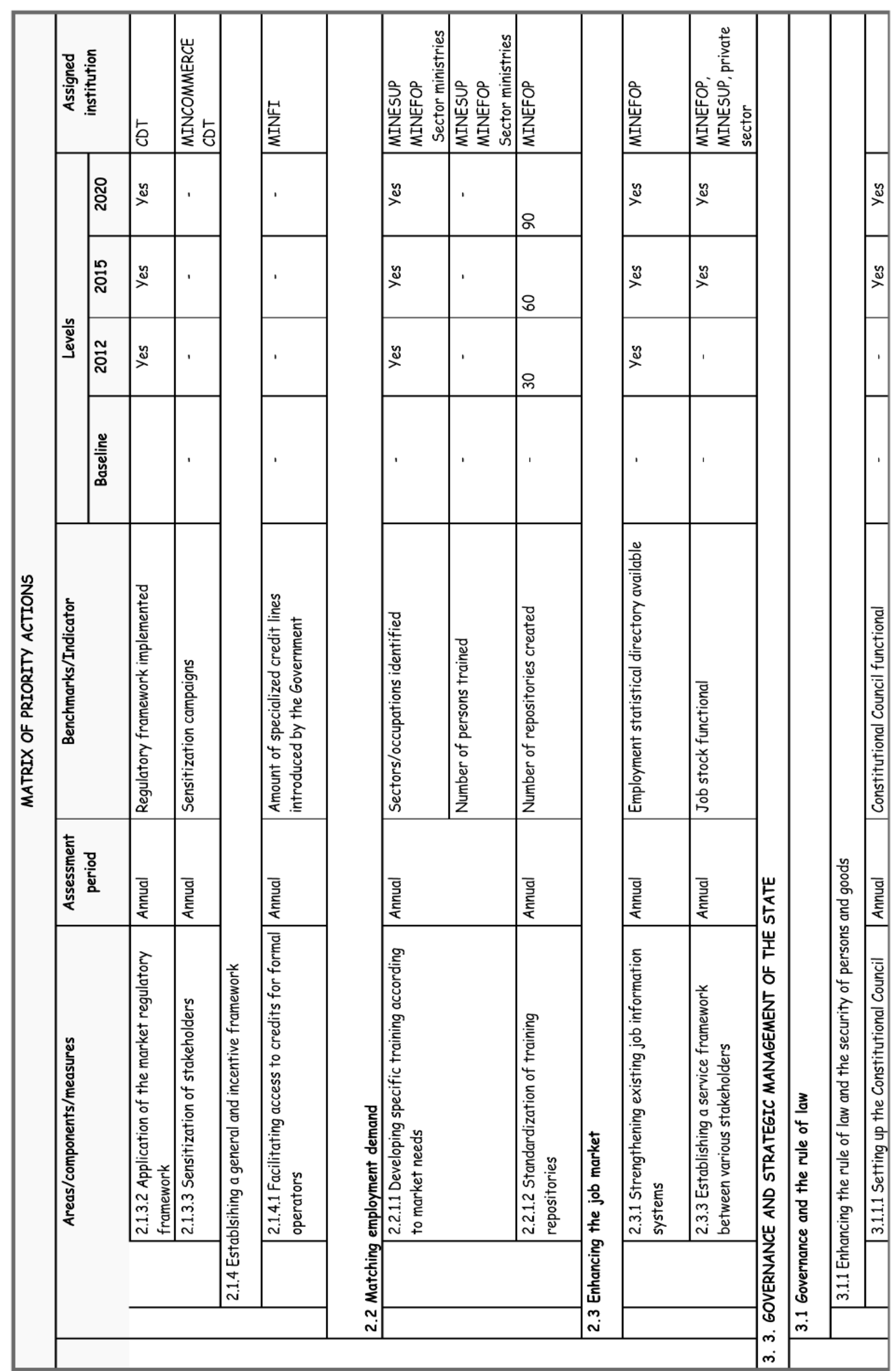




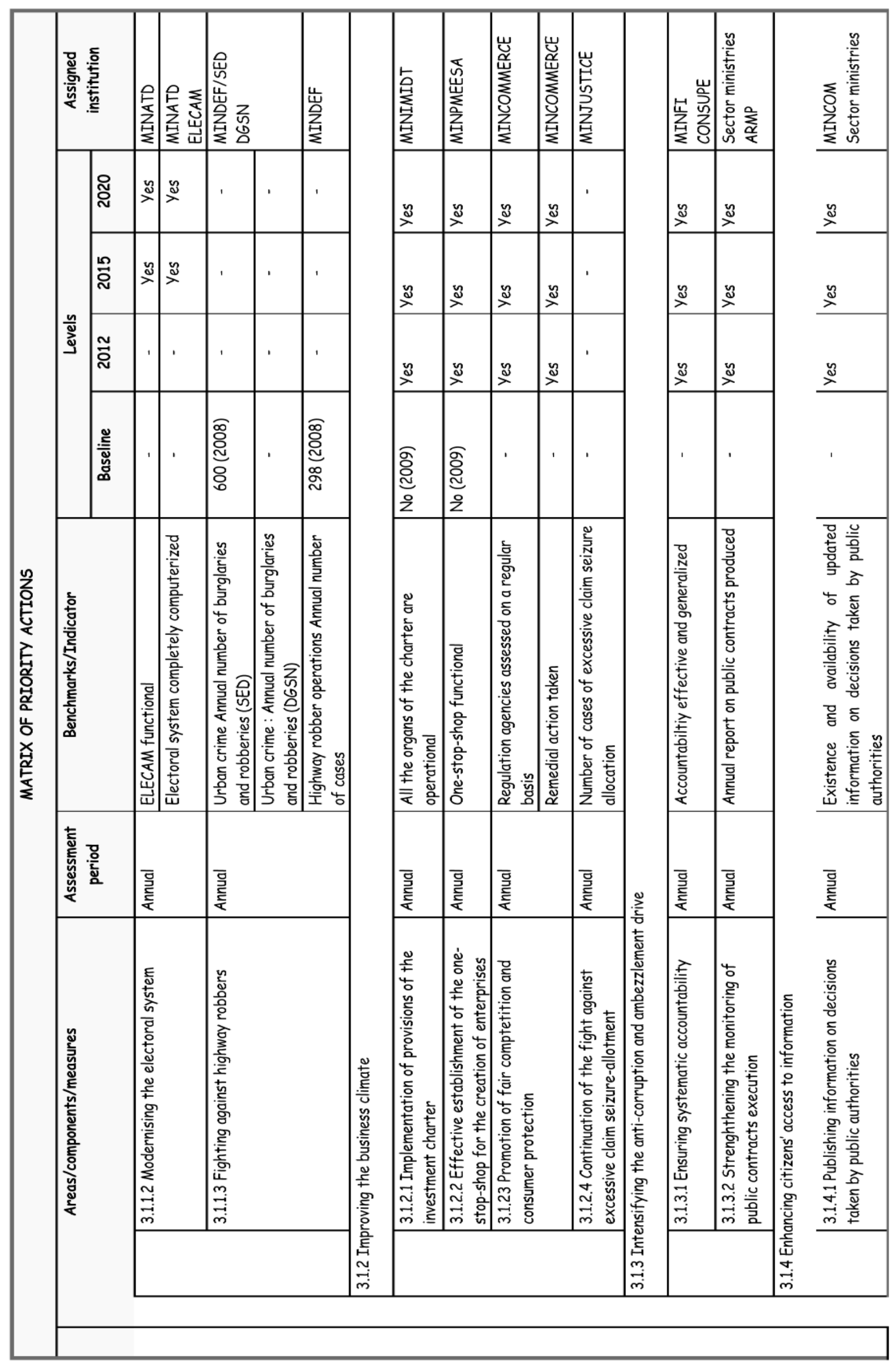




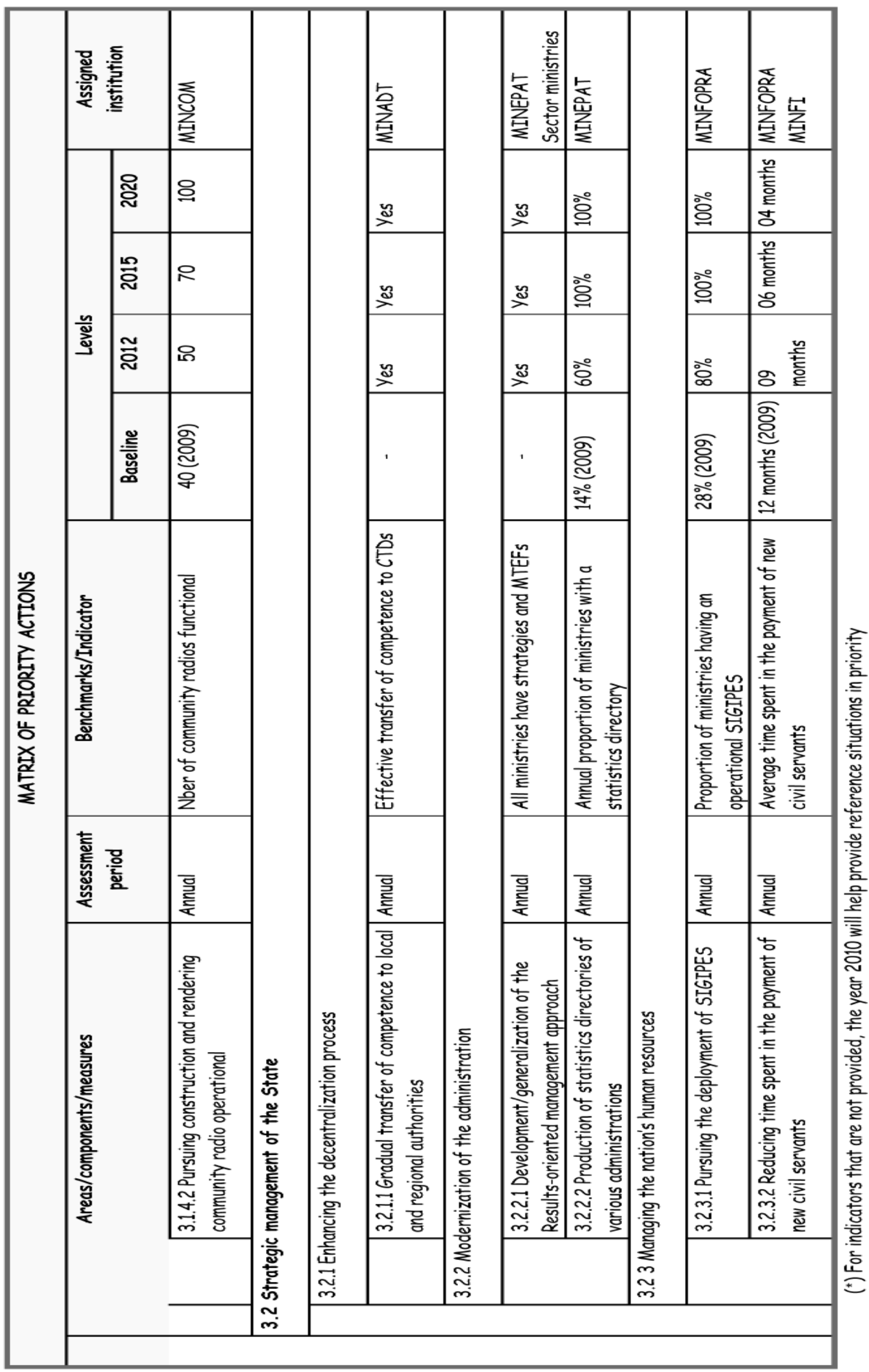


ANNEX THREE: LIST OF ADDITIONAL INDICATORS FOR MONITORING SECTOR PROGRAMMES

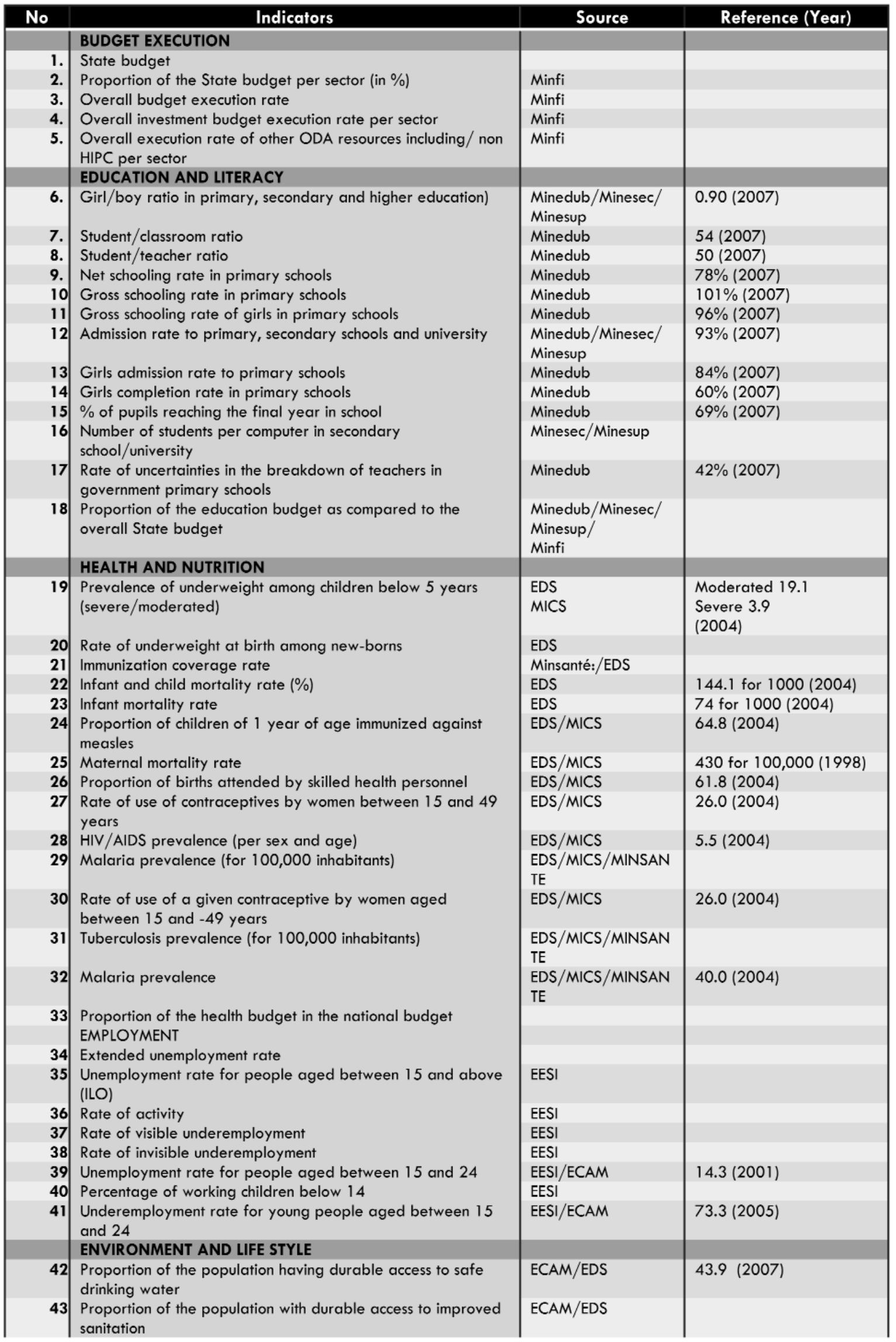




\begin{tabular}{|c|c|c|c|}
\hline No & Indicators & Source & Reference (Year) \\
\hline 44 & $\begin{array}{l}\text { Percentage of households with improved and functional } \\
\text { latrines }\end{array}$ & ECAM/EDS & $44.7(2001)$ \\
\hline 45 & Proportion of households with a TV set & ECAM/EDS & \\
\hline 46 & $\begin{array}{l}\text { Percentage of households using solid fuel (wood and by- } \\
\text { products) }\end{array}$ & ECAM/EDS & $82.4(2001)$ \\
\hline 47 & $\begin{array}{l}\text { Proportion of the population living in houses built with durable } \\
\text { material }\end{array}$ & ECAM & $22.7(2001)$ \\
\hline 48 & Electrification rate per settlement & ECAM/EDS & \\
\hline 49 & Urbanization rate & & $50.1(2003)$ \\
\hline 50 & Proportion of protected land for biodiversity conservation & MINEP & $13.0(2000)$ \\
\hline 51 & Number of micro-computers per 100 inhabitants & $\begin{array}{l}\text { ECAM/SCAN- } \\
\text { ICT/ART/UIT }\end{array}$ & $10(2006)$ \\
\hline 52 & Number of Internet users per 100 inhabitants & $\begin{array}{l}\text { ECAM/SCAN- } \\
\text { ICT/ART/UIT }\end{array}$ & $5.2(2006)$ \\
\hline 53 & Number of fixed telephone lines per 100 inhabitants & $\begin{array}{l}\text { ECAM/SCAN- } \\
\text { ICT/ART/UIT }\end{array}$ & $0.3(2007)$ \\
\hline 54 & $\begin{array}{l}\text { Number of mobile telephone line subscribers per } 100 \\
\text { inhabitants }\end{array}$ & $\begin{array}{l}\text { ECAM/SCAN- } \\
\text { ICT/ART/UIT }\end{array}$ & $17.1(2007)$ \\
\hline & INFRASTRUCTURE AND ENERGY & & \\
\hline 55 & Linear of national tarred roads & MINTP & \\
\hline 56 & Linear of rural roads maintained & MINTP & \\
\hline 57 & Linear of rehabilitated roads & MINTP & \\
\hline 58 & Number of newly electrified households & MINEE/AES Sonel & \\
\hline 59 & Number of households newly supplied with water & $\begin{array}{l}\text { MINEE/Camerounais } \\
\text { e des Eaux }\end{array}$ & \\
\hline & RURAL SECTOR & & \\
\hline 60 & Production of basic agricultural and forest export products & $\begin{array}{l}\text { MINCOMMERCE/MI } \\
\text { NADER/MINEF }\end{array}$ & \\
\hline 61 & Production of basic food and fishery products & MINADER/MINEPIA & \\
\hline 62 & $\begin{array}{l}\text { Number of schools/vocational training centres for the rural } \\
\text { trade }\end{array}$ & $\begin{array}{l}\text { MINCOMMERCE/MI } \\
\text { NADER/MINEF }\end{array}$ & \\
\hline 63 & $\begin{array}{l}\text { Number of active youth that received assistance for the } \\
\text { creation of SME/VSE in rural areas }\end{array}$ & MINJEUN/MINEFOP & \\
\hline 64 & Average duration of preventive detention & $\begin{array}{l}\text { MINJUSTICE/Courts } \\
\text { of Appeal }\end{array}$ & \\
\hline 65 & Percentage of listed cases sentenced & $\begin{array}{l}\text { MINJUSTICE/Courts } \\
\text { of Appeal }\end{array}$ & \\
\hline 66 & Percentage of public resources allocated to local authorities & MINADT/DGB & \\
\hline 67 & Rate of excision & EDS/MICS & \\
\hline 68 & Percentage of women head of households & ECAM & \\
\hline 69 & $\begin{array}{l}\text { Female/male literacy ratio (among the population aged } \\
\text { between } 15 \text { and } 24 \text { ) }\end{array}$ & ECAM & \\
\hline 70 & Girl/boy ratio in primary education & Minedub & \\
\hline 71 & Girl/boy ratio in secondary education & Minesec & \\
\hline 72 & Girl/boy ratio in higehr education & Minesup & \\
\hline 73 & Proportion of women working in the non agricultural sector & ECAM & \\
\hline 74 & Participation rate based on gender & ECAM & \\
\hline 75 & Number of posts held by women in the national parliament & NIS/MINATD & $19(2002-2007)$ \\
\hline
\end{tabular}




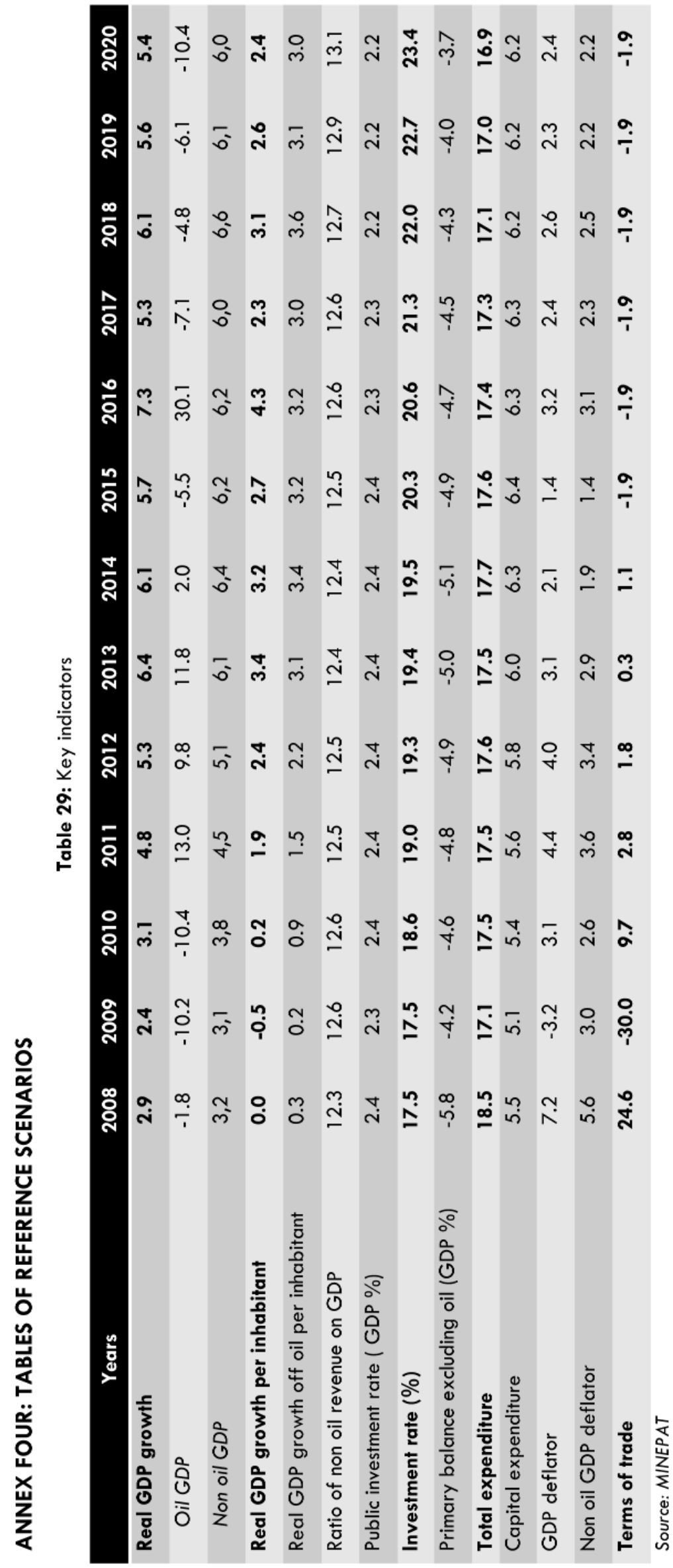




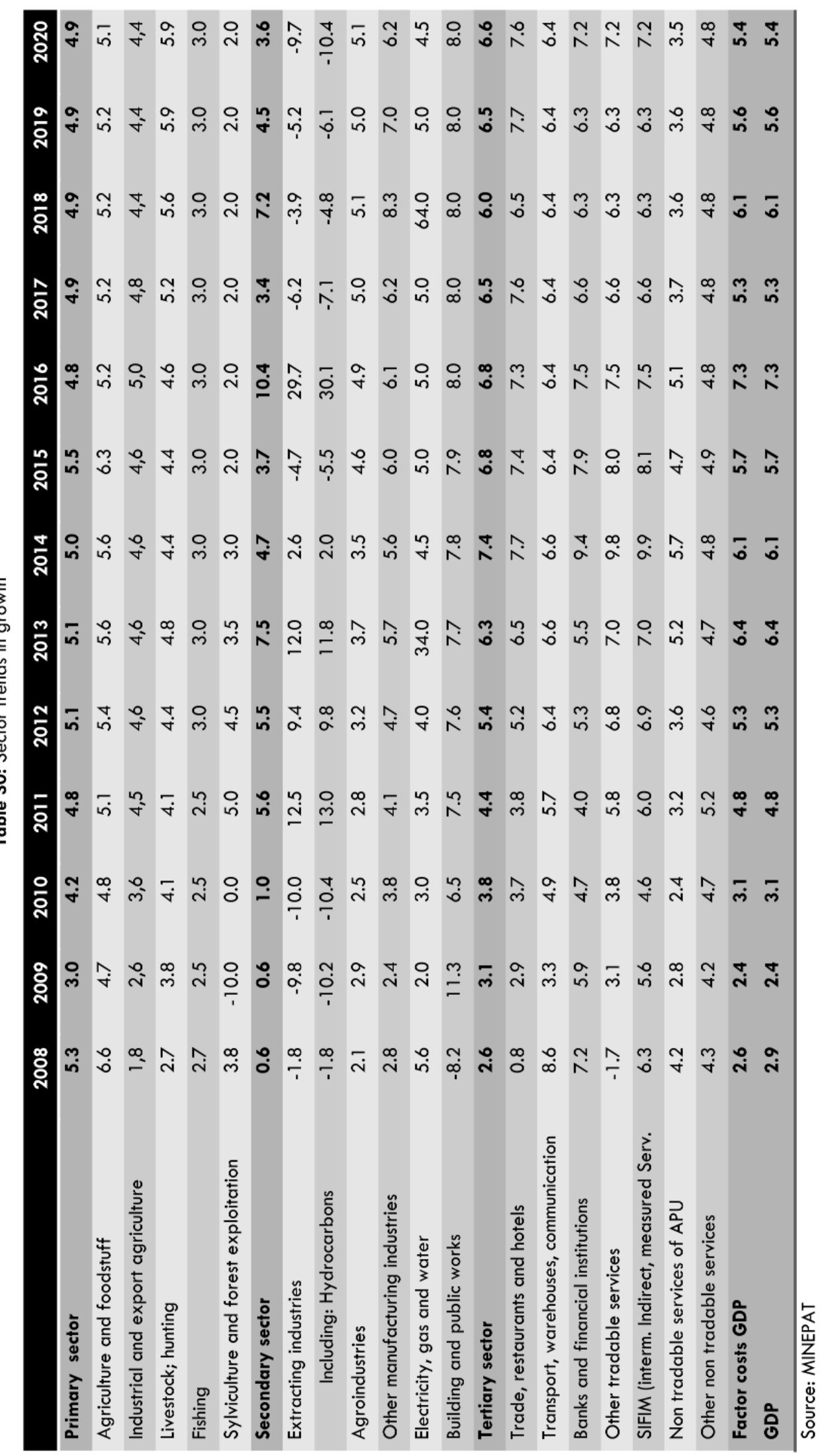




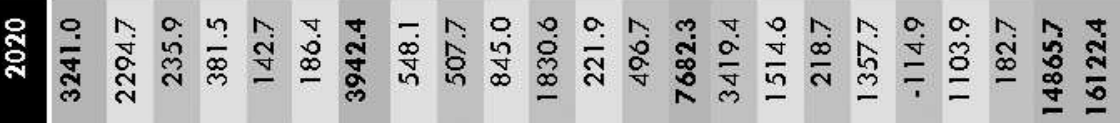

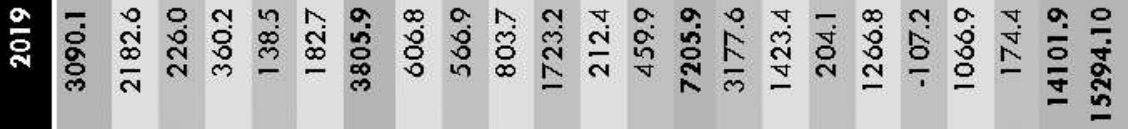

赵 वे वे స ल

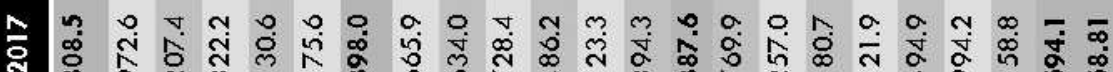
๙

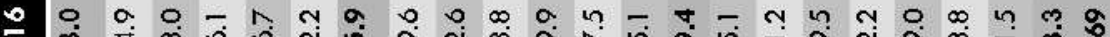

Бิ

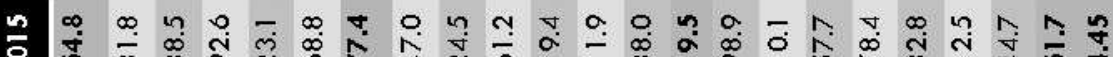
究

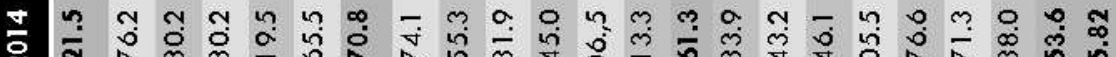
สิ

m- $\infty$ 4

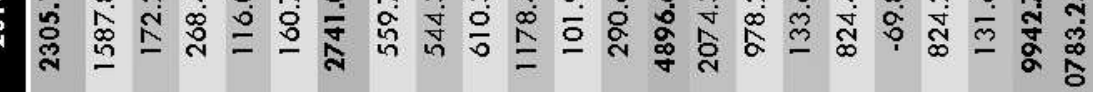

ป

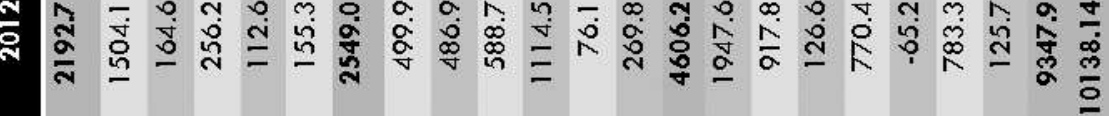

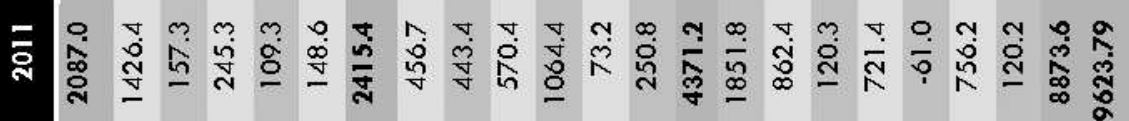

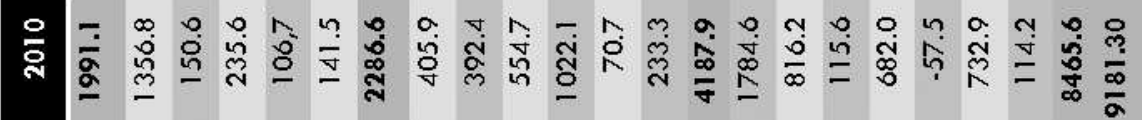

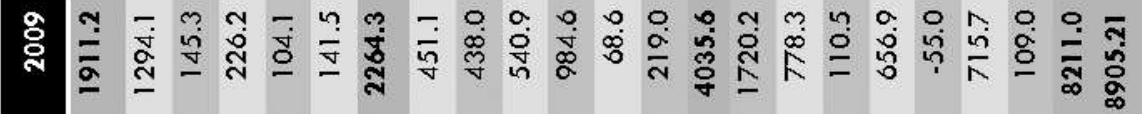

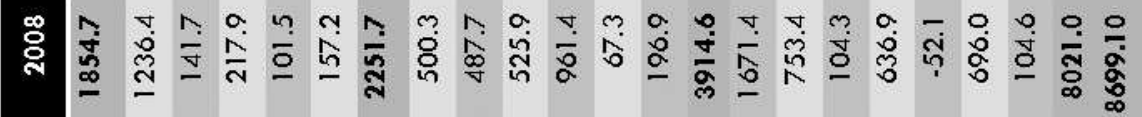

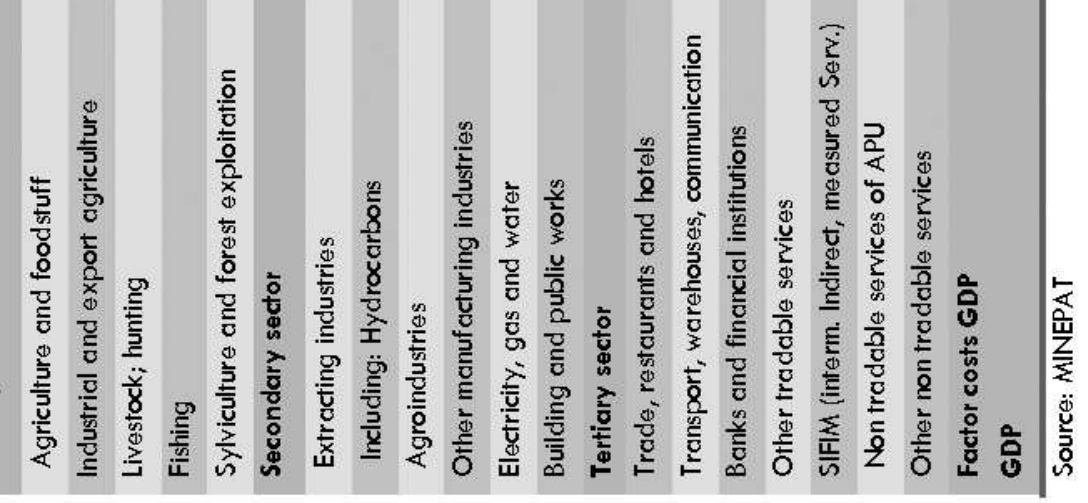




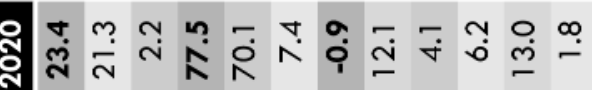

a ชิ



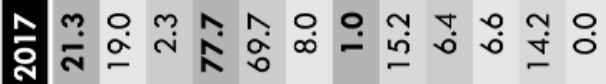

잉

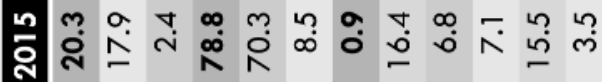
व

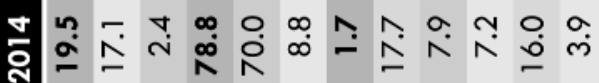

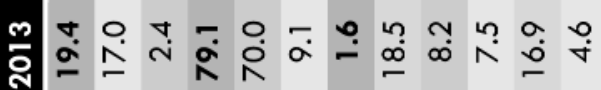

হั)

= กิ

은

응

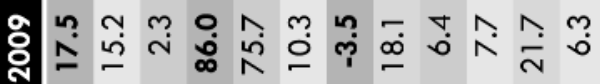

ஜํำ

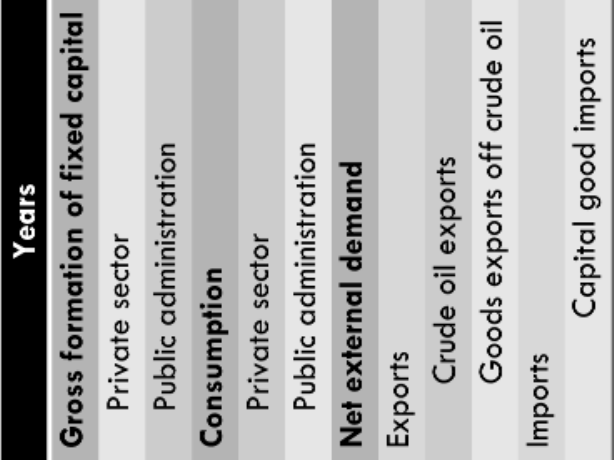

ชิ

可

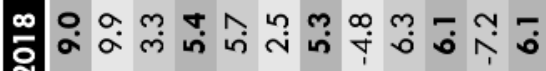

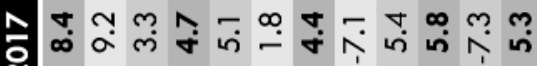

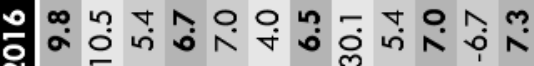

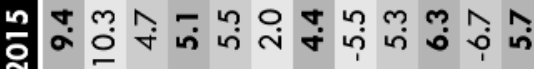

은

㸴

$\frac{\overline{0}}{\frac{\mathrm{n}}{2}}$

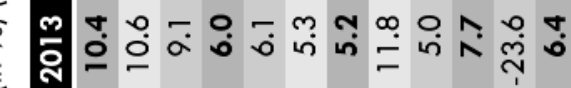

$\frac{5}{\frac{5}{3}}$

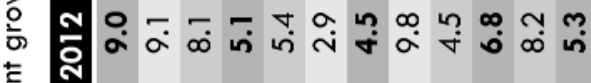

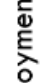

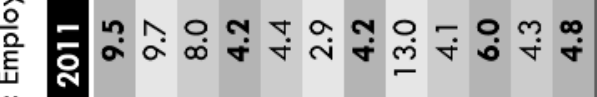

$\ddot{m}$

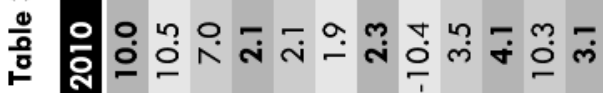

\&্ำ

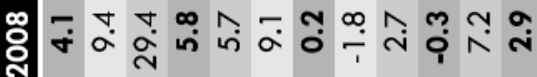

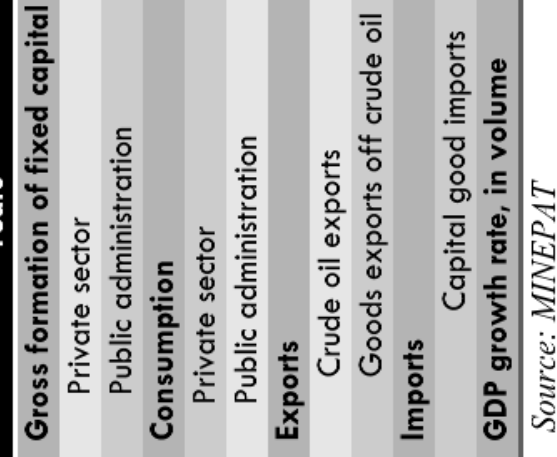




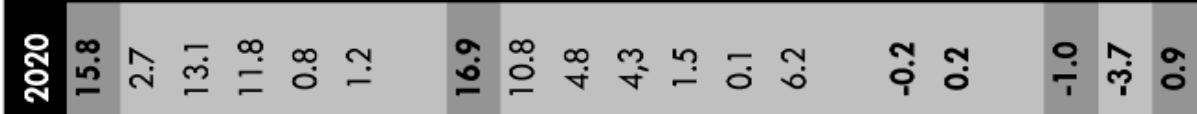

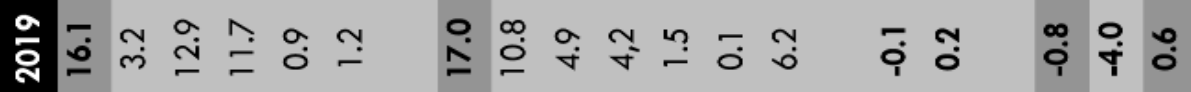
产苞

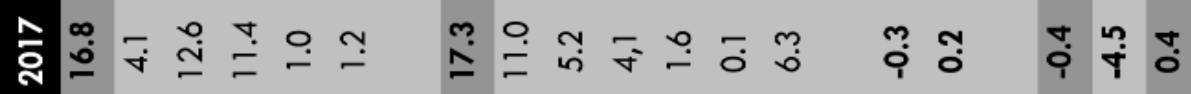

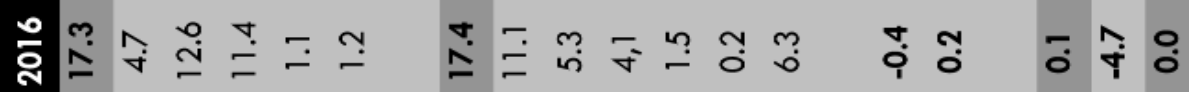

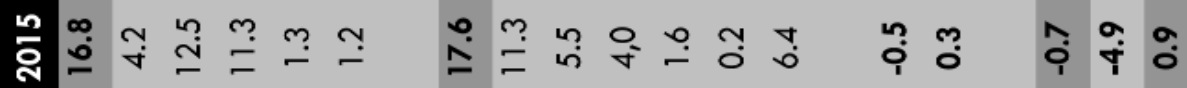
$\stackrel{\Xi}{\circ}$

ปั่ ○.

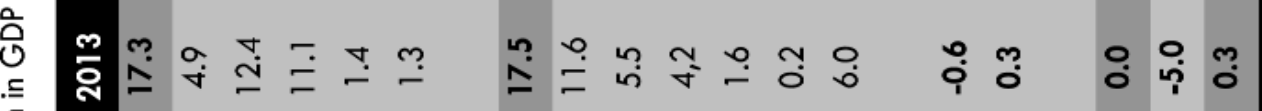


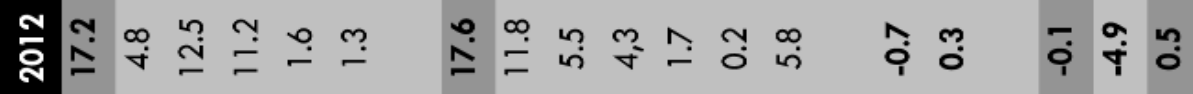

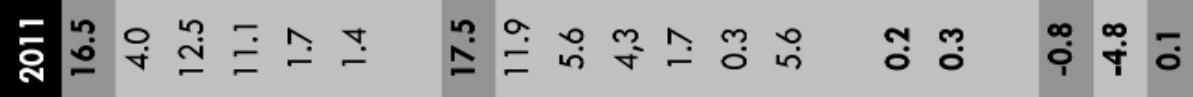

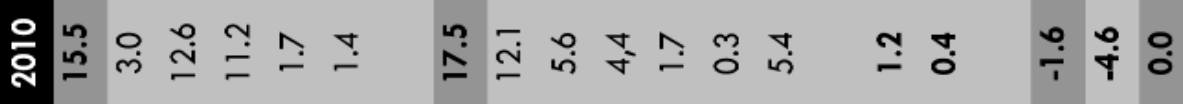
চั

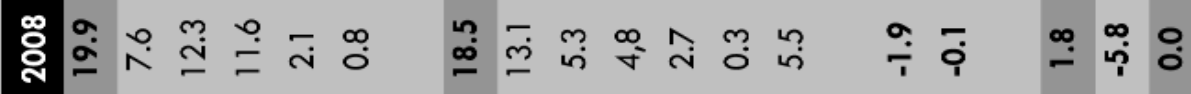

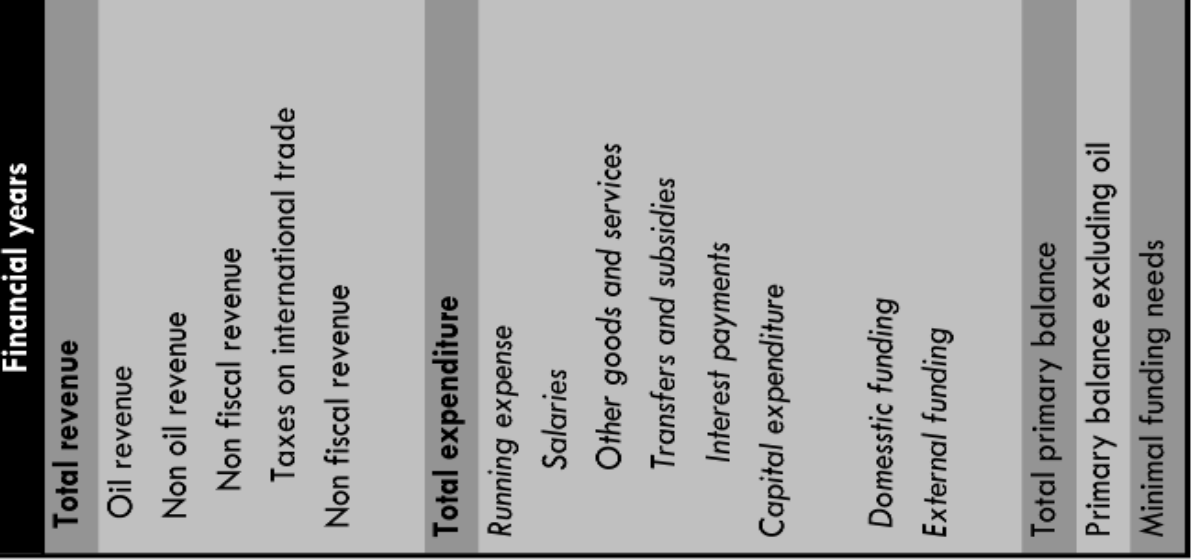


a. - - त ๓

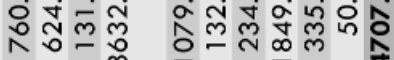

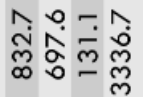

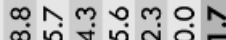

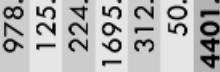

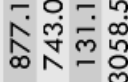

A. - m. mo

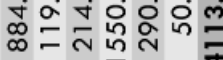

mก-

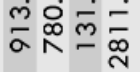

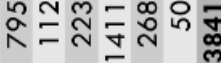

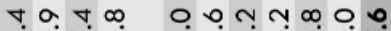

ลู่

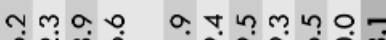

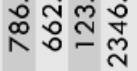

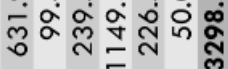

a mon

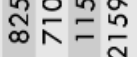

$m-m \Lambda-0 \infty$

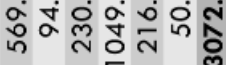

3

空

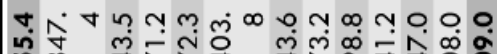

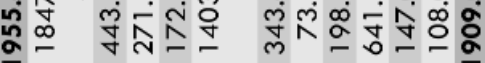

\%

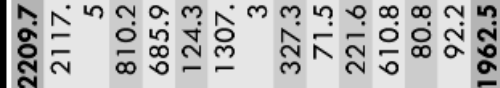

今े

n

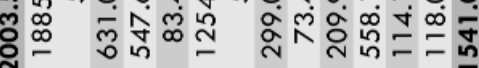

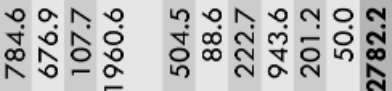

-0-ㅇ mm

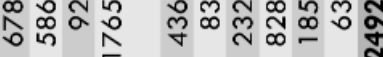

$m \infty n$

ก ำำ

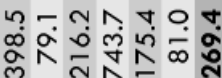

m nmono

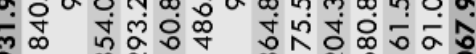
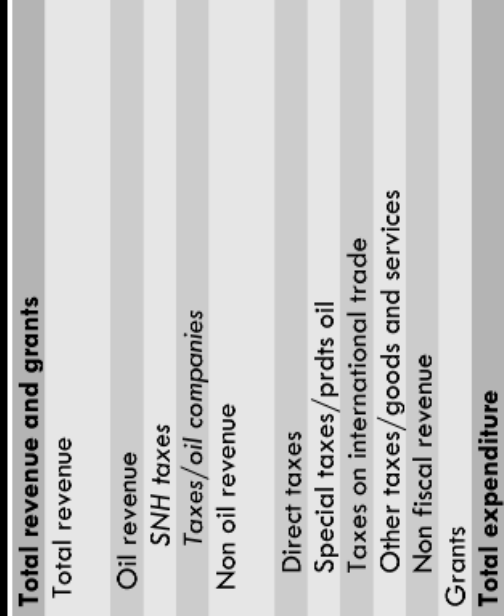

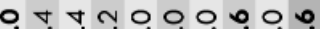

มू่

-

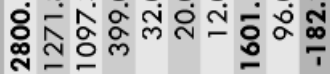

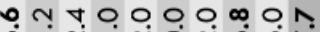

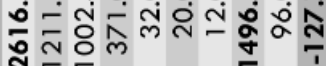

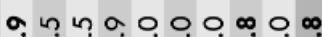

ปู่

m 우웅ㅇำ

ठ্లু

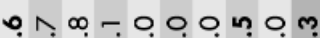

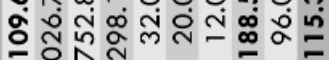

tonno jootor

๙ู่

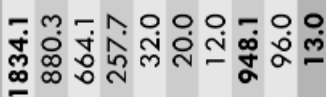

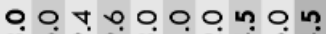

:

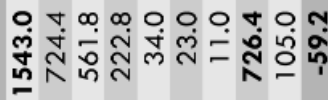

ด.

ลั่ํำ

웅웅웅ำ

นุ n 0 o 0 .

ণิ้

น

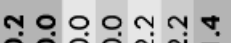

m으웅

จุด

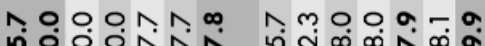

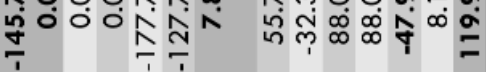

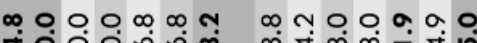

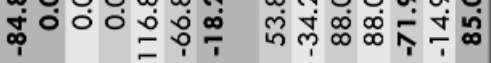

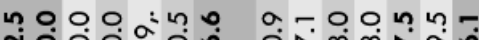

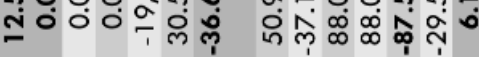

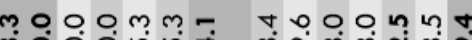

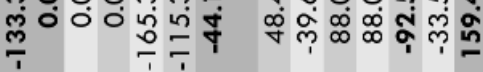

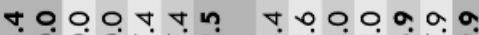
นุ่

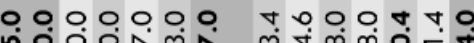
भिं0ல்

n

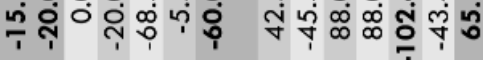

4 ㅇำ ชิ่

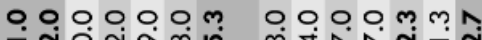

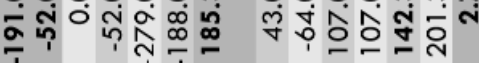

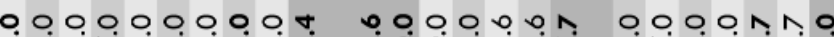

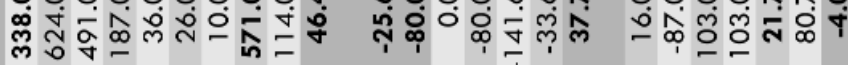

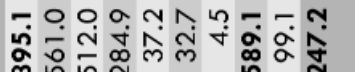

กุด m. มู

우웅우우웅 n

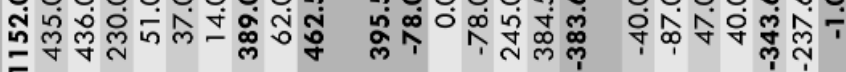

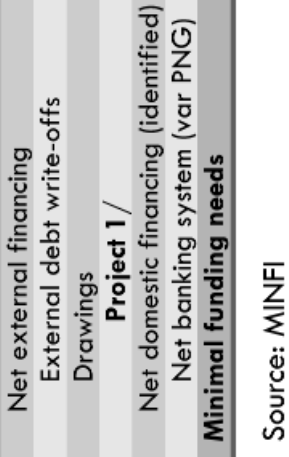




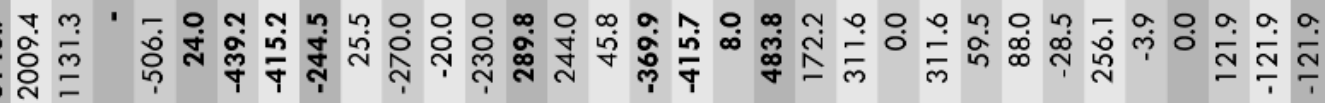

0.0 , n t n

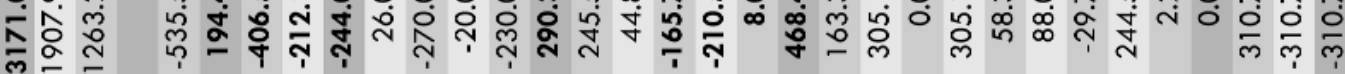

0 m - - a n ก্ল

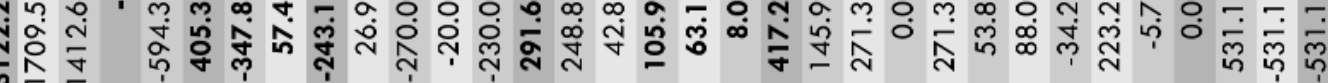

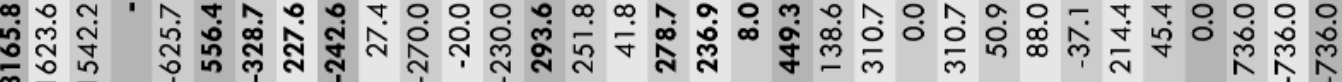

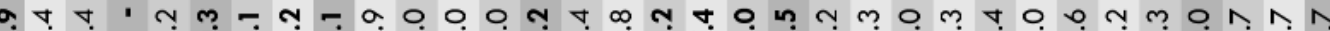

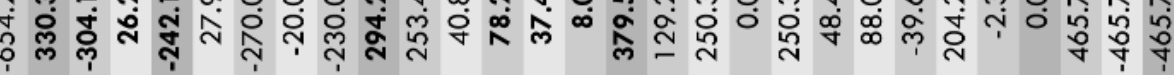

m

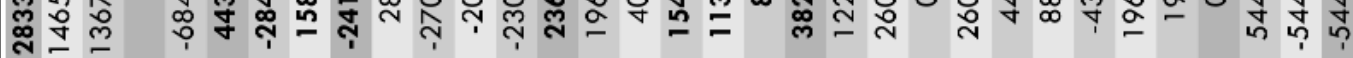

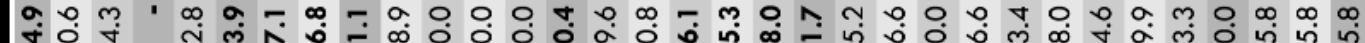

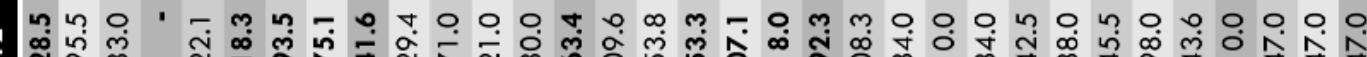

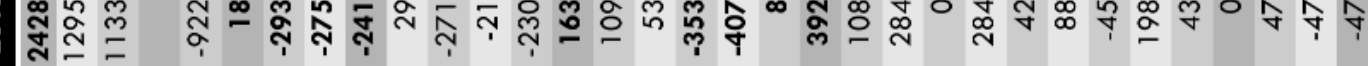

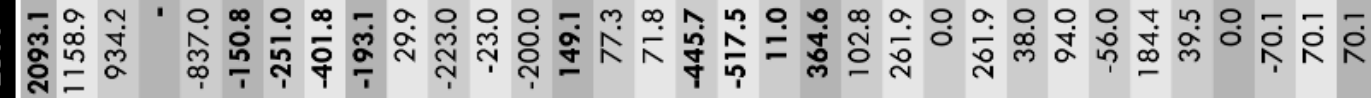
芦

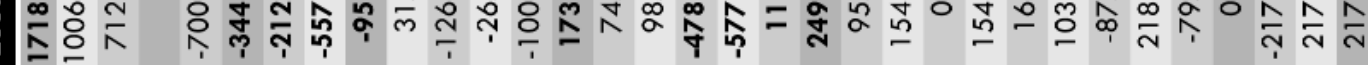
d to , o n m m n m n

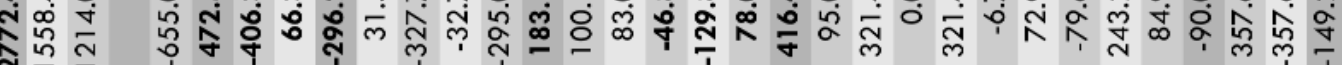

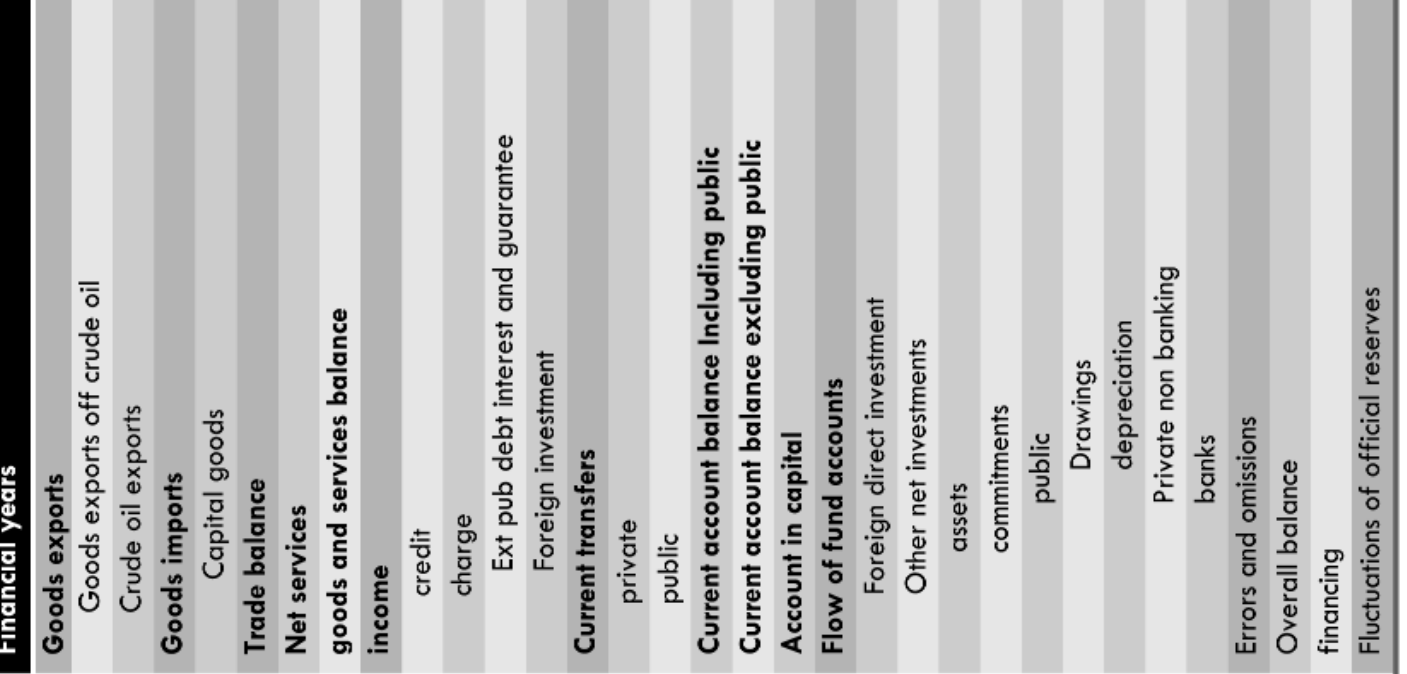




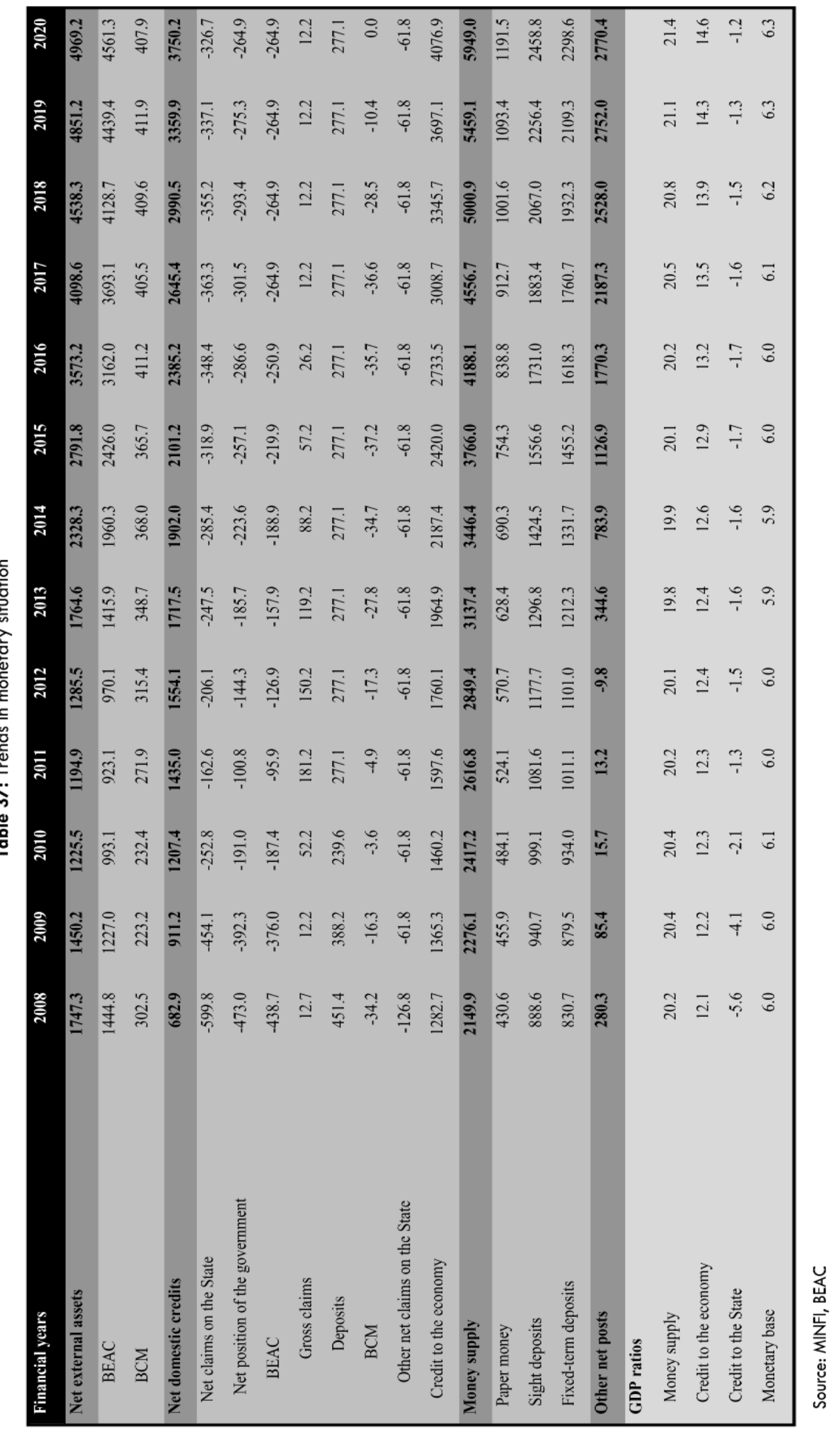




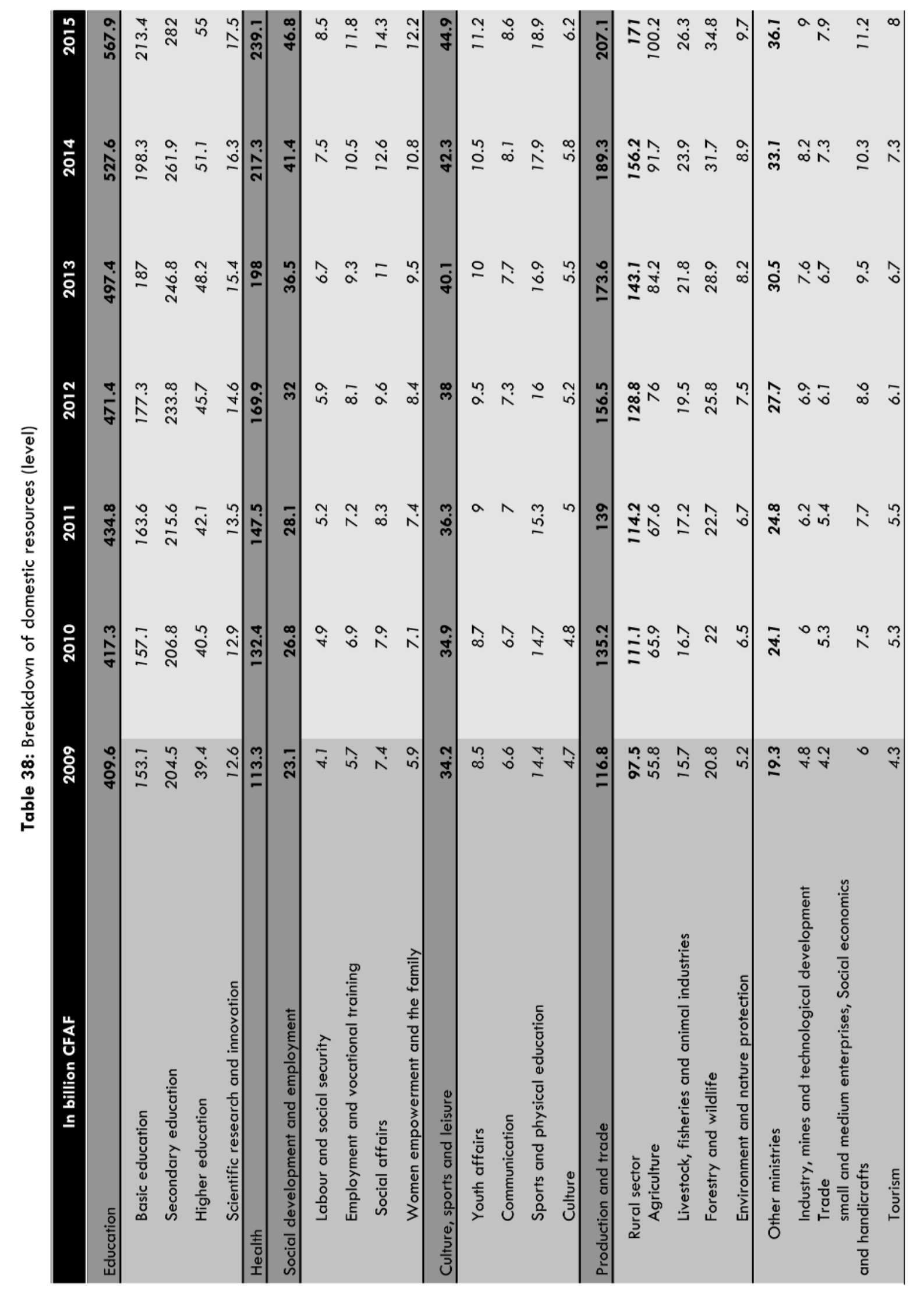




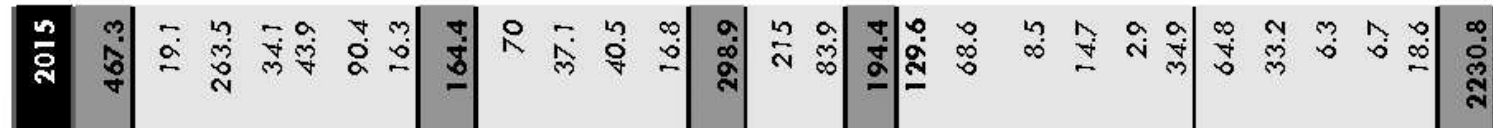

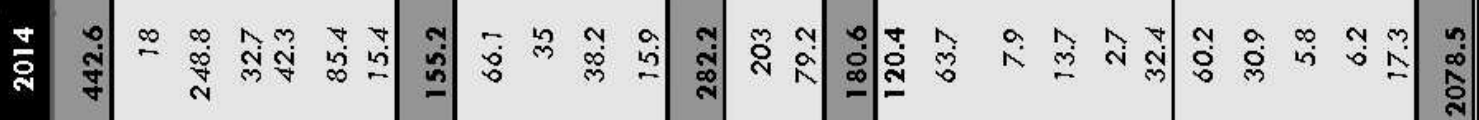

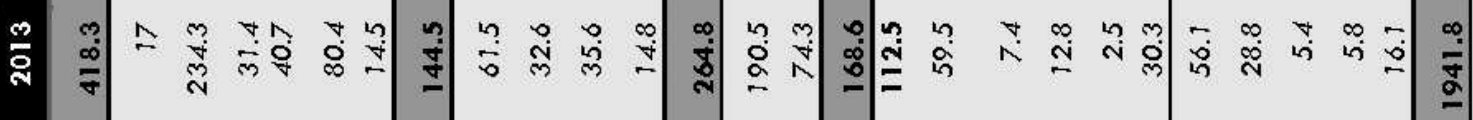

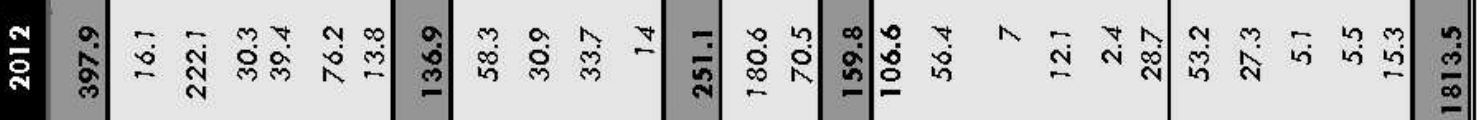

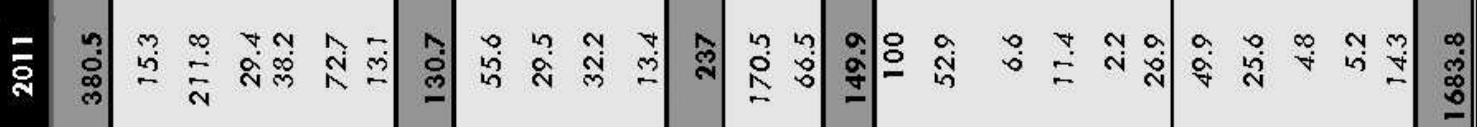

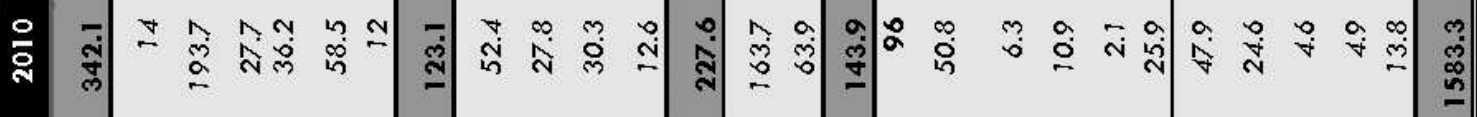

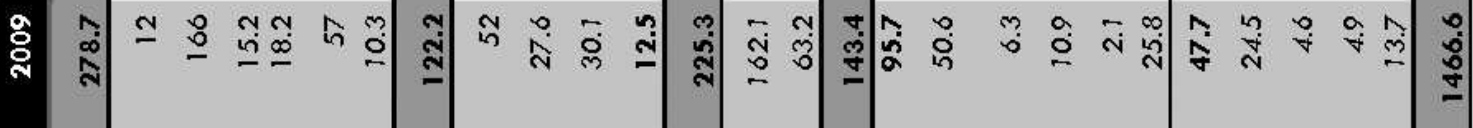

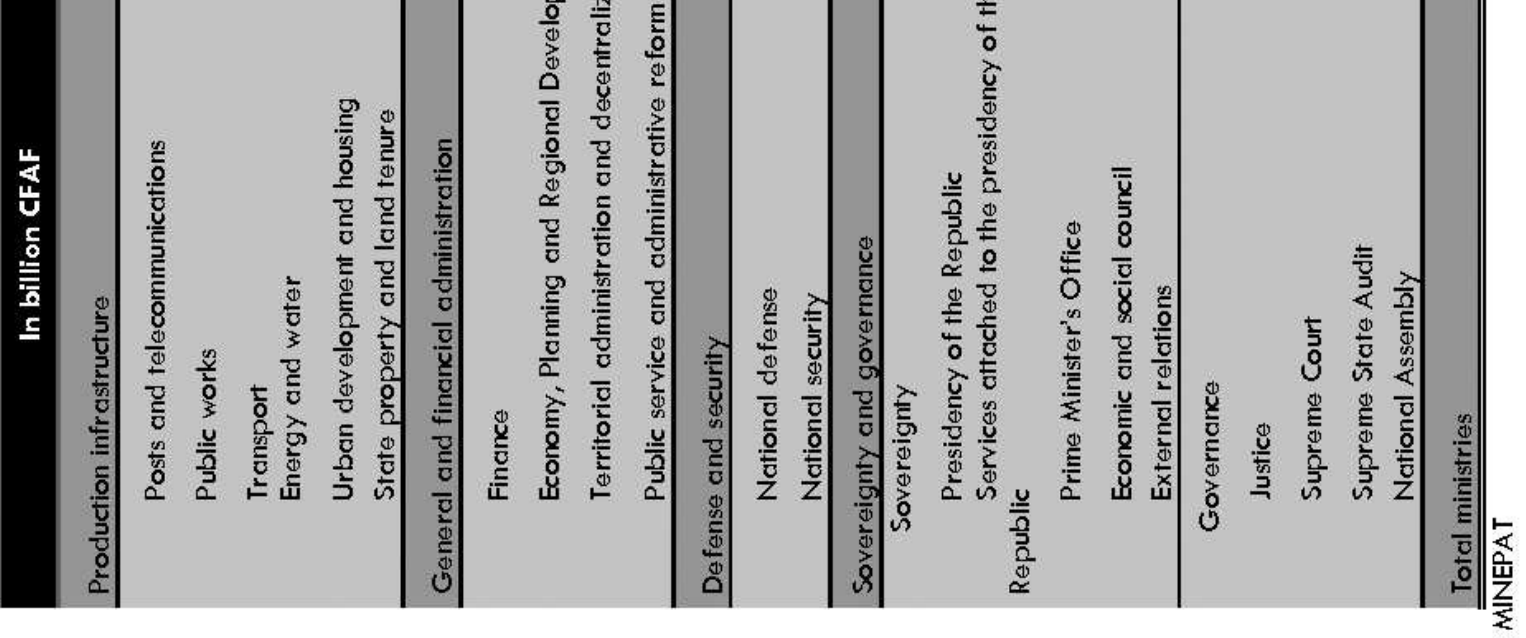




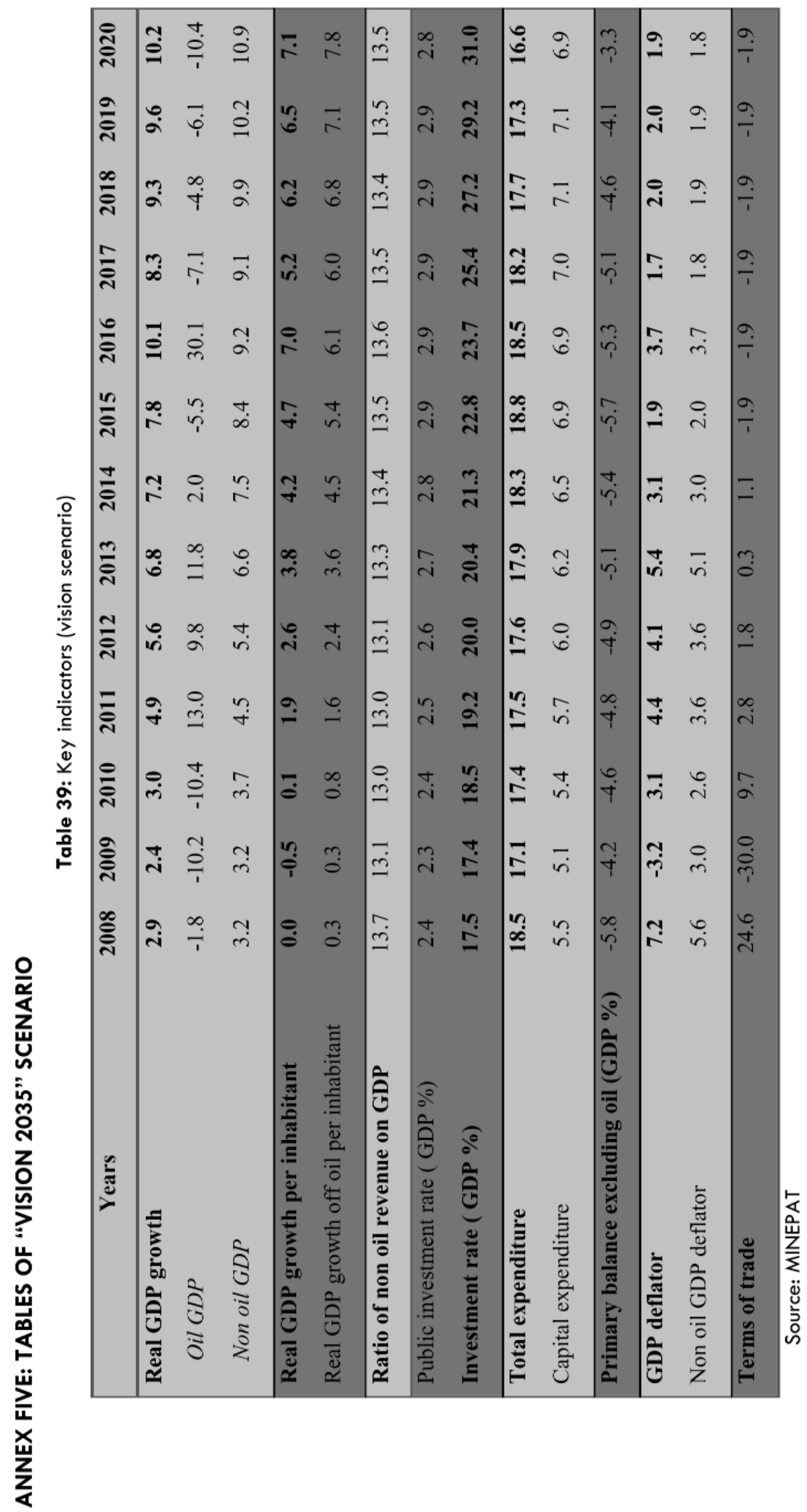




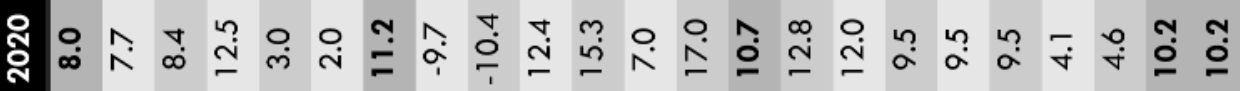

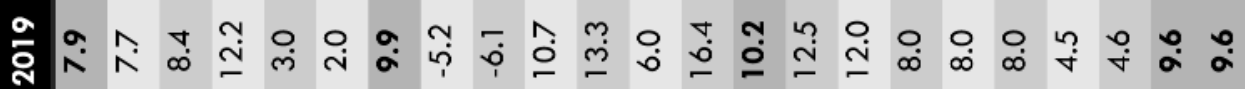

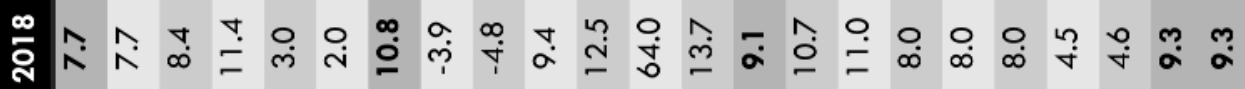

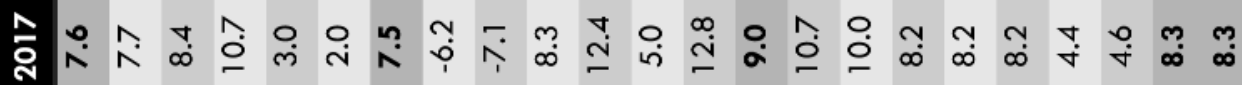

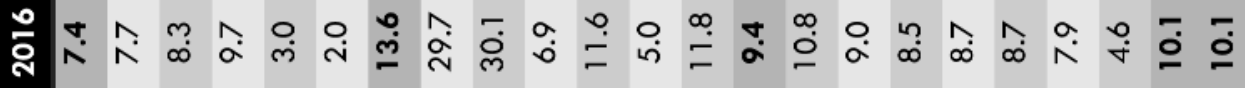

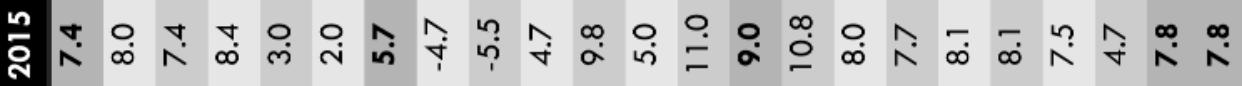

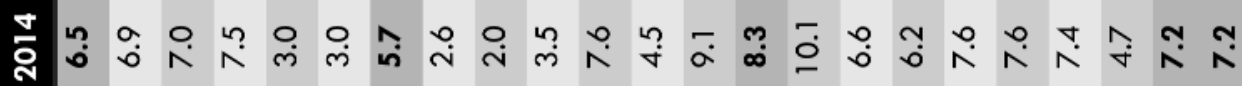

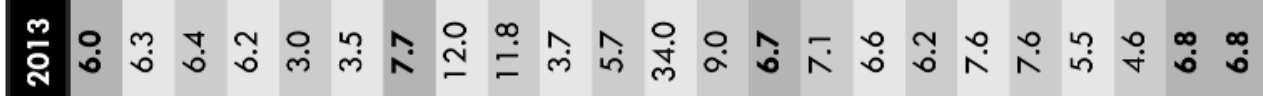

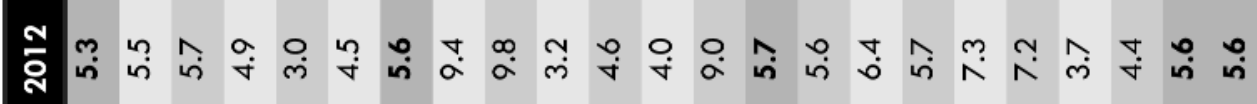

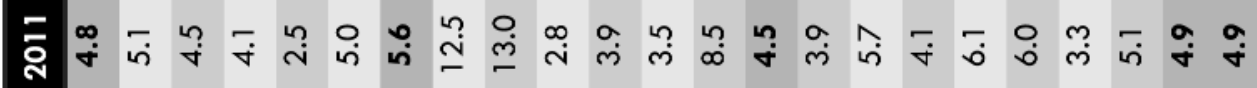

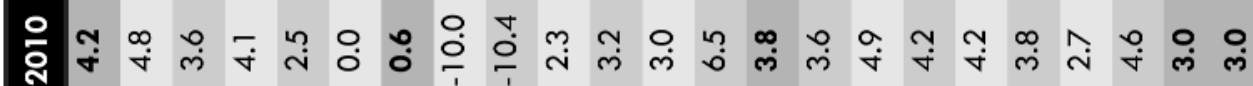

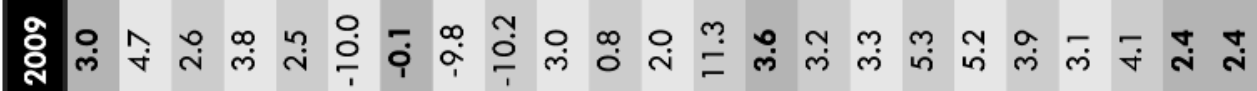

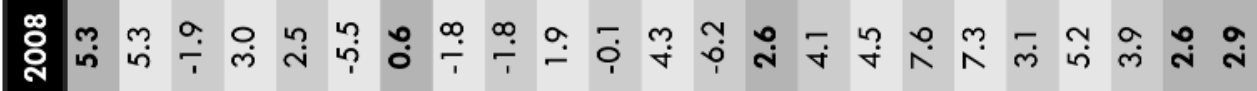

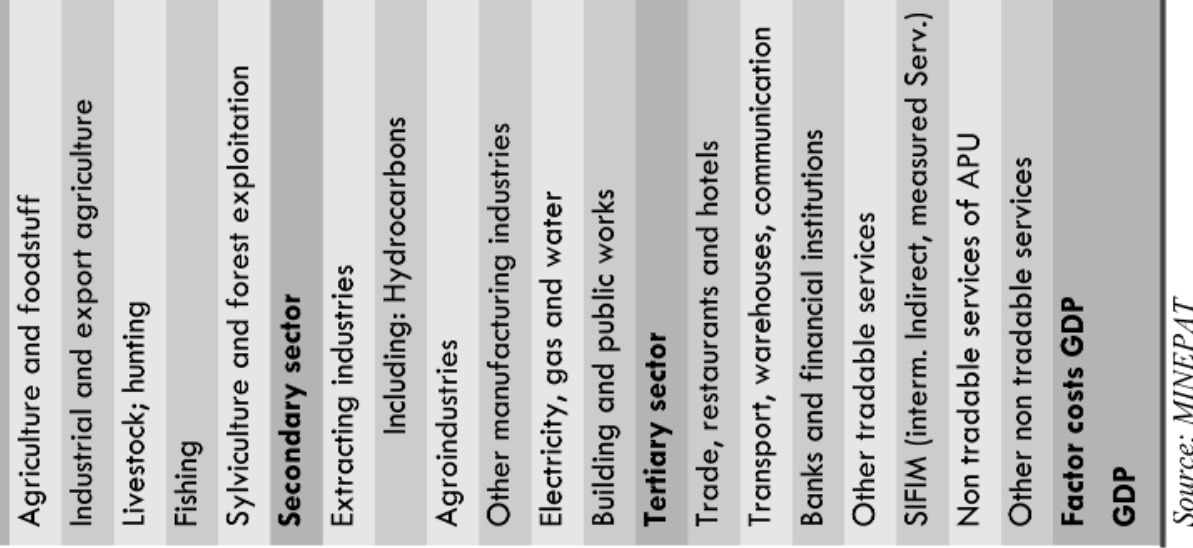




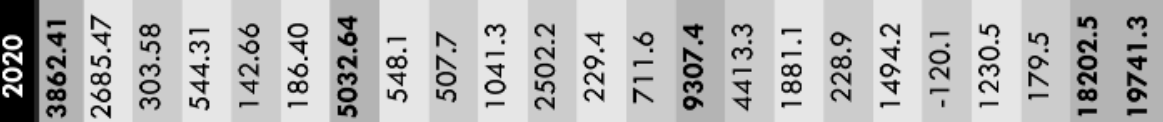

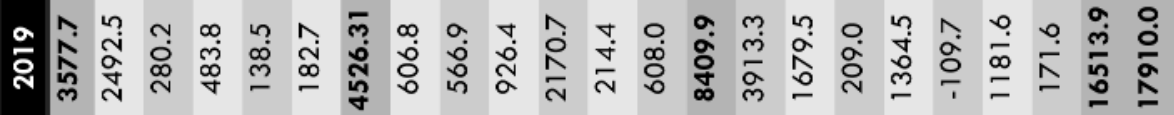

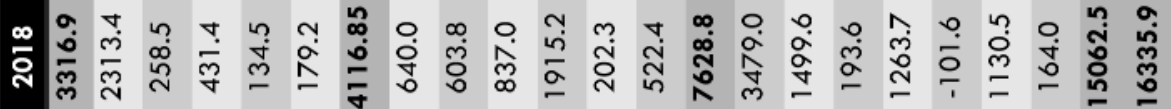

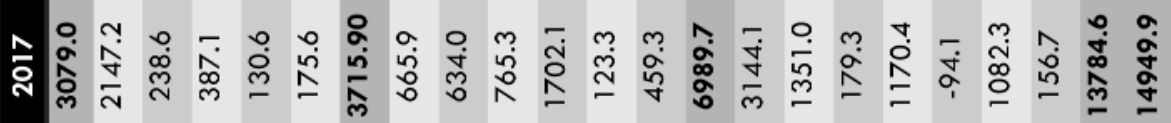

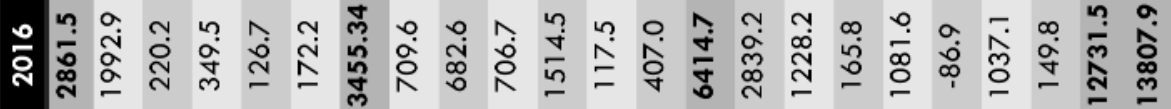

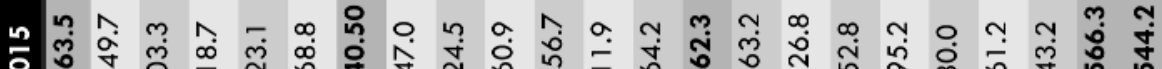
递

旁 嵌

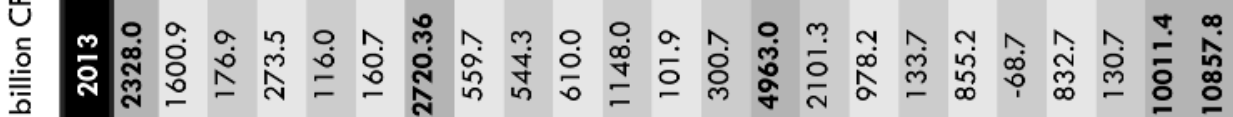
$\cong$ 范 के

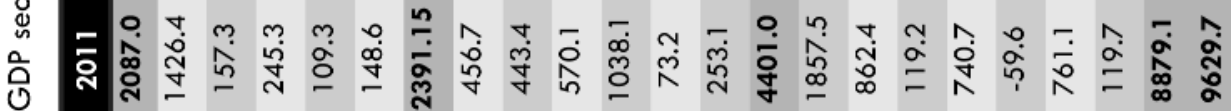
$\ddot{\bar{z}}$

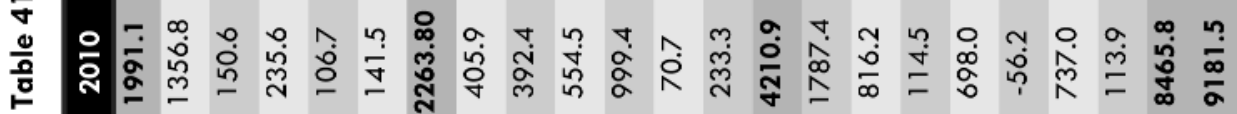
סิ

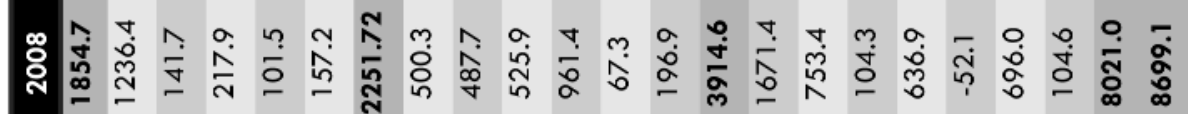

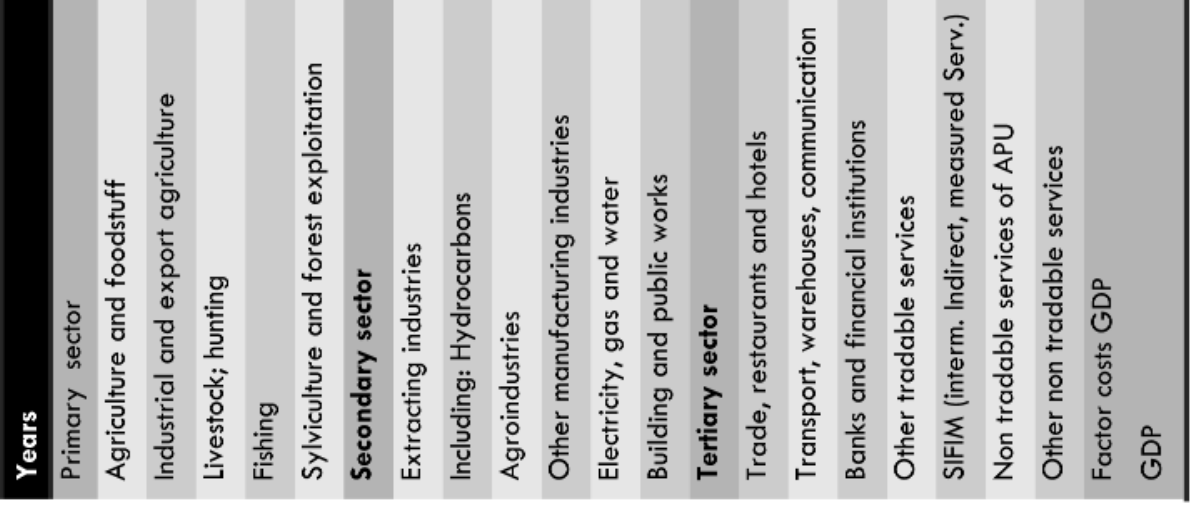




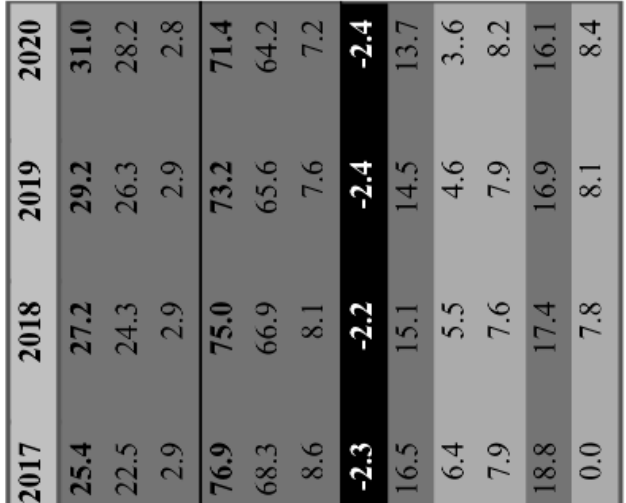

啇

党

음

Uू

을

\%

喜

\%

Oิ

$\subseteq$

ํํำ

‡

응

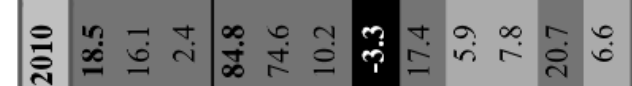

$\ddot{\text { ช }}$

$\frac{0}{\frac{0}{5}}$

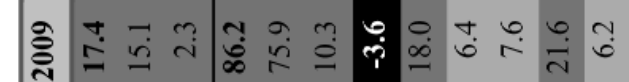

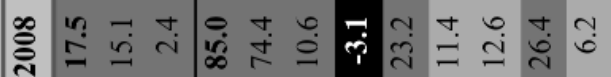

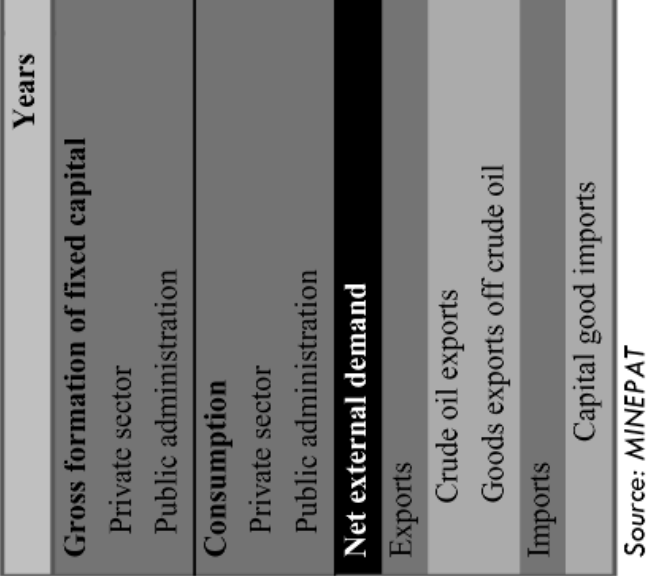

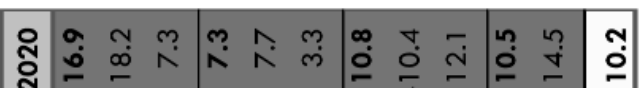

둘

๓

들

윰

ก

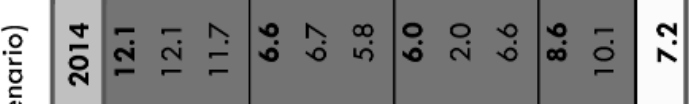

๓⿴囗十

ำ

도

을 을

율

ஜํำ

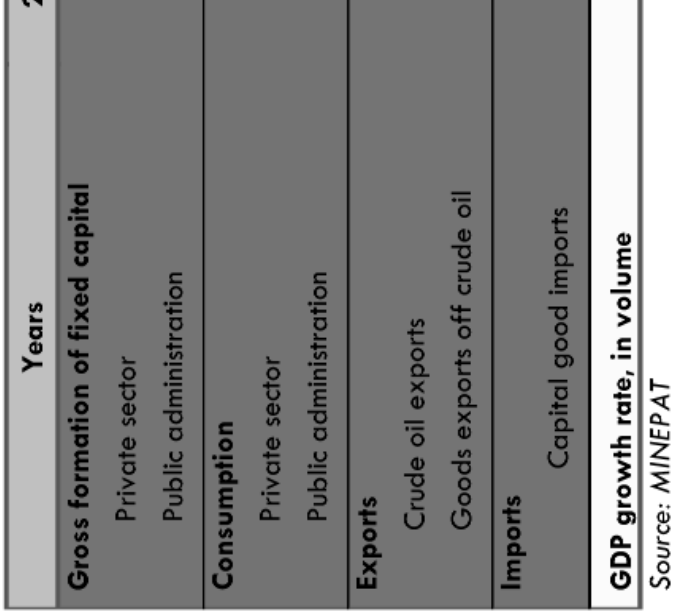


○ m ส্

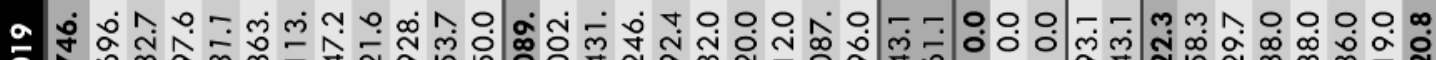
స్

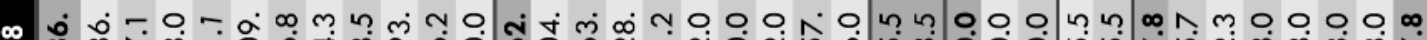
ప্ন

人

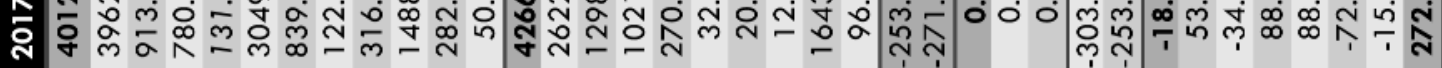

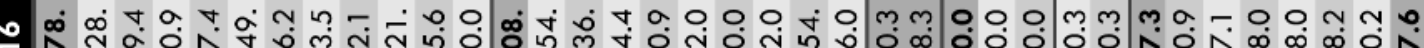

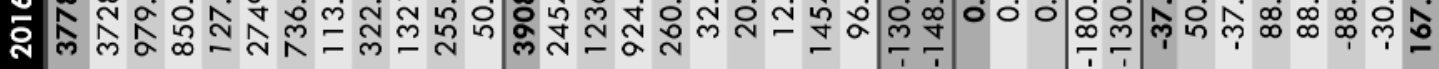

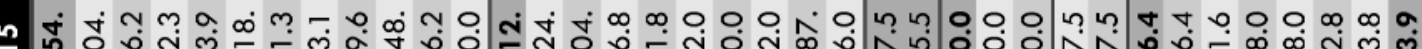
항

4 m. สั้

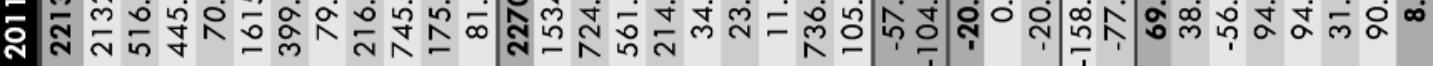

일

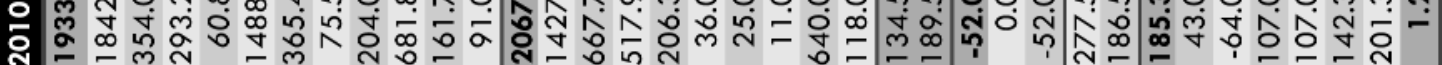

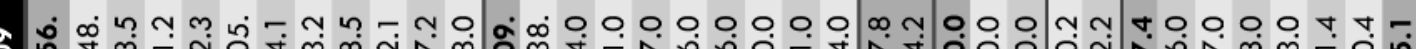
ठ্ণ

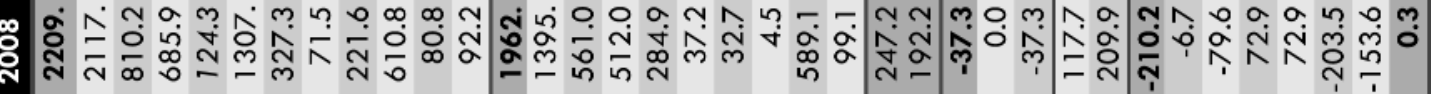

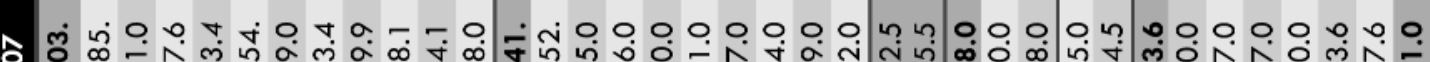
ర్đે

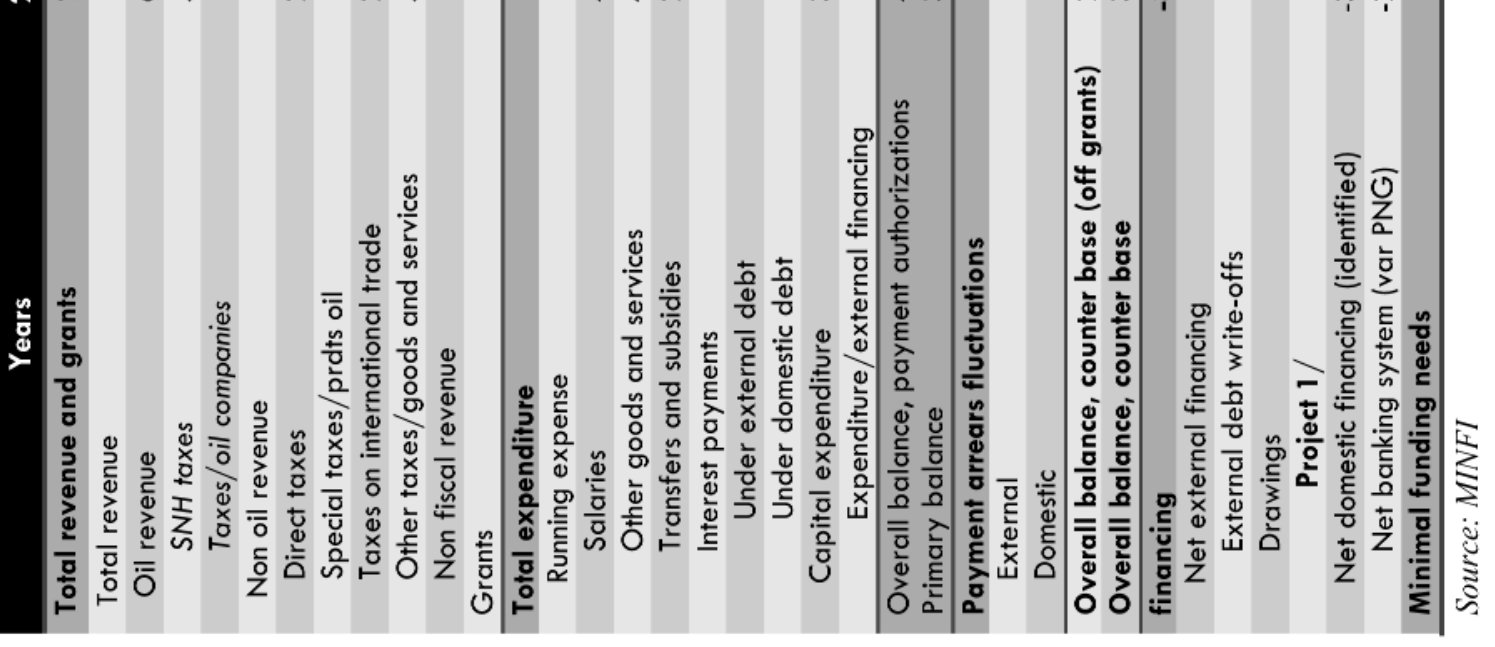




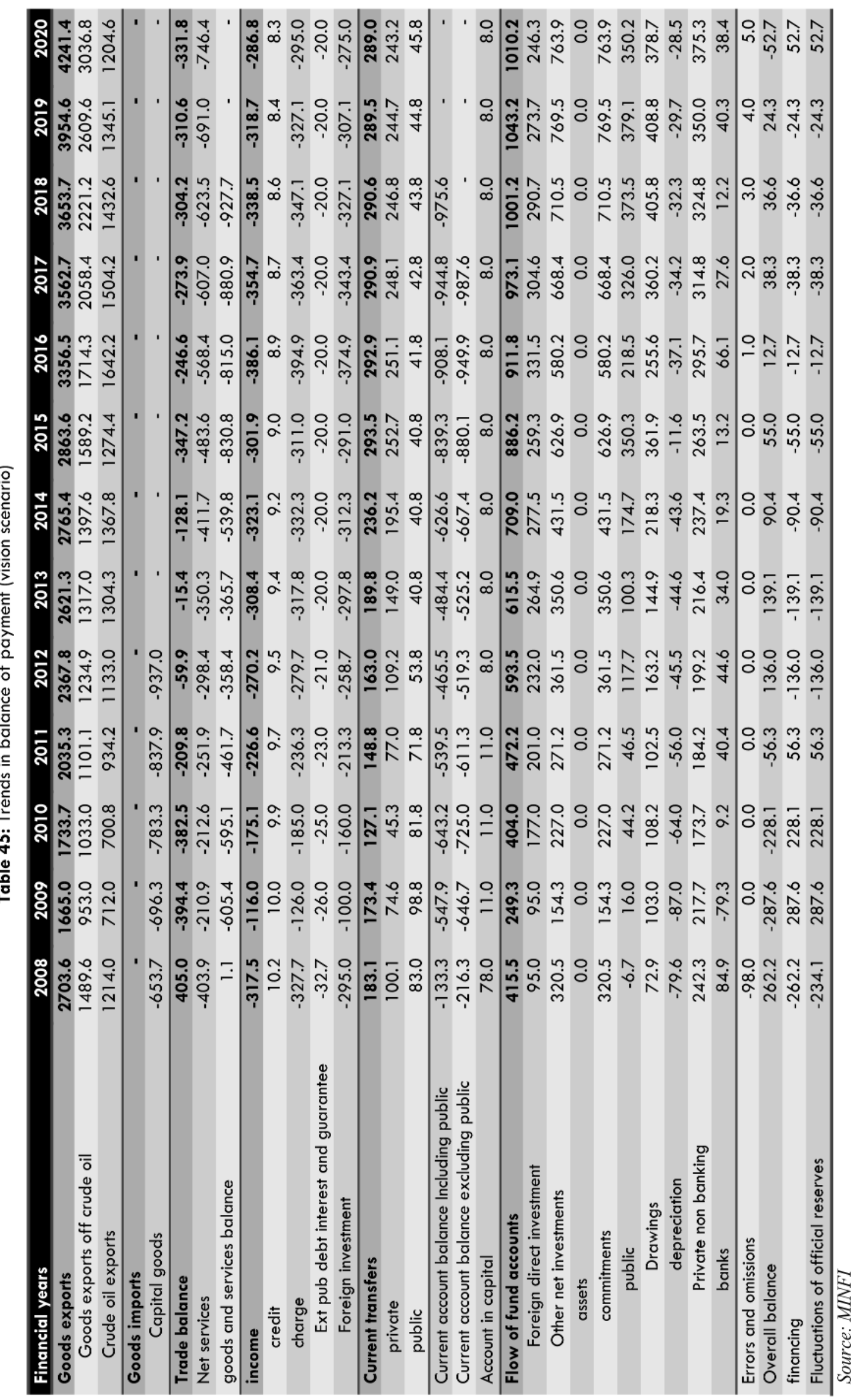




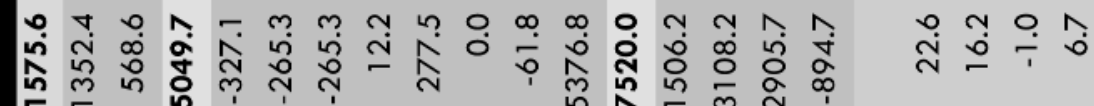

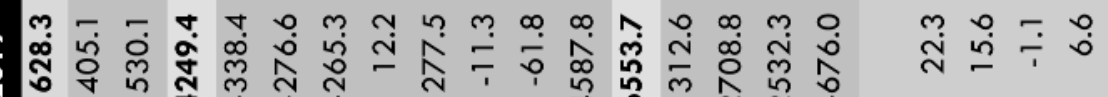

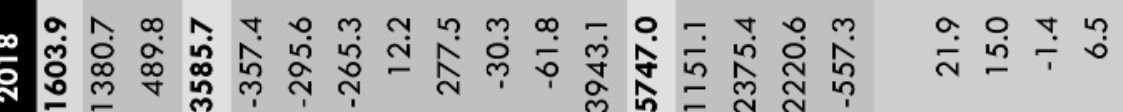

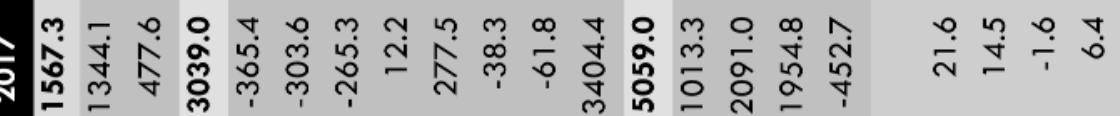

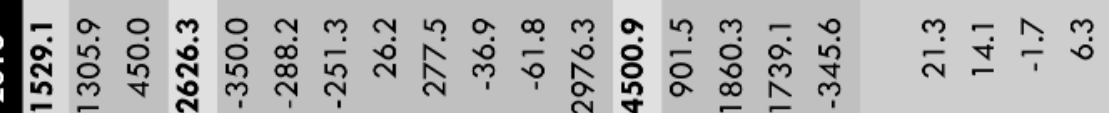

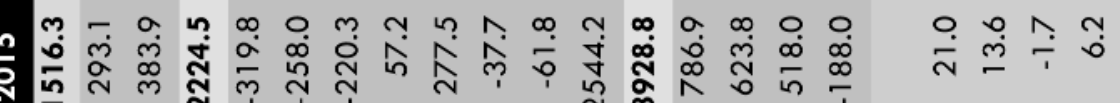

을

$\frac{.0}{4}$

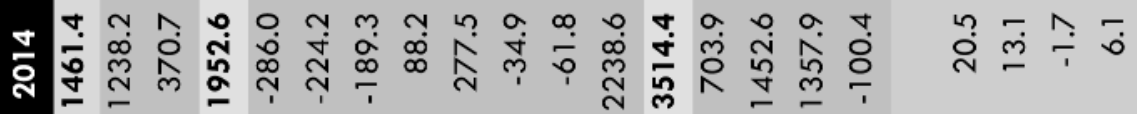

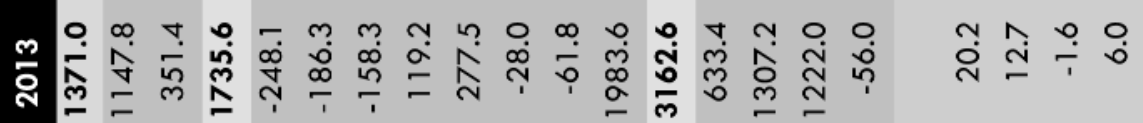

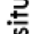

늘

ก ำ

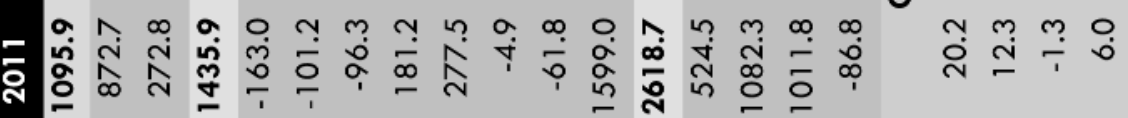
荥

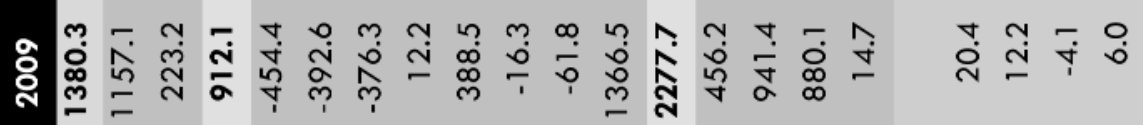

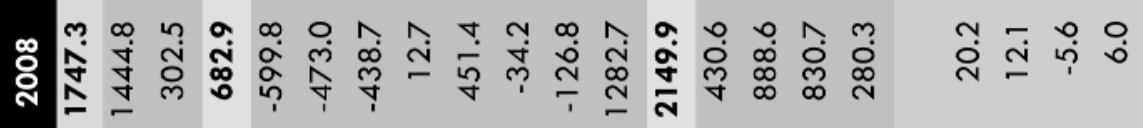

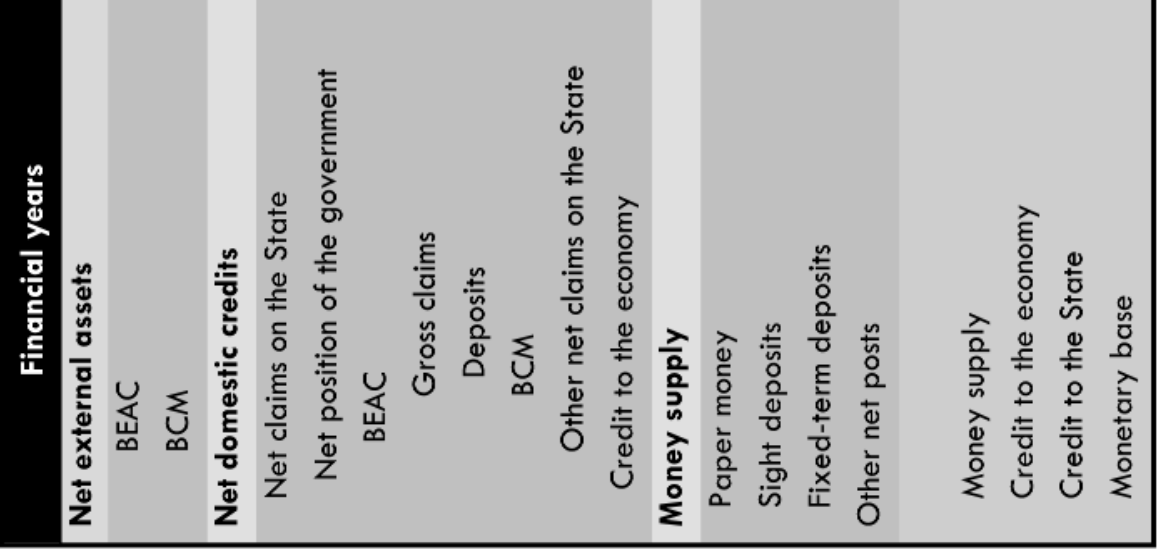


Growth and employment strategy paper 2010/2020

Table 47 : Simulation of poverty rate based on growth scenarios

\begin{tabular}{|cccccccc|}
\hline & \multicolumn{2}{c}{ Reference scenario } & \multicolumn{3}{c|}{ Vision scenario } \\
\hline primary & industry & services & Total & primary & industry & services & Total \\
\hline 58.8 & 24.8 & 17.0 & 39.9 & 58.8 & 24.8 & 17 & 39.9 \\
\hline 58.4 & 27.7 & 16.5 & 39.6 & 58.4 & 27.7 & 16 & 39.6 \\
\hline 58.1 & 29.8 & 16.2 & 39.5 & 58.1 & 29.9 & 15.5 & 39.5 \\
\hline 56.9 & 32.6 & 16.0 & 38.8 & 56.9 & 30.9 & 15 & 38.8 \\
\hline 55.4 & 29.9 & 15.1 & 38.4 & 55.4 & 28.9 & 14 & 37.4 \\
\hline 53.5 & 28.1 & 13.7 & 37.3 & 53.4 & 26.9 & 13.3 & 36 \\
\hline 51.7 & 24.3 & 12.3 & 36.5 & 51.1 & 23.6 & 11.7 & 33.8 \\
\hline 50.4 & 23.5 & 11.6 & 36.0 & 48.5 & 22.2 & 9.8 & 31.6 \\
\hline 48.2 & 23.8 & 10.7 & 35.2 & 44.9 & 21.4 & 7.7 & 28.8 \\
\hline 46.6 & 21.8 & 8.8 & 34.4 & 41.4 & 16.7 & 6.4 & 26 \\
\hline 45.1 & 20.8 & 8.3 & 33.4 & 38.5 & 13.9 & 5.7 & 23.7 \\
\hline 43.3 & 15.8 & 7.4 & 31.7 & 34.7 & 10.5 & 4.3 & 20.9 \\
\hline 43.2 & 15.1 & 5.8 & 30.2 & 31.5 & 7.4 & 3.3 & 18.5 \\
\hline 42.6 & 14.5 & 5.0 & 28.7 & 27.8 & 5.5 & 2.5 & 16.1 \\
\hline
\end{tabular}

Source: MINEPAT

Table 48: Trends in poverty incidence and other MDGs indicators

\begin{tabular}{|c|c|c|c|c|c|c|}
\hline \multirow[t]{2}{*}{ variables } & \multirow{2}{*}{$\begin{array}{l}\text { Level at the } \\
\text { reference } \\
\text { Year }\end{array}$} & \multirow{2}{*}{$\begin{array}{l}\text { Target } \\
2015\end{array}$} & \multicolumn{2}{|c|}{ Reference scenario } & \multicolumn{2}{|c|}{ Vision scenario } \\
\hline & & & 2015 & 2020 & 2015 & 2020 \\
\hline \multicolumn{7}{|l|}{ Real growth on annual average (in \%) } \\
\hline Real GDP & & & 5.7 & 5.4 & 7.8 & 10.2 \\
\hline \multicolumn{7}{|l|}{ Real growth on public expenditure annual average } \\
\hline Education & & & 8 & 5 & 12.6 & 10.3 \\
\hline Health & & & 9.8 & 7.4 & 15 & 12.8 \\
\hline Rural sector (agriculture and lifestock) & & & 12.1 & 8.5 & 14.14 & 11.5 \\
\hline Money poverty rate (\%) & $39.9(2007)$ & 25 & 35.2 & 28.7 & 28.8 & 16.1 \\
\hline \multicolumn{7}{|l|}{ Other MDGs } \\
\hline \multicolumn{7}{|l|}{ Education } \\
\hline Net schooling rate in primary schools & 75 (2007) & 100 & 88.6 & 98.8 & 90.3 & 100 \\
\hline \multicolumn{7}{|l|}{ Health } \\
\hline $\begin{array}{l}\text { Maternal mortality rate (for 100,000 live } \\
\text { births) }\end{array}$ & 669 (2004) & 350 & 410 & 325.6 & 392.4 & 272.3 \\
\hline \multicolumn{7}{|l|}{ Feeding } \\
\hline $\begin{array}{l}\text { Percentage of moderated underweight } \\
\text { children under } 5\end{array}$ & 19.3 (2006) & 8 & 13.4 & 10.2 & 12.3 & 8.8 \\
\hline
\end{tabular}

Source: MINEPAT 
- AFRISTAT, Cadre de référence et support méthodologique Minimum Commun pour la conception d'un système d'information pour le suivi des DSRP et des OMD, February 2006

- Rural Electrification Agency, Plan d'Action National Energie pour la Réduction de la Pauvreté, December 2005

- World Bank, Development Policy Review, June 2004

- World Bank, Doing Business, 2007

- Central Bureau of Population Census, Rapports provisoires du troisième Recensement Général de la Population et de l'Habitat, 2008

- Cabinet Green Research and Consulting, Elaboration d'un mécanisme de suivi et d'évaluation des stratégies sectorielles au Cameroun, June 2008

- Cabinet Premium consulting Agency, Eléments clés pour la Charte des Investissements et la politique industrielle (Rapport de synthèse), November 1999

- Comité de Pilotage de la Stratégie de Développement du Secteur Rural, Stratégie de Développement du Secteur Rural, 2005

- Comité de Pilotage de la Stratégie du Secteur de l'Eudcation, Stratégie globale du Secteur de l'Education, 2006

- Technical Committee charged with monitoring and evaluation of PRSP implementation, Progress Reports 2004, 2005, 2006, 2007

- Technical Committee charged with monitoring and evaluation of PRSP implementation, Rapports régionaux et nationaux d'évalaution participative du DSPR, 2004, 2005, 2006, 2007

- Technical Committee charged with monitoring and evaluation of PRSP implementation, Rapports départementaux, régionaux et national des consultations participatives, avril 2008

- European Union Commission, étude d'impact de l'APE sur l'économie camerounaise, 2009

- Enquête sur l'Emploi et le Secteur informel

- International Monetary Fund \&World Bank, Joint Staff Advisory Note, 2004, 2005, 2006, 2007

- International Monetary Fund \&World Bank, Joint Staff Assessment, July 2003

- GTZ, Business climat Survey, 2009

- National Institute of Statistics \&UNDP, Reporting des OMD, 2009

- National Institute of Statistics, Enquête Camerounaise auprès des Ménages, 2008

- National Institute of Statistics, Enquête sur le Cadre de Vie des Populations de Yaoundé et Douala, 2003

- National Institute of Statistics, Suivi de la situation des enfants et des femmes - Enquête par Grappes à Indicateurs Multiples (MICS), 2006

- National Institute of Statistics, Troisième Enquête de Démographie et de Santé, 2004

- Japan International Cooperation Agency, Etude sur la Formulation du Plan Directeur (P/P) pour le développement des Petites et Moyennes Entreprises en République du Cameroun (Rapport final), January 2009

- MANGA AKOA Armand, Modèle de Régression Segmentée à Réadaptation des Prédicteurs (RSRP), 2008

- MINEPAT-PNUD-Global Water Partnership Central Africa, Stratégie Nationale sur la gestion durable des eaux et des sols dans l'espace Agro-sylvo-Pastoral au Cameroun, November 2007

- Ministry of Territorial Administration and Decentralization, Stratégie sectorielle de l'administration territoriale et décentralisation, 2009 
- Ministry of Economy, Planning and Regional Development, Etudes sur les sources de la croissance, 2008

- Ministry of Economy, Planning and Regional Development, Guide d'évaluation de la dimension sociale des projets de développement au Cameroun, November 2007

- Ministry of Economy, Planning and Regional Development \& UNDP, Costing des OMD, 2008

- Ministry of Economy, Planning and Regional Development, Revue des grands projets, 2009

- Ministry of Employment and Vocational Training, Actes des états généraux sur l'emploi, 2005

- Ministry of Environment and Nature Portection, Plan d'action National de lutte contre la désertification, 2008

- Ministry of Youth Affairs, Plan d'action pour Emploi des Jeunes, 2007

- Ministry of Youth Affairs, Politique Nationale de la Jeunesse, 2005

- Ministry of Public Health, Stratégie Sectorielle de la Santé, 2009

- Ministry of Economic Affairs, Programming and Regional Development \& sector ministries, Stratégie du secteur du développement social, 2005

- Ministry of Social Affairs, Plan d'action national de protection des personnes handicapées, 2006/2009

- Ministry of Social Affairs, Rapport du Cameroun sur la mise en œuvre du plan d'action interministériel de Madrid sur le vieillissement 5 ans après

- Ministry of Finance, Etude de l'impact de l'APE sur l'économie camerounaise, 2009

- Ministry of Public Works, Elaboration du modèle économétrique "I BTP et croissance économique ", 2007

- Ministry of Public Works, Plan de Développement du Secteur de l'Electricité (PDSE), 2004

- Ministry of Public Works, Plan Directeur Routier, 2006

- Ministry of Public Works, Stratégie sectorielle des Bâtiments et Travaux Publics, 2006

- Premier rapport périodique de la mise en œuvre de la convention des Nations unies sur les droits des enfants

- United Nations Development Programme, Analyse Pays des défis de développement au Cameroun (Bilan commun du Système des Nations Unies fondé sur le DSRP du Gouvernement du Cameroun, dec. 2006

- National Governance Programme, Etat de la Gouvernance au Cameroun 2006/2007

- République du Cameroun \& République Française, Document Cadre de Partenariat entre la République du Cameroun et République Française pour la période 2006-2010, 2006

- République du Cameroun, Cadre juridique et contrat de partenariat au Cameroun : lois et textes d'application

- République du Cameroun, Déclaration de la Politique Nationale de Population, mars 2002

- Republic of Cameroon, Poverty Reduction Strategy Paper, April 2003

- Republic of Cameroon, Poverty Reduction Strategy Paper, April 2003

- République du Cameroun, Loi n²007/006 du 26 décembre 2007 portant régime financier de l'Etat

- République du Cameroun, lois et textes sur la décentralisation, 2004

- Republic of Cameroon, Long term Development Vision, 2009

- Société de Formation et de Gestion, Elaboration de la méthodologie du Suivi Participatif de mise en œuvre du DSRP, mars 2005 